UNIVERSIDADE DE SÃO PAULO

INSTITUTO DE QUÍMICA DE SÃO CARLOS

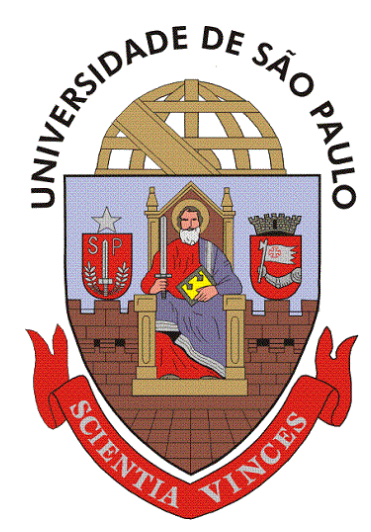

\title{
SÍNTESE DE ADUTOS DE KNOEVENAGEL E $4 H$ - CROMENOS POR IRRADIAÇÃO MICRO-ONDAS E REAÇÕES DE BIOTRANSFORMAÇÃO
}

Lucas Lima Zanin

São Carlos, 2018 
Lucas Lima Zanin

\section{SÍNTESE DE ADUTOS DE KNOEVENAGEL E $4 \mathrm{H}$ - CROMENOS POR IRRADIAÇÃO MICRO-ONDAS E REAÇÕES DE BIOTRANSFORMAÇÃO}

Dissertação apresentada ao Instituto de Química de São Carlos da Universidade de São Paulo como parte dos requisitos para a obtenção do título de Mestre em Ciências

Área de concentração: Química Orgânica e Biológica

Orientador: Prof. Dr. André Luiz Meleiro Porto 


\section{AGRADECIMENTOS}

Dedico este trabalho ao meu pai Valcenir Aparecido Zanin, minha mãe Vera Lúcia de Oliveira Lima Zanin, ao meu irmão Guilherme Lima Zanin e a minha avó Elvira de Oliveira Lima, por estarem sempre ao meu lado me apoiando, com muito amor, em todos meus passos durante toda minha vida.

A Giovanna, pelo companheirismo, paciência, amor, carinho e apoio durante esses dois anos de mestrado, me incentivando a lutar sempre pelos meus objetivos.

Ao Prof. Dr. André Luiz Meleiro Porto, pelos dois anos de orientação, paciência, amizade e ensinamentos que foram fundamentais na minha formação pessoal e profissional.

Aos meus amigos, colegas e funcionários do Laboratório de Química Orgânica e Biocatálise Aline, Charlene, Erika, Darlissom, Edivânia, Fabiano, Iara, Juliana Galan, Juliana Barreiro, Jaqueline, Matheus, Marília, Samuel, Thayane, Matheus, Rafaely e William, por dividirem comigo inúmeros momentos e ensinamentos durante as rotinas diárias. Vocês foram fundamentais para o desenvolvimento deste trabalho.

Ao David, em especial, pela amizade desenvolvida nestes anos e pelo apoio nas atividades laboratoriais.

A Universidade de São Paulo e ao Instituto de Química de São Carlos (USP - IQSC) por fornecer todo suporte e infraestrutura necessários para o desenvolvimento deste trabalho.

A Universidade Estadual Paulista "Júlio de Mesquita Filho" e ao Instituto de Química de Araraquara (UNESP -IQ/CAr) por serem responsáveis pela minha base, a qual foi essencial para eu chegar até aqui.

A todos meus amigos de Araraquara, os moradores da república Atécubanos (2013-2016) e agregados, em especial a Jaqueline, Raí, Cogumelo, Tripodis, Caio Fima, Varoni, Tinga, Rafel, Sumido, Steak, Fetão, Zero1, Xynelo e Beto pela amizade e momentos vividos. E também aos meus amigos de longa data de São Carlos, em especial ao Guilherme Roiz, Virso, Fernandinho e Murillo.

A Coordenação de Aperfeiçoamento de Pessoal de Nível Superior (CAPES) pela bolsa concedida para apoiar a realização deste trabalho. 


\section{RESUMO}

Neste trabalho foi desenvolvida uma metodologia sintética verde para as reações de condensação de Knoevenagel entre aldeídos aromáticos e o cianoacetato de metila 2'. As reações foram assistidas pelo método de aquecimento via irradiação micro-ondas, realizadas em 30 minutos, em uma temperatura de $65-85^{\circ} \mathrm{C}$ e $55 \mathrm{~W}$ de potência. Foram realizadas as sínteses de doze compostos 2a-l utilizando água ou etanol como solvente e forneceram bons rendimentos na faixa de 70-90\%. A metodologia desenvolvida para a síntese destes compostos envolveu uma simples estratégia de purificação, a qual utilizou-se de lavagens com hexano a quente para obter os produtos isolados. Sequencialmente, com intuito de dar aplicabilidade aos adutos de Knoevenagel previamente sintetizados, foi realizada uma série sintética de $4 \mathrm{H}$ cromenos, uma classe estrutural de moléculas que possuem um potencial bioativo. A metodologia utilizada foi adaptada da utilizada na síntese dos adutos de Knoevenagel 2a-l e uma série sintética foi realizada, resultando na síntese de dez $4 H$-cromenos 3a-j, dos quais 5 foram inéditos na literatura. As reações foram realizadas em 90 minutos, a $85^{\circ} \mathrm{C}, 55 \mathrm{~W}$ de potência, utilizando água como solvente e forneceram rendimentos na faixa de 40-60\%. Também foram realizadas neste estudo reações de condensação de Knoevenagel utilizando cetonas aromáticas e a malononitrila 5'. Duas metodologias foram empregadas, sendo que a primeira utilizou $\mathrm{NaOH}$ como base e a segunda metodologia utilizou trietilamina. Foram sintetizados sete adutos de Knoevenagel 5a-c e 5e-i, em 24 h de reação, a $50{ }^{\circ} \mathrm{C}$ em chapa de aquecimento e agitação convencional e utilizando tetraidrofurano como solvente. Foram obtidos valores de conversão (CG-EM) na faixa de $0-38 \%$, com exceção do aduto 5e (c = 90\%). Já a metodologia que utilizou trietilamina foi realizada via reação one-pot. Foi verificado que as reações se comportaram mais efetivamente na ausência de solventes e assim, foram sintetizados 6 adutos de Knoevenagel 5a-b, 5d-f e 5i em 1 h de reação, a $85^{\circ} \mathrm{C}, 10 \mathrm{~W}$ de potência. Os adutos $\mathbf{5 b}$, 5f e $\mathbf{5 i}$ foram isolados com respectivamente 3\%, 5\% e 6\% de rendimento. Por fim, foram selecionados quatro adutos de Knoevenagel, 2d, 2g, 2j e $2 \mathbf{k}$, sintetizados entre aldeídos e o cianoacetato de metila 2' para realizar reações de biotransformação com o fungo de ambiente marinho Penicillium citrinum CBMAI 1186. Inicialmente o objetivo destas reações era reduzir a ligação dupla carbono-carbono dos adutos, o que resultaria em um centro estereogênico. Foram realizadas reações em 1, 2, 3 e 5 dias e não foram observadas reações de bio-hidrogenação, mas sim, reações de biotransformação, pois foram observados os produtos oxidados (como ácidos carboxílicos) e reduzidos (como álcoois) dos respectivos aldeídos formadores dos adutos de Knoevenagel entre outros compostos. A partir deste estudo, foi possível concluir que o fungo Penicillium citrinum CBMAI 1186 teve maior capacidade em biotransformar os adutos de Knoevenagel do que reduzir estereosseletivamente a ligação dupla carbono-carbono. Em suma, a partir de metodologias ambientalmente sustentáveis, foram obtidos 31 compostos, sendo 5 inéditos na literatura. e a grande maioria dos restantes foram sintetizados pela primeira vez sob efeito da irradiação micro-ondas. 


\begin{abstract}
In this work a synthetic green methodology was developed for Knoevenagel condensation reactions between aromatic aldehydes and methyl cyanoacetate 2 '. The reactions were assisted by the microwave irradiation method, carried out in 30 minutes at a temperature of $65-85^{\circ} \mathrm{C}$ and $55 \mathrm{~W}$ of power. Twelve compounds $\mathbf{2 a - 1}$ were synthesized using water or ethanol as the solvent and provided good yields in the $70-90 \%$ range. The methodology developed for the synthesis of these compounds involved a simple purification strategy, which was used of hot hexane washes to obtain the isolated products. Sequentially, in order to give applicability to previously synthesized Knoevenagel adducts, a synthetic series of $4 H$-chromenes was performed, a structural class of molecules that have a bioactive potential. The methodology used was adapted from that used in the synthesis of the Knoevenagel adducts 2a-l and a synthetic series was performed, resulting in the synthesis of ten $4 H$-chromenes $\mathbf{3 a}-\mathbf{j}$, of which 5 were unpublished in the literature. The reactions were carried out in 90 minutes at $85^{\circ} \mathrm{C}, 55$ $\mathrm{W}$ of power, using water as solvent and provided yields in the range of 40-60\%. Also carried out in this study are Knoevenagel condensation reactions using aromatic ketones and 5 'malononitrile. Two methodologies were used, the first using $\mathrm{NaOH}$ as the base and the second using triethylamine. Seven Knoevenagel adducts 5a-c and 5e-1 were synthesized within $24 \mathrm{~h}$ of reaction at $50{ }^{\circ} \mathrm{C}$ in conventional stirring and heating plate and using tetrahydrofuran as solvent. Conversion values (CG-MS) were obtained in the 0-38\% range, with the exception of the adduct 5e $(\mathrm{c}=90 \%)$. The methodology using triethylamine was carried out via a one-pot reaction. It was verified that the reactions behaved more effectively in the absence of solvents and thus, 6 Knoevenagel adducts $5 \mathbf{a}-\mathbf{b}, \mathbf{5 d - f}$ and $\mathbf{5 i}$ were synthesized in $1 \mathrm{~h}$ of reaction at $85^{\circ} \mathrm{C}$, $10 \mathrm{~W}$ of potency. The adducts $\mathbf{5 b}, \mathbf{5 f}$ and $\mathbf{5 i}$ were isolated with respectively $3 \%, 5 \%$ and $6 \%$ yield. Finally, four Knoevenagel adducts, 2d, 2g, 2j and $\mathbf{2 k}$, synthesized between aldehydes and the methyl cyanoacetate 2' were selected to perform biotransformation reactions with the marine environment fungus Penicillium citrinum CBMAI 1186. Initially the purpose of these reactions was reduce the adduct's carbon-carbon double bond, which would result in a stereogenic center. Reactions were carried out in 1, 2, 3 and 5 days and no biohydrogenation reactions were observed, but biotransformation reactions were observed, since the oxidized products (as carboxylic acids) and reduced (as alcohols) of the respective forming aldehydes of Knoevenagel adducts among other compounds. From this study, it was possible to conclude that the fungus Penicillium citrinum CBMAI 1186 had a greater ability to biotransform the Knoevenagel adducts than to stereoselectively reduce the carbon-carbon double bond. In short, from the environmentally sustainable methodologies, 31 compounds were obtained, of which 5 were unpublished in the literature. and the vast majority of the rest were synthesized for the first time under the effect of microwave irradiation.
\end{abstract}




\section{LISTA DE FIGURAS}

Figura 1. Representação do espectro eletromagnético.

Figura 2. Esquema ilustrando a diferença entre o aquecimento convencional e o aquecimento por irradiação micro-ondas.

Figura 3. Representação do comportamento das moléculas na presença de um campo eletromagnético (E). (A) Moléculas com seus polos alinhados com o campo eletromagnético aplicado. (B) Desordem observada quando o campo eletromagnético é removido. Energia previamente absorvida no alinhamento agora é liberada na forma de calor.

Figura 4. Representação do mecanismo de condução iônica na presença de um campo eletromagnético, onde os cátions migram em direção ao polo negativo e os ânions ao polo positivo.

Figura 5. Exemplos de cromenos com atividades biológicas comprovadas. ...........................22

Figura 6. Ilustração do efeito do mecanismo de polarização dipolar em moléculas polares sob o efeito de um campo elétrico oscilante.

Figura 7. Cromatogramas das reações de síntese do aduto 2a. O cromatogramas em azul é referente a reação realizada em reator MO utilizando TEA. O cromatograma em rosa é referente a reação realizada em chapa de aquecimento. Ambas as reações foram realizadas a $85^{\circ} \mathrm{C}$....59

Figura 8. Estrutura dos adutos de Knoevenagel 2a-i sintetizados via irradiação MO na presença de água ou etanol como solventes próticos.

Figura 9. Espectro de absorção na região do infravermelho (puro, $\mathrm{cm}^{-1}$ ) do aduto $\mathbf{2 b}$............62

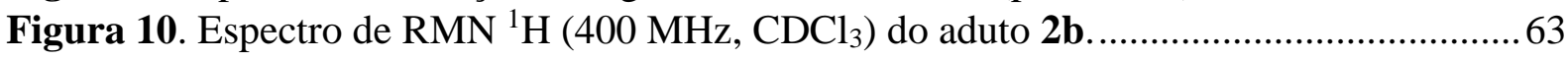

Figura 11. Espectro de $\mathrm{RMN}{ }^{13} \mathrm{C}\left(100 \mathrm{MHz}, \mathrm{CDCl}_{3}\right)$ do aduto $\mathbf{2 b}$........................................64

Figura 12. Espectro de massas do aduto $\mathbf{2 b}$ realizado com método de ionização por IE $(70 \mathrm{eV})$.

Figura 13. (A) Cromatograma da fração 12 (em azul) e da fração 17 (em rosa). (B) Espectro de massas do aduto de Knoevenagel $\mathbf{2 j}$ etoxilado referente ao pico eluído em $25 \mathrm{~min}$. (C) Espectro de massas do aduto de Knoevenagel $\mathbf{2} \mathbf{j}$ referente ao pico eluído em 24 min. (D) Espectro de massas referente ao pico eluído em $30 \mathrm{~min}\left(\mathbf{3 g}^{\mathbf{g}}\right)$.

Figura 14. Estruturas dos derivados de $4 H$-cromenos 3a-j sintetizados por irradiação MO via

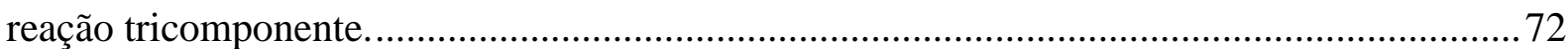

Figura 15. Espectro de absorção na região do infravermelho (puro, $\mathrm{cm}^{-1}$ ) do derivado de $4 H$ cromeno $\mathbf{3 b}$

Figura 16. Modelo ORTEP e a estrutura do $4 H$-cromeno 3k utilizado como referência para as atribuições dos sinais de $\mathrm{RMN}{ }^{1} \mathrm{H}$ e ${ }^{13} \mathrm{C}$ .74

Figura 17. Espectro de RMN ${ }^{1} \mathrm{H}\left(400 \mathrm{MHz}\right.$, DMSO- $\left.d_{6}\right)$ do derivado de $4 H$-cromeno $3 \mathbf{b}$..... 75

Figura 18. Espectro de $\mathrm{RMN}{ }^{13} \mathrm{C}\left(100 \mathrm{MHz}, \mathrm{DMSO}-d_{6}\right)$ do derivado de $4 H$-cromeno $3 \mathbf{b} . . .76$

Figura 19. Espectro de massas do derivado de $4 H$-cromeno $3 \mathbf{b}$ realizado em um espectrômetro de massas LTQ-Orbitrap Velos (Thermo Scientific) com fonte de ionização eletronspray em modo positivo $[\mathrm{M}+\mathrm{H}]^{+}$.

Figura 20. Ilustração da reatividade de cetonas e aldeídos por efeitos eletrônicos................. 78

Figura 21. Trajetória de Bürgi-Dunitz observada em ataques nucleofílicos a carbonila. .......79

Figura 22. Síntese do aduto $5 \mathbf{i}$ que resultou no produto 6a. (A) Cromatograma obtido da síntese

(B) Espectro de massas do produto identificado como $\mathbf{6 a}$.

Figura 23. Cromatogramas referentes as reações realizadas pela metodologia base forte $(\mathrm{NaOH})$ e o espectro de massas (IE, $70 \mathrm{eV}$ ) do respectivo aduto de Knoevenagel, 5a-c e 5e-h. (A) aduto $5 \mathbf{b}(\mathrm{B})$ aduto $\mathbf{5 c}(\mathrm{C})$ aduto $5 \mathbf{e}(\mathrm{D})$ aduto $\mathbf{5 f}(\mathrm{E})$ aduto $\mathbf{5 g}(\mathrm{F})$ aduto $\mathbf{5 h}$ 
Figura 24. Cromatogramas referente as reações realizadas pela metodologia em meio básico (TEA) e o espectro de massas (IE, $70 \mathrm{eV}$ ) dos respectivos adutos de Knoevenagel, 5a, 5d e 5i. (A) aduto $5 \mathbf{a}(\mathrm{B})$ aduto $\mathbf{5 d}(\mathrm{C})$ aduto $\mathbf{5 i}$.

Figura 25. Espectro de absorção na região do infravermelho (puro, $\mathrm{cm}^{-1}$ ) do aduto 5i..........90

Figura 26. Espectro de $\mathrm{RMN}{ }^{1} \mathrm{H}\left(400 \mathrm{MHz}, \mathrm{DMSO}-d_{6}\right)$ do aduto de Knoevenagel 5i...........91

Figura 27. Espectro de RMN ${ }^{13} \mathrm{C}\left(100 \mathrm{MHz}, \mathrm{DMSO}-d_{6}\right)$ do aduto de Knoevenagel 5i. ........ 92

Figura 28. Proposta de adição do íon hidreto pela ene-redutase contida no fungo $P$. citrinum CBMAI 1186.

Figura 29. Cromatogramas das biotransformações do aduto $\mathbf{2 d}$ com o fungo $P$. citrinum

CBMAI 1186 e os espectros de massas dos produtos de biotransformações

.96

Figura 30. Biotransformação do aduto $2 \mathrm{~g}$ realizada pelo fungo $P$. citrinum CBMAI 1186. ..98

Figura 31. Biotransformação do aduto $2 \mathbf{j}$ realizada pelo fungo $P$. citrinum CBMAI 1186..101

Figura 32. Biotransformação do aduto 2k realizada pelo fungo P. citrinum CBMAI 1186. 104

Figura 33. Reação controle do aduto $2 d$ realizada em 5 dias. 107 


\section{LISTA DE TABELAS}

Tabela 1. Exemplos de adutos de Knoevenagel utilizados na síntese de compostos com atividades biológicas.

Tabela 2. Condensação de Knoevenagel entre aldeídos aromáticos e o cianoacetato de etila ou a malononitrila catalisadas por TPP.

Tabela 3. Sínteses de Knoevenagel utilizando condições convencionais em comparação a radiação MO.

Tabela 4. Condensação de Knoevenagel entre cetonas, a malononitrila ou o cianoacetato de etila utilizando líquido iônico como catalisador.

Tabela 5. Condensação de Knoevenagel entre cetonas, a malononitrila ou o cianoacetato de etila utilizando um polímero como catalisador.

Tabela 6. Síntese de derivados de $4 H$-cromenos utilizando a radiação micro-ondas descritos na literatura.

Tabela 7. Metodologias desenvolvidas recentemente para a síntese do aduto de Knoevenagel 2a entre o benzaldeído 1a e o cianoacetato de metila 2' e o primeiro exemplo desta reação assistida por radiação MO.

Tabela 8. Otimização da condensação de Knoevenagel para a síntese do aduto 2a por irradiação $\mathrm{MO}$ em presença de $\mathrm{H}_{2} \mathrm{O}$.

Tabela 9. Otimização da condensação de Knoevenagel para a síntese do aduto 2a por irradiação $\mathrm{MO}$ em presença de $\mathrm{H}_{2} \mathrm{O}$ e TEA.

Tabela 10. Síntese de adutos de Knoevenagel 2a-l, entre aldeídos aromáticos e o cianoacetato de metila 2' sob irradiação $\mathrm{MO}$ utilizando $\mathrm{H}_{2} \mathrm{O}$ ou EtOH.

Tabela 11. Fator de dissipação de alguns solventes orgânicos [81].

Tabela 12. Metodologias descritas na literatura sobre a síntese bicomponente do derivado de $4 H$-cromeno 3a utilizando o aduto de Knoevenagel 2a e a dimedona 3'

Tabela 13. Metodologias descritas na literatura sobre a síntese tricomponente do $4 H$-cromeno 3a utilizando o benzaldeído 1a, o cianoacetato de metila 2' e a dimedona 3'.

Tabela 14. Síntese one-pot tricomponente de derivados de $4 H$-cromenos 3a-j por irradiação MO.

Tabela 15. Reação de Knoevenagel entre a malononitrila 2' e a acetofenona 1a, utilizando diferentes solventes pela metodologia por base forte $(\mathrm{NaOH})$.

Tabela 16. Síntese de adutos de Knoevenagel em meio básico $(\mathrm{NaOH})$ utilizando diferentes cetonas em THF.

Tabela 17. Uso de diferentes solventes na síntese one-pot do aduto 2a utilizando TEA........86 Tabela 18. Síntese de adutos de Knoevenagel entre cetonas aromáticas e a malononitrila 5' utilizando TEA por irradiação MO. 


\section{LISTA DE ESQUEMAS}

Esquema 1. Mecanismo geral para a reação de Knoevenagel entre a acetofenona e a

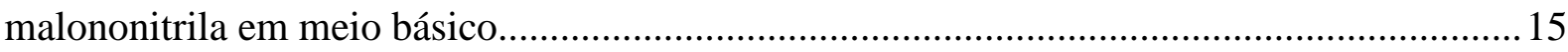

Esquema 2. Condensação de Knoevenagel aplicada na síntese do fármaco Atorvastatina. ... 17

Esquema 3. Adutos de Knoevenagel sintetizados utilizando condições brandas.................... 18

Esquema 4. Adutos de Knoevenagel sintetizados utilizando PAMAM. ................................ 18

Esquema 5. Síntese de adutos de Knoevenagel utilizando aldeídos aromáticos e a malononitrila

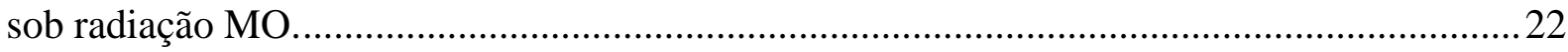

Esquema 6. Condensação de Knoevenagel entre cetonas e a cianoacetamida na presença de [Ti(OiPr)4] e piridina como catalisador.

Esquema 7. Exemplos de transformações sintéticas que podem ser realizadas com os adutos de

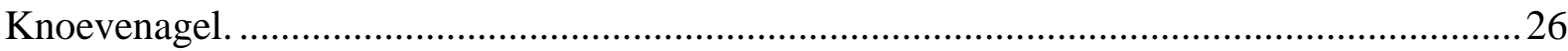

Esquema 8. Fusão dos anéis benzeno e pirano resultando em $2 H$ e $4 H$-cromenos................. 26

Esquema 9. Representação mecanística da síntese de derivados de $4 H$-cromenos a partir de

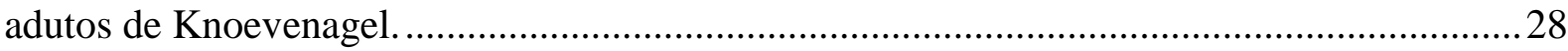

Esquema 10. Síntese tricomponente de derivados de $4 \mathrm{H}$-cromenos utilizando $\mathrm{KF}-\mathrm{Al}_{2} \mathrm{O}_{3}$ em EtOH.

Esquema 11. Síntese tricomponente de derivados de $4 H$-cromenos em meio aquoso utilizando $\mathrm{FeNi}_{3}-\mathrm{SiO}_{2}$.

Esquema 12. Síntese tricomponente de derivados de $4 H$-cromenos em meio aquoso utilizando DBU.

Esquema 13. Síntese tricomponente de derivados de $4 H$-cromenos utilizando EtONa na

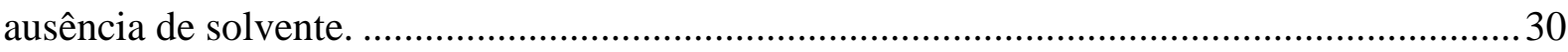

Esquema 14. Síntese tricomponente de derivados de $4 \mathrm{H}$-cromenos utilizando $\left(\mathrm{NH}_{4}\right)_{2} \mathrm{HPO}_{4} \mathrm{em}$ $\mathrm{H}_{2} \mathrm{O} / \mathrm{EtOH}$..

Esquema 15. (A) Reação de biotransformação de pesticida por fungos de ambiente marinho

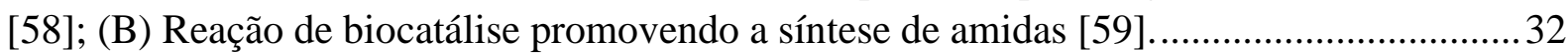

Esquema 16. Síntese da acrilamida pelo método químico ou biocatalítico. ............................33

Esquema 17. Reações de bio-hidrogenação realizadas pelo fungo P. citrinum CBMAI 1186. (A) Bio-hidrogenação de adutos de Knoevenagel (B) Bio-hidrogenação de cetonas $\alpha, \beta$ insaturadas.

Esquema 18. Síntese de adutos de Knoevenagel entre aldeídos aromáticos e o cianoacetato de metila 2' utilizando TEA em reator MO.

Esquema 19. Síntese one-pot tricomponente de derivados de $4 H$-cromenos entre aldeídos aromáticos, o cianoacetato de metila 2' e a 5,5-dimetilciclo-hexano-1,3-diona 3', utilizando TEA em reator MO.

Esquema 20. Síntese de adutos de Knoevenagel entre cetonas aromáticas e a malononitrila 5' utilizando $\mathrm{NaOH}$.

Esquema 21. Síntese de adutos de Knoevenagel entre cetonas aromáticas e a malononitrila 5'

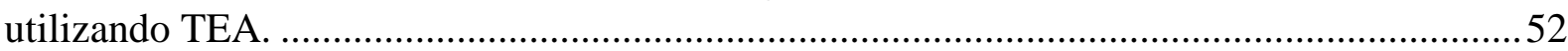

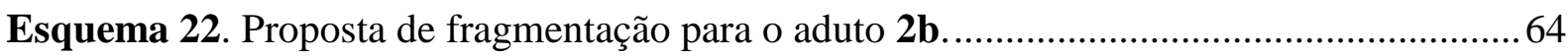

Esquema 23. Reação do EtOH com o cianoacetato de metila seguida da síntese do $4 H$-cromeno 3g.

Esquema 24. Proposta de formação do produto 6a via reação de Michael entre a malononitrila 5' e o aduto de Knoevenagel 5i. 
Esquema 25. Formação de dióis, hemicetais e acetais a partir de cetonas em solventes

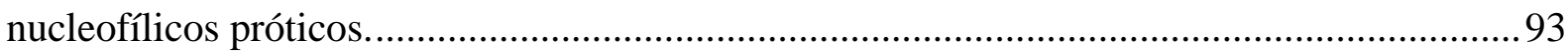

Esquema 26. Proposta de biorredução do aduto 2d pelo fungo P. citrinum CBMAI 1186 ...95

Esquema 27. Proposta de rotas de biotransformações do aduto 2d pelo fungo $P$. citrinum

CBMAI 1186.

Esquema 28. Proposta de rota de biotransformação do aduto $2 \mathrm{~g}$ pelo fungo $P$. citrinum $\mathrm{CBMAI}$

1186.

Esquema 29. Proposta de rota de biotransformação do aduto $2 \mathbf{j}$ pelo fungo $P$. citrinum CBMAI 1186. 103

Esquema 30. Proposta de rota de biotransformação do aduto $2 \mathbf{k}$ pelo fungo $P$. citrinum CBMAI 1186. 


\section{Lista de abreviações}

$\mathrm{AC}=$ aquecimento convencional

$\mathrm{MO}=$ micro-ondas

QV = química verde

$\mathrm{TEA}=$ trietilamina

RMN = ressonância magnética nuclear

$\mathrm{IV}=$ infra-vermelho

CG-EM = cromatografia gasosa espectrometria de massas

$\mathrm{THF}=$ tetraidrofurano

AcOEt $=$ acetato de etila

$\mathrm{MeOH}=$ metanol

$\mathrm{EtOH}=$ etanol 


\section{ÍNDICE}

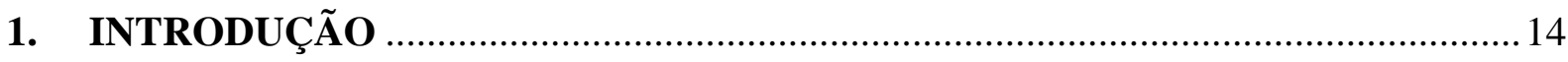

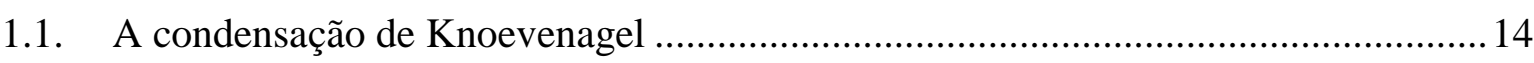

1.1.1. O uso da radiação micro-ondas em condensações de Knoevenagel................... 19

1.2. Síntese de derivados de $4 H$-cromenos a partir de adutos de Knoevenagel.................26

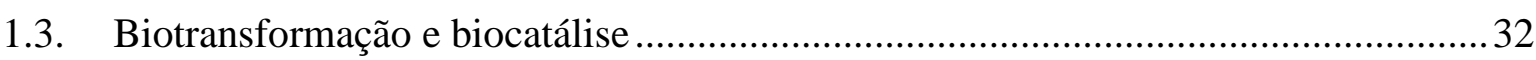

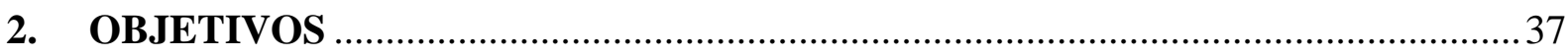

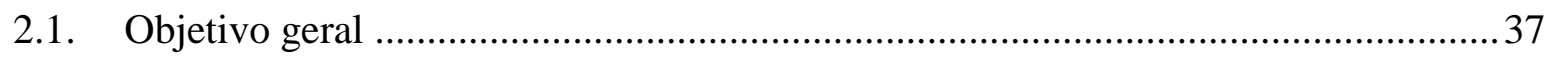

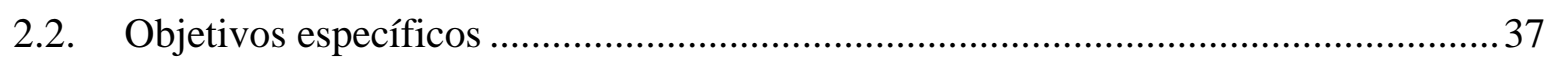

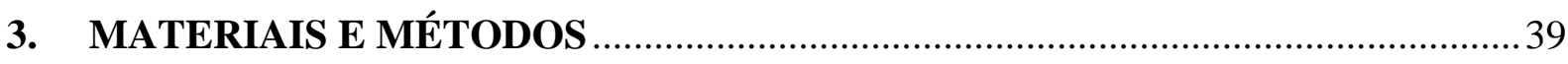

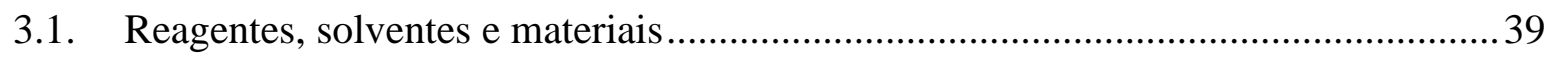

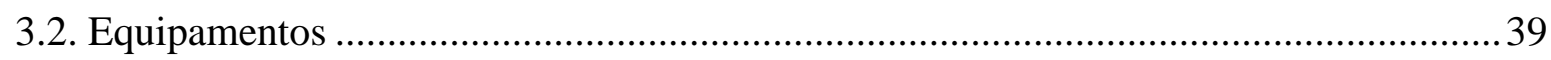

3.2.1. Cromatógrafo a gás acoplado ao espectrômetro de massas (CG/EM) ................... 39

3.2.2. Espectroscopia de Infravermelho-Transformada de Fourier (IV) .......................... 40

3.2.3. Espectroscopia de Ressonância Magnética Nuclear (RMN) ................................ 40

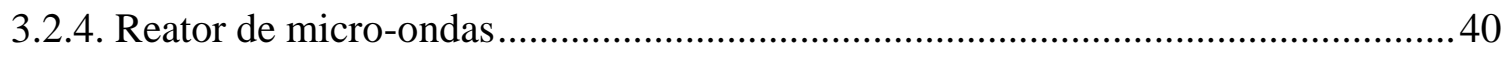

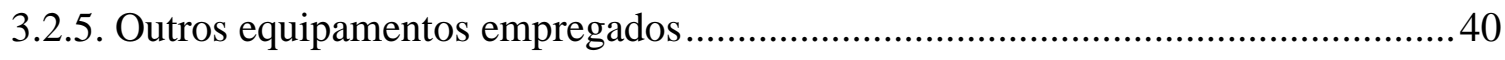

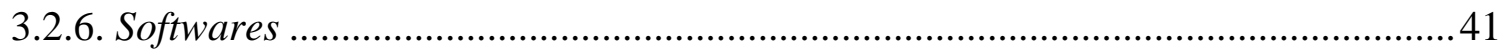

3.3. Metodologias de sínteses e biotransformações.............................................................. 41

3.3.1. Síntese de adutos de Knoevenagel entre aldeídos e cianoacetato de metila 2' por

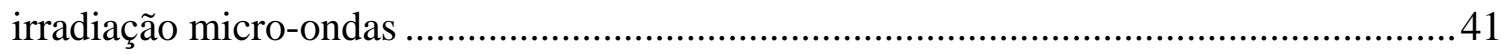

3.3.2 Síntese one-pot tricomponente de derivados de $4 H$-cromenos por irradiação micro-ondas

3.3.3. Síntese de adutos de Knoevenagel entre cetonas aromáticas e a malononitrila 5'.50

3.4. Biotransformação dos adutos de Knoevenagel $\mathbf{2 d}, \mathbf{2 g}, \mathbf{2 j}$ e $\mathbf{2 k}$ sintetizados entre aldeídos aromáticos e cianoacetato de metila $\mathbf{2}$ '

3.4.1. Isolamento e cultivo do fungo marinho P. citrinum CBMAI 1186 53

3.4.2. Biotransformação dos adutos $\mathbf{2 d}, \mathbf{2 g}, \mathbf{2 j}$ e $\mathbf{2 k}$ pelo fungo $P$. citrinum CBMAI 1186 53

4. RESULTADOS E DISCUSSÃO 55

4.1. Condensação de Knoevenagel entre os aldeídos aromáticos e o cianoacetato de metila 2'

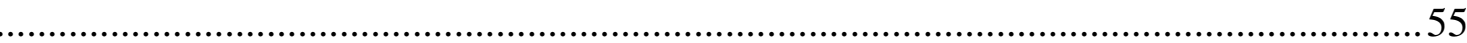

4.2. Síntese one-pot tricomponente de derivados de $4 H$-cromenos ...................................65

4.3. Condensação de Knoevenagel entre cetonas aromáticas e a malononitrila $\mathbf{5}$ '..............78 
4.4. Biotransformação de adutos de Knoevenagel obtidos a partir de aldeídos e cianoacetato

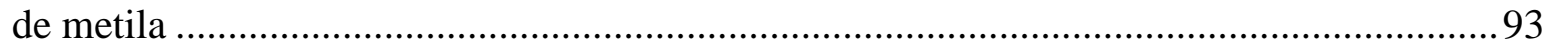

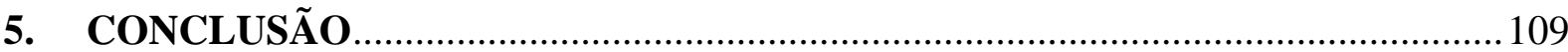

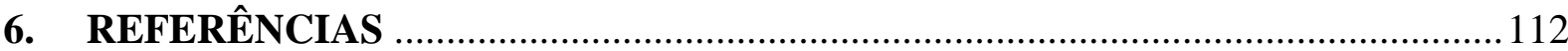

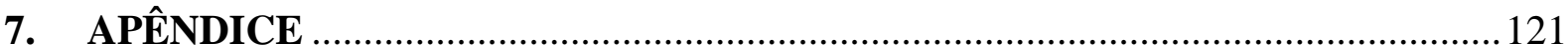

7.1. Espectros dos adutos 2a-l sintetizados entre aldeídos aromáticos e o cianoacetato de metila 2', 121

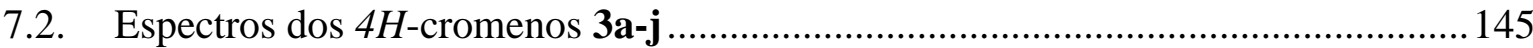

7.3. Espectros dos adutos $\mathbf{5 b}$, 5e e $\mathbf{5 f}$ sintetizados entre cetonas aromáticas e a malononitrila 5 , 

INTRODUÇÃO 


\section{INTRODUÇÃO}

\subsection{A condensação de Knoevenagel}

A síntese orgânica convencional teve uma significante contribuição na produção de uma série de compostos, principalmente moléculas com potencial para aplicações farmacêuticas [1]. No entanto, muitos procedimentos sintéticos convencionais são caracterizados por um forte impacto negativo quando estes são avaliados pelos princípios da Química Verde (QV), como o uso de solventes tóxicos, grande consumo de energia ou a baixa economia atômica [2]. É possível notar a incorporação gradativa destes parâmetros na síntese orgânica contemporânea, avaliando a evolução dos procedimentos sintéticos utilizados, por exemplo, na condensação de Knoevenagel, um tipo de condensação aldólica, desde sua descoberta no século 20.

A condensação de Knoevenagel sempre esteve presente em uma ampla gama de reações na química orgânica devido ao seu potencial para formar novas ligações carbono-carbono [3]. Esta reação é geralmente realizada entre substâncias carboniladas (aldeídos ou cetonas) e compostos metilênicos ativos (moléculas portadores de hidrogênios ácidos) na presença de diferentes tipos de catalisadores como ácidos, bases e também solventes [4]. Sendo assim, o que difere a condensação de Knoevenagel frente às reações aldólicas clássicas é a elevada acidez dos compostos metilênicos ativos $(p K a<15)$ quando comparados aos hidrogênios $\alpha$ carbonílicos ( $p K a$ 19-22) das cetonas e dos aldeídos [5].

O mecanismo geral desta reação é demonstrado no Esquema 1. A etapa inicial envolve a desprotonação do composto metilênico ativo (malononitrila - $p K a$ 11) pela trietilamina (TEA), a qual exerce a função de catalisador. Após a geração do ânion, a acetofenona sofre o ataque nucleofílico do mesmo, gerando um intermediário que, ao eliminar uma molécula de água (condensação), resulta no aduto de Knoevenagel funcionalizado. 
Esquema 1. Mecanismo geral para a reação de Knoevenagel entre a acetofenona e a malononitrila em meio básico.

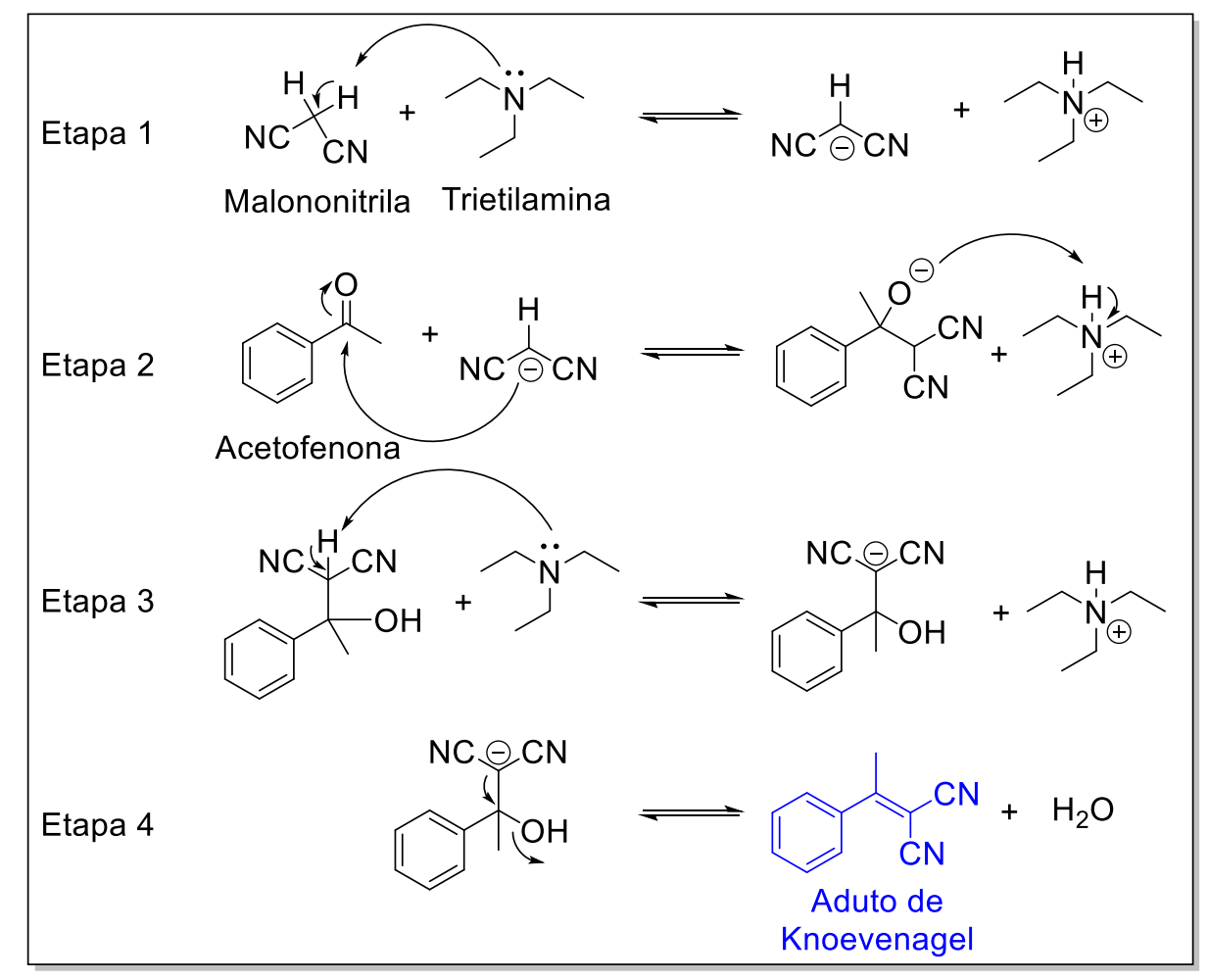

Quanto a sua aplicabilidade, os adutos de Knoevenagel e a reação de condensação possuem relevância na produção de compostos com atividade biológica e na indústria farmacêutica, principalmente como intermediários sintéticos, usualmente nomeados como "blocos construtores" de moléculas mais complexas. A Tabela 1 ilustra alguns exemplos de aplicações de diferentes adutos de Knoevenagel na síntese de compostos com atividades biológicas. 
Tabela 1. Exemplos de adutos de Knoevenagel utilizados na síntese de compostos com atividades biológicas.

$$
\begin{aligned}
& \begin{array}{ll}
\text { Reação } & \text { Aplicação/Referência }
\end{array} \\
& \text { CN } \\
& \mathrm{MgO} \\
& \underset{\text { t.a., } 15 \mathrm{~min}}{\stackrel{\text { Sem solvente }}{\longrightarrow}} \\
& \text { (N) } \\
& \text { (rend }=75 \% \text { ) } \\
& \text { (rend=85\%) } \\
& \overbrace{\mathrm{CN}}^{\mathrm{CN}}+{ }_{\mathrm{CN}}^{\mathrm{Et}} \\
& (\text { rend }=77 \%) \\
& \text { 住 } \\
& \text { (N) } \\
& \text { (rend }=72 \% \text { ) }
\end{aligned}
$$




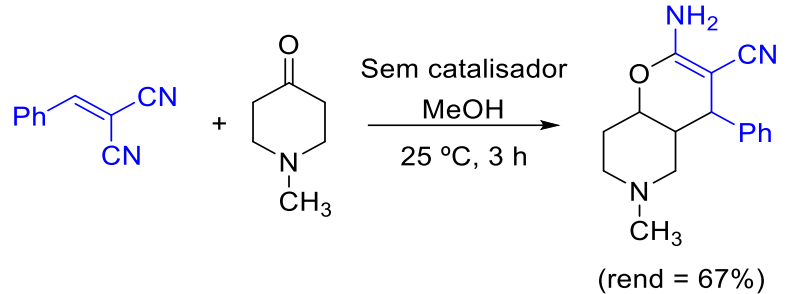

Propriedades vasodilatadoras Girgis et al. [13]

TEA = Trietilamina. DMF = Dimetilformamida. TBAI = Iodeto de tetrabutilamônio. DMA = Dimetilacetamida.

A consequência destas propriedades (bioatividades) é o alto valor agregado a alguns compostos. Entre os 20 medicamentos mais vendidos em 2010, a Atorvastatina estava no topo, correspondendo a US\$12,6 bilhões em vendas [14]. Na síntese de Atorvastatina utiliza-se a condensação de Knoevenagel para se obter um produto intermediário deste fármaco (Esquema 2) $[15]$.

Esquema 2. Condensação de Knoevenagel aplicada na síntese do fármaco Atorvastatina.

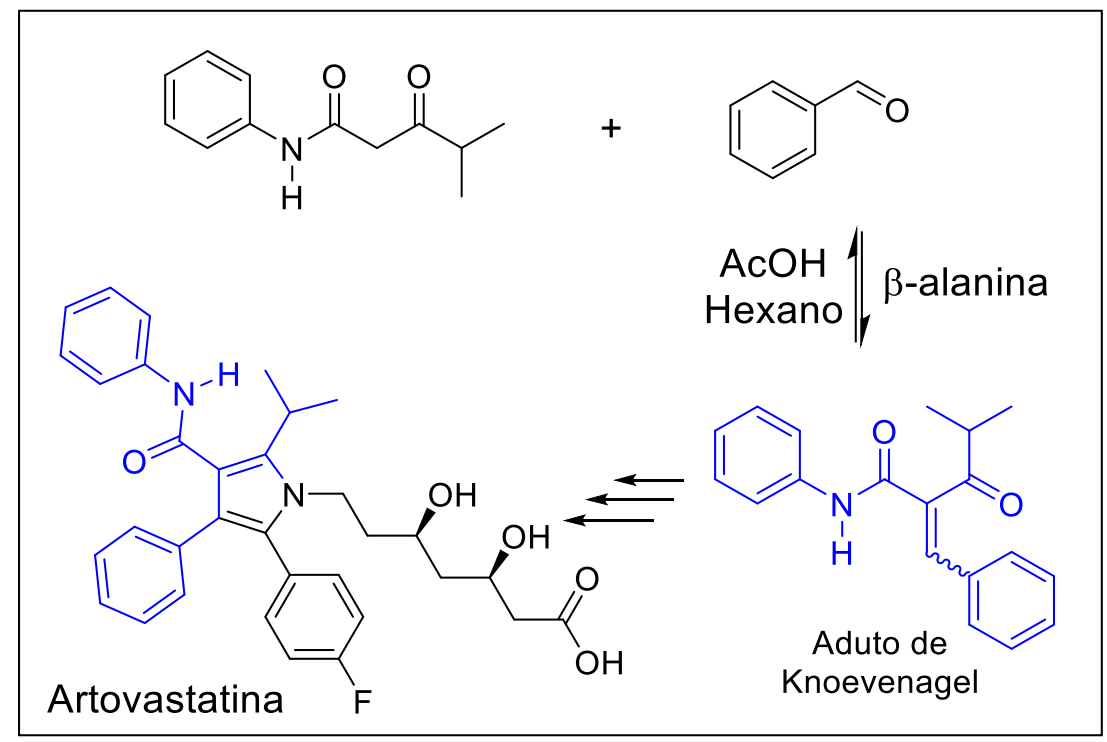

Diversos autores já descreveram um número significativo de metodologias sintéticas usando diferentes condições de reação, diferentes tipos de bases [16], ácidos de Lewis [17], catalisadores metálicos [18], fibras sintéticas [19], uso de ultra-som [20] ou polímeros [21]. Essas metodologias, nomeadas como convencionais pois em alguns aspectos não estão alinhadas aos princípios da QV, demostraram algumas desvantagens, como a baixa capacidade de reutilização dos catalisadores, bem como o custo elevado ou a sua disponibilidade limitada, temperatura e tempos reacionais elevados para obter altos rendimentos ou o uso de solventes tóxicos. 
Por esta razão, o desenvolvimento de uma nova geração da reação de Knoevenagel baseada em procedimentos sintéticos mais limpos e não nocivos ao ambiente tornou-se necessária. Uma metodologia sintética "verde" foi proposta por Trotzki et al. [22]. Os autores obtiveram adutos de Knoevenagel com $>99 \%$ de rendimento a $25{ }^{\circ} \mathrm{C}$ utilizando solventes menos tóxicos como o etanol, porém em um longo tempo reacional de $24 \mathrm{~h}$ (Esquema 3).

Esquema 3. Adutos de Knoevenagel sintetizados utilizando condições brandas.

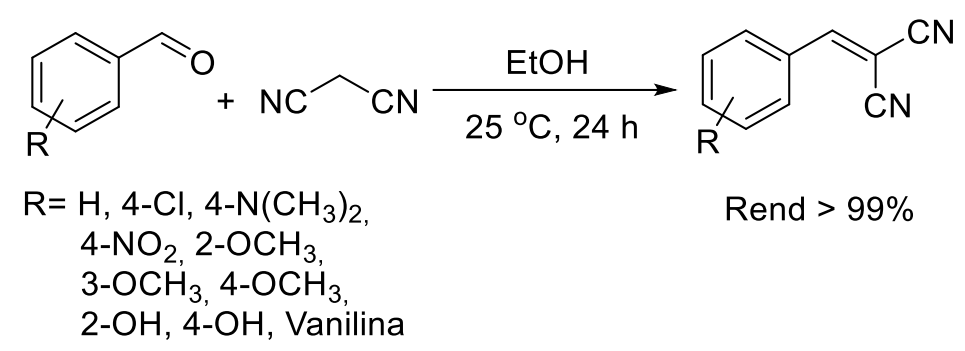

Krishnan et al. [23] desenvolverem uma metodologia sintética empregando a poliamidamina (PAMAM) na condensação de Knoevenagel (Esquema 4). Essas reações resultaram em rendimentos elevados para a síntese dos adutos de Knoevenagel (>97\%) em curtos períodos de reação (2-4 min). Os destaques deste trabalho estão associados ao uso de $\mathrm{H}_{2} \mathrm{O}$ como solvente e por não haver necessidade de purificação dos produtos devido aos valores de rendimentos elevados.

Esquema 4. Adutos de Knoevenagel sintetizados utilizando PAMAM.

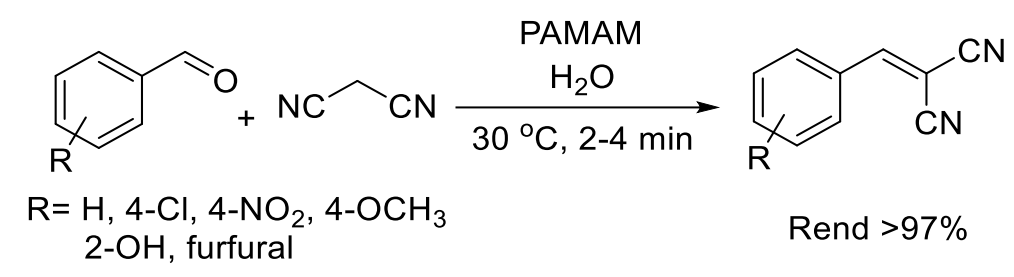

As metodologias anteriores demostraram ser bons procedimentos sintéticos, porém ainda foram dependentes de catalisadores [23] ou de longos períodos reacionais [22] para atingir valores elevados de rendimentos.

Com o objetivo de otimizar ainda mais as metodologias sintéticas existentes e torná-las mais benignas ao meio ambiente, os pesquisadores começaram a testar e implementar novas estratégias para realizar a reação de condensação de Knoevenagel. Uma alternativa bemsucedida foi o uso da radiação micro-ondas (MO), a qual permitiu uma redução nos tempos 
reacionais, bem como possibilitou o uso de solventes "verdes" e, em alguns casos, dispensando o uso de catalisadores de alto custo e até mesmo de solventes.

\subsubsection{O uso da radiação micro-ondas em condensações de Knoevenagel}

As MO estão localizadas no espectro eletromagnético entre as radiações na região do infravermelho e as ondas de rádio, na faixa de frequência de 300 a $300.000 \mathrm{MHz}$ (Figura 1) [1] e [24].

Figura 1. Representação do espectro eletromagnético.

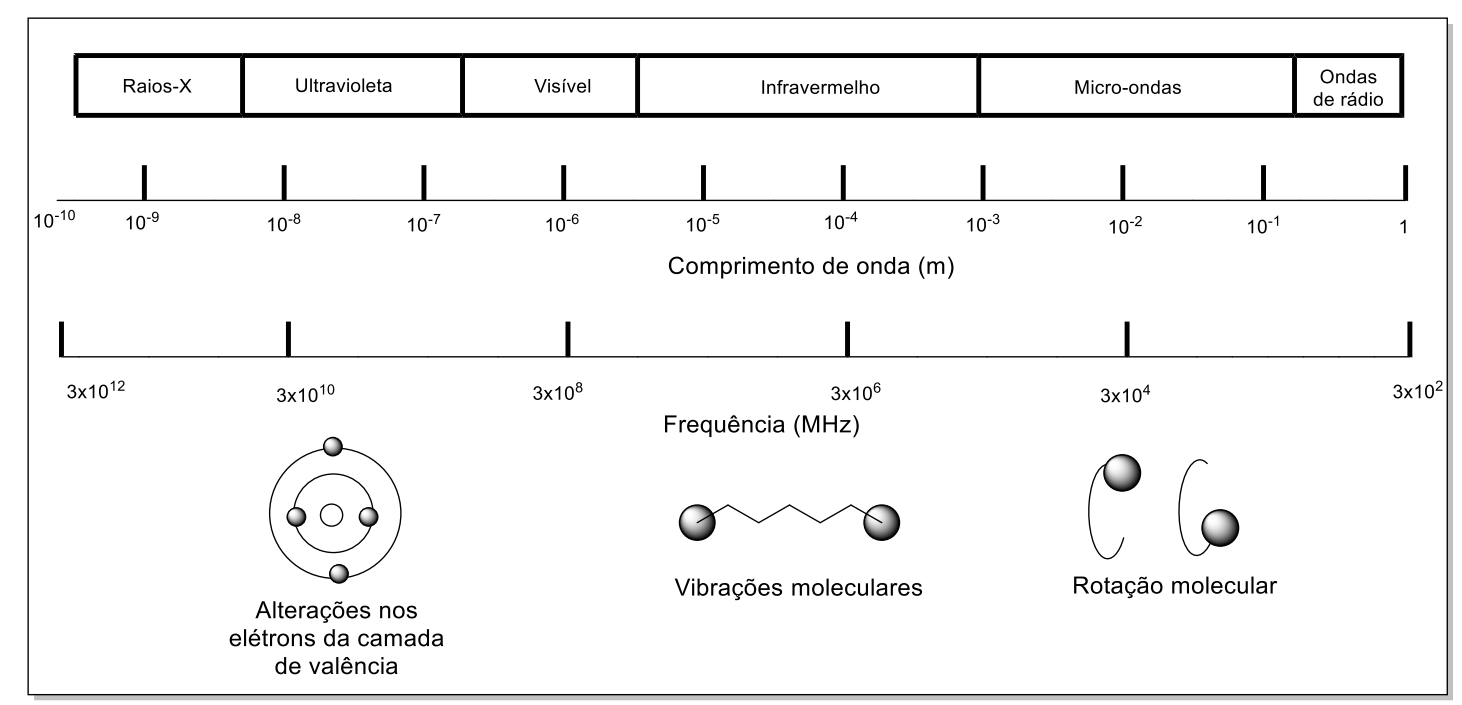

Mesmo com os fornos MO sendo produzidos desde 1970 para o uso doméstico, o primeiro relato do uso desta radiação para promover reações orgânicas ocorreu somente em 1986. Os estudos foram desenvolvidos por Gedye [25] e Giguerre [26], nos quais foi utilizado um forno de MO doméstico para auxiliar as reações de esterificação e de cicloadição.

Apesar dos fornos de MO domésticos mostrarem-se eficientes para desenvolver sínteses orgânicas, os riscos associados à inflamabilidade dos solventes orgânicos e a falta de sistemas disponíveis parar controlar a temperatura, a pressão e a potência foram as principais razões para o desenvolvimento de reatores de MO específicos para sínteses orgânicas. Hoje, nestes reatores é possível controlar todos os parâmetros descritos e ainda possuem sistemas de agitação magnética e refluxo, garantindo maior reprodutibilidade e segurança nos experimentos [1] e [2].

Um exemplo do avanço desta técnica foi observado quando a radiação MO foi utilizada para auxiliar as reações de condensação de Knoevenagel, diminuindo significativamente o 
tempo reacional, em alguns casos de horas para minutos. Corroborando com a eficiência desta técnica, muitos estudos na literatura aplicaram diferentes condições reacionais (em sua maioria utilizando aldeídos como compostos carbonilados) e comprovaram as vantagens e os benefícios do uso da radiação MO em comparação ao método de aquecimento convencional [4].

Yadav et al. [27] realizaram um estudo comparativo da condensação de Knoevenagel entre o método convencional de aquecimento e o aquecimento via radiação MO. Em ambos os casos, a trifenilfosfina (TPP) foi utilizada como catalisador (base de Lewis) e um grande número de aldeídos aromáticos foram combinados com o cianoacetato de etila ou a malononitrila. Em geral, foram obtidos altos rendimentos em ambas as metodologias. Bem como, observou-se um significante contraste de tempo entre as reações em realizadas com aquecimento convencional (AC), na faixa de 4 horas, e por radiação $\mathrm{MO}$, em apenas 2 a 5 minutos devido à eficiência da técnica por aquecimento via radiação MO. Todas as reações foram realizadas a $80^{\circ} \mathrm{C}$ (Tabela 2).

Tabela 2. Condensação de Knoevenagel entre aldeídos aromáticos e o cianoacetato de etila ou a malononitrila catalisadas por TPP.

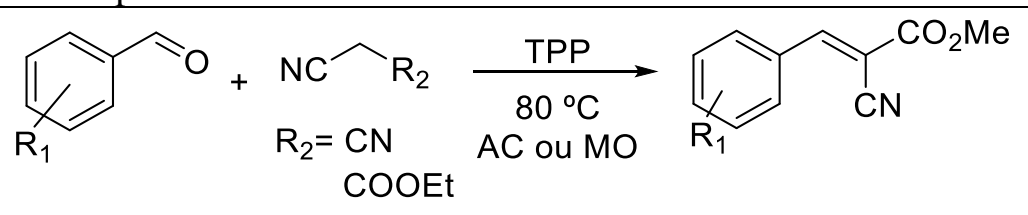

\begin{tabular}{|c|c|c|c|c|c|}
\hline $\mathrm{R}_{1}$ & $\mathrm{R}_{2}$ & $\begin{array}{c}\text { Tempo } \\
\text { (h) }\end{array}$ & $\begin{array}{c}\text { Rendimento }^{\mathrm{a}} \\
\mathrm{O}(\mathrm{c})\end{array}$ & $\begin{array}{c}\text { Tempo } \\
\text { (min) }\end{array}$ & Rendimento $_{(\%)}^{\mathrm{b}}$ \\
\hline $\mathrm{H}$ & COOEt & 4,0 & 85 & 3 & 90 \\
\hline $4-\mathrm{Cl}$ & COOEt & 3,0 & 87 & 3 & 92 \\
\hline $4-\mathrm{NO}_{2}$ & COOEt & 2,5 & 90 & 2 & 95 \\
\hline $4-\mathrm{OCH}_{3}$ & COOEt & 4,5 & 82 & 4 & 85 \\
\hline $4-\mathrm{CH}_{3}$ & COOEt & 3,5 & 85 & 3 & 91 \\
\hline 4-OH & COOEt & 5,0 & 78 & 4 & 82 \\
\hline $\begin{array}{c}3-\mathrm{OCH}_{3}, 4- \\
\mathrm{OCH}_{3}, 5- \\
\mathrm{OCH}_{3}\end{array}$ & COOEt & 5,0 & 79 & 4 & 82 \\
\hline 2-OH & COOEt & 5,5 & 85 & 5 & 89 \\
\hline $4-\mathrm{OCH}_{3}$ & $\mathrm{CN}$ & 4,0 & 83 & 4 & 86 \\
\hline
\end{tabular}

Rai et al. [28] desenvolveram a síntese de piridonas na qual utilizaram a condensação de Knoevenagel como uma etapa chave de todo o processo. De acordo com este estudo foram obtidos rendimentos mais elevados e tempos de reação significativamente inferiores quando a 
síntese foi assistida com a radiação MO em comparação com a síntese que foi realizada em chapa de aquecimento convencional e agitação magnética (Tabela 3 ).

Tabela 3. Sínteses de Knoevenagel utilizando condições convencionais em comparação a radiação MO.<smiles>[R]c1ccc(C=[O+])cc1</smiles>

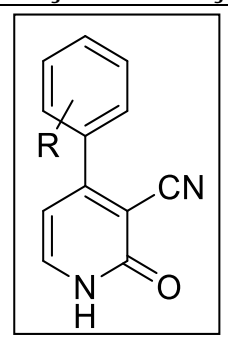

Moléculas alvo (piridonas)

\begin{tabular}{ccccc}
\hline $\mathrm{R}$ & $\begin{array}{c}\text { Tempo } \\
(\mathrm{h})\end{array}$ & Rendimento $^{\mathrm{a}}(\%)$ & $\begin{array}{c}\text { Tempo } \\
(\mathrm{s})\end{array}$ & Rendimento $^{\mathrm{b}}(\%)$ \\
\hline $\mathrm{C}_{6} \mathrm{H}_{5}$ & 4 & 98 & 20 & 99 \\
$4-\mathrm{ClC}_{6} \mathrm{H}_{4}$ & 6 & 92 & 30 & 98 \\
$3-\mathrm{OCH}_{3}, 4-$ & 7,5 & 91 & 50 & 98 \\
$\mathrm{OCH}_{3} \mathrm{C}_{6} \mathrm{H}_{4}$ & 7 & 93 & 40 & 97 \\
$4-\mathrm{CH}_{3} \mathrm{OC}_{6} \mathrm{H}_{4}$ & 7 & 94 & 25 & 99 \\
$4-\mathrm{CH}_{3} \mathrm{C}_{6} \mathrm{H}_{4}$ & 5 & 85 & 60 & 96 \\
$3-\mathrm{NO}_{2} \mathrm{C}_{6} \mathrm{H}_{4}$ & 8 & 75 & 70 & 92 \\
$2-\mathrm{NO}_{2} \mathrm{C}_{6} \mathrm{H}_{4}$ & 9 & 80 & 65 & 95 \\
$4-\mathrm{NO}_{2} \mathrm{C}_{6} \mathrm{H}_{4}$ & 8,5 & &
\end{tabular}

Recentemente em nosso grupo de pesquisa foi desenvolvido um estudo sobre a condensação de Knoevenagel sob efeito da radiação MO. Jimenez et al. [29] utilizaram o metanol como solvente, $60{ }^{\circ} \mathrm{C}, 30 \mathrm{~min}$ e $20 \mathrm{~W}$ de potência para sintetizar uma série de adutos de Knoevenagel entre aldeídos aromáticos e a malononitrila com rendimentos na faixa de 8599\% (Esquema 5). Somando a eficiência deste processo, os cristais puros foram obtidos de maneira simples, apenas por lavagens com solventes quentes (diclorometano e hexano 1:1) o que facilitou o processo de isolamento dos produtos. 
Esquema 5. Síntese de adutos de Knoevenagel utilizando aldeídos aromáticos e a malononitrila sob radiação $\mathrm{MO}$.

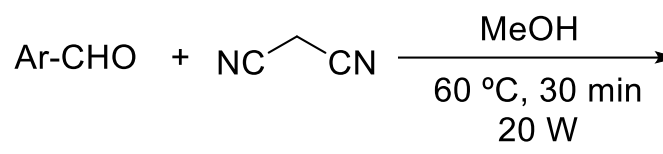<smiles>N#CC(C#N)=C[Al]</smiles>

$$
\begin{aligned}
\mathrm{Ar}= & \mathrm{C}_{6} \mathrm{H}_{5}(\text { rend }=98 \%) \\
& 4-\mathrm{BrC}_{6} \mathrm{H}_{4}(\text { rend }=93 \%) \\
& 4-\mathrm{ClC}_{6} \mathrm{H}_{4}(\text { rend }=95 \%) \\
& 4-\mathrm{FC}_{6} \mathrm{H}_{4}(\text { rend }=98 \%) \\
& 4-\mathrm{NO}_{2} \mathrm{C}_{6} \mathrm{H}_{4}(\text { rend }=95 \%) \\
& 4-\mathrm{OHC}_{6} \mathrm{H}_{4}(\text { rend }=93 \%) \\
& 4-\mathrm{CH}_{3} \mathrm{OC}_{6} \mathrm{H}_{4}(\text { rend }=99 \%) \\
& \text { 2-furano }(\text { rend }=95 \%) \\
& \text { 3-nicotina (rend }=90 \%) \\
& \text { 2-tiofeno (rend }=85 \%)
\end{aligned}
$$

A vantagem do uso de radiação MO está fundamentada nos mecanismos de aquecimento. O processo de aquecimento convencional é fundamentalmente diferente do aquecimento por irradiação de MO (Figura 2). No aquecimento convencional, uma fonte externa de energia atinge as paredes do recipiente e o calor é transferido da superfície do frasco para o interior da solução (reagentes e solventes), resultando em um aquecimento não homogêneo do sistema. Em contraste, o aquecimento por radiação de MO a energia é transferida diretamente para as substâncias por meio de dois mecanismos: a rotação dipolar e a condução iônica [1] e [30].

Figura 2. Esquema ilustrando a diferença entre o aquecimento convencional e o aquecimento por irradiação micro-ondas.

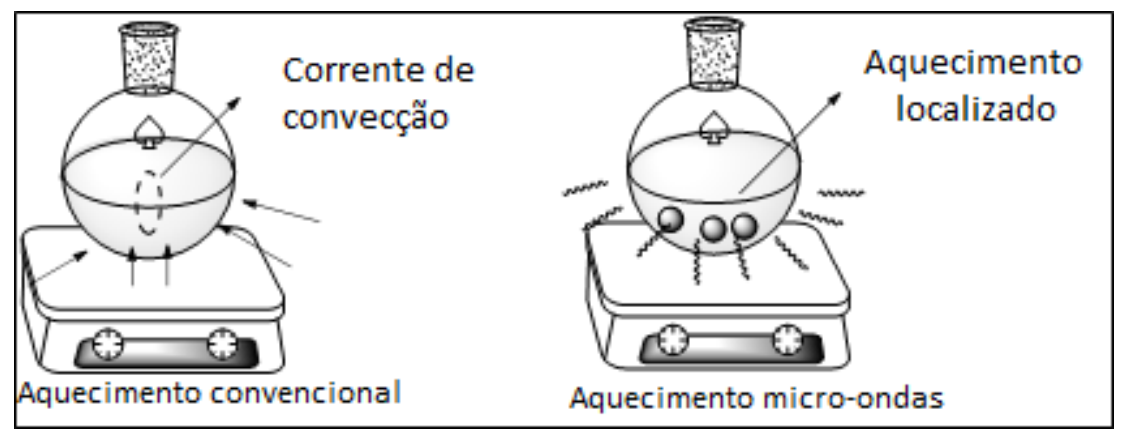

Fonte: Autoria própria 
A rotação dipolar (Figura 3) é o efeito que as moléculas polares sofrem (se alinham) com o campo elétrico aplicado. Quando o campo elétrico é removido, as moléculas retornam a desordem e liberam a energia previamente absorvida na forma de calor [1] e [30].

Figura 3. Representação do comportamento das moléculas na presença de um campo eletromagnético (E). (A) Moléculas com seus polos alinhados com o campo eletromagnético aplicado. (B) Desordem observada quando o campo eletromagnético é removido. Energia previamente absorvida no alinhamento agora é liberada na forma de calor.

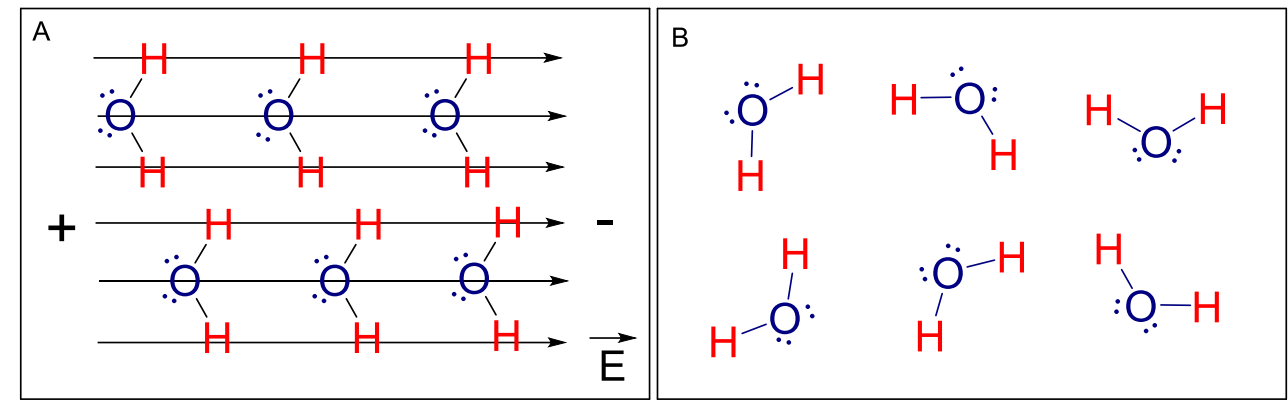

A condução iônica (Figura 4) refere-se à migração dos íons no sentido do campo eletromagnético, sendo esta migração suscetível a choques entre íons de cargas opostas, fenômeno responsável por resultar em calor. Assim, pode-se inferir que o aquecimento via radiação MO é realizado de maneira localizada para as moléculas [1] e [30].

Figura 4. Representação do mecanismo de condução iônica na presença de um campo eletromagnético, onde os cátions migram em direção ao polo negativo e os ânions ao polo positivo.

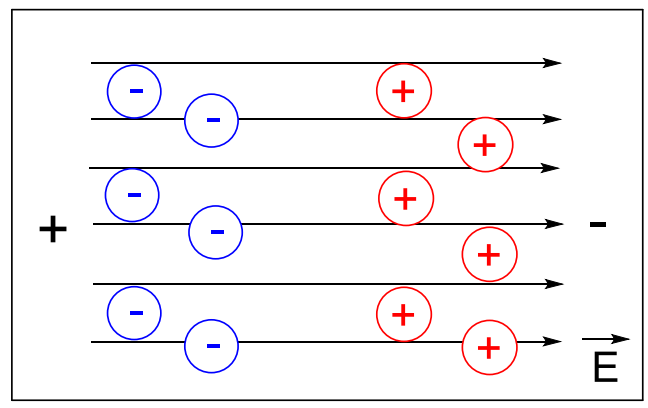

A partir do que foi exposto, é notável constatar que a grande maioria dos estudos desenvolvidos na literatura envolvem o uso de aldeídos como compostos carbonílicos devido as suas altas reatividades, sendo assim, facilitando a obtenção de altos rendimentos em curtos períodos reacionais para os adutos de Knoevenagel. Contudo, esta reação torna-se mais difícil quando se trata de cetonas, que são compostos carbonílicos menos reativos frente a reações de adições nucleofílicas. Na grande maioria dos estudos descritos na literatura sobre a condensação 
de Knoevenagel utilizando cetonas, catalisadores específicos foram necessários, altas temperaturas ou geralmente longos períodos reacionais.

Gupta et al. [31] realizaram três condensações utilizando diferentes cetonas aromáticas, a malononitrila ou o cianoacetato de etila (Tabela 4). Neste trabalho, foram obtidos bons rendimentos dos adutos de Knoevenagel na faixa de $84-85 \%$, em tempos reacionais de $2-5 \mathrm{~h}$, a $60{ }^{\circ} \mathrm{C}$. Contudo, se fez necessário o uso de um líquido iônico, o brometo de 1-butil-3metilimidazólio $[\mathrm{Bmim}]^{+}[\mathrm{Br}]^{-}$, como catalisador, o que pode limitar a viabilidade do processo.

Tabela 4. Condensação de Knoevenagel entre cetonas, a malononitrila ou o cianoacetato de etila utilizando líquido iônico como catalisador.

\begin{tabular}{|c|c|c|c|}
\hline & & $\begin{array}{l}\mathrm{H}_{2} \mathrm{O} \\
\mathrm{O} \text { iônico }\end{array}$ & \\
\hline $\mathrm{R}_{1}$ & $\mathrm{R}_{2}$ & Tempo (h) & Rendimento (\%) \\
\hline $\mathrm{H}$ & $\mathrm{CN}$ & 2 & 85 \\
\hline $\mathrm{Br}$ & $\mathrm{CO}_{2} \mathrm{Et}$ & 5 & 84 \\
\hline $\mathrm{NO}_{2}$ & $\mathrm{CO}_{2} \mathrm{Et}$ & 4 & 85 \\
\hline
\end{tabular}

Krishnan e colaboradores [32] descreveram o uso de dendrímeros de poliamidamina (PAMAM) em suporte de poliestireno como um catalisador básico que auxilia na formação de novas ligações $\mathrm{C}-\mathrm{C}$ partindo de cetonas. Neste trabalho o $\mathrm{EtOH}$ foi utilizado como solvente, a $50{ }^{\circ} \mathrm{C}$, em 30-45 min e obtiveram rendimentos elevados (> 95\%, Tabela 5). Porém, novamente empregou-se um catalisador específico que pode limitar a viabilidade da reação.

Tabela 5. Condensação de Knoevenagel entre cetonas, a malononitrila ou o cianoacetato de etila utilizando um polímero como catalisador.

\begin{tabular}{ccc}
\hline & Tempo (min) & Rendimento (\%) \\
\hline $\mathrm{R}_{2}$ & 30 & 98 \\
$\mathrm{CO}_{2} \mathrm{Et}$ & 45 & 95 \\
\hline
\end{tabular}

Robichaud e colaboradores [33] descreveram o uso de um sistema catalítico composto por tetraisopropóxido de titânio $\left[\mathrm{Ti}(\mathrm{OiPr})_{4}\right]$ e piridina em condensações de Knoevenagel com a 
cianoacetamida e derivados da acetofenona. Foram obtidos rendimentos elevados dos adutos de Knoevenagel (> 93\%), utilizando o tetraidrofurano (THF) como solvente, à temperatura ambiente (t.a.) durante 15-72 h de reação (Esquema 6).

Esquema 6. Condensação de Knoevenagel entre cetonas e a cianoacetamida na presença de [Ti( $\left.(\mathrm{OiPr})_{4}\right]$ e piridina como catalisador.

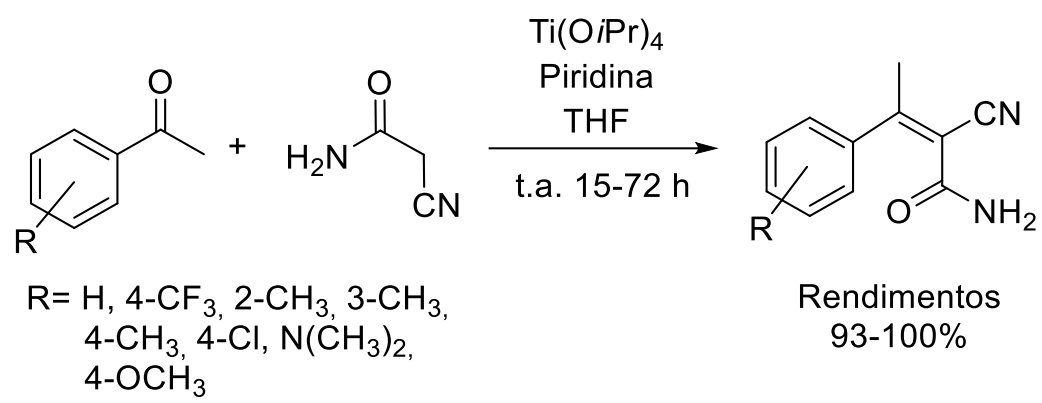

Todos estes exemplos refletem de certa forma a dificuldade em utilizar cetonas na condensação de Knoevenagel, pois, em alguns casos os catalisadores não são de fácil acesso. Com isso uma das frentes deste trabalho foi desenvolver processos sintéticos simples para a obtenção de adutos a partir de cetonas aromáticas e a malononitrila, explorando também o efeito da radiação MO nestas reações.

Destaca-se que os adutos de Knoevenagel obtidos são compostos polifuncionalizados, o que possibilita uma gama de transformações sintéticas e biocatalíticas levando em produtos de interesse (algumas destas reações estão exemplificadas no Esquema 7). Outra frente deste trabalho foi sintetizar $4 H$-cromenos, que são moléculas mais complexas com aplicações biológicas já conhecidas [14, 19, 20], a partir de adutos de Knoevenagel provenientes de aldeídos aromáticos. Adicionalmente, foi realizado um estudo de biotransformação destes adutos pelo fungo de ambiente marinho Penicillium citrinum CBMAI 1186, o qual já foi avaliado pelo nosso grupo de pesquisa com potencial redutor de ligações duplas $\alpha, \beta$-insaturadas carbono-carbono [29]. 
Esquema 7. Exemplos de transformações sintéticas que podem ser realizadas com os adutos de Knoevenagel.

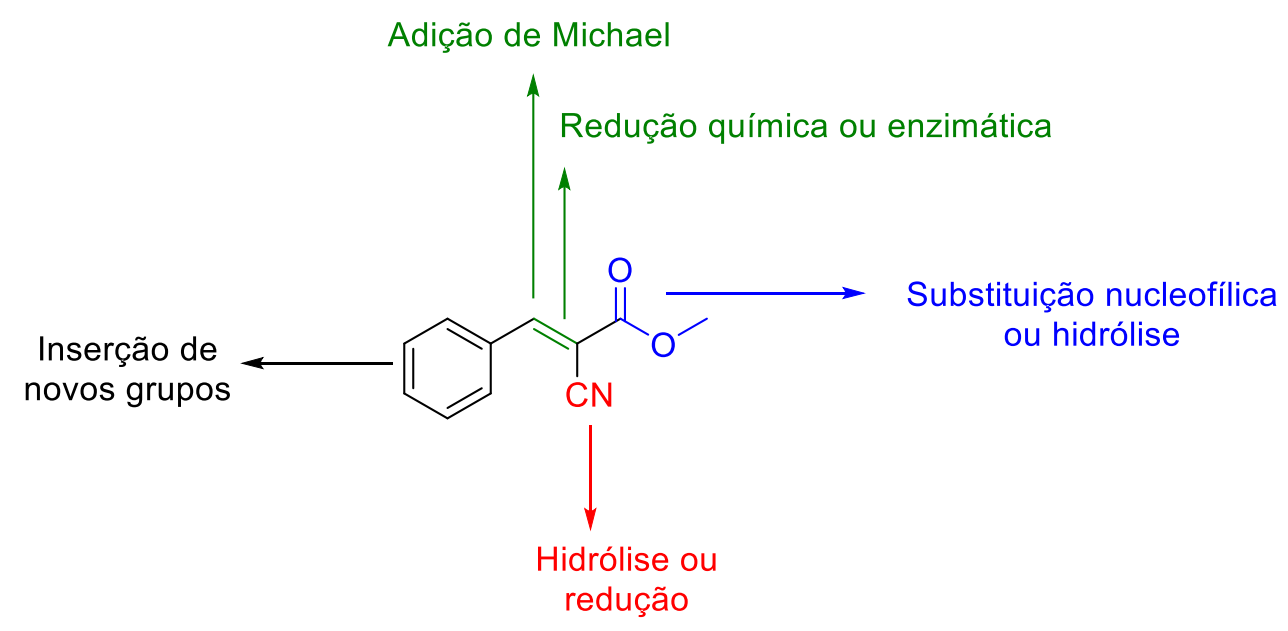

\subsection{Síntese de derivados de $4 H$-cromenos a partir de adutos de Knoevenagel}

A fusão de um anel benzênico com um anel $2 H$ ou $4 H$-pirano nas posições 5 e 6 resulta em um composto bicíclico e heterocíclico nomeado pela IUPAC como $2 \mathrm{H}$-1-benzopirano ou $4 \mathrm{H}$ 1-benzopirano (Esquema 8). Estes núcleos benzopiranos são usualmente conhecidos como $2 \mathrm{H}$ cromeno e $4 H$-cromeno. O índice numérico ( 2 ou 4) é devido a posição do átomo de carbono com hibridização $\mathrm{sp}^{3}$ no anel pirano [34].

Esquema 8. Fusão dos anéis benzeno e pirano resultando em $2 H$ e $4 H$-cromenos.

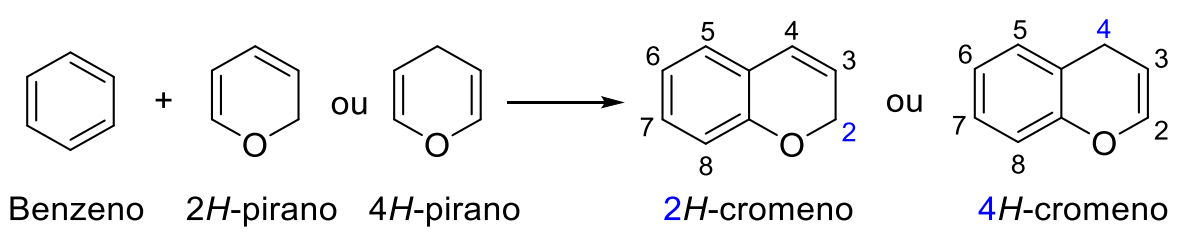

Os cromenos e seus derivados estão presentes em diversas classes de produtos naturais [35]. Após serem isolados, em muitos casos, foram identificadas distintas atividades biológicas para esta classe de compostos, sendo elas antitumorais [36], antifúngicas [37], [38] e [39], antibacterianas [40] e [41], anti-inflamatórias [42], antioxidantes [43] e [44], antivirais [45]. Algumas destas moléculas são ilustradas na Figura 5. 
Figura 5. Exemplos de cromenos com atividades biológicas comprovadas.

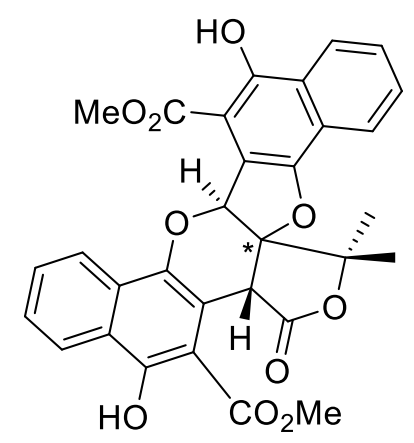

Antitumoral [36]<smiles>CC(C)=CCC[C@]1(C)C=Cc2cc(C(=O)O)cc(CC=C(C)C)c2O1</smiles>

Antifúngico [38]<smiles>CC(C)=CCc1c2c(cc3c1OC[C@](O)(c1ccc(O)cc1O)C3=O)C=CC(C)(C)O2</smiles>

Antibacteriano [40]<smiles>CC(C)=C/C(C=O)=C(/C)CCC/C(C)=C/CC[C@]1(C)CCc2cc(O)cc(C)c2O1</smiles>

Existem diferentes rotas para sintetizar cromenos e seus derivados. Contudo, uma delas envolve o uso de adutos de Knoevenagel como intermediários sintéticos. Nesta rota, ocorre uma reação de adição de Michael ao aduto, que após algumas etapas resulta no derivado de $4 \mathrm{H}$ cromeno, demonstrado mecanisticamente no Esquema 9. Esta reação inicia-se com uma base (B-) abstraindo o hidrogênio ácido da malononitrila, para gerar um ânion nucleofílico o qual promove a condensação de Knoevenagel com o aldeído. Posteriormente a base abstrai o hidrogênio ácido da dimedona formando o íon enolato. Este íon enolato ataca o aduto de Knoevenagel via uma adição de Michael, gerando um estado intermediário tetraédrico que posteriormente sofre uma ciclização intramolecular de transferência de prótons e tautomerização, resultando no derivado de $4 H$-cromeno [46]. 
Esquema 9. Representação mecanística da síntese de derivados de $4 H$-cromenos a partir de adutos de Knoevenagel.

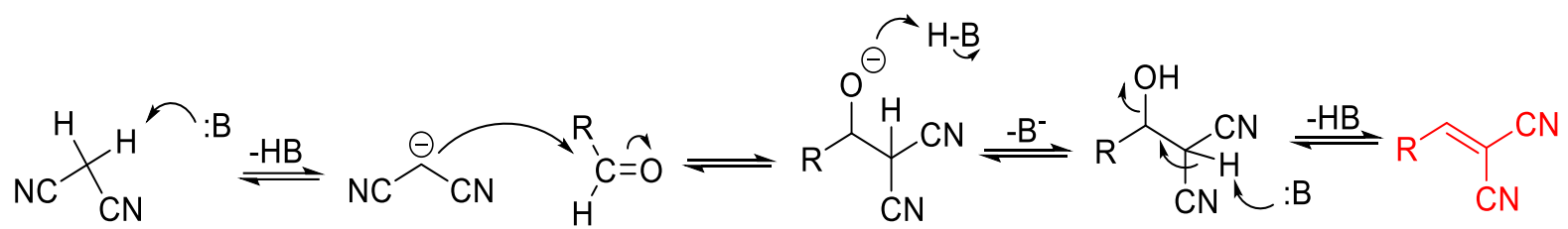

$$
B=\text { base }
$$

$\mathrm{R}=\mathrm{Ar}$

Aduto de Knoevenagel<smiles>CC(C)CC1C(=O)CC(C)(C)CC1=O</smiles>

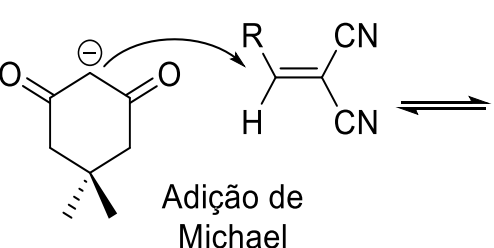

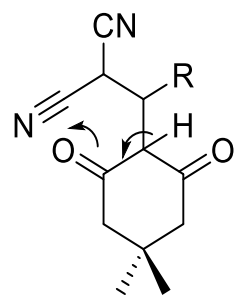

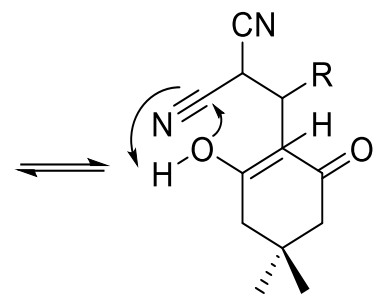<smiles>[R]C1C2=C(CC(C)(C)CC2=O)OC(=N)[C@H]1C#N</smiles><smiles>C1CCCC1</smiles><smiles>[R]C1C(C#N)=C(N)OC2=C1C(=O)CC(C)(C)C2</smiles>

Derivado de $4 \mathrm{H}$-cromeno

Baseado no exposto, diversas metodologias sintéticas estão sendo desenvolvidas para a síntese de núcleos derivados de cromenos (4H-cromenos especificamente) a partir de adutos de Knoevenagel, pois são moléculas com potenciais bioativos que podem resultar em um alto valor agregado. É de interesse que, estas metodologias sejam de baixo custo, não sejam nocivas ao ambiente, tenham um curto tempo reacional, proporcionem altos valores de rendimento e que as condições reacionais estejam alinhadas aos princípios da Química Verde.

Kharbangar et al. [47] demonstraram a eficiência do uso de $\mathrm{KF}^{-} \mathrm{Al}_{2} \mathrm{O}_{3}$ na síntese tricomponente de anéis $4 H$-piranos por meio da reação entre aldeídos aromáticos, a malononitrila e compostos metilênicos 1,3-carbonílicos ativos em etanol como solvente (Esquema 10). A reação ocorreu a t.a., entre $2-5 \mathrm{~h}$ e forneceu $4 H$-cromenos com bons rendimentos $(63-91 \%)$. 
Esquema 10. Síntese tricomponente de derivados de $4 \mathrm{H}$-cromenos utilizando $\mathrm{KF}-\mathrm{Al}_{2} \mathrm{O}_{3}$ em EtOH.<smiles>[R]c1ccc(C([CH2+])=O)cc1</smiles>

$$
\begin{array}{r}
\mathrm{R}=\mathrm{H}, \mathrm{Br}, \mathrm{Cl}, \mathrm{CH}_{3}, \\
\mathrm{~F}, \mathrm{NO}_{2}, \mathrm{OCH}_{3}
\end{array}
$$<smiles>[R]c1ccc(C2C(C#N)=C(N)OC(C)=C(C(C)=O)C2C)cc1</smiles>

Nasseri et al. [48] também descreveram a síntese de derivados de $4 H$-cromenos via reação tricomponente utilizando aldeídos aromáticos, a malononitrila e a pentano-2,4-diona na presença de nanopartículas de $\mathrm{FeNi}_{3}-\mathrm{SiO}_{2}$ em $\mathrm{H}_{2} \mathrm{O}$ (Esquema 11). O sistema foi altamente efetivo, pois as reações ocorreram em um curto período (40 min) fornecendo excelentes rendimentos (>91\%) e o catalisador foi recuperado com um imã e reutilizado em outras reações, sem perda significante em sua eficiência.

Esquema 11. Síntese tricomponente de derivados de $4 H$-cromenos em meio aquoso utilizando $\mathrm{FeNi}_{3}-$ $\mathrm{SiO}_{2}$.

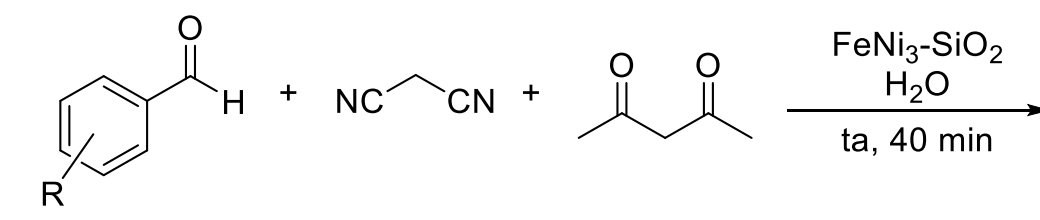

$\mathrm{R}=\mathrm{H}, 2-\mathrm{Br}, 2-\mathrm{Cl}, 4-\mathrm{Cl}, 4-\mathrm{CH}_{3}$, $4-\mathrm{F}, 4-\mathrm{NO}_{2}, 4-\mathrm{OCH}_{3}$<smiles>[R]c1ccc(C2C(C#N)=C(N)OC(C)=C2C(C)=O)cc1</smiles>

$($ rend $=91-98 \%)$

Khuarana et al. [49] desenvolveram uma metodologia de síntese multicomponente de derivados de $4 H$-cromenos, através de uma reação entre aldeídos aromáticos, o cianoacetato de etila ou a malononitrila e a dimedona em $\mathrm{H}_{2} \mathrm{O}$ utilizando DBU (1,8-diazabiciclo[5.4.0]undec7-eno) como catalisador básico (Esquema 12). É destacável o curto tempo reacional observado nesta metodologia, bem como o solvente utilizado ser a água e os elevados valores de rendimentos (85-92\%). 
Esquema 12. Síntese tricomponente de derivados de $4 H$-cromenos em meio aquoso utilizando DBU.

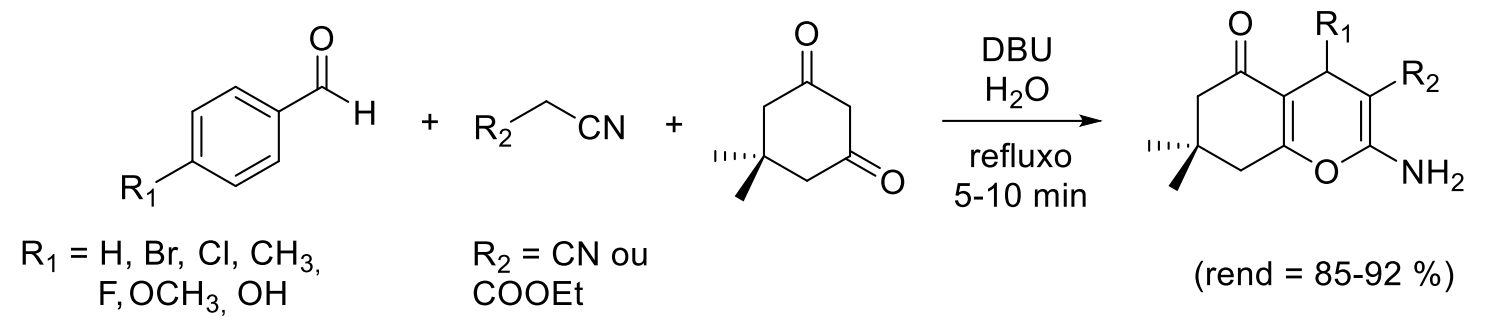

Thangamani [50] relatou a síntese de derivados de $4 H$-cromenos a partir de aldeídos aromáticos, a malononitrila e a dimedona, em um sistema livre de solventes, na presença de EtONa como catalisador (Esquema 13). Elevados valores de rendimentos foram obtidos (8797\%) em curtos períodos reacionais (4-7 $\mathrm{min})$.

Esquema 13. Síntese tricomponente de derivados de $4 H$-cromenos utilizando EtONa na ausência de solvente.

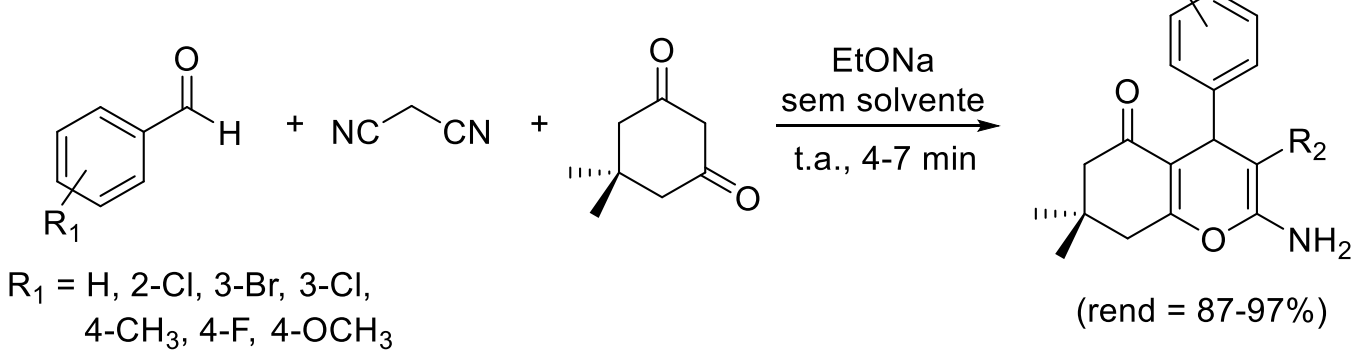

Balalaie et al. [51] reportaram um sistema sintético que fez o uso de um sal básico, $\left(\mathrm{NH}_{4}\right)_{2} \mathrm{HPO}_{4}$, como catalisador na síntese de uma série derivados de $4 H$-cromenos utilizando aldeídos aromáticos, a dimedona, a malononitrila, o cianoacetato de metila ou o cianoacetato de etila. Solventes verdes $\left(\mathrm{H}_{2} \mathrm{O}\right.$ e EtOH$)$ foram utilizados, em uma temperatura de $50{ }^{\circ} \mathrm{C}$. Elevados valores de rendimentos foram obtidos entre 0,5-2 h de reação (Esquema 14).

Esquema 14. Síntese tricomponente de derivados de $4 H$-cromenos utilizando $\left(\mathrm{NH}_{4}\right)_{2} \mathrm{HPO}_{4}$ em $\mathrm{H}_{2} \mathrm{O} / \mathrm{EtOH}$.

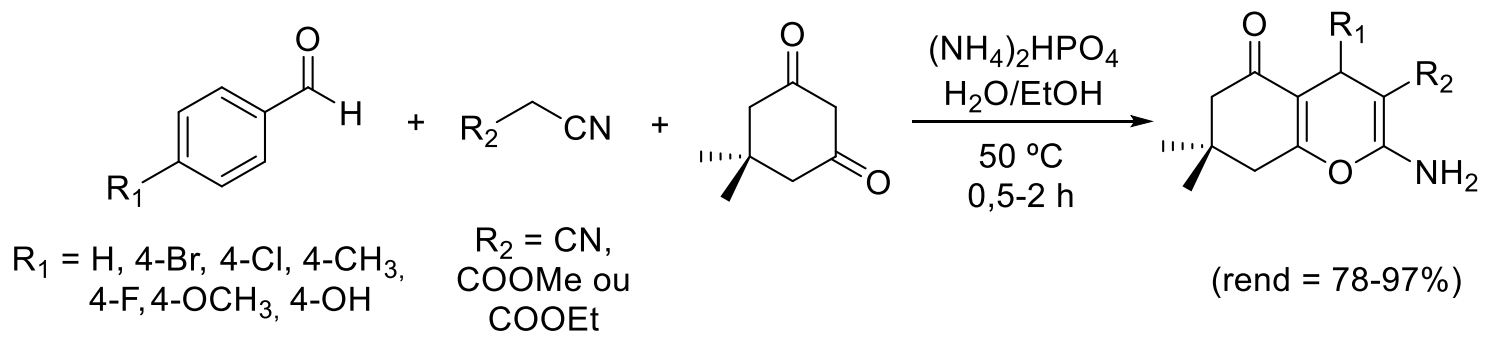


$\mathrm{Na}$ tentativa de otimizar os processos sintéticos convencionais e buscar metodologias alternativas, alguns trabalhos foram descritos na literatura utilizando a radiação MO como fonte de aquecimento na síntese de derivados de $4 H$-cromenos a partir de adutos de Knoevenagel. Como exposto na Tabela 6, os trabalhos desenvolvidos utilizando a radiação MO (geralmente com potências elevadas) forneceram bons rendimentos em períodos reacionais na escala de minutos. Também não empregaram solventes tóxicos ao meio ambiente ou até mesmo não os utilizaram. Contudo, esses trabalhos não são numerosos e geralmente empregaram como composto metilênico ativo a malononitrila, fatores que abrem espaço para o desenvolvimento de novas metodologias e abordagens que possam explorar ainda mais esta classe de reação.

Tabela 6. Síntese de derivados de $4 H$-cromenos utilizando a radiação micro-ondas descritos na literatura.

$$
\text { [55] }
$$




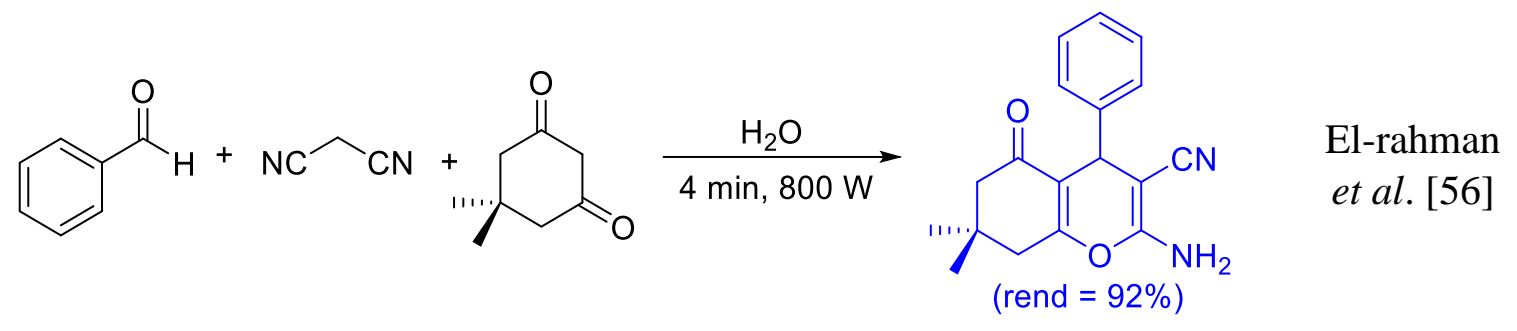

NDEAP = sílica suportada com 3-N,N-dietilaminopropilato

\subsection{Biotransformação e biocatálise}

A Biotransformação e a Biocatálise são processos em que os catalisadores biológicos (enzimas isoladas ou não isoladas) são empregados para transformar um substrato xenobiótico em um produto via reações enzimáticas [57].

A Biotransformação envolve o uso de enzimas que estão contidas nas células vivas, enquanto a Biocatálise utiliza as enzimas que estão na forma isoladas, imobilizadas, mas que não fazem parte de uma célula viva e que catalisam reações em substratos xenobióticos [57].

No Esquema 15 pode-se observar um exemplo de Biotransformação descrito por Birolli e colaboradores [58]. Neste trabalho, os fungos de ambiente marinho Aspergillus sp. CBMAI 1829, Acremonium sp. CBMAI 1676, Microsphaeropsis sp. CBMAI 1675 e Westerdykella sp. CBMAI 1679 foram utilizados para biotransformar o pesticida Cialotrina, resultando em moléculas menos tóxicas. Bem como, um exemplo de Biocatálise foi desenvolvido por Lima e Porto [59]. Neste trabalho foi utilizada a lipase de Candida antarctica (CAL-B) para catalisar uma série de reações de aminólise com alta eficiência.

Esquema 15. (A) Reação de biotransformação de pesticida por fungos de ambiente marinho [58]; (B) Reação de biocatálise promovendo a síntese de amidas [59].

(A) Biotransformação

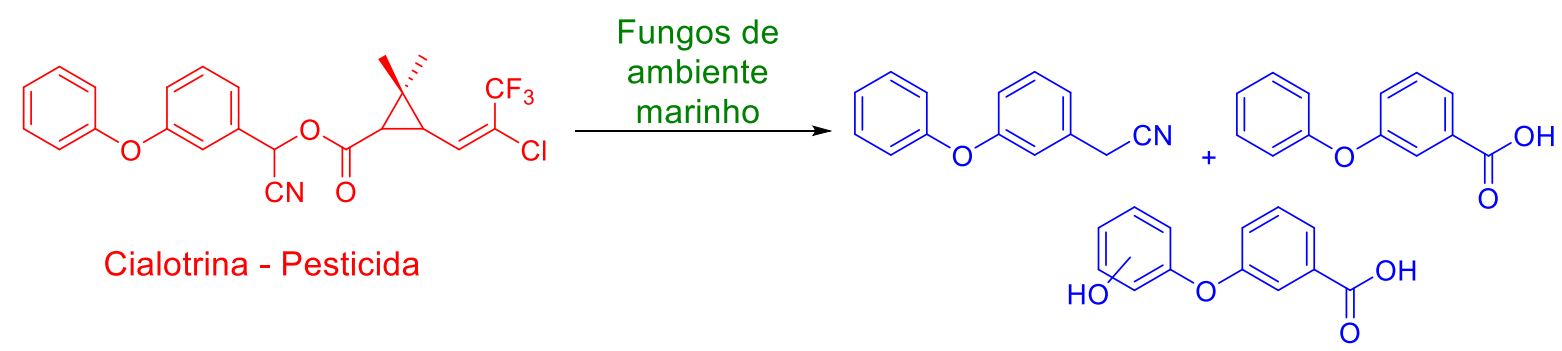


(B) Biocatálise

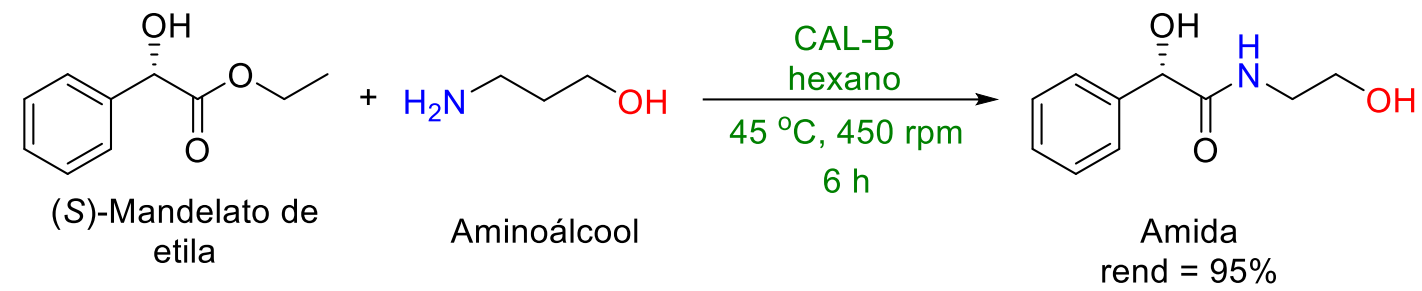

As metodologias de biocatálise e biotransformação estão cada vez mais relevantes na química orgânica sintética e tem emergido como alternativas viáveis frente aos métodos sintéticos não enzimáticos, visto os benefícios e as vantagens agregadas, sendo um dos mais estudados na obtenção de moléculas enantiopuras em condições reacionais brandas [60],[61] e [62].

Um exemplo bem sucedido que reflete os benefícios da biocatálise em relação aos métodos químicos sintéticos tradicionais está na produção da acrilamida, um importante produto químico utilizado para sintetizar poliacrilamida, que por sua vez é empregada em tratamento de águas residuais, na recuperação de petróleo e na fabricação de papel [63]

Tradicionalmente, a acrilamida pode ser produzida quimicamente pela oxidação da acrilonitrila usando $\mathrm{H}_{2} \mathrm{SO}_{4}$ como catalisador e altas temperaturas [64], porém, este processo gera poluentes para o meio ambiente. Como alternativa, a nitrila hidratase vem sendo utilizada para a produção de acrilamida. A enzima, que é expressada pela bactéria Rhodococcus rhodochrous, converte eficientemente a acrilonitrila em acrilamida em até $45 \%$ de rendimento sob condições brandas de reação (Esquema 16). No Japão, este processo biocatalítico produz mais de 650 toneladas de acrilamida por ano [63].

Esquema 16. Síntese da acrilamida pelo método químico ou biocatalítico.

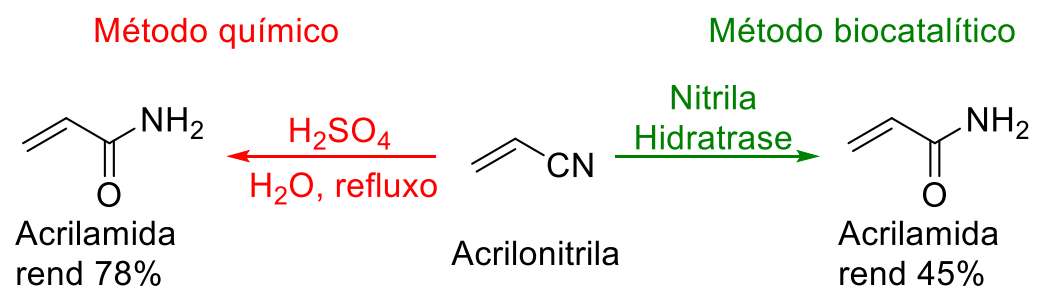

A redução régio e quimiosseletiva de compostos carbonílicos $\alpha, \beta$-insaturados catalisada por enzimas ene-redutases também é um exemplo de catálise emergente. Metodologias sintéticas para a hidrogenação de ligações duplas carbono-carbono são frequentemente relatadas pela utilização de metais como catalisadores, por exemplo, o rutênio [65], o paládio 
[66] e [67], o cobre [68] e o ródio [69]. Uma vez que estes métodos empregam metais de elevados custos e que são finitos na natureza, os métodos enzimáticos estão sendo desenvolvidos a fim de serem uma alternativa viável para a redução desta classe de compostos [70], [71] e [72].

Em nosso grupo de pesquisa já foram realizados estudos que comprovaram a eficiência do fungo de ambiente marinho Penicillium citrinum CBMAI 1186 como um agente redutor régio e quimiosseletivo de ligações duplas $\alpha, \beta$-insaturadas. Ferreira et al. realizaram reduções com este fungo em cetonas $\alpha, \beta, \gamma, \delta$ insaturadas e rendimentos satisfatórios foram obtidos [73]. No Esquema 17 está ilustrado um exemplo de bio-hidrogenação desenvolvida neste estudo. Jimenez et al. [29] desenvolveram um estudo sobre a biorredução de adutos de Knoevenagel sintetizados com diferentes aldeídos aromáticos e a malononitrila. Neste trabalho, foram obtidos rendimentos significativamente elevados (66-99\%), comprovando novamente a eficiência deste fungo e a compatibilidade dos adutos aos processos biocatalíticos. No Esquema 17 estão ilustrados alguns adutos de Knoevenagel que foram bio-hidrogenados pelo fungo $P$. citrinum CBMAI 1186. Em ambos os estudos desenvolvidos, observou-se a redução exclusivamente do sistema $\alpha, \beta$-insaturado comprovando a rpegio e a quimiosseletividade das bio-hidrogenações.

Esquema 17. Reações de bio-hidrogenação realizadas pelo fungo P. citrinum CBMAI 1186. (A) Biohidrogenação de adutos de Knoevenagel (B) Bio-hidrogenação de cetonas $\alpha, \beta$-insaturadas.

(A)

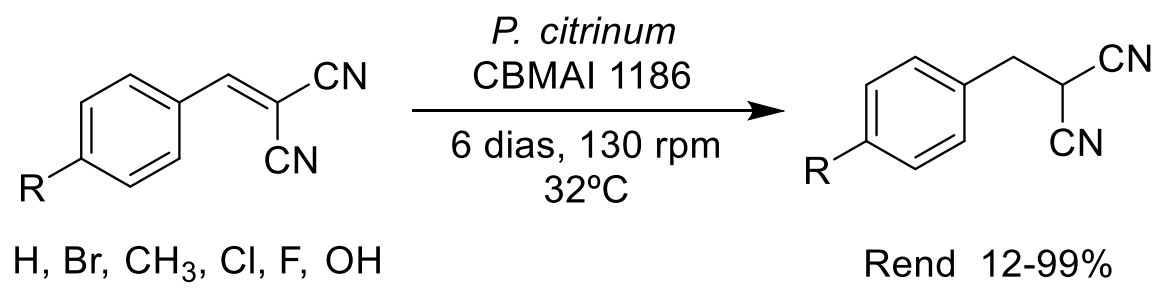

(B)<smiles>O=C(/C=C/C=C/c1ccccc1)c1ccccc1</smiles>

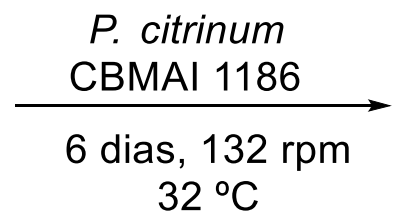<smiles>O=C(CC/C=C/c1ccccc1)c1ccccc1</smiles>

Devido ao potencial biorredutor já avaliado do fungo P. citrinum CBMAI 1186, este microrganismo foi utilizado nas reações de redução de adutos de Knoevenagel sintetizados neste trabalho. Destaca-se que, os adutos de Knoevenagel sintetizados a partir de cetonas ou de 
adeídos, possuem estruturas pró quirais, sendo assim ao reduzi-los, o produto será quiral e é possível obter excessos enantioméricos devido a estereoespecificidade das enzimas presentes no fungo.

Assim, este trabalho foi norteado pela síntese de adutos de Knoevenagel e suas possíveis aplicações utilizando metodologias com protocolos sustentáveis. 


\section{OBJETIVOS}




\section{OBJETIVOS}

\subsection{Objetivo geral}

O objetivo geral deste trabalho foi avaliar os benefícios do aquecimento via irradiação MO frente a síntese de adutos de Knoevenagel e seus derivados $4 H$-cromenos. Bem como, selecionar alguns dos compostos sintetizados para aplicar em reações de biotransformação com o fungo de ambiente marinho P. citrinum CBMAI 1186.

\subsection{Objetivos específicos}

- Desenvolver uma metodologia sintética verde em reator MO para a condensação de Knoevenagel entre aldeídos aromáticos e o cianoacetato de metila 2';

- Aplicar os adutos de Knoevenagel sintetizados para a síntese de moléculas mais complexas, no caso, a síntese one-pot tricomponente de $4 \mathrm{H}$-cromenos em reator $\mathrm{MO}$;

- Avaliar a reatividade de cetonas como compostos carbonílicos frente a reação de condensação de Knoevenagel;

- Realizar reações de biotransformação com alguns adutos de Knoevenagel sintetizados com o fungo de ambiente marinho $P$. citrinum CBMAI 1186. 


\section{MATERIAIS E MÉTODOS}




\section{MATERIAIS E MÉTODOS}

\subsection{Reagentes, solventes e materiais}

Benzaldeído 1a (99\%), 4-bromobenzaldeído 1b (99\%), 4-formilbenzoato de metila 1c (99\%) 4-clorobenzaldeído 1d (99\%), (99\%), 4-flúor-benzaldeído $1 e \quad$ (99\%), 4dimetilaminobenzaldeído 1f, 4-nitrobenzaldeído 1g (99\%), 4-metoxibenzaldeído 1h (99\%), 4hidroxibenzaldeído 1i (99\%), vanilina 1j (99\%), 3,4,5-trimetoxibenzaldeído 1k (99\%), furfural 11 (99\%), cianoacetato de metila 2' (99\%), 5,5-dimetilciclo-hexano-1,3-diona 3' (99\%), acetofenona 4a (99\%), 4-bromoacetofenona 4b (99\%), 4-metilacetofefona 4c (99\%), 4clorocetofefona 4d (98\%), 2,4-diclorocetofefona 4e (98\%), 4-flúor-acetofenona 4f (99\%), 4metoxiacetofenona $4 \mathbf{g}$ (99\%), 4-hidroxiacetofenona 4h (99\%) 2-acetilfurano 4i (99\%), malononitrila 5' (99\%), trietilamina (95\%), e os solventes hexano, acetato de etila, metanol, THF, DMSO, acetona, etanol, DMSO- $d_{6}(99,9 \%), \mathrm{MeOD}(99,9 \%), \mathrm{CDCl}_{3}(99,8 \%)$ e acetona$d_{6}(99,9 \%)$ foram obtidos de fontes comerciais e utilizados sem prévia purificação (Aldrich, Fluka, Synth, Merck e Vertec). As cromatografias em camada delgada foram realizadas em placas da marca DC-Fertigfolien ALUGRAM® XTra SIL G/UV ${ }_{254}$, com camada de 0,20 mm de sílica gel 60 com indicador fluorescente $\mathrm{UV}_{254 .}$

\subsection{Equipamentos}

\subsubsection{Cromatógrafo a gás acoplado ao espectrômetro de massas (CG/EM)}

As análises por cromatografia a gás acoplada ao espectrômetro de massas (GC-EM) foram realizadas em um aparelho da marca Shimadzu/GC 2010 com um auto-injetor Shimadzu/AOC500 e um detector de massas MS2010 plus com impacto de elétrons (IE, $70 \mathrm{eV}$ ), equipado com uma coluna de sílica fundida DB-5MS (Agilent J\&W Advances $30 \mathrm{~m}$ x 0,25 mm x 0,25 $\mu \mathrm{m}$ ). Hélio foi utilizado como gás de arraste com um fluxo constante de $0,75 \mathrm{~mL} / \mathrm{min}$ à 46,5 Kpa e o volume de injeção foi de $0,5 \mu \mathrm{L}$ de solução, com concentrações de 1 a $3 \mathrm{mg} / \mathrm{mL}$. O método de análise realizado consistiu inicialmente em manter a coluna a $90{ }^{\circ} \mathrm{C}$ durante 4 minutos e posteriormente em uma rampa de aquecimento de $6^{\circ} \mathrm{C} / \mathrm{min}$ até atingir a temperatura de $280^{\circ} \mathrm{C}$, a qual a coluna foi mantida durante 5 minutos. As injeções foram realizadas no modo split em uma razão 1:20. Os fragmentos dos íons foram detectados no intervalo de 40-500 Da. As análises foram realizadas no Laboratório de Química Orgânica e Biocatálise (IQSC-USP). 


\subsubsection{Espectroscopia de Infravermelho-Transformada de Fourier (IV)}

Os espectros de absorção no infravermelho foram obtidos em um espectrofotômetro de infravermelho com transformada de Fourier com calibração interna de marca Shimadzu, modelo IRAffinity-1. As análises foram realizadas utilizando pastilhas de $\mathrm{KBr}$ para as amostras sólidas e uma placa de cristal de silício par as amostras líquidas. As frequências de absorção foram expressas em $\mathrm{cm}^{-1}$ na faixa de $400-4000 \mathrm{~cm}^{-1}$. Todas as análises foram realizadas na Central de Análises Químicas Instrumentais (CAQI).

\subsubsection{Espectroscopia de Ressonância Magnética Nuclear (RMN)}

Os espectros de $\mathrm{RMN}$ de ${ }^{1} \mathrm{H}$ e ${ }^{13} \mathrm{C}$ foram obtidos em um espectrômetro Agilent 400/54 Premium Shielded operado na frequência de $400 \mathrm{MHz}\left(\mathrm{RMN}\right.$ de $\left.{ }^{1} \mathrm{H}\right)$ e $100 \mathrm{MHz}\left(\mathrm{RMN}{ }^{13} \mathrm{C}\right)$ ou Agilent 500/54 Premium Shielded operado na frequência de $500 \mathrm{MHz}\left(\mathrm{RMN}\right.$ de ${ }^{1} \mathrm{H}$ ) e 125 e $100 \mathrm{MHz}\left(\mathrm{RMN}^{13} \mathrm{C}\right)$. Os deslocamentos químicos $(\delta)$ foram expressos em partes por milhão (ppm), referenciados em relação ao sinal do padrão interno de tetrametilsilano (TMS) ou aos solventes deuterados utilizados $\left(\mathrm{CDCl}_{3}: \delta_{\mathrm{H}} 7,26, \mathrm{CDCl}_{3}: \delta_{\mathrm{C}} 77,16\right.$; DMSO- $d_{6}: \delta_{\mathrm{H}} 2,50, \delta_{\mathrm{C}}: 39,52$ e Acetona- $\left.d_{6}: \delta_{\mathrm{H}} 2,05, \delta_{\mathrm{C}}: 206,26\right)$. As análises de RMN foram realizadas na CAQI-IQSC.

\subsubsection{Reator de micro-ondas}

As reações foram realizadas em um reator de micro-ondas CEM Discover reflux open vessel de $300 \mathrm{~W}$, contendo sensor de infravermelho para o monitoramento da temperatura em até $300{ }^{\circ} \mathrm{C}$, uma cavidade monomodo com capacidade de uso de balões de 10-125 mL, sistema de agitação com barra magnética, entrada de ar comprimido para acelerar o resfriamento do sistema e com porta com interloque de segurança. O software acoplado ao reator, Sinergy, foi utilizado na preparação dos métodos sintéticos e para controlar as potências que neste trabalho foram na faixa de 10-55 W. As análises foram realizadas no Laboratório de Química Orgânica e Biocatálise (IQSC-USP).

\subsubsection{Outros equipamentos empregados}

Balança analítica modelo AY-220 da marca Shimadzu, pHmetro modelo 8010 da marca Qualxtron, autoclave vertical modelo Phoenix, câmara de fluxo laminar da marca Veco, Vortex motion da marca Logen Scientific, rotaevaporadores Fisaton e Tecnal T-210 equipados com bomba de vácuo TE-058 e refrigeração Tecnal modelo TE 2005, agitadores rotativos modelo 
Tecnal TE-421, Superohm G-25 ou SI-600R da analítica, aparelho de ponto de fusão Fisatom modelo 431 e câmara escura da marca Tecnal com lâmpada de UV 254 e 366 nm.

\subsubsection{Softwares}

Os nomes dos compostos sintetizados foram atribuídos segundo o software ChemBioDraw Ultra, versão 11.0, que cumpre as regras da International Union of Pure and Applied Chemistry (IUPAC). Os espectros de RMN foram analisados pelo software Mestre Nova versão 9.0.

\subsection{Metodologias de sínteses e biotransformações}

3.3.1. Síntese de adutos de Knoevenagel entre aldeídos e cianoacetato de metila 2' por irradiação micro-ondas

Em um balão reacional de $25 \mathrm{~mL}$ foram adicionados $1 \mathrm{mmol}$ de aldeído aromático 1a-l, 1 mmol de cianoacetato de metila 2' e uma mistura de $\mathrm{H}_{2} \mathrm{O} / \mathrm{TEA}$ ou EtOH/TEA ( $\left.5 \mathrm{~mL} / 15 \mu \mathrm{L}\right)$. A reação foi realizada em um reator micro-ondas, com agitação magnética por 30 min a $85{ }^{\circ} \mathrm{C}$, quando foi utilizada a água, e a $65^{\circ} \mathrm{C}$ quando foi utilizado o etanol, com uma potência de 55 W. O progresso da reação foi monitorado por CCD utilizando como eluente uma mistura de hexano e acetato de etila ( $7: 3$ ou $6: 4)$.

Posteriormente, realizou-se a extração líquido-líquido adicionando $10 \mathrm{~mL}$ de $\mathrm{H}_{2} \mathrm{O}$ e $\mathrm{AcOEt}$ $(3 \times 20 \mathrm{~mL})$. As fases orgânicas foram combinadas e o $\mathrm{Na}_{2} \mathrm{SO}_{4}$ anidro foi adicionado. Em seguida, filtrou-se e o solvente foi removido em rotaevaporador à pressão reduzida. Já as reações realizadas em EtOH foram concentradas no rotaevaporador diretamente.

Os produtos sintetizados foram purificados por lavagem com hexano quente ou por cromatografia em coluna utilizando sílica gel (35-70 $\mu \mathrm{m}$ de diâmetro de partícula e $6 \mathrm{~nm}$ de diâmetro de poro). Os adutos de Knoevenagel obtidos foram identificados e caracterizados por IV, EM e RMN ${ }^{1} \mathrm{He}^{13} \mathrm{C}$. O Esquema 18 ilustra a síntese dos adutos em meio básico utilizando TEA em reator MO. 
Esquema 18. Síntese de adutos de Knoevenagel entre aldeídos aromáticos e o cianoacetato de metila 2' utilizando TEA em reator MO.

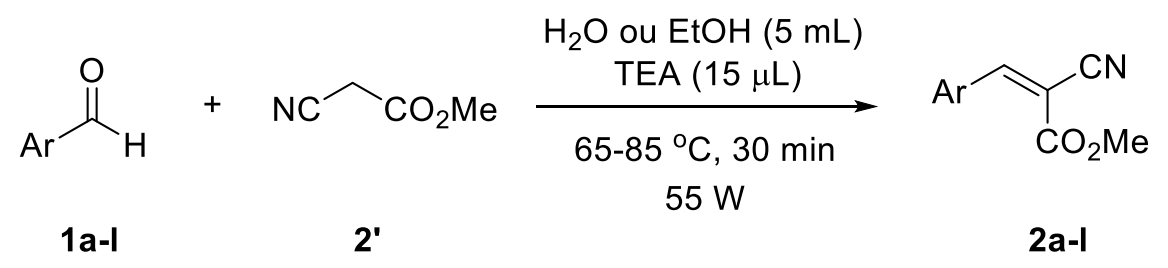

$\mathrm{Ar}=\mathrm{C}_{6} \mathrm{H}_{5}(\mathbf{2 a}) 4-\mathrm{BrC}_{6} \mathrm{H}_{4}(\mathbf{2} \mathbf{b}), 4-\mathrm{C}_{2} \mathrm{H}_{3} \mathrm{O}_{2} \mathrm{C}_{6} \mathrm{H}_{4}(\mathbf{2 c}), 4-\mathrm{ClC}_{6} \mathrm{H}_{4}(\mathbf{2 d}), 4-\mathrm{FC}_{6} \mathrm{H}_{4}$

(2e), 4-N $\left(\mathrm{CH}_{3}\right)_{2} \mathrm{C}_{6} \mathrm{H}_{4}(\mathbf{2 f}), 4-\mathrm{NO}_{2} \mathrm{C}_{6} \mathrm{H}_{4}(\mathbf{2 g}), 4-\mathrm{OCH}_{3} \mathrm{C}_{6} \mathrm{H}_{4}(2 \mathrm{~h}), 4-\mathrm{OHC}_{6} \mathrm{H}_{4}(\mathbf{2 i})$, 4-OH, 3- $\mathrm{OCH}_{3} \mathrm{C}_{6} \mathrm{H}_{4}(2 \mathrm{j}) 5-\mathrm{OCH}_{3}, 4-\mathrm{OCH}_{3}, 3-\mathrm{OCH}_{3} \mathrm{C}_{6} \mathrm{H}_{2}(\mathbf{2 k})$, furano (2I)

\section{(E)-2-ciano-3-fenil-acrilato de metila (2a)}<smiles>COC(=O)/C=C(\C#N)c1ccccc1</smiles>

$\mathrm{C}_{11} \mathrm{H}_{9} \mathrm{NO}_{2}, 187,20$ g.mol ${ }^{-1}$; (89\% de rendimento); cristal branco, p.f. = 88-89 ${ }^{\circ} \mathrm{C} ; \mathrm{IV} v_{\max }\left(\mathrm{cm}^{-1}\right)=3450,3034,2956,2358,2220,1728,1602$, $1571,1496,1435,1323,1271,1207,1091,964,842,771,686,576,480$;

$\mathrm{RMN}$ de ${ }^{1} \mathrm{H}\left(400 \mathrm{MHz}, \mathrm{CDCl}_{3}\right) \delta(\mathrm{ppm})=8,27(\mathrm{~s}, 1 \mathrm{H})$ 8,00 (m, 2H), 7,53 (m, 3H), 3,94 (s, $3 \mathrm{H}) ; \mathrm{RMN}$ de ${ }^{13} \mathrm{C}\left(100 \mathrm{MHz}, \mathrm{CDCl}_{3}\right) \delta(\mathrm{ppm})=159,9,134,6,130,7,129,6,113,7,112,5,82,9$;

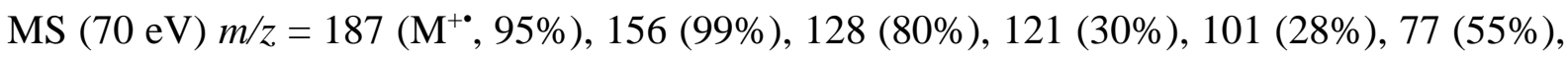
$51(30 \%)$.

(E)-2-ciano-3-(4-bromo-fenil)-acrilato de metila (2b)<smiles>CC(=O)/C=C(\C#N)c1ccc(Br)cc1</smiles>

$\mathrm{C}_{11} \mathrm{H}_{8} \mathrm{BrNO}_{2}, 205,96$ g.mol ${ }^{-1}$; (82\% de rendimento); sólido branco, p.f. $=104-105^{\circ} \mathrm{C} ; \mathrm{IV} v_{\max }\left(\mathrm{cm}^{-1}\right)=3093,3030,2958,2223,1782,1610$, $1581,1485,1436,1400,1288,1203,1184,1120,1070,1004,960,819$, 792, 758, 702, 580, 487; RMN de ${ }^{1} \mathrm{H}\left(400 \mathrm{MHz}, \mathrm{CDCl}_{3}\right) \delta(\mathrm{ppm})=8,20(\mathrm{~s}, 1 \mathrm{H}), 7,86(\mathrm{~d}, J=$ $8,4 \mathrm{~Hz}, 2 \mathrm{H}), 7,65(\mathrm{~d}, J=8,4 \mathrm{~Hz}, 2 \mathrm{H}), 3,94(\mathrm{~s}, 1 \mathrm{H}) ; \mathrm{RMN} \mathrm{de}{ }^{13} \mathrm{C}\left(100 \mathrm{MHz}, \mathrm{CDCl}_{3}\right) \delta(\mathrm{ppm})=$ $162,88,153,93,132,84,132,41,130,33,128,55,115,34,103,32,53,67 ; \mathrm{MS}(70 \mathrm{eV}) \mathrm{m} / \mathrm{z}=265$ $\left(\mathrm{M}^{+\bullet}, 90 \%\right), 236$ (55\%), 207 (10\%), 199 (15\%) 155 (75\%), 127 (100\%), 100 (30\%), 75 (30\%), $50(25 \%)$.

(E)-4-(2-ciano-3-metoxi-3-oxoprop-1-en-1-il)benzoato de metila (2c)<smiles>COC(=O)c1ccc(/C=C(\C#N)C(C)=O)cc1</smiles>

$\mathrm{C}_{13} \mathrm{H}_{11} \mathrm{NO}_{4}, 245,23$ g.mol ${ }^{-1}$; (82\% de rendimento); sólido branco, p.f. $=139-140^{\circ} \mathrm{C} ; \mathrm{IV} v_{\max }\left(\mathrm{cm}^{-1}\right)=3080,3020,2948,2221,1772$, $1615,1584,1480,1436,1402,1288,1200,1181,1114,1070,1004$, 960, 819, 777, 758, 700; RMN de ${ }^{1} \mathrm{H}\left(400 \mathrm{MHz}, \mathrm{CDCl}_{3}\right) \delta(\mathrm{ppm})=8,27(\mathrm{~s}, 1 \mathrm{H}), 8,14(\mathrm{~d}, J=$ 
$8,3 \mathrm{~Hz}, 2 \mathrm{H}), 8,02(\mathrm{~d}, J=8,3 \mathrm{~Hz}, 2 \mathrm{H}), 3,95(\mathrm{~s}, 6 \mathrm{H}) ; \mathrm{RMN} \mathrm{de}{ }^{13} \mathrm{C}\left(100 \mathrm{MHz}, \mathrm{CDCl}_{3}\right) \delta(\mathrm{ppm})=$ $165,94,162,58,153,86,135,21,133,96,130,89,130,39,115,06,105,04,53,73,52,67$; MS (70 eV) $m / z=245\left(\mathrm{M}^{+\bullet}, 90 \%\right), 230(10 \%), 214(100 \%), 186(10 \%), 128(10 \%)$.

(E)-2-ciano-3-(4-cloro-fenil)-acrilato de metila (2d)<smiles>COC(=O)/C(C#N)=C/c1ccc(Cl)cc1</smiles>

$\mathrm{C}_{11} \mathrm{H}_{8} \mathrm{ClNO}_{2}, 221,64$ g.mol ${ }^{-1}$; (80\% de rendimento); sólido branco, p.f. $=122-123{ }^{\circ} \mathrm{C}$; IV $v_{\max }\left(\mathrm{cm}^{-1}\right)=3078,3030,2958,2222,1726,1606$, 1587, 1492, 1427, 1207, 1089, 1012, 968, 839, 817, 794, 761, 709, 584, 493; RMN de ${ }^{1} \mathrm{H}\left(500 \mathrm{MHz}, \mathrm{CDCl}_{3}\right) \delta(\mathrm{ppm})=8,21(\mathrm{~s}, 1 \mathrm{H}), 7,93(\mathrm{~d}, J=8,5 \mathrm{~Hz}, 2 \mathrm{H}), 7,48$ $(\mathrm{d}, J=8,5,2 \mathrm{H}), 3,94(\mathrm{~s}, 1 \mathrm{H}) ; \mathrm{RMN} d{ }^{13} \mathrm{C}\left(125 \mathrm{MHz}, \mathrm{CDCl}_{3}\right) \delta(\mathrm{ppm})=162,89,153,80,139,87$, 132,38, 129,94, 129,85, 115,35, 103,18, 53,65; MS (70 eV) $\mathrm{m} / \mathrm{z}=221\left(\mathrm{M}^{+\bullet}, 100 \%\right), 190(97 \%)$, 162 (48\%), 136 (15\%), 127 (60\%), 100 (20\%), 75 (45\%), 50 (20\%).

(E)-2-ciano-3-(4-flúor-fenil)-acrilato de metila (2e)<smiles>CC(=O)/C(C#N)=C/c1ccc(F)cc1</smiles>

$\mathrm{C}_{11} \mathrm{H}_{8} \mathrm{FNO}_{2}, 205,19$ g.mol${ }^{-1}$; (80\% de rendimento); sólido branco, p.f. $=91-92{ }^{\circ} \mathrm{C} ; \mathrm{IV} v_{\max }\left(\mathrm{cm}^{-1}\right)=3055,3028,2962,2222,1905,1726,1598$, $1514,1435,1282,1246,1205,1161,1091,968,837,813,761,715$, 584, 509; RMN de ${ }^{1} \mathrm{H}\left(400 \mathrm{MHz}, \mathrm{CDCl}_{3}\right) \delta(\mathrm{ppm})=8,22(\mathrm{~s}, 1 \mathrm{H}), 8,03(\mathrm{~m}, 2 \mathrm{H}), 7,19(\mathrm{~m}, 2 \mathrm{H})$, $3,93(\mathrm{~s}, 1 \mathrm{H}) ; \mathrm{RMN} d e{ }^{13} \mathrm{C}\left(100 \mathrm{MHz}, \mathrm{CDCl}_{3}\right) \delta(\mathrm{ppm})=165,61\left(\mathrm{~d},{ }^{1} J_{C F}=257,9 \mathrm{~Hz}\right), 163,04$, $153,89\left(\mathrm{~d},{ }^{5} J_{C F}=0,6 \mathrm{~Hz}\right), 133,78\left(\mathrm{~d},{ }^{3} J_{C F}=9,2 \mathrm{~Hz}\right), 127,93\left(\mathrm{~d},{ }^{4} J_{C F}=3,2 \mathrm{~Hz}\right), 116,88\left(\mathrm{~d},{ }^{2} J_{C F}\right.$ $=22,1 \mathrm{~Hz}) 115,53,102,27\left(\mathrm{~d},{ }^{6} J_{C F}=2,5 \mathrm{~Hz}\right), 53,58 ; \mathrm{MS}(70 \mathrm{eV}) \mathrm{m} / \mathrm{z}=205\left(\mathrm{M}^{+\bullet}, 95 \%\right), 174$ (100\%), 146 (70\%), 126 (60\%), 95 (20\%), 75 (30\%), 50 (10\%).

(E)-2-ciano-3-(4-dimetilamina-fenil)-acrilato de metila (2f)<smiles>CC(=O)/C(C#N)=C/c1ccc(N(C)C)cc1</smiles>

$\mathrm{C}_{13} \mathrm{H}_{14} \mathrm{~N}_{2} \mathrm{O}_{2}, 230,27$ g.mol ${ }^{-1}$; (71\% de rendimento); cristal laranja, p.f. $=145-146{ }^{\circ} \mathrm{C} ; \mathrm{IV} v_{\max }\left(\mathrm{cm}^{-1}\right)=2906,2821,2731,2713,2210,1712$, $1662,1604,1527,1438,1373,1330,1276,1228,1165,1091,1064$, 999, 939, 812, 725, 594; RMN de ${ }^{1} \mathrm{H}\left(400 \mathrm{MHz}, \mathrm{CDCl}_{3}\right) \delta(\mathrm{ppm})=8,07$ (s, 1H), 7,93 (d, $J=$ 9,2 Hz, 2H), 6,69 (d, J = 9,2 Hz, 2H), 3,88 (s, 3H), 3,10 (s, 6H); RMN de ${ }^{13} \mathrm{C}\left(100 \mathrm{MHz}, \mathrm{CDCl}_{3}\right)$ $\delta(\mathrm{ppm})=164,93,154,89,153,78,134,25,119,45,117,70,111,63,93,62,52,91,40,14 ;$ MS (70 $\mathrm{eV}), m / z=230\left(\mathrm{M}^{+\bullet}, 100 \%\right), 214(5 \%), 199(25 \%), 171(25 \%), 128(10 \%) 115(8 \%), 85(8 \%)$, $77(10 \%), 42(5 \%)$. 
(E)-2-ciano-3-(4-nitro-fenil)-acrilato de metila (2g)<smiles>CC(=O)/C=C(\C#N)c1ccc([N+](=O)[O-])cc1</smiles>

$\mathrm{C}_{11} \mathrm{H}_{8} \mathrm{~N}_{2} \mathrm{O}_{4}, 232,20$ g.mol ${ }^{-1}$; (89\% de rendimento); cristal amarelo, p.f. $=176-178{ }^{\circ} \mathrm{C} ; \mathrm{IV} v_{\max }\left(\mathrm{cm}^{-1}\right)=3400,3118,2223,1730,1612,1597$, $1527,1438,1409,1346,1288,1205,1122,1089,954,858,790,763$, 684, 526; RMN de ${ }^{1} \mathrm{H}\left(400 \mathrm{MHz}, \mathrm{CDCl}_{3}\right) \delta(\mathrm{ppm})=8,31(\mathrm{~s}, 1 \mathrm{H}), 8,35(\mathrm{~d}, J=8,6 \mathrm{~Hz}, 2 \mathrm{H})$, $8,13(\mathrm{~d}, J=8,6 \mathrm{~Hz}, 2 \mathrm{H}), 3,97(\mathrm{~s}, 1 \mathrm{H})$; RMN de ${ }^{13} \mathrm{C}\left(100 \mathrm{MHz}, \mathrm{CDCl}_{3}\right) \delta(\mathrm{ppm})=162,05$, 153,60, 152,13, 136,93, 131,68, 124,60,107,05, 53,98; MS (70 eV) $m / z=232\left(\mathrm{M}^{+\bullet}, 100 \%\right), 215$ (25\%), 185 (60\%), 155 (55\%), 128 (40\%), 115 (50\%), 100 (40\%), 76 (35\%), 50 (25\%).

(E)-2-ciano-3-(4-metoxi-fenil)-acrilato de metila (2h)<smiles>COc1ccc(/C=C(\C#N)C(C)=O)cc1</smiles>

$\mathrm{C}_{12} \mathrm{H}_{11} \mathrm{NO}_{3}, 217,22$ g.mol $^{-1}$; (70\% de rendimento); sólido amarelo, p.f. $=145-146{ }^{\circ} \mathrm{C} ; \mathrm{IV} v_{\max }\left(\mathrm{cm}^{-1}\right)=3086,3008,2951,2846,2214$, $1718,1585,1558,1510,1425,1263,1211,1174,1122,1089,1020$, 966, 839, 810, 761, 586, 551; RMN de ${ }^{1} \mathrm{H}\left(500 \mathrm{MHz}, \mathrm{CDCl}_{3}\right) \delta(\mathrm{ppm})=8,17(\mathrm{~s}, 1 \mathrm{H}), 7,99(\mathrm{~d}$, $J=8,8 \mathrm{~Hz}, 2 \mathrm{H}), 6,99(\mathrm{~d}, J=8,8 \mathrm{~Hz}, 2 \mathrm{H}), 3,91$ (s, 3H), 3,89 (s, 3H); RMN de ${ }^{13} \mathrm{C}(125 \mathrm{MHz}$, $\left.\mathrm{CDCl}_{3}\right) \delta(\mathrm{ppm})=164,01,163,76,154,78,133,83,124,42,116,32,114,91,98,97,55,75,53,30$; MS (70 eV) $m / z=217\left(\mathrm{M}^{+\bullet}, 100 \%\right), 186(80 \%), 158(30 \%), 143(15 \%), 115(15 \%), 88(10 \%)$, $77(10 \%), 51(5 \%)$.

(E)-2-ciano-3-(4-hidroxi-fenil)-acrilato de metila (2i)<smiles>CC(=O)/C=C(\C#N)c1ccc(O)cc1</smiles>
$\mathrm{C}_{11} \mathrm{H}_{9} \mathrm{NO}_{3}, 203,20$ g.mol $^{-1}$; (88\% de rendimento); sólido amarelo, p.f. $=210-211{ }^{\circ} \mathrm{C} ; \mathrm{IV} v_{\max }\left(\mathrm{cm}^{-1}\right)=3344,3022,2935,2223,1724,1585$, $1519,1442,1382,1269,1207,1170,1114,1089,968,850,813,863$, 651, 588; RMN de ${ }^{1} \mathrm{H}\left(400 \mathrm{MHz}\right.$, acetona- $\left.d_{6}\right) \delta(\mathrm{ppm})=8,21(\mathrm{~s}, 1 \mathrm{H}), 8,04(\mathrm{~d}, J=8,6 \mathrm{~Hz}, 2 \mathrm{H})$, $7,03(\mathrm{~d}, J=8,6 \mathrm{~Hz}, 2 \mathrm{H}), 3,87(\mathrm{~s}, 3 \mathrm{H}) ; \mathrm{RMN} \mathrm{de}{ }^{13} \mathrm{C}\left(100 \mathrm{MHz}\right.$, Acetona- $\left.d_{6}\right) \delta(\mathrm{ppm})=164,10$, $163,45,155,22,134,80,124,36,117,19,98,96,53,50 ; \mathrm{MS}(70 \mathrm{eV}) \mathrm{m} / z=203\left(\mathrm{M}^{+\bullet}, 95 \%\right), 172$ (100\%), 144 (45\%), $116(30 \%), 89(45 \%), 63$ (15\%).

(E)-2-ciano-3-(4-hidroxi-3-metoxi-fenil)-acrilato de metila $(\mathbf{2} \mathbf{j})$<smiles>COc1cc(/C=C(\C#N)C(C)=O)ccc1O</smiles>

$\mathrm{C}_{12} \mathrm{H}_{11} \mathrm{NO}_{4}, 233,22$ g.mol ${ }^{-1}$; (88\% de rendimento); sólido amarelo; p.f. $=159-160{ }^{\circ} \mathrm{C} ; \mathrm{IV} v_{\max }\left(\mathrm{cm}^{-1}\right)=3385,2964,2222,1730,1583,1514$, 1433, 1386, 1278, 1176, 1091, 1020, 844, 808, 758, 623; RMN de ${ }^{1} \mathrm{H}$ $\left(400 \mathrm{MHz}, \mathrm{CDCl}_{3}\right) \delta(\mathrm{ppm})=8,15(\mathrm{~s}, 1 \mathrm{H}), 7,85(\mathrm{~d}, J=2,1 \mathrm{~Hz}, 1 \mathrm{H}), 7,38(\mathrm{dd}, J=8,4 ; 2,0 \mathrm{~Hz}$, $1 \mathrm{H}), 6,99(\mathrm{~d}, J=8,3 \mathrm{~Hz}, 1 \mathrm{H}), 3,97$ (s, 3H), 3,91 (s, 3H).; RMN de ${ }^{13} \mathrm{C}\left(100 \mathrm{MHz}, \mathrm{CDCl}_{3}\right) \delta$ 
$(\mathrm{ppm})=163,78,155,25,161,15,147,00,129,08,128,67,124,35,116,54,115,09,111,31,98,63$, 56,30, 53,33; MS (70 eV), m/z= $233\left(\mathrm{M}^{+\bullet}, 100 \%\right), 218(5 \%), 202(25 \%), 170(40 \%), 130(20 \%)$, $114(20 \%), 102(10 \%), 76(20 \%), 51(5 \%)$.

(E)-2-ciano-3-(3,4,5-trimetoxi-fenil)-acrilato de metila (2k)

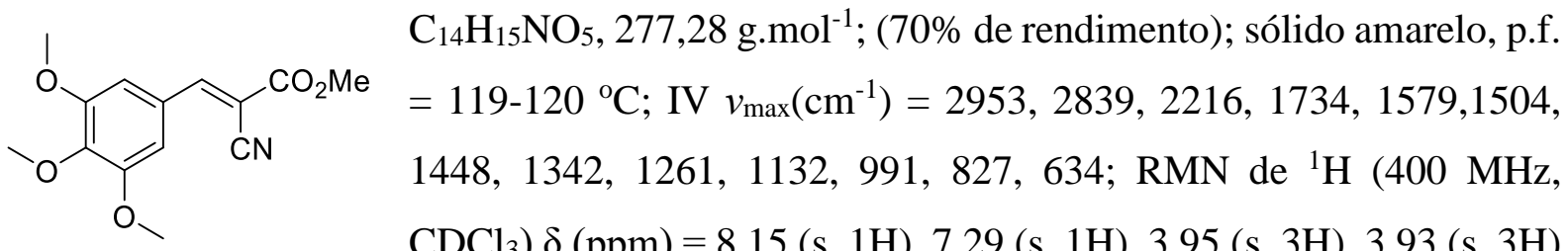
$\left.\mathrm{CDCl}_{3}\right) \delta(\mathrm{ppm})=8,15(\mathrm{~s}, 1 \mathrm{H}), 7,29(\mathrm{~s}, 1 \mathrm{H}), 3,95(\mathrm{~s}, 3 \mathrm{H}), 3,93(\mathrm{~s}, 3 \mathrm{H})$ $3,91(\mathrm{~s}, 6 \mathrm{H}) ; \mathrm{RMN} \mathrm{de}{ }^{13} \mathrm{C}\left(100 \mathrm{MHz}, \mathrm{CDCl}_{3}\right) \delta(\mathrm{ppm})=163,39,155,23,153,42,143,03,126,60$, 116,09, 108,81, 100,89, 61,24, 56,44, 53,47; MS (70 eV) m/z= $277\left(\mathrm{M}^{+\bullet}, 100 \%\right), 262(70 \%)$, $234(20 \%), 202(25 \%)$.

(E)-2-ciano-3-furano-acrilato de metila (2l)<smiles>COC(=O)/C(C#N)=C/c1ccco1</smiles>
$\mathrm{C}_{9} \mathrm{H}_{7} \mathrm{NO}_{3}$ 177,16 g. $\mathrm{mol}^{-1}$; (90\% de rendimento); sólido marrom, p.f. = 94$95{ }^{\circ} \mathrm{C}$; IV $v_{\max }\left(\mathrm{cm}^{-1}\right)=3128,3041,2954,2223,1730,1616,1539,1462$, 1429, 1388, 1257, 1211, 1091, 1016, 975, 925, 881, 817, 758, 704, 590; $\mathrm{RMN}$ de ${ }^{1} \mathrm{H}\left(400 \mathrm{MHz}, \mathrm{CDCl}_{3}\right) \delta(\mathrm{ppm})=8,02(\mathrm{~s}, 1 \mathrm{H}), 7,75(\mathrm{~d}, J=1,7 \mathrm{~Hz}, 1 \mathrm{H}), 7,39(\mathrm{~d}, J=$ $3,7 \mathrm{~Hz}, 1 \mathrm{H}), 6,66(\mathrm{dd}, J=3,7$ e 1,7 Hz, $1 \mathrm{H}), 3,90(\mathrm{~s}, 3 \mathrm{H}) ; \mathrm{RMN}$ de ${ }^{13} \mathrm{C}\left(100 \mathrm{MHz}, \mathrm{CDCl}_{3}\right) \delta$ $(\mathrm{ppm})=163,22,148,83,148,50,139,78,122,05,115,42,114,02,98,31,53,40 ; \mathrm{MS}(70 \mathrm{eV})$, $m / z=177\left(\mathrm{M}^{+}, 80 \%\right), 146(100 \%), 105$ (30\%), 90 (45\%), 63 (50\%) 59 (30\%) $51(5 \%)$.

\subsubsection{Síntese one-pot tricomponente de derivados de $4 H$-cromenos por irradiação micro- ondas}

Em um balão reacional de $25 \mathrm{~mL}$ foram adicionados o aldeído aromático (1,0 mmol), o cianoacetato de metila 2' (1,0 mmol), a 5,5-dimetilciclo-hexano-1,3-diona 3' (1,0 mmol) e uma mistura de $\mathrm{H}_{2} \mathrm{O} / \mathrm{TEA}$ ou EtOH/TEA $(5 \mathrm{~mL} / 30 \mu \mathrm{L})$. A reação foi realizada em um reator microondas, com agitação magnética por $90 \mathrm{~min}$ a $85^{\circ} \mathrm{C}$, quando a água foi utilizada e a $65^{\circ} \mathrm{C}$ quando o etanol foi utilizado. A potência programada no reator foi de $55 \mathrm{~W}$. O progresso da reação foi monitorado por CCD utilizando como eluente uma mistura de hexano e acetato de etila (7:3 ou 6:4).

Posteriormente, realizou-se a extração líquido-líquido adicionando $10 \mathrm{~mL}$ de $\mathrm{H}_{2} \mathrm{O}$ e AcOEt $(3 \times 20 \mathrm{~mL})$. As fases orgânicas foram combinadas e o $\mathrm{Na}_{2} \mathrm{SO}_{4}$ anidro foi adicionado. Em 
seguida, filtrou-se e o solvente foi removido em rotaevaporador à pressão reduzida. Já as reações realizadas em EtOH foram concentradas no rotaevaporador diretamente.

Os produtos foram purificados por cromatografia em coluna utilizando sílica gel (35-70 $\mu \mathrm{m}$ de diâmetro de partícula e $6 \mathrm{~nm}$ de diâmetro de poro) utilizando como eluente uma mistura de hexano e acetato de etila ( $7: 3$ ou $6: 4)$. Os $4 H$-cromenos obtidos foram identificados e caracterizados por IV, EM e RMN. Os dados dos espectros de massas (IE, $70 \mathrm{eV}$ ) de todos os derivados de $4 H$-cromenos não foram realizados, pois apresentaram degradação térmica no autoinjetor. Contudo, foram realizadas análises de espectrometria de massas de alta resolução para os $4 H$-cromenos inéditos. O Esquema 19 ilustra a síntese dos $4 H$-cromenos utilizando TEA em reator MO.

Esquema 19. Síntese one-pot tricomponente de derivados de $4 H$-cromenos entre aldeídos aromáticos, o cianoacetato de metila 2' e a 5,5-dimetilciclo-hexano-1,3-diona 3', utilizando TEA em reator MO.

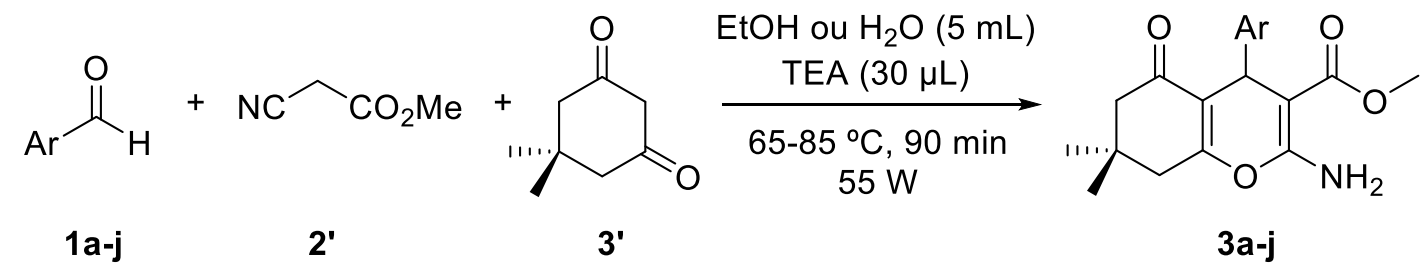

$\mathrm{Ar}=\mathrm{C}_{6} \mathrm{H}_{5}(\mathbf{3 a}), 4-\mathrm{BrC}_{6} \mathrm{H}_{5}(\mathbf{3 b}), 4-\mathrm{ClC}_{6} \mathrm{H}_{5}(\mathbf{3 c}), 4-\mathrm{FC}_{6} \mathrm{H}_{5}(\mathbf{3 d}), 4-\mathrm{NO}_{2} \mathrm{C}_{6} \mathrm{H}_{5}(\mathbf{3 e})$, 4$\mathrm{OHC}_{6} \mathrm{H}_{5}$ (3f), 4-OH, 3-OCH $\mathrm{C}_{6} \mathrm{H}_{5}(\mathbf{3 g}), 3-\mathrm{OCH}_{3}, 4-\mathrm{OCH}_{3}, 5-\mathrm{OCH}_{3} \mathrm{C}_{6} \mathrm{H}_{5}(\mathbf{3 h}), 4-$ $\mathrm{OCH}_{3} \mathrm{C}_{6} \mathrm{H}_{5}(\mathbf{3 i})$, furfural (3j)

2-amino-7,7-dimetil-5-oxo-4-fenil-5,6,7,8-tetraidro-4H-cromeno-3-carboxilato de metila (3a)<smiles>CC(=O)C1=C(N)OC2=C(C(=O)CC(C)(C)C2)C1c1ccccc1</smiles>
$\mathrm{C}_{19} \mathrm{H}_{21} \mathrm{NO}_{4}, 327,15$ g.mol ${ }^{-1}$; (44\% de rendimento); sólido amorfo amarelo; IV $v_{\max }\left(\mathrm{cm}^{-1}\right)=3408,3305,2957,1735,1661,1615,1525$, 1438, 1366, 1294, 1263, 1162,1036, 729, 698; RMN de ${ }^{1} \mathrm{H}(500 \mathrm{MHz}$, DMSO- $\left.d_{6}\right) \delta(\mathrm{ppm})=7,54(\mathrm{~s}, 2 \mathrm{H}), 7,20(\mathrm{~m}, 2 \mathrm{H}), 7,11(\mathrm{~m}, 3 \mathrm{H}), 4,51(\mathrm{~s}$, $1 \mathrm{H}), 3,50(\mathrm{~s}, 3 \mathrm{H}) 2,54(\mathrm{~d}, J=17,6,1 \mathrm{H}), 2,46$ (d, $J=17,6 \mathrm{~Hz}, 1 \mathrm{H}), 2,26$ $(\mathrm{d}, J=16,1 \mathrm{~Hz}, 1 \mathrm{H}), 2,05$ (d, $J=16,1,1 \mathrm{H}) 1,03$ (s, 3H), 0,88 (s, 3H); RMN de ${ }^{13} \mathrm{C}(125 \mathrm{MHz}$, DMSO-d6) $\delta(\mathrm{ppm})=198,81,168,33,162,22,159,33,146,32,127,85,127,48,125,87,115,72$, $77,69,50,52,49,98,39,59,33,12,31,91,28,67,26,44$. 
2-amino-4-(4-bromofenil)-7,7-dimetil-5-oxo-4-fenil-5,6,7,8-tetraidro-4H-cromeno-3carboxilato de metila $(\mathbf{3 b})$

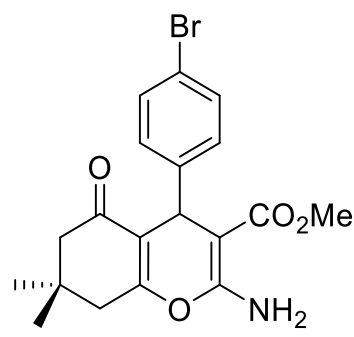

$\mathrm{C}_{19} \mathrm{H}_{20} \mathrm{BrNO}_{4}, 405,06$ g.mol ${ }^{-1}$; (51\% de rendimento); sólido amarelo, p.f. $=166-168{ }^{\circ} \mathrm{C} ; \mathrm{IV} v_{\max }\left(\mathrm{cm}^{-1}\right)=3408,3305,2957,1735,1661,1615$, $1525,1438,1366,1294,1263,1162,1036,729,698 ; \mathrm{RMN}$ de ${ }^{1} \mathrm{H}(400$ MHz, DMSO- $\left.d_{6}\right) \delta(\mathrm{ppm})=7,59(\mathrm{~s}, 2 \mathrm{H}), 7,39(\mathrm{~d}, J=8,4 \mathrm{~Hz}, 2 \mathrm{H}), 7,09$ $(\mathrm{d}, J=8,4 \mathrm{~Hz}, 2 \mathrm{H}), 4,48(\mathrm{~s}, 1 \mathrm{H}), 3,50(\mathrm{~s}, 3 \mathrm{H}), 2,55(\mathrm{~d}, J=17,6 \mathrm{~Hz}, 1 \mathrm{H})$, $2,45(\mathrm{~d}, J=17,6 \mathrm{~Hz}, 1 \mathrm{H}), 2,26(\mathrm{~d}, J=16,2 \mathrm{~Hz}, 1 \mathrm{H}), 2,06(\mathrm{~d}, J=16,2 \mathrm{~Hz}, 1 \mathrm{H}), 1,03(\mathrm{~s}, 3 \mathrm{H})$, 0,88 (s, 3H).; RMN de ${ }^{13} \mathrm{C}\left(100 \mathrm{MHz}, \mathrm{DMSO}-d_{6}\right) \delta(\mathrm{ppm})=195,78,168,13,162,30,159,23$, $145,74,130,68,129,79,118,81,115,10,77,04,50,52,49,90,39,78,32,91,31,86,28,59,26,46$.

2-amino-4-(4-clorofenil)-7,7-dimetil-5-oxo-4-fenil-5,6,7,8-tetraidro-4H-cromeno-3carboxilato de metila $(\mathbf{3 c})$<smiles>CC(=O)C1=C(N)OC2=C(C(=O)CC(C)(C)C2)C1c1ccc(Cl)cc1</smiles>

$\mathrm{C}_{19} \mathrm{H}_{20} \mathrm{ClNO}_{4}, 361,11$ g.mol ${ }^{-1}$; (52\% de rendimento); sólido branco, p.f. $=170-171^{\circ} \mathrm{C}$; IV $v_{\max }\left(\mathrm{cm}^{-1}\right)=3412,3307,2957,1741,1693,1663$, 1526, 1489, 1438, 1368, 1296, 1250, 1164, 1090, 1036; RMN de ${ }^{1} \mathrm{H}$ $\left(500 \mathrm{MHz}, \mathrm{DMSO}-d_{6}\right) \delta(\mathrm{ppm})=7,59(\mathrm{~s}, 2 \mathrm{H}), 7,26(\mathrm{~d}, J=8,5 \mathrm{~Hz}, 2 \mathrm{H})$, 7,14 (d, $J=8,5 \mathrm{~Hz}, 2 \mathrm{H}), 4,49(\mathrm{~s}, 1 \mathrm{H}), 3,49(\mathrm{~s}, 3 \mathrm{H}), 2,54$ (d, $J=17,5$ $\mathrm{Hz}, 1 \mathrm{H}), 2,45(\mathrm{~d}, J=17,5 \mathrm{~Hz}, 1 \mathrm{H}), 2,26(\mathrm{~d}, J=16,0 \mathrm{~Hz}, 1 \mathrm{H}), 2,06(\mathrm{~d}$, $J=16,0 \mathrm{~Hz}, 1 \mathrm{H}) 1,03(\mathrm{~s}, 3 \mathrm{H}), 0,87(\mathrm{~s}, 3 \mathrm{H}) ; \mathrm{RMN}$ de ${ }^{13} \mathrm{C}\left(125 \mathrm{MHz}, \mathrm{DMSO}-d_{6}\right) \delta(\mathrm{ppm})=$ $196,26,168,62$, 162,78, 159,72, 145,78, 130,80, 129,84, 128,25, 115,64, 77,58, 51,00, 50,38, $33,30,32,33,29,07,26,92$,

2-amino-4-(4-flúor-fenil)-7,7-dimetil-5-oxo-5,6,7,8-tetraidro-4H-cromeno-3-carboxilato de metila (3d)<smiles>CC(=O)C1=C(N)OC2=C(C(=O)CC(C)(C)C2)C1c1ccc(F)cc1</smiles>

$\mathrm{C}_{19} \mathrm{H}_{20} \mathrm{FNO}_{4}, 345,14$ g.mol ${ }^{-1}$; (58\% de rendimento); sólido amorfo amarelo; IV $v_{\max }\left(\mathrm{cm}^{-1}\right)=3408,3305,2957,1735,1691,1617,1525$, 1506, 1440, 1292, 1263, 1164, 1036, 853, 731; RMN de ${ }^{1} \mathrm{H}(400 \mathrm{MHz}$, DMSO- $\left.d_{6}\right) \delta(\mathrm{ppm})=7,56(\mathrm{~s}, 2 \mathrm{H}), 7,14(\mathrm{~m}, 2 \mathrm{H}), 7,02(\mathrm{~m}, 2 \mathrm{H}), 4,51(\mathrm{~s}$, 1H), 3,50 (s, 3H), 2,54 (d, $J=17,6 \mathrm{~Hz}, 1 \mathrm{H}), 2,45$ (d, $J=17,6 \mathrm{~Hz}, 1 \mathrm{H})$, 2,26 (d, $J=16,1 \mathrm{~Hz}, 1 \mathrm{H}), 2,06(\mathrm{~d}, J=16,1 \mathrm{~Hz}, 1 \mathrm{H}), 1,03$ (s, 3H), 0,88 $(\mathrm{s}, 3 \mathrm{H}) ; \mathrm{RMN} d{ }^{13} \mathrm{C}\left(100 \mathrm{MHz}, \mathrm{DMSO}-d_{6}\right) \delta(\mathrm{ppm})=195.82,168.22,162.21,160.45\left(\mathrm{~d},{ }^{1} J_{C F}\right.$ 
$=241.7 \mathrm{~Hz}), 159.27,142.48\left(\mathrm{~d},{ }^{4} J_{C F}=3.1 \mathrm{~Hz}\right), 129.21\left(\mathrm{~d},{ }^{3} J_{C F}=8.0 \mathrm{~Hz}\right), 115.49,114.49(\mathrm{~d}$, $\left.{ }^{2} J_{C F}=21.1 \mathrm{~Hz}\right), 77.44,50.53,49.94,39.56,32.56,31.88,28.62,26.45$.

2-amino-4-(4-nitro-fenil)-7,7-dimetil-5-oxo-5,6,7,8-tetraidro-4H-cromeno-3-carboxilato de metila (3e)<smiles>CC(=O)C1=C(N)OC2=C(C(=O)CC(C)(C)C2)C1c1ccc([N+](=O)[O-])cc1</smiles>
$\mathrm{C}_{19} \mathrm{H}_{20} \mathrm{~N}_{2} \mathrm{O}_{6}, 372,13$ g.mol ${ }^{-1}$; (60\% de rendimento); sólido vermelho, p.f. $=186-188^{\circ} \mathrm{C} ; \mathrm{IV} v_{\max }\left(\mathrm{cm}^{-1}\right)=3414,3309,2957,1733,1656,1611$, 1512, 1438, 1366, 1271, 1201, 1166, 1034; RMN de ${ }^{1} \mathrm{H}(400 \mathrm{MHz}$, DMSO- $\left.d_{6}\right) \delta(\mathrm{ppm})=\delta 8,10(\mathrm{~d}, J=8,8 \mathrm{~Hz}, 2 \mathrm{H}), 7,69(\mathrm{~s}, 2 \mathrm{H}), 7,41(\mathrm{~d}$, $J=8,8 \mathrm{~Hz}, 2 \mathrm{H}), 4,62(\mathrm{~s}, 1 \mathrm{H}), 3,50(\mathrm{~s}, 3 \mathrm{H}), 2,58(\mathrm{~d}, J=17,7 \mathrm{~Hz}, 1 \mathrm{H})$, 2,28 (d, $J=16,1 \mathrm{~Hz}, 1 \mathrm{H}), 2,07$ (d, $J=16,1 \mathrm{~Hz}, 1 \mathrm{H}), 1,04$ (s, 3H), 0,88 $(\mathrm{s}, 3 \mathrm{H}) ; \mathrm{RMN} d \mathrm{de}{ }^{13} \mathrm{C}\left(100 \mathrm{MHz}, \mathrm{DMSO}-d_{6}\right) \delta(\mathrm{ppm})=195,76,167,93,162,74,159,21,154,03$, $145,73,128,88,123,15,114,40,76,39,50,56,49,81,39,56,33,74,31,86,28,54,26,48$.

2-amino-4-(4-hidroxifenil)-7,7-dimetil-5-oxo-5,6,7,8-tetraidro-4H-cromeno-3-carboxilato de metila (3f)<smiles>CC(=O)C1=C(N)OC2=C(C(=O)CC(C)(C)C2)C1c1ccc(O)cc1</smiles>

$\mathrm{C}_{19} \mathrm{H}_{21} \mathrm{NO}_{5}, 343,14$ g.mol ${ }^{-1}$; (40\% de rendimento); sólido amorfo amarelo; IV $v_{\max }\left(\mathrm{cm}^{-1}\right)=3315,2957,1735,1687,1611,1512,1440$, 1370, 1250, 1203, 1164, 1036; RMN de ${ }^{1} \mathrm{H}$ (500 MHz, DMSO- $\left.d_{6}\right) \delta$ $(\mathrm{ppm})=\delta 9,12(\mathrm{~s}, 1 \mathrm{H}), 7,46(\mathrm{~s}, 2 \mathrm{H}), 6,90(\mathrm{~d}, J=8,6 \mathrm{~Hz}, 1 \mathrm{H}), 6,57(\mathrm{~d}$, $J=8,6 \mathrm{~Hz}, 1 \mathrm{H}), 4,40(\mathrm{~s}, 1 \mathrm{H}), 3,50(\mathrm{~s}, 3 \mathrm{H}), 2,42(\mathrm{~d}, J=17,7 \mathrm{~Hz}, 1 \mathrm{H})$, $2,24(\mathrm{~d}, J=16,1 \mathrm{~Hz}, 1 \mathrm{H}), 2,04(\mathrm{~d}, J=15,4 \mathrm{~Hz}, 1 \mathrm{H}), 1,02$ (s, 3H), 0,88 $(\mathrm{s}, 3 \mathrm{H}) ; \mathrm{RMN} d \mathrm{de}{ }^{13} \mathrm{C}\left(125 \mathrm{MHz}, \mathrm{DMSO}-d_{6}\right) \delta(\mathrm{ppm})=195,81,168,44,161,78,159,24,155,35$, $136,75,128,30,116,11,114,56,78,13,50,46,50,04,39,58,32,06,31,87,28,67,26,45$.

2-amino-4-(4-hidroxi-3-metoxifenil)-7,7-dimetil-5-oxo-5,6,7,8-tetraidro-4H-cromeno-3carboxilato de metila $\mathbf{( 3 g})$<smiles>COc1cc(C2C(C(C)=O)=C(N)OC3=C2C(=O)CC(C)(C)C3)ccc1O</smiles>

$\mathrm{C}_{20} \mathrm{H}_{23} \mathrm{NO}_{6}, 373,15$ g.mol ${ }^{-1}$; (42\% de rendimento); sólido amorfo amarelo; IV $v_{\max }\left(\mathrm{cm}^{-1}\right)=3414,3309,2957,1689,1656,1611,1512$, 1438, 1366, 1201, 1166, 1034; RMN de ${ }^{1} \mathrm{H}$ (400 MHz, DMSO-d6) $\delta$ $(\mathrm{ppm})=8,66(\mathrm{~s}, 2 \mathrm{H}), 7,47(\mathrm{~s}, 2 \mathrm{H}), 6,68(\mathrm{~d}, J=2,0 \mathrm{~Hz}, 1 \mathrm{H}), 6,60(\mathrm{~d}, J$ $=8,1 \mathrm{~Hz}, 1 \mathrm{H}), 6,48(\mathrm{dd}, J=8,2$ e $2,1 \mathrm{~Hz}, 1 \mathrm{H}), 4,43(\mathrm{~s}, 1 \mathrm{H}), 3,69(\mathrm{~s}$, 1H), 3,53 (s, 1H), 2,54 (d, $J=17,7 \mathrm{~Hz}, 1 \mathrm{H}), 2,44$ (d, $J=17,7 \mathrm{~Hz}, 1 \mathrm{H})$, 2,26 (d, $J=16,1 \mathrm{~Hz}, 1 \mathrm{H}), 2,07(\mathrm{~d}, J=16,8 \mathrm{~Hz}, 1 \mathrm{H}), 1.03$ (s, 3H), $0.91(\mathrm{~s}, 3 \mathrm{H})$; RMN de ${ }^{13} \mathrm{C}$ 
$\left(100 \mathrm{MHz}, \mathrm{DMSO}-d_{6}\right) \delta(\mathrm{ppm})=195,89,168,46,161,99,159,22,146,81,144,67,137,41$, $119,41,115,97,115,02,112,06,78,11,55,55,50,45,50,03,39,59,32,35,31,86,31,36,28,75$, 26,37 .

2-amino-4-(3,4,5-trimetoxifenil)-7,7-dimetil-5-oxo-5,6,7,8-tetraidro-4H-cromeno-3carboxilato de metila $\mathbf{( 3 h})$<smiles>COC(=O)C1=C(N)OC2=C(C(=O)CC(C)(C)C2)C1c1cc(OC)c(OC)c(OC)c1</smiles>

$\mathrm{C}_{22} \mathrm{H}_{27} \mathrm{NO}_{7}, 417,18$ g. $\mathrm{mol}^{-1}$; (41\% de rendimento); sólido amorfo amarelo; IV $v_{\max }\left(\mathrm{cm}^{-1}\right)($ puro $)=3410,3307,2955,1689,1661,1590$, 1459, 1421, 1366, 1232, 1201, 1168, 1125, 1036, 1007; RMN de ${ }^{1} \mathrm{H}$ $\left(400 \mathrm{MHz}, \mathrm{DMSO}-d_{6}\right) \delta(\mathrm{ppm})=7,52(\mathrm{~s}, 2 \mathrm{H}), 6,39(\mathrm{~s}, 2 \mathrm{H}), 4,49(\mathrm{~s}$, $1 \mathrm{H}), 3,69$ (s, 6H), 3,60 (s, 3H), 3,57 (s, 3H), 2,57 (d, $J=17,1 \mathrm{~Hz}, 1 \mathrm{H})$, $2,29(\mathrm{~d}, J=16,0 \mathrm{~Hz}, 1 \mathrm{H}), 2,11(\mathrm{~d}, J=16,0 \mathrm{~Hz}, 1 \mathrm{H}), 1,05$ (s, 3H), 0,97 $(\mathrm{s}, 3 \mathrm{H}) ; \mathrm{RMN} d{ }^{13} \mathrm{C}\left(100 \mathrm{MHz}, \mathrm{DMSO}-d_{6}\right) \delta(\mathrm{ppm})=195,95,168,36,162,65,159,26,152,37$, $141,89,135,81,115,42,104,63,77,75,59,91,55,74,50,50,49,98,39,61,33,12$, 31,88, 28,82, 26,35 .

2-amino-7,7-dimetil-5-oxo-4-(4-metóxifenil)-5,6,7,8-tetraidro-4H-cromeno-3-carboxilato de metila (3i)<smiles>COc1ccc(C2C(C(C)=O)=C(N)OC3=C2C(=O)CC(C)(C)C3)cc1</smiles>

$\mathrm{C}_{20} \mathrm{H}_{23} \mathrm{NO}_{5}$, 357,16 g.mol ${ }^{-1}$; (56\% de rendimento); sólido amorfo amarelo; p.f. $=129-131{ }^{\circ} \mathrm{C}$; IV $v_{\max }\left(\mathrm{cm}^{-1}\right)($ puro $)=3410,3305,2957$, $1741,1689,1661,1609,1510,1440,1366,1296,1246,1201,1164$, 1034; RMN de ${ }^{1} \mathrm{H}\left(500 \mathrm{MHz}, \mathrm{DMSO}-d_{6}\right) \delta(\mathrm{ppm})=7,51$ (s, 2H), 7,03 $(\mathrm{d}, J=8,7 \mathrm{~Hz}, 2 \mathrm{H}), 6,76(\mathrm{~d}, J=8,7 \mathrm{~Hz}, 2 \mathrm{H}), 4,46$ (s, 1H), 3,67 (s, 3H), $3,50(\mathrm{~s}, 3 \mathrm{H}), 2,53(\mathrm{~d}, J=17,7 \mathrm{~Hz}, 1 \mathrm{H}), 2,44(\mathrm{~d}, J=17,7 \mathrm{~Hz}, 1 \mathrm{H}), 2,25$ $(\mathrm{d}, J=16,0 \mathrm{~Hz}, 1 \mathrm{H}), 2,05$ (d, $J=16,0 \mathrm{~Hz}, 1 \mathrm{H}), 1,03$ (s, 3H), 0,88 (s, 3H); RMN de ${ }^{13} \mathrm{C}(125$ MHz, DMSO- $\left.d_{6}\right) \delta(\mathrm{ppm})=195,79,168,37,161,89,159,24,157,34,138,42,128,38,115,90$, $113,20,77,90,54,88,50,48,50,00,39,57,32,19,31,86,28,65,26,47$. 

metila $(\mathbf{3 j})$<smiles>CC(=O)C1=C(N)OC2=C(C(=O)CC(C)(C)C2)C1c1ccco1</smiles>

$\mathrm{C}_{17} \mathrm{H}_{19} \mathrm{NO}_{5}, 317,13$ g.mol ${ }^{-1}$; (54\% de rendimento); sólido marrom amorfo; IV $v_{\max }\left(\mathrm{cm}^{-1}\right)$ (puro) $=3408,3307,2957,1691,1615,1527$, 1440, 1364, 1294, 1199, 1166, 1036, 733; RMN de ${ }^{1} \mathrm{H}(500 \mathrm{MHz}$, DMSO- $\left.d_{6}\right) \delta(\mathrm{ppm})=7,56(\mathrm{~s}, 2 \mathrm{H}), 7,36(\mathrm{dd}, J=1,8$ e $0,9 \mathrm{~Hz}, 1 \mathrm{H}), 6.24$ $(\mathrm{dd}, J=3,1 \mathrm{e} 1.8 \mathrm{~Hz}, 1 \mathrm{H}), 5,93(\mathrm{~d}, J=3,2 \mathrm{~Hz}, 1 \mathrm{H}), 4,68(\mathrm{~s}, 1 \mathrm{H}), 3,57$ (s, 3H), 2,53 (d, $J=16,6 \mathrm{~Hz}, 1 \mathrm{H}), 2,42(\mathrm{~d}, J=16,6 \mathrm{~Hz}, 1 \mathrm{H}), 2,29(\mathrm{~d}, J=16,0 \mathrm{~Hz}, 1 \mathrm{H}), 2,14$ (d, $J=16,0 \mathrm{~Hz}, 1 \mathrm{H}), 1,04(\mathrm{~s}, 3 \mathrm{H}), 0,94(\mathrm{~s}, 3 \mathrm{H}) ; \mathrm{RMN}$ de ${ }^{13} \mathrm{C}\left(125 \mathrm{MHz}, \mathrm{DMSO}-d_{6}\right) \delta(\mathrm{ppm})=\delta$ $195,55,168,17,163,28,159,87,157,04,140,92$, 112,92, 110,27, 104,47, 74,4, 50,60, 49,91, $39,63,31,89,28,68,26,71,26,28$.

\subsubsection{Síntese de adutos de Knoevenagel entre cetonas aromáticas e a malononitrila 5'}

\subsubsection{Síntese em meio básico $(\mathrm{NaOH})$}

Em um balão de $10 \mathrm{~mL}$ foram adicionados $1,0 \mathrm{mmol}$ de malononitrila 5' e $5 \mathrm{~mL}$ de solvente (THF, EtOH ou $\mathrm{H}_{2} \mathrm{O}$ ). Na sequência, $30 \mu \mathrm{L}$ de $\mathrm{NaOH}$ ( $5 \mathrm{~mol} / \mathrm{L}$ ) foram adicionados ao sistema, o qual foi submetido à agitação magnética, à temperatura de $50^{\circ} \mathrm{C}$, durante 10 minutos. Posteriormente, $1 \mathrm{mmol}$ da respectiva cetona foi adicionado ao sistema, o qual permaneceu em agitação constante $(600 \mathrm{rpm})$, a $50{ }^{\circ} \mathrm{C}$ por 24 horas. $\mathrm{O}$ progresso da reação foi monitorado por cromatografia em camada delgada (CCD) utilizando como eluente uma mistura de hexano e acetato de etila (7:3).

Posteriormente, para a reação que utilizou $\mathrm{H}_{2} \mathrm{O}$ como solvente, foi realizada uma extração líquido-líquido adicionando $10 \mathrm{~mL}$ de $\mathrm{H}_{2} \mathrm{O}$ e AcOEt $(3 \times 20 \mathrm{~mL})$. As fases orgânicas foram combinadas e o $\mathrm{Na}_{2} \mathrm{SO}_{4}$ anidro foi adicionado. Em seguida, filtrou-se e o solvente foi removido em rotaevaporador à pressão reduzida.

Os produtos sintetizados foram analisados via CG-EM e em alguns casos purificados por cromatografia em coluna de sílica gel $(35-70 \mu \mathrm{m}$ de diâmetro de partícula e $6 \mathrm{~nm}$ de diâmetro de poro). Posteriormente, os compostos purificados foram identificados e caracterizados por $\mathrm{RMN}{ }^{1} \mathrm{H},{ }^{13} \mathrm{C}$. O Esquema 20 ilustra a síntese dos adutos em meio básico utilizando $\mathrm{NaOH}$. 
Esquema 20. Síntese de adutos de Knoevenagel entre cetonas aromáticas e a malononitrila 5' utilizando $\mathrm{NaOH}$.

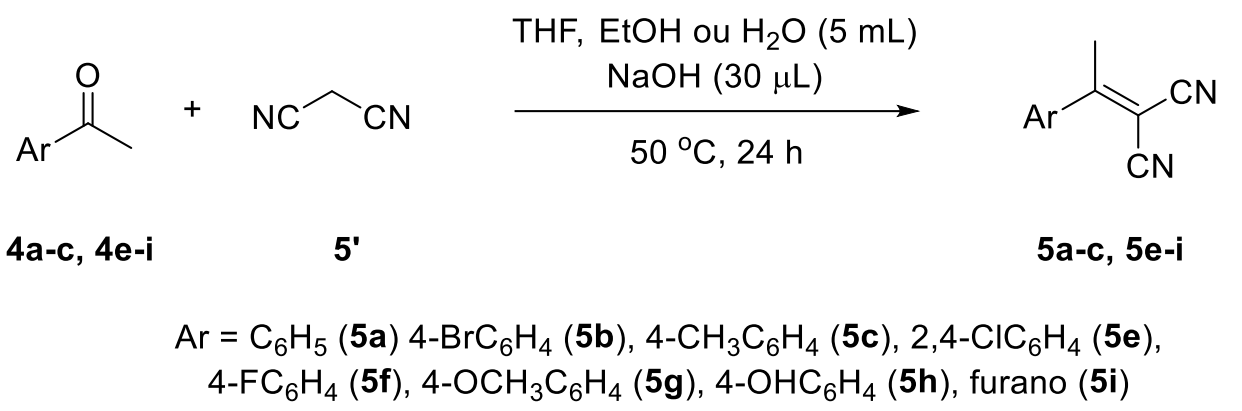

2-(1-(4-bromofenil)etilideno)malononitrila (5b)<smiles>CC(=C(C#N)C#N)c1ccc(Br)cc1</smiles>

$\mathrm{C}_{11} \mathrm{H}_{7} \mathrm{BrN}_{2}, 246,00$ g.mol ${ }^{-1}$; (3\% de rendimento); sólido amorfo marrom,

p.f. $=95-96{ }^{\circ} \mathrm{C} ; \mathrm{RMN} \mathrm{de}{ }^{1} \mathrm{H}\left(400 \mathrm{MHz}\right.$, Acetona- $\left.d_{6}\right) \delta(\mathrm{ppm})=7,77(\mathrm{~d}, J$ $=8,8 \mathrm{~Hz}, 2 \mathrm{H}), 7,66(\mathrm{~d}, J=8,8 \mathrm{~Hz}, 2 \mathrm{H}), 2,68(\mathrm{~s}, 3 \mathrm{H}) ; \mathrm{RMN} \mathrm{de}{ }^{13} \mathrm{C}(100$ $\mathrm{MHz}$, Acetona- $\left.d_{6}\right) \delta(\mathrm{ppm})=175,29,135,66,132,09,132,08,129,52,125,80,112,83,112,72$,

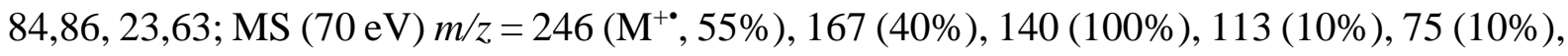
$50(10 \%)$.

\section{2-(1-(2,4-diclorofenil etilideno)malononitrila (5e)}<smiles>CC(=C(C#N)C#N)c1ccc(Cl)cc1Cl</smiles>

$\mathrm{C}_{11} \mathrm{H}_{6} \mathrm{Cl}_{2} \mathrm{~N}_{2}, 236,00$ g.mol ${ }^{-1}$; (40\% de rendimento); sólido verde escuro p.f. $=110-111^{\circ} \mathrm{C} ; \mathrm{RMN}$ de ${ }^{1} \mathrm{H}(400 \mathrm{MHz}, \mathrm{MeOD}) \delta(\mathrm{ppm})=\delta 7,68(\mathrm{~d}, J$ $=1,9 \mathrm{~Hz}, 1 \mathrm{H}), 7,51(\mathrm{dd}, J=8,4 \mathrm{e} 2,0 \mathrm{~Hz}, 1 \mathrm{H}), 7,41(\mathrm{~d}, J=8,3 \mathrm{~Hz}, 1 \mathrm{H})$, $2,58(\mathrm{~s}, 3 \mathrm{H}) ; \mathrm{RMN} d e{ }^{13} \mathrm{C}\left(100 \mathrm{MHz}, \mathrm{CDCl}_{3}\right) \delta(\mathrm{ppm})=175,91,175,89$, $138,27,136,00,132,64,131,22,130,82,129,22,112,48,91,00,24.63 ;$ MS $(70 \mathrm{eV}) \mathrm{m} / z=236$ $\left(\mathrm{M}^{+\bullet}, 100.0 \%\right), 196$ (30\%), 174 (45\%), 138 (20\%), 99 (10\%), 75 (10\%), 41 (10\%).

\section{2-(1-(4-flúor-fenil)etilideno)malononitrila (5f)}<smiles>CC(C#N)=C(C#N)c1ccc(F)cc1</smiles>

$\mathrm{C}_{11} \mathrm{H}_{7} \mathrm{FN}_{2}, 186,19$ g.mol ${ }^{-1}$; (5\% de rendimento); sólido marrom, p.f. = 89$90{ }^{\circ} \mathrm{C}$; RMN de ${ }^{1} \mathrm{H}(500 \mathrm{MHz}, \mathrm{MeOD}) \delta(\mathrm{ppm})=\delta$ 7,72 (m, 2H), 7,28 (m, $2 \mathrm{H}), 2,63(\mathrm{~s}, 3 \mathrm{H})$; RMN de ${ }^{13} \mathrm{C}(125 \mathrm{MHz}, \mathrm{MeOD}) \delta(\mathrm{ppm})=176,54$, $166.14\left(\mathrm{~d},{ }^{1} J_{C F}=252.5 \mathrm{~Hz}\right), 133.96\left(\mathrm{~d},{ }^{4} J_{C F}=3.4 \mathrm{~Hz}\right), 131.46\left(\mathrm{~d},{ }^{3} J_{C F}=9.2 \mathrm{~Hz}\right), 117.08(\mathrm{~d}$, $\left.{ }^{2} J_{C F}=22.4 \mathrm{~Hz}\right), 114,09,113,86,24,49 ; \mathrm{MS}(70 \mathrm{eV}) \mathrm{m} / \mathrm{z}=186\left(\mathrm{M}^{+\bullet}, 100 \%\right), 158(30 \%), 121$ (20\%), 96 (25\%), $75(20 \%), 41(5 \%)$.

Os adutos $\mathbf{5 a}, \mathbf{5 c}, \mathbf{5 g}, \mathbf{5 h}$ e $\mathbf{5 i}$ não foram isolados nesta etapa. 


\subsubsection{Síntese one-pot em meio básico (TEA) por irradiação micro-ondas}

Em um balão de $10 \mathrm{~mL}$ foram adicionados $1 \mathrm{mmol}$ do composto carbonílico e 1,0 mmol de malononitrila 2'. Em seguida, $15 \mu \mathrm{L}$ de base (TEA) foram adicionados. A reação foi realizada em um reator $\mathrm{MO}$, a $85{ }^{\circ} \mathrm{C}$ e $10 \mathrm{~W}$ durante 1 hora. $\mathrm{O}$ progresso da reação foi monitorado por CCD utilizando como eluente uma mistura de hexano e acetato de etila (7:3).

Posteriormente, realizou-se a extração líquido-líquido adicionando $10 \mathrm{~mL}$ de $\mathrm{H}_{2} \mathrm{O}$ e AcOEt $(3 \times 20 \mathrm{~mL})$. As fases orgânicas foram combinadas e o $\mathrm{Na}_{2} \mathrm{SO}_{4}$ anidro foi adicionado. Em seguida, filtrou-se e o solvente foi removido em rotaevaporador à pressão reduzida.

Os produtos sintetizados foram analisados via CG-EM e somente o aduto $\mathbf{5 j}$ foi purificado por cromatografia em coluna de sílica gel (35-70 $\mu \mathrm{m}$ de diâmetro de partícula e 6 $\mathrm{nm}$ de diâmetro de poro). Posteriormente, o composto purificado foi caracterizado por RMN ${ }^{1} \mathrm{H} \mathrm{e}{ }^{13} \mathrm{C}$. O Esquema 21 ilustra a síntese dos adutos de Knoevenagel em meio básico utilizando TEA sob irradiação MO.

Esquema 21. Síntese de adutos de Knoevenagel entre cetonas aromáticas e a malononitrila 5' utilizando TEA.

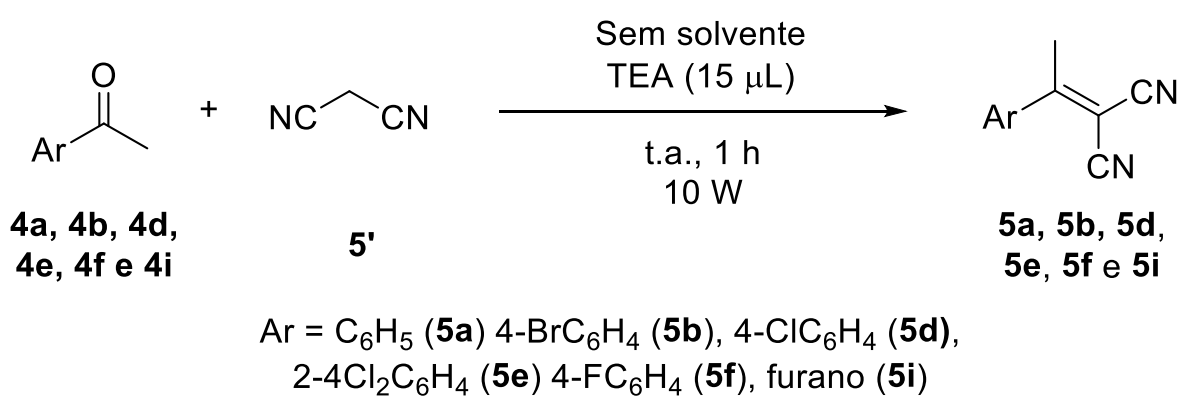

2-(1-(furan-2-il)etilideno)malononitrila (5i)

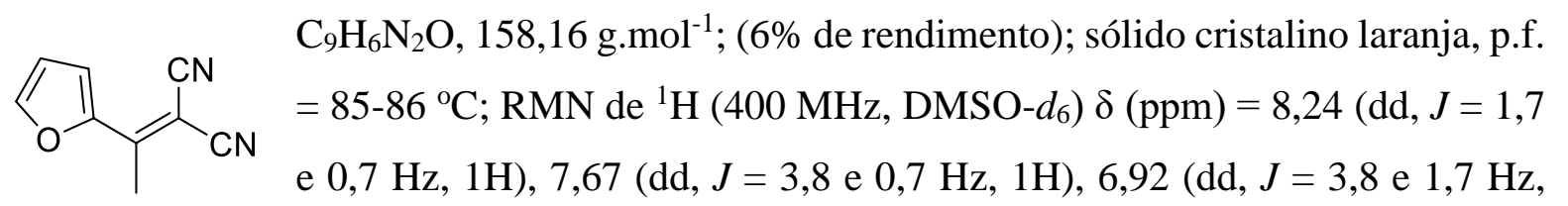

1H), 2,52 (s, 3H); RMN de ${ }^{13} \mathrm{C}\left(100 \mathrm{MHz}, \mathrm{DMSO}-d_{6}\right) \delta(\mathrm{ppm})=156,54,149,93,149,27$, 122,60, 114,51, 114,15, 113,89, 75,02, 19,45; MS (70 eV), m/z = $158\left(\mathrm{M}^{+\bullet}, 100 \%\right), 129$ (50\%), $103(30 \%), 76(25 \%), 51(10 \%)$.

Os adutos $\mathbf{5 a}, \mathbf{5 b}, \mathbf{5 d}, \mathbf{5 e}$ e $\mathbf{5 f}$ não foram isolados nesta metodologia. 


\subsection{Biotransformação dos adutos de Knoevenagel $2 \mathrm{~d}, 2 \mathrm{~g}, 2 \mathrm{j}$ e $2 \mathrm{k}$ sintetizados entre aldeídos aromáticos e cianoacetato de metila 2'}

\subsubsection{Isolamento e cultivo do fungo marinho P. citrinum CBMAI 1186}

O fungo P. citrinum CBMAI 1186 foi isolado da alga marinha Caulerpa sp. na cidade de São Sebastião, São Paulo, Brasil pelo grupo de Química Orgânica de Sistemas Biológicos (QOSBio) coordenado pelo Prof. Dr. Roberto G. S. Berlinck (IQSC), identificado no Centro Pluridisciplinar de Pesquisas Químicas, Biológicas e Agrícolas (CPQBA) da Universidade de Campinas e foi depositado na Coleção Brasileira de Microrganismos de Ambiente e Indústria - CBMAI (https://www.cpqba.unicamp.br/colecoes/cbmai.html).

A cultura do fungo de ambiente marinho $P$. citrinum CBMAI 1186 em meio líquido foi realizada pela transferência de fragmentos do meio sólido $(0,5 \mathrm{~cm} \times 0,5 \mathrm{~cm})$ contendo os micélios da cultura estoque para inocular em $600 \mathrm{~mL}$ de meio de cultura em extrato de malte 2\% (Acumedia) em água do mar artificial contidos em um frasco Erlenmeyer (2 L). O micélio foi incubado durante 7 dias à temperatura de $32^{\circ} \mathrm{C}$ em agitador orbital (130 rpm).

A composição da água do mar artificial foi constituída por uma mistura de sais: $\mathrm{CaCl}_{2} \cdot 2 \mathrm{H}_{2} \mathrm{O}\left(1,36\right.$ g.L $\left.\mathrm{L}^{-1}\right), \mathrm{MgCl}_{2} \cdot 6 \mathrm{H}_{2} \mathrm{O}\left(9,68 \mathrm{~g} . \mathrm{L}^{-1}\right), \mathrm{KCl}\left(0,6 \mathrm{~g} . \mathrm{L}^{-1}\right), \mathrm{NaCl}\left(30,0\right.$ g.L $\left.\mathrm{L}^{-1}\right), \mathrm{Na}_{2} \mathrm{HPO}_{4}$ $\left(0,014 \mathrm{mg} . \mathrm{L}^{-1}\right), \mathrm{Na}_{2} \mathrm{SO}_{4}\left(3,47\right.$ g.L $\left.\mathrm{L}^{-1}\right), \mathrm{NaHCO}_{3}\left(0,17\right.$ g.L $\left.\mathrm{L}^{-1}\right), \mathrm{KBr}\left(0,1\right.$ g.L $\left.\mathrm{L}^{-1}\right), \mathrm{SrCl}_{2} \cdot 6 \mathrm{H}_{2} \mathrm{O}(0,040$ g.L $\left.\mathrm{L}^{-1}\right), \mathrm{H}_{3} \mathrm{BO}_{3}\left(0,030\right.$ g.L $\left.\mathrm{L}^{-1}\right)$ em $\mathrm{pH} 8$.

\subsubsection{Biotransformação dos adutos $2 \mathrm{~d}, 2 \mathrm{~g}, 2 \mathrm{j}$ e $2 \mathrm{k}$ pelo fungo $P$. citrinum CBMAI 1186}

Após o crescimento os micélios do fungo P. citrinum CBMAI 1186 foram recolhidos via filtração em funil Buchner. Em seguida foram adicionados $5 \mathrm{~g}$ (massa úmida) dos micélios e suspensos em $100 \mathrm{~mL}$ de solução tampão fosfato $\left(\mathrm{Na}_{2} \mathrm{HPO}_{4} / \mathrm{KH}_{2} \mathrm{PO}_{4}, \mathrm{pH}=7,0,1 \mathrm{~mol} / \mathrm{L}\right)$ em frasco Erlenmeyer $(250 \mathrm{~mL})$. Os adutos de Knoevenagel 2d, 2g, 2j e 2k (50 mg) foram previamente dissolvidos em dimetilsulfóxido $(400 \mu \mathrm{L})$ e em seguida foram adicionados ao meio de cultura. A mistura foi mantida de 1 a 5 dias em um agitador orbital (32 $\left.{ }^{\circ} \mathrm{C}, 130 \mathrm{rpm}\right)$. As reações foram monitoradas usando CCD a cada $24 \mathrm{~h}$. Os produtos de biotransformação foram isolados por extração com AcOEt (3x50 mL), analisados e identificados via CG-EM, baseados na biblioteca Wiley de compostos.

Para cada dia de reação foi realizado um experimento indepentende, sendo interrompido no respectivo tempo, extraído e analisado por CG-EM. Todas as reações foram realizadas em duplicatas. 
RESULTADOS E DISCUSSÃO 


\section{RESULTADOS E DISCUSSÃO}

\subsection{Condensação de Knoevenagel entre os aldeídos aromáticos e o cianoacetato de metila 2'}

Ao realizar um levantamento bibliográfico recente (2013-2018) na base de dados Reaxys (acesso: 05/2018) sobre a síntese do aduto de Knoevenagel 2a utilizando o benzaldeído 1a (o mais comumente aldeído utilizado) e o cianoacetato de metila 2', notou-se que algumas metodologias eficientes foram descritas. Nestes estudos, valores de rendimentos superiores a 60\% para a síntese do aduto 2a foram descritos (Tabela 7, entradas 1-6) e podem ser caracterizadas como metodologias verdes, pois utilizaram solventes amigáveis ao meio ambiente, como $\mathrm{H}_{2} \mathrm{O}$, EtOH e $\mathrm{MeOH}$. Contudo, os tempos das reações em alguns casos foram elevados (14-24 h) e foi necessário o uso de catalisadores específicos, como polímeros, nanopartículas magnéticas funcionalizadas, sais, bases ou líquidos iônicos [74-79].

Também de acordo com o levantamento da literatura, para nosso conhecimento, existe apenas um estudo descrevendo o uso de MO aplicada nesta reação, descrito por AYOUBI [80]. Este trabalho (1994) utilizou a piperidina como um aditivo básico e demonstrou ser eficiente, visto os baixos tempos reacionais necessários ( $3 \mathrm{~min}$ ), elevado valor de rendimento obtido $(97 \%)$ e por não utilizar solvente (Tabela 7, entrada 7). Porém, se fez necessário o uso de uma alta potência $(250 \mathrm{~W})$. Sendo assim, constatando que as radiações MO foram pouco exploradas na literatura para este tipo de reação e se mostraram promissoras, pois atendem alguns dos princípios da Química Verde, foram desenvolvidas neste trabalho metodologias sintéticas alternativas para a síntese de adutos de Knoevenagel utilizando este tipo de energia eletromagnética. 
Tabela 7. Metodologias desenvolvidas recentemente para a síntese do aduto de Knoevenagel 2a entre o benzaldeído 1a e o cianoacetato de metila 2' e o primeiro exemplo desta reação assistida por radiação MO.

\begin{tabular}{|c|c|c|c|c|}
\hline & \multicolumn{2}{|r|}{$\begin{array}{l}\text { aditivo } \\
\text { solvente }\end{array}$} & \multirow[b]{2}{*}{$2 a$} & \\
\hline & $1 \mathrm{a}$ & & & \\
\hline Entrada & Catalisador & Condição de reação & $\begin{array}{c}\text { Rendimento } \\
(\%)\end{array}$ & Referência \\
\hline 1 & $\begin{array}{l}\text { Nanopartículas de } \mathrm{Fe}_{3} \mathrm{O}_{4} \\
\text { revestidas com } \mathrm{SiO}_{2}\end{array}$ & $\mathrm{H}_{2} \mathrm{O}, 75^{\circ} \mathrm{C}, 30 \mathrm{~min}$ & 80 & $\begin{array}{l}\text { RESENDE } \\
\text { FILHO } \text { et al. } \\
\text { (2017) [74] }\end{array}$ \\
\hline 2 & $\begin{array}{l}\text { Poliuretano com } \\
\text { microporos }\end{array}$ & $\mathrm{THF}, 50^{\circ} \mathrm{C}, 14 \mathrm{~h}$ & 60 & $\begin{array}{l}\text { DEY et al. } \\
\text { (2016) [75] } \\
\text { CAMERINO }\end{array}$ \\
\hline 3 & Piperidina & $\mathrm{MeOH}$, refluxo, $16 \mathrm{~h}$ & 96 & $\begin{array}{c}\text { et al. }(2016) \\
{[76]}\end{array}$ \\
\hline 4 & $\mathrm{CaHPO}_{4} \cdot 2 \mathrm{H}_{2} \mathrm{O}$ & EtOH, t.a., $10 \mathrm{~min}$ & 84 & $\begin{array}{l}\text { BENZEKRI } e t \\
\text { al. (2016) [77] }\end{array}$ \\
\hline 5 & $\begin{array}{l}\text { Líquidos iônicos } \\
\text { funcionalizados com } \\
\text { aminas }\end{array}$ & $\mathrm{MeOH}, 25^{\circ} \mathrm{C}, 24 \mathrm{~h}$ & 89 & $\begin{array}{l}\text { FORD et al. } \\
\text { (2015) [78] }\end{array}$ \\
\hline 6 & Poliguanidina & $\mathrm{H}_{2} \mathrm{O}$, t.a., 15 min & 92 & $\begin{array}{l}\text { ZHAO et al. } \\
\text { (2013) [79] }\end{array}$ \\
\hline 7 & Piperidina & $\begin{array}{c}\text { Sem solvente, t.a., } 3 \\
\min , 250 \mathrm{~W}\end{array}$ & 97 & $\begin{array}{l}\text { AYOUBI et } \\
\text { al. (1994) [80] }\end{array}$ \\
\hline
\end{tabular}

t.a. $=$ temperatura ambiente

Recentemente, no trabalho desenvolvido em nosso grupo de pesquisa por Jimenez et al. [29], utilizado como modelo para desenvolver este estudo, foi realizada uma série de reações de condensação de Knoevenagel entre aldeídos aromáticos e a malononitrila 5', utilizando $\mathrm{MeOH}$ como solvente, $60^{\circ} \mathrm{C}, 20 \mathrm{~W}$ de potência, na ausência de catalisadores e em 30 minutos foram obtidos valores de rendimentos superiores a $85 \%$ para os adutos de Knoevenagel.

Alternativamente, neste estudo a $\mathrm{H}_{2} \mathrm{O}$ foi selecionada como o solvente da reação. Vale observar que, em geral, moléculas polares sofrem maiores efeitos da radiação MO, principalmente pelo mecanismo de polarização dipolar. As moléculas de água possuem dipolos permanentes em suas estruturas, e estes se alinham ao campo elétrico aplicado no sistema. Ao ser retirado o campo elétrico, as moléculas retornam ao estado de desordem emitindo ao meio a energia previamente absorvida no alinhamento das moléculas na forma de calor. Este mecanismo pode ser observado na Figura 6. 
Figura 6. Ilustração do efeito do mecanismo de polarização dipolar em moléculas polares sob o efeito de um campo elétrico oscilante.

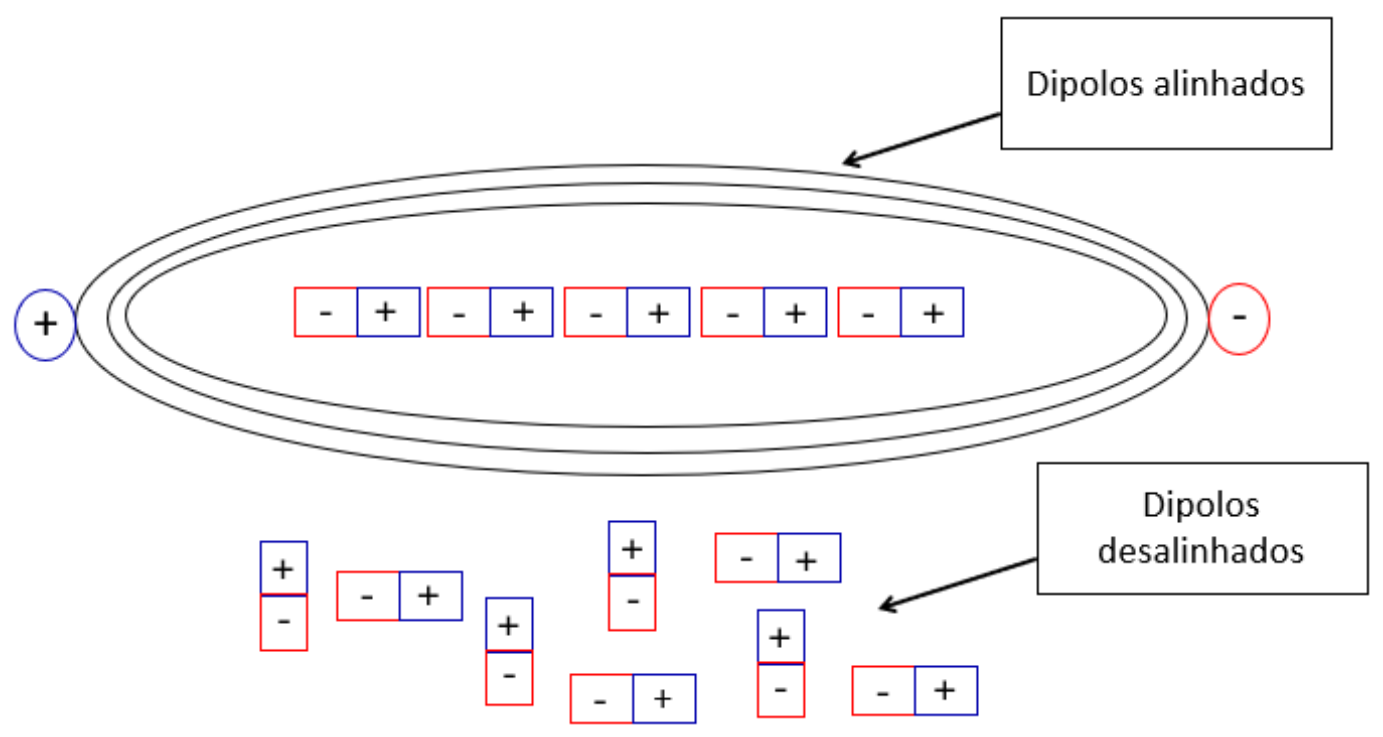

Fonte: Autoria própria.

Então, inicialmente o benzaldeído 1a foi utilizado no processo de otimização da reação, pois é um substrato de fácil acesso e sem a presença de efeitos eletrônicos de substituintes no anel aromático. As reações entre este aldeído 1a e o cianoacetato de metila 2' foram realizadas utilizando a $\mathrm{H}_{2} \mathrm{O}$ como solvente em reator $\mathrm{MO}$ durante $30 \mathrm{~min}$, a $85^{\circ} \mathrm{C}$ e a $55 \mathrm{~W}$ de potência. Alíquotas de $50 \mu \mathrm{L}$ foram retiradas durante o progresso da reação, por um tempo máximo de 30 minutos e a conversão do benzaldeído 1a no aduto 2a foi determinada via CG-EM (Tabela 8). Somando ao processo, uma reação também foi conduzida em chapa de aquecimento por um tempo máximo de 70 minutos, sob a mesma temperatura, para observar os efeitos da condução térmica frente à formação do aduto $\mathbf{2 a}$.

Tabela 8. Otimização da condensação de Knoevenagel para a síntese do aduto 2a por irradiação MO em presença de $\mathrm{H}_{2} \mathrm{O}$.

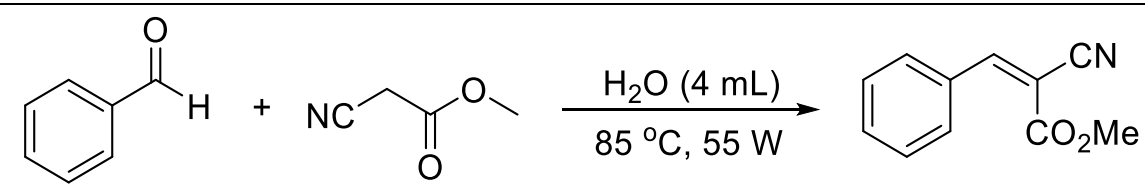

1a 2' 2a

\begin{tabular}{cc}
\hline Tempo (minutos) & Conversão $^{\mathrm{a}}(\%)$ \\
\hline 10 & 20 \\
20 & 37 \\
30 & 55 \\
$70^{\mathrm{b}}$ & 36 \\
\hline
\end{tabular}

${ }^{a}$ conversão determinada por CG-EM.

${ }^{\mathrm{b}}$ reação realizada em chapa de aquecimento. 
Neste estudo foi constatado que, os valores de conversão foram inferiores em comparação ao estudo descrito por Jimenez et al. [29] no qual as condensações de Knoevenagel foram realizadas entre aldeídos aromáticos e a malononitrila 5' onde rendimentos superiores a $85 \%$ foram obtidos. Outra comparação que pode ser feita é que a reação que foi realizada em reator MO em 30 min obteve um valor de conversão de 55\% superior à reação conduzida em 70 min em chapa de aquecimento $(\mathrm{c}=36 \%)$ para a síntese do aduto $\mathbf{2 a}$. Contudo, como estes valores de conversão não foram satisfatórios $(c=20-55 \%)$, então o processo de otimização passou por novas metodologias de estudo.

Analisando a acidez dos compostos metilênicos ativos, sabe-se que os hidrogênios ácidos da malononitrila possuem um valor de $p K a$ 11, inferiores aos do cianoacetato de metila 2' que possui $p K a$ 12,8. Sendo assim, devido a menor acidez do cianoacetato de metila 2 ' foi proposta a adição de um aditivo ao sistema reacional, neste caso utilizou-se a trietilamina (TEA), uma base orgânica acessível, comumente utilizada em procedimentos sintéticos. Para analisar a influência deste aditivo, o mesmo estudo sobre a conversão dos reagentes em produto foi realizado via CG-EM (Tabela 9).

Tabela 9. Otimização da condensação de Knoevenagel para a síntese do aduto 2a por irradiação MO em presença de $\mathrm{H}_{2} \mathrm{O}$ e TEA.

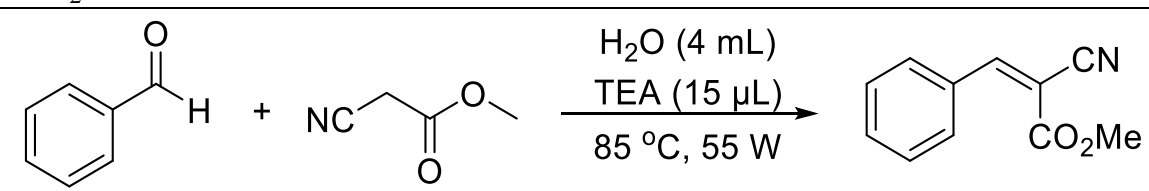

$1 \mathrm{a}$ $\mathbf{2}^{\prime}$ 2a

\begin{tabular}{cc}
\hline Tempo (minutos) & Conversão $^{\mathrm{a}}(\%)$ \\
\hline 10 & 30 \\
20 & 55 \\
30 & 79 \\
$30^{\mathrm{b}}$ & 44 \\
$70^{\mathrm{b}}$ & 80 \\
\hline
\end{tabular}

${ }^{a}$ conversão determinada por CG-EM;

${ }^{\mathrm{b}}$ reação realizada em chapa de aquecimento.

A presença da TEA no sistema reacional favoreceu os valores de conversão na formação do aduto 2a tanto das reações realizadas em MO, onde foi obtido 79\% de conversão em 30 min, quanto da reação realizada em chapa de aquecimento, onde foi obtido $80 \%$ de conversão em 70 min (Tabela 9). Estes valores de conversão foram significativamente superiores em comparação as reações realizadas na ausência da TEA, na qual a reação conduzida em reator MO em 30 min resultou em 55\% de conversão e em 70 min em condições convencionais de aquecimento resultou em $36 \%$ de conversão (Tabela 8 ). 
Os resultados demonstraram que com a adição da TEA, o ânion do cianoacetato de metila 2' deve ter sido mais efetivamente formado, acarretando um melhor desempenho da reação. A Figura 7 é composta pelos cromatogramas das duas reações realizadas em 30 minutos, na qual a reação representada pela curva azul foi realizada em reator MO e a reação representada pela curva rosa foi realizada em chapa de aquecimento convencional.

Figura 7. Cromatogramas das reações de síntese do aduto 2a. O cromatogramas em azul é referente a reação realizada em reator $\mathrm{MO}$ utilizando TEA. O cromatograma em rosa é referente a reação realizada em chapa de aquecimento. Ambas as reações foram realizadas a $85^{\circ} \mathrm{C}$.

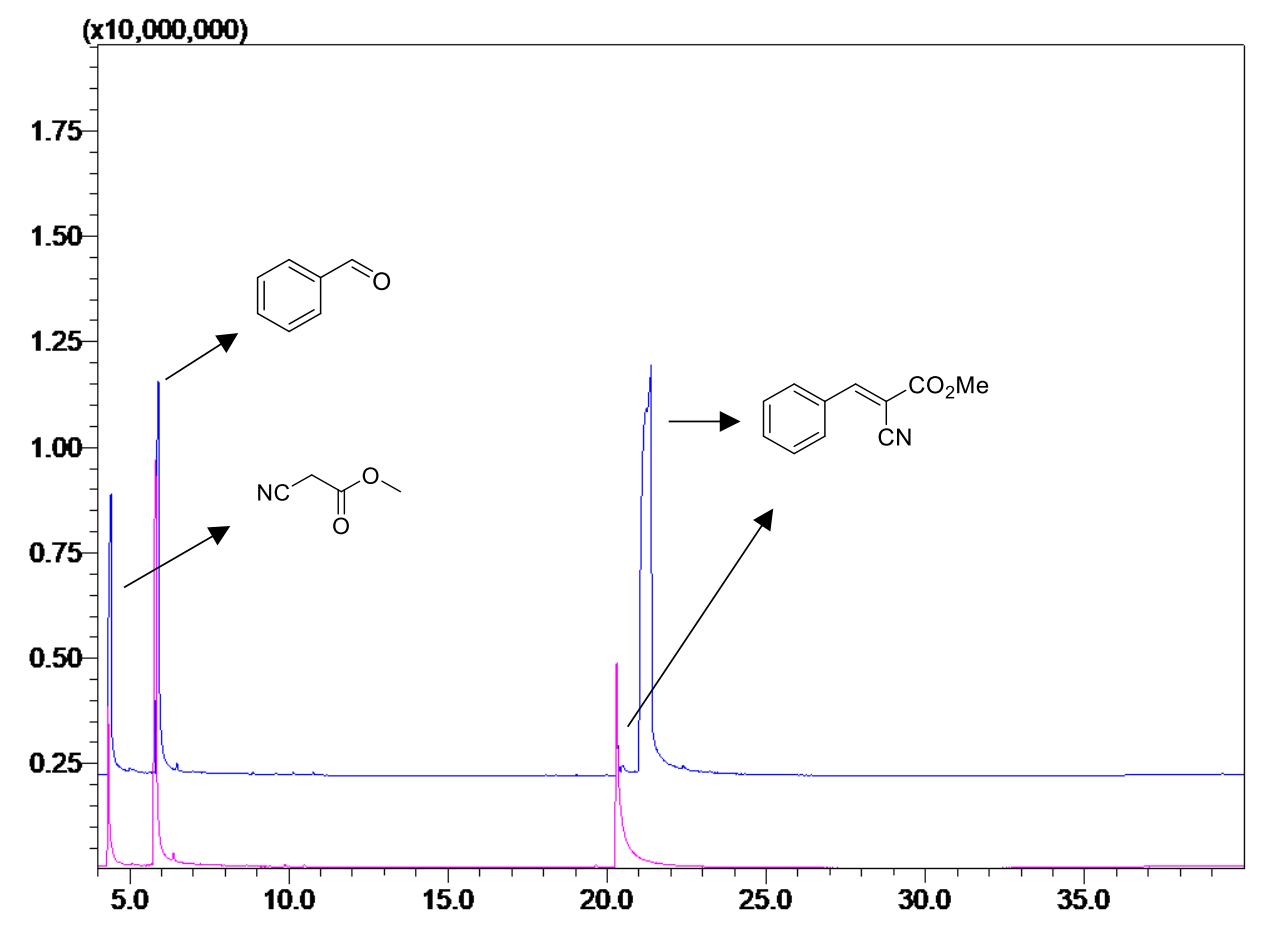

Sequencialmente, uma série de adutos de Knoevenagel 2a-l foram sintetizados utilizando diferentes aldeídos aromáticos nas condições da reação otimizadas por irradiação MO $(15 \mu \mathrm{L}$ de TEA, $30 \mathrm{~min}, 55 \mathrm{~W}$ e $5 \mathrm{~mL}$ de $\mathrm{H}_{2} \mathrm{O}$ ). Neste estudo foram obtidos bons valores de rendimentos (45-90\%). Porém, para os adutos $\mathbf{2 a}, \mathbf{2 b}, \mathbf{2 d}, \mathbf{2 e}, \mathbf{2 h}$ e $\mathbf{2 l}$ que obtiveram rendimentos inferiores a 70\%, foi proposta uma alteração na metodologia, fazendo a troca do solvente prótico. Assim, o EtOH foi utilizado nestes casos específicos, a uma temperatura de $65^{\circ} \mathrm{C}$, devido ao seu menor valor de ponto de ebulição. Os resultados demonstraram que os rendimentos aumentaram significativamente, como por exemplo na síntese do aduto $2 \mathbf{a}$, que em $\mathrm{H}_{2} \mathrm{O}$ obteve $61 \%$ de rendimento e em EtOH forneceu 89\%. A vantagem da troca de solvente neste caso foi a redução da temperatura da reação e o melhor rendimento quando realizada em etanol. Todos os resultados estão expostos na Tabela 10. 
A Figura 8 ilustra todas as estruturas dos adutos de Knoevenagel sintetizados por irradiação MO utilizando água ou etanol como solventes próticos.

Tabela 10. Síntese de adutos de Knoevenagel 2a-l, entre aldeídos aromáticos e o cianoacetato de metila 2' sob irradiação $\mathrm{MO}$ utilizando $\mathrm{H}_{2} \mathrm{O}$ ou EtOH.

\begin{tabular}{|c|c|c|c|c|}
\hline $\mathrm{Ar}_{\mathrm{H}}$ & $\prod_{0}$ & $\begin{array}{c}\mathrm{H}_{2} \mathrm{O} \text { ou EtOH }(5 \mathrm{~mL}) \\
\underset{\text { TEA }(15 \mu \mathrm{L})}{\longrightarrow} \\
\underset{65-85^{\circ} \mathrm{C}, 30 \mathrm{~min}}{55 \mathrm{~W}}\end{array}$ & $\mathrm{Ar} \overbrace{2 \mathrm{C}-\mathrm{I}}^{\mathrm{Ar}}$ & \\
\hline $\mathrm{Ar}$ & $\begin{array}{r}\text { Rendimento } \\
\mathrm{H}_{2} \mathrm{O}( \\
\end{array}$ & $\begin{array}{l}\text { isolado em } \\
(\%)^{\mathrm{a}}\end{array}$ & $\begin{array}{l}\text { limento isolado em } \\
\text { EtOH }(\%)^{\mathrm{b}}\end{array}$ & $\begin{array}{l}\text { Ponto de } \\
\text { fusão }\left({ }^{\circ} \mathrm{C}\right)\end{array}$ \\
\hline $\mathrm{C}_{6} \mathrm{H}_{5}(\mathbf{2 a})$ & 61 & & 89 & $88-89$ \\
\hline $4-\mathrm{BrC}_{6} \mathrm{H}_{4}(\mathbf{2 b})$ & 51 & & 82 & $104-105$ \\
\hline $4-\mathrm{C}_{2} \mathrm{H}_{3} \mathrm{O}_{2} \mathrm{C}_{6} \mathrm{H}_{4}(\mathbf{2 c})$ & 82 & & $(-)$ & $139-140$ \\
\hline $4-\mathrm{ClC}_{6} \mathrm{H}_{4}(\mathbf{2 d})$ & 48 & & 80 & $122-123$ \\
\hline $4-\mathrm{FC}_{6} \mathrm{H}_{4}(\mathbf{2 e})$ & 54 & & 80 & $91-92$ \\
\hline $4-\mathrm{N}\left(\mathrm{CH}_{3}\right)_{2} \mathrm{C}_{6} \mathrm{H}_{4}(\mathbf{2 f})$ & 71 & & $(-)$ & $145-146$ \\
\hline $4-\mathrm{NO}_{2} \mathrm{C}_{6} \mathrm{H}_{4}(\mathbf{2 g})$ & 90 & & $(-)$ & $176-178$ \\
\hline $4-\mathrm{OCH}_{3} \mathrm{C}_{6} \mathrm{H}_{4}(\mathbf{2 h})$ & 55 & & 70 & $145-146$ \\
\hline $4-\mathrm{OHC}_{6} \mathrm{H}_{4}(2 \mathbf{i})$ & 88 & & $(-)$ & $165-166$ \\
\hline $4-\mathrm{OH}, 3-\mathrm{OCH}_{3} \mathrm{C}_{6} \mathrm{H}_{3}(\mathbf{2} \mathbf{j})$ & 88 & & $(-)$ & $159-160$ \\
\hline $\begin{array}{l}\text { 3- } \mathrm{OCH}_{3}, 4-\mathrm{OCH}_{3}, 5- \\
\mathrm{OCH}_{3} \mathrm{C}_{6} \mathrm{H}_{2}(\mathbf{2 k})\end{array}$ & 70 & & $(-)$ & $119-120$ \\
\hline Furfural (2l) & 46 & & 90 & 94-95 \\
\hline
\end{tabular}

${ }^{a}$ temperatura: $85^{\circ} \mathrm{C}$;

${ }^{b}$ temperatura: $65^{\circ} \mathrm{C}$;

(-) reação não foi realizada em EtOH.

Figura 8. Estrutura dos adutos de Knoevenagel 2a-i sintetizados via irradiação MO na presença de água ou etanol como solventes próticos.

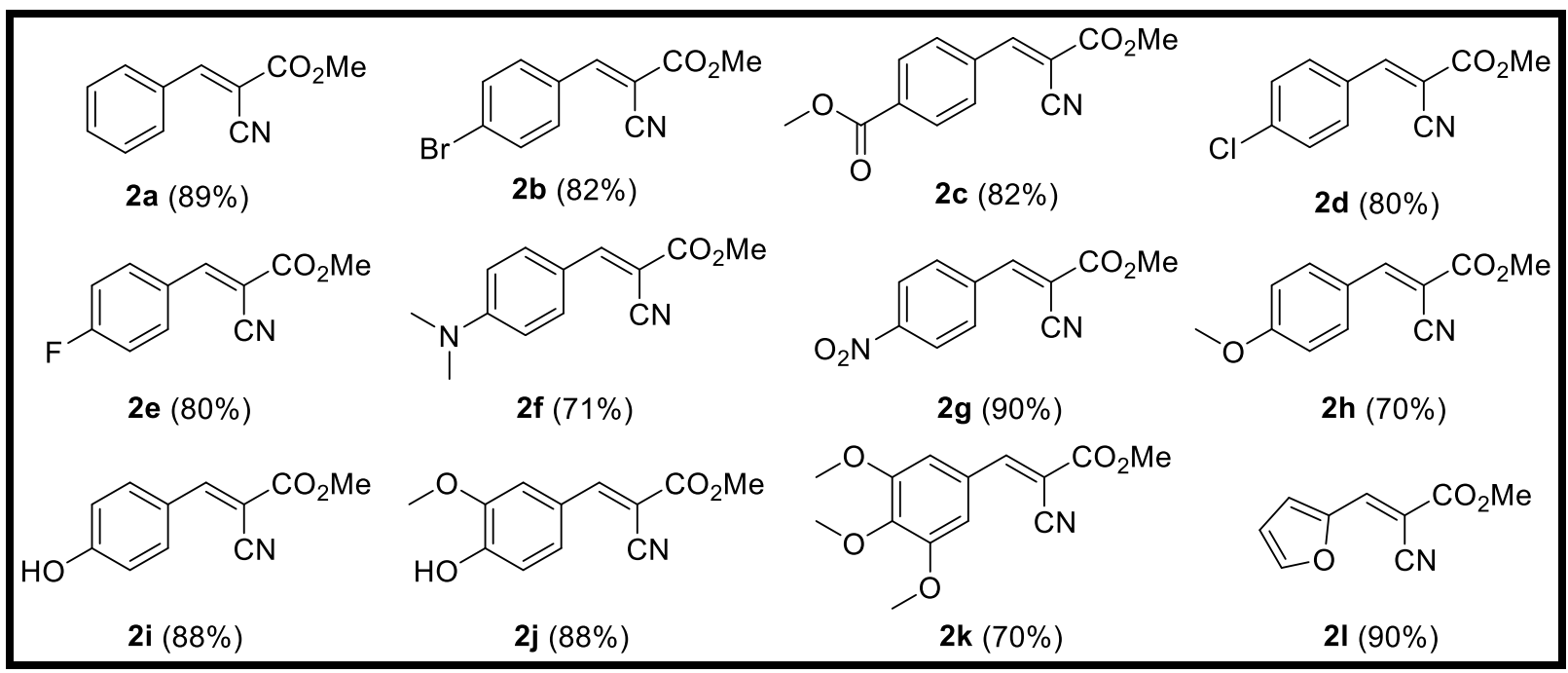

O melhor desempenho nos rendimentos reacionais pode ser atribuído a dois fatores: a solubilidade dos reagentes e o maior fator de dissipação (tangente de $\delta$ ) do EtOH. Os aldeídos 
e o cianoacetato de metila 2' são pouco solúveis em $\mathrm{H}_{2} \mathrm{O}$. Em contrapartida, em EtOH os reagentes tornam-se mais solúveis e devido a esta propriedade, um maior número de choques efetivos entre as moléculas dos reagentes podem ocorrer, resultando em um aumento na cinética reacional.

Quanto ao valor de tangente de $\delta$, o EtOH possui um valor maior que a $\mathrm{H}_{2} \mathrm{O}$ (Tabela 11). Este fator reflete na capacidade de um solvente em transformar a energia eletromagnética emitida em forma de calor e quanto maior este fator, maior é a sua capacidade. Sendo assim, o EtOH mostrou-se um solvente mais apropriado em relação a $\mathrm{H}_{2} \mathrm{O}$ na síntese dos adutos de Knoevenagel 2a-l realizadas em reator MO como fonte de aquecimento.

Tabela 11. Fator de dissipação de alguns solventes orgânicos [81].

\begin{tabular}{cc} 
Solvente & $\begin{array}{c}\text { Fator de dissipação } \\
\text { (tangente de } \delta \text { ) }\end{array}$ \\
\hline $\mathrm{H}_{2} \mathrm{O}_{(\mathrm{s})}$ & 0,0009 \\
$\mathrm{EtOH}$ & 0,25 \\
$\mathrm{H}_{2} \mathrm{O}_{(\mathrm{l})}$ & 0,15 \\
$\mathrm{Tolueno}_{\mathrm{THF}}$ & 0,04 \\
$\mathrm{CCl}_{4}$ & 0,047 \\
$\mathrm{Heptano}$ & 0,0004 \\
\hline
\end{tabular}

Todos os adutos de Knoevenagel 2a-I foram sintetizados com bons valores de rendimentos (Tabela 10) e foram purificados de maneira simples, realizando lavagens do extrato reacional seco com hexano a quente, visto que não foram observadas diferenças significativas nos valores de rendimentos quando os adutos foram purificados por cromatografia em coluna. Após esta etapa, todos os compostos foram caracterizados por técnicas espectroscópicas $\left(\mathrm{RMN}{ }^{1} \mathrm{H},{ }^{13} \mathrm{C} \mathrm{e}\right.$ IV) e espectrométrica (CG-EM).

A caracterização do aduto $\mathbf{2 b}$, obtido com $82 \%$ de rendimento, foi utilizada como exemplo do que foi realizado com todos adutos sintetizados neste estudo.

No espectro de infravermelho $\left(\mathrm{KBr}, \mathrm{cm}^{-1}\right)$, ilustrado na Figura 9, foram observadas quatro bandas mais relevantes referentes as deformações axiais características da ligação $C \equiv \mathrm{N}$ em $2223 \mathrm{~cm}^{-1}$ do grupo ciano, da ligação $\mathrm{C}=\mathrm{O}$, em $1728 \mathrm{~cm}^{-1}$ e C-O em $1288 \mathrm{~cm}^{-1}$, do grupo éster. Bem como, foram observadas bandas referentes as vibrações de deformação axial da ligação $\mathrm{C}=\mathrm{C}$ alifática, em $1610 \mathrm{~cm}^{-1}$ e da ligação $\mathrm{C}=\mathrm{C}$ aromática em $1581 \mathrm{~cm}^{-1}$. Outras bandas também foram observadas, em 3093, 3030, 2958, 1485, 1436, 1400, 1288, 1184, 1070, 1004, 960, 819, $758,702,580,487 \mathrm{~cm}^{-1}$. 
Figura 9. Espectro de absorção na região do infravermelho $\left(\right.$ puro, $\mathrm{cm}^{-1}$ ) do aduto $\mathbf{2 b}$.

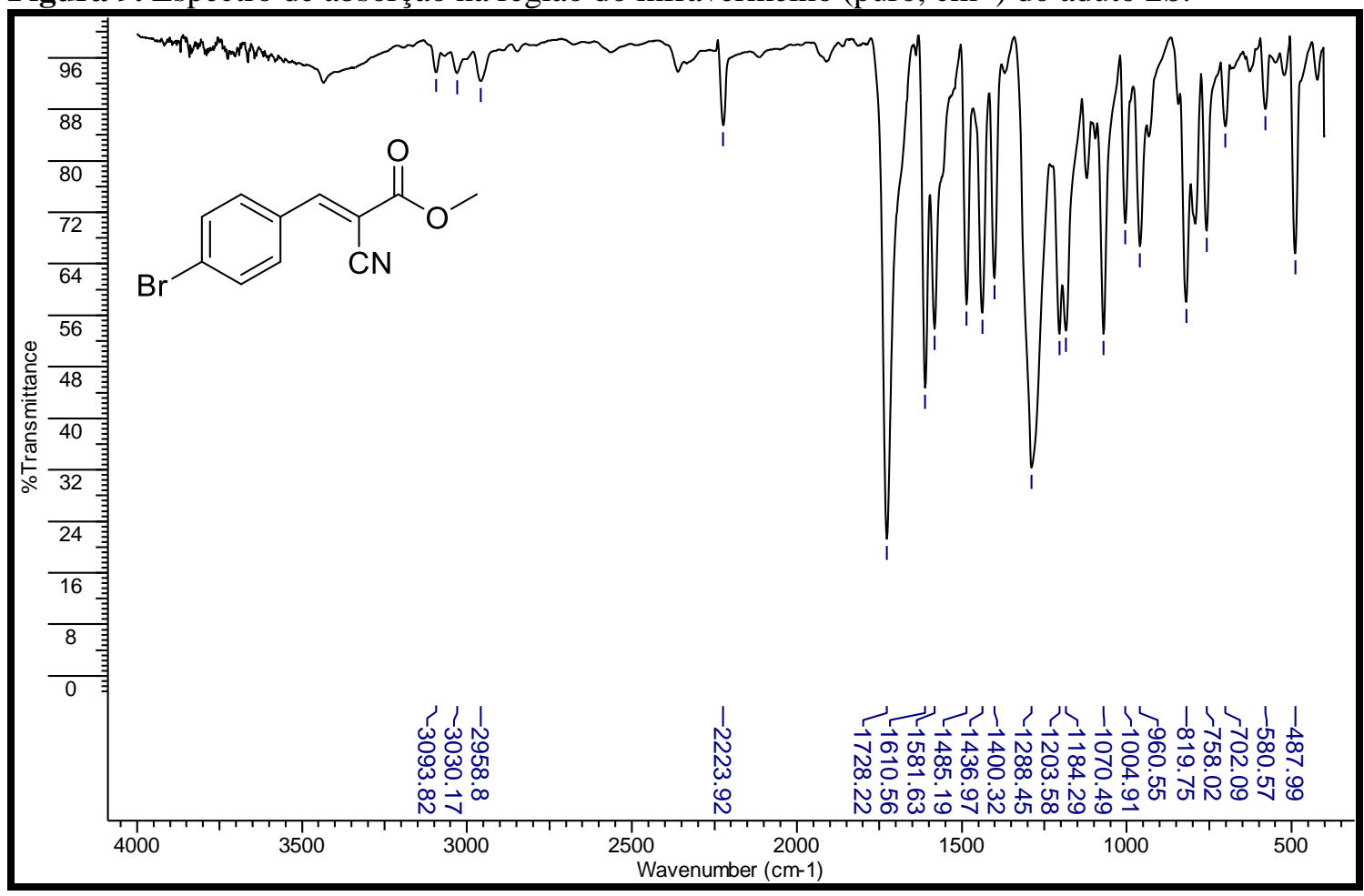

O espectro de RMN de ${ }^{1} \mathrm{H}\left(400 \mathrm{MHz}, \mathrm{CDCl}_{3}\right)$ apresentou um singleto em 8,19 ppm $(\mathrm{s}, 1 \mathrm{H})$ referente ao hidrogênio olefínico; um dubleto em 7,85 ppm $(\mathrm{d}, J=8,4 \mathrm{~Hz}, 2 \mathrm{H})$ referente aos hidrogênios do anel aromático na posição meta em relação ao bromo; um dubleto em 7,64 ppm (d, $J=8,4 \mathrm{~Hz}, 2 \mathrm{H})$ referente aos hidrogênios do anel aromático na posição orto em relação ao bromo; um singleto em 3,94 ppm (s, 3H) referente ao grupo metila da função éster. Todos estes sinais podem ser observados na Figura 10. 
Figura 10. Espectro de $\mathrm{RMN}{ }^{1} \mathrm{H}\left(400 \mathrm{MHz}, \mathrm{CDCl}_{3}\right)$ do aduto $\mathbf{2 b}$.

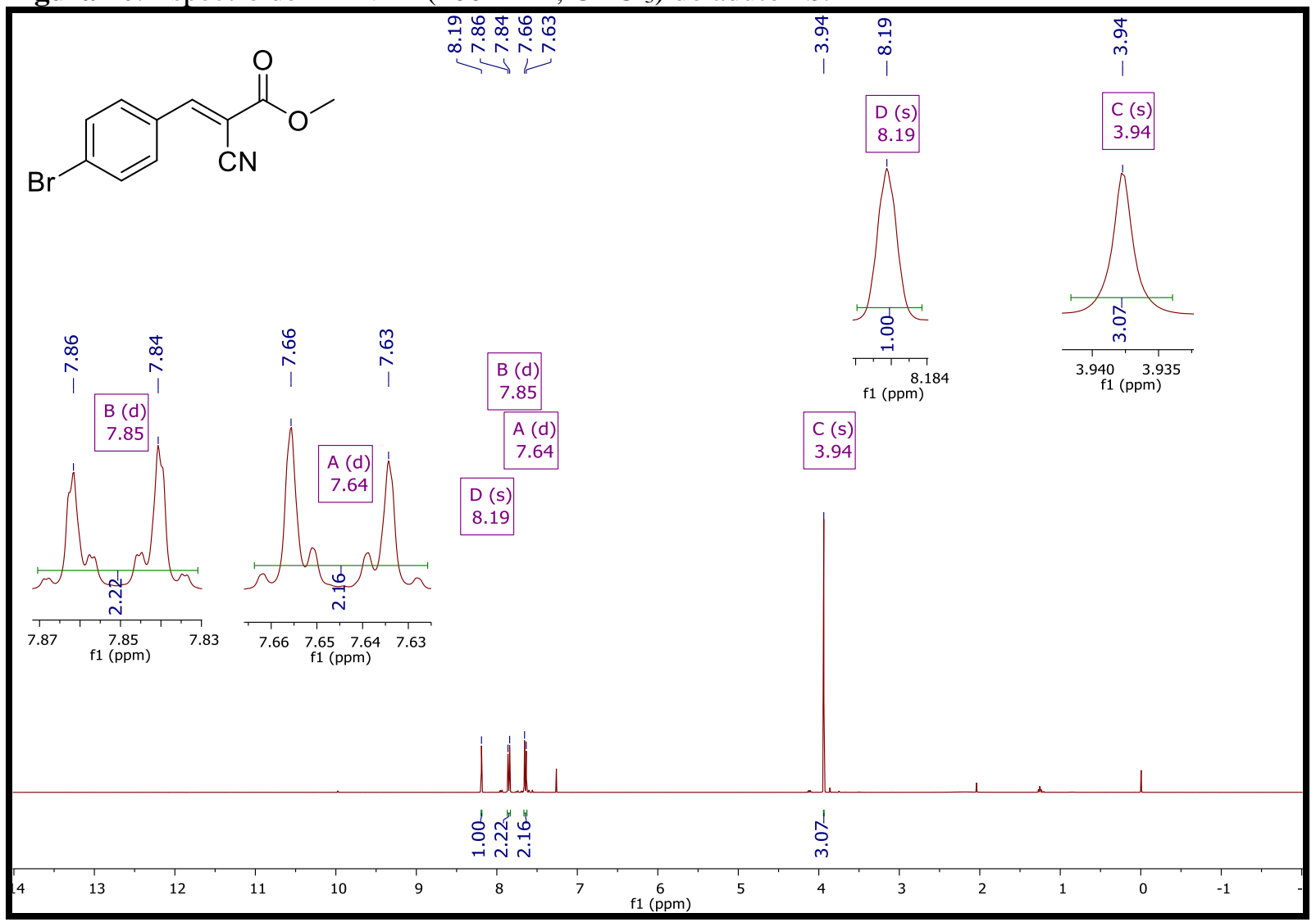

$\mathrm{O}$ espectro de $\mathrm{RMN}$ de ${ }^{13} \mathrm{C}\left(100 \mathrm{MHz}, \mathrm{CDCl}_{3}\right)$ apresentou um sinal em 162,89 ppm característico de carbono da função éster; um sinal em 159,94 ppm referente ao carbono metínico da olefina; um sinal em 132,85 ppm referente aos carbonos aromáticos na posição orto em relação ao bromo; um sinal em 132,41 ppm referente aos carbonos do anel aromático na posição meta em relação ao bromo; um sinal em 130,34 ppm referente ao carbono ipso do anel aromático ligado ao grupamento olefínico; um sinal em 128,56 ppm referente ao carbono ipso do anel aromático ligado ao átomo de bromo; um sinal em 115,34 ppm referente ao carbono do grupo ciano; um sinal em 103,33 referente ao carbono quaternário ligado às funções éster e nitrila e um sinal em 53,66 ppm referente ao grupo metila da função éster. Todos estes sinais podem ser observados na Figura 11. 
Figura 11. Espectro de $\mathrm{RMN}{ }^{13} \mathrm{C}\left(100 \mathrm{MHz}, \mathrm{CDCl}_{3}\right)$ do aduto $\mathbf{2 b}$.

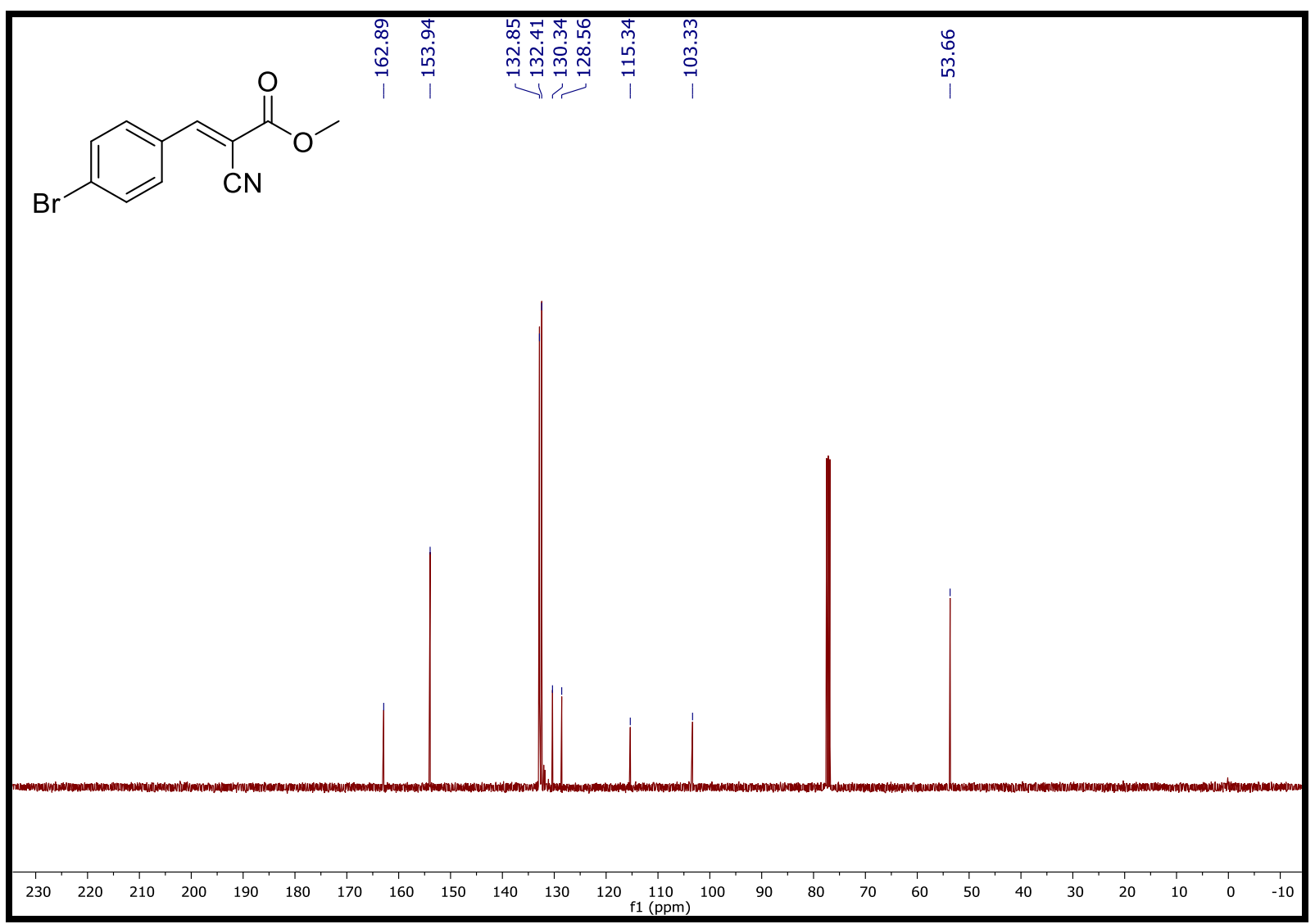

$\mathrm{O}$ espectro de massas (impacto de elétrons a $70 \mathrm{eV}$ ) apresentou o pico de íon molecular $m / z 265\left(\mathrm{M}^{+}, 70 \%\right)$. Este íon sofre a perda de um radical metoxila $\left(\cdot \bullet^{\circ} \mathrm{OH}_{3}\right)$ gerando o íon de $m / z$ 234. Este íon por sua vez perde um radical bromo $(\bullet B r)$, gerando o íon-radical de $m / z, 155$ que sequencialmente perde uma molécula de neutra de CO resultando no íon-radical de $\mathrm{m} / \mathrm{z}$ 127, o qual foi o pico base, o íon mais abundante observado no espectro (Figura 12). Esta proposta de fragmentação está demonstrada no Esquema 22.

Esquema 22. Proposta de fragmentação para o aduto $\mathbf{2 b}$.

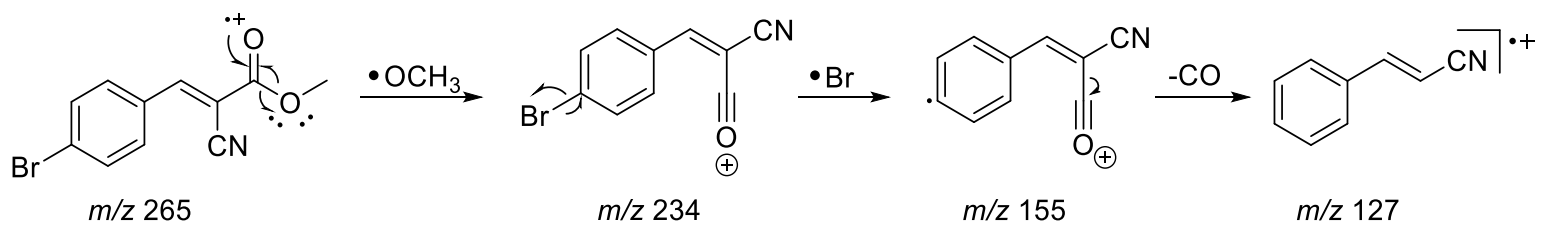


Figura 12. Espectro de massas do aduto $\mathbf{2 b}$ realizado com método de ionização por IE ( $70 \mathrm{eV})$.

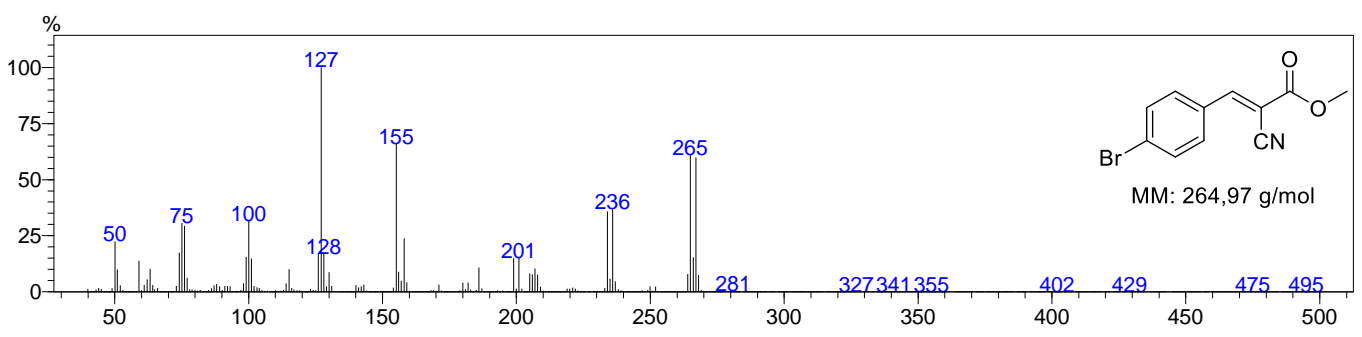

Como pode ser observado nos resultados obtidos na síntese dos adutos de Knoevenagel 2aI (Tabela 10, p. 60), independentemente do tipo de grupo substituinte ligado ao anel aromático, seja eletrodoador ou eletrorretirador, do número de grupos substituintes, e da natureza do núcleo aromático presente (benzenóide ou furano), os rendimentos dos adutos obtidos foram elevados (70-90\%) em um curto período reacional de 30 minutos, utilizando como aditivo básico a TEA, base comumente presente em laboratórios de pesquisa e a água ou o etanol como solventes próticos.

Outra vantagem desta metodologia foi o fácil processo de purificação. Foi constatado que os valores dos rendimentos isolados foram similares quando a purificação foi realizada por cromatografia em coluna ou por lavagem com hexano a quente, provavelmente pelo fato de que os adutos de Knoevenagel sintetizados serem sólidos. Assim, a maioria dos adutos foram purificados por esta lavagem, visto a maior praticidade deste procedimento.

Embora a síntese de todos estes adutos já foram relatadas na literatura por diferentes metodologias, para nosso conhecimento, exceto o aduto $(E)$-2-ciano-3-fenilacrilato de metila 2a, todos os demais foram sintetizados pela primeira vez empregando a metodologia de aquecimento via irradiação MO. Esta metodologia destaca-se por estar em concordância com alguns dos princípios da Química Verde e por apresentar períodos reacionais vantajosos.

\subsection{Síntese one-pot tricomponente de derivados de $4 H$-cromenos}

Visando aplicar os adutos de Knoevenagel na síntese de moléculas mais complexas, foi desenvolvida uma metodologia para a síntese de derivados de $4 H$-cromenos.

Como já destacado na Introdução, os $4 H$-cromenos são moléculas com diversas aplicações biológicas já comprovadas. Sendo assim, é de grande importância o conhecimento sobre novas metodologias sintéticas de fácil preparo, baixo custo, rápidas e que forneçam altos rendimentos para a obtenção destes compostos com potenciais propriedades bioativas.

Ao realizar um levantamento bibliográfico sobre a síntese de $4 H$-cromenos na literatura envolvendo aldeídos aromáticos, o cianoacetato de metila, 2' e a dimedona, 3', existem cinco 
trabalhos que relataram esta síntese de duas maneiras diferentes: via reação bicomponente $[8$, 9] ou via reação tricomponente (one-pot) $[10,11,12]$. Na síntese bicomponente, utilizou-se como reagente de partida o aduto de Knoevenagel 2a, previamente sintetizado entre o benzaldeído 1a, o cianoacetato de metila 2' e a dimedona 3'. Utilizando este procedimento, dois trabalhos foram realizados resultando em bons rendimentos (78-92\%) em períodos reacionais de 10 a 180 min (Tabela 12).

Tabela 12. Metodologias descritas na literatura sobre a síntese bicomponente do derivado de $4 \mathrm{H}$ cromeno 3a utilizando o aduto de Knoevenagel 2a e a dimedona 3'.

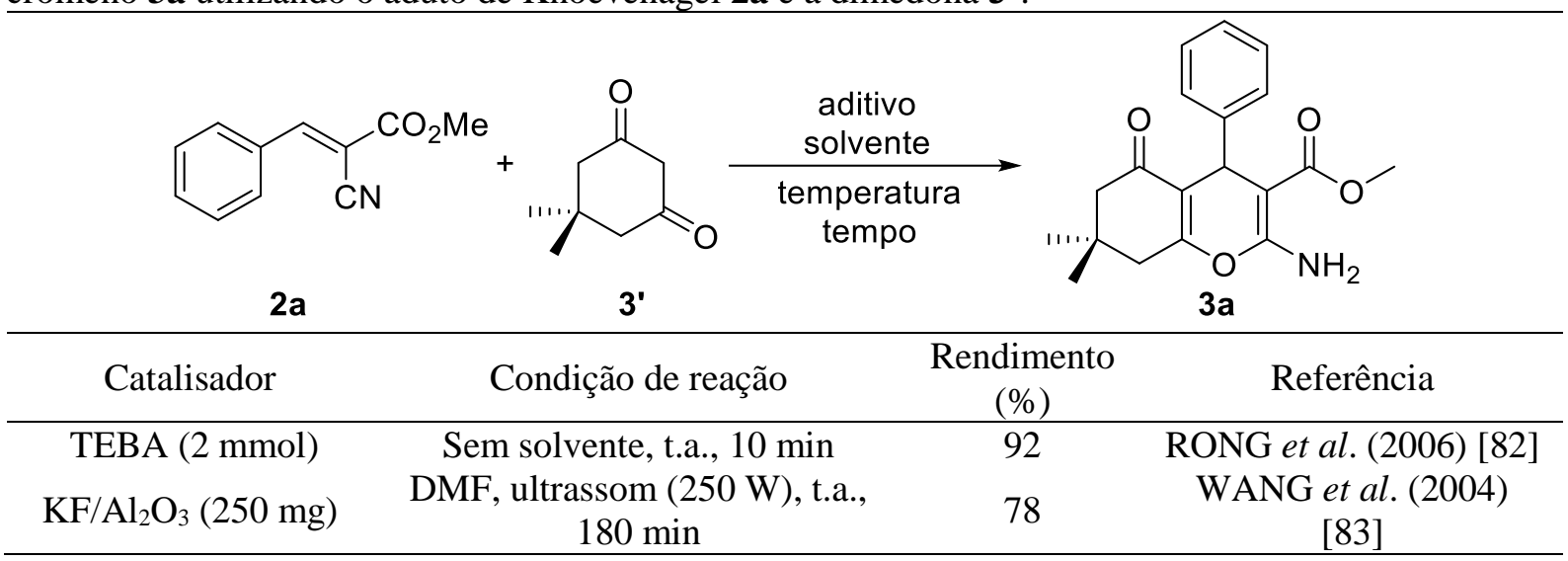

TEBA = cloreto de trietilbenzilamônio; DMF = dimetilformamida; t.a. = temperatura ambiente .

Já na síntese tricomponente, o benzaldeído 1a, o cianoacetato de metila 2' e a dimedona 3', foram adicionados ao recipiente reacional simultaneamente. Utilizando este procedimento, três trabalhos foram reportados alcançando também bons rendimentos (81-95\%) em períodos de 1 a 5 h (Tabela 13). Tempos reacionais maiores seriam esperados para esta metodologia, pois o aduto de Knoevenagel precisa ser formado inicialmente in situ, seguido da adição de Michael para fornecer o derivado de $4 H$-cromeno $3 a$. 
Tabela 13. Metodologias descritas na literatura sobre a síntese tricomponente do derivado de $4 H$ cromeno 3a utilizando o benzaldeído 1a, o cianoacetato de metila 2' e a dimedona 3'.

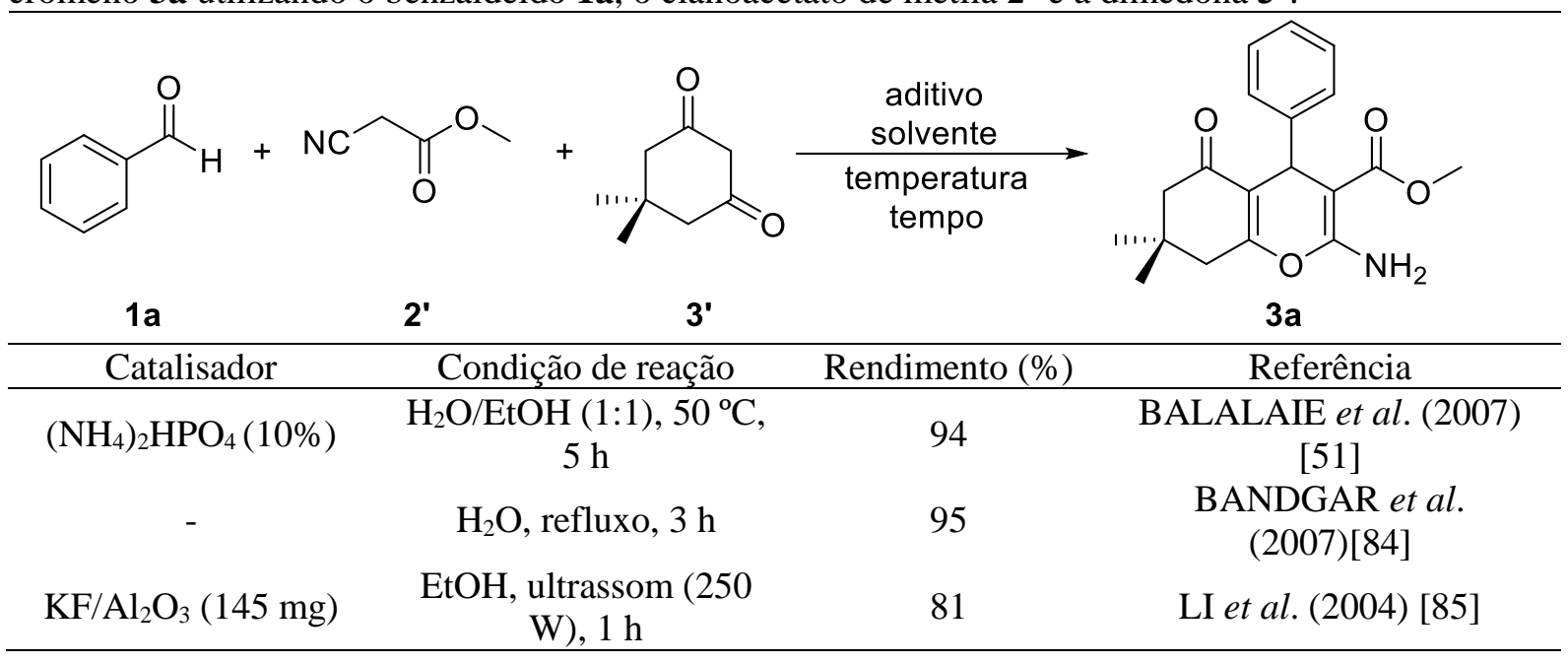

Analisando os rendimentos reacionais do derivado de $4 H$-cromeno 3a obtidos na literatura, o uso de solventes verdes, ou ausência destes, todos os estudos apresentaram-se como metodologias sintéticas eficientes (Tabelas 12 e 13). Contudo, na maioria dos trabalhos longos períodos reacionais (3-5 h) foram requeridos e o uso de catalisadores específicos e em grandes quantidades, como o $\mathrm{KF} / \mathrm{Al}_{2} \mathrm{O}_{3}$ ou TEBA, o que pode limitar a viabilidade destas metodologias.

Outra observação realizada é que não consta na literatura, para o nosso conhecimento, o uso da radiação MO assistida na síntese dessa classe de compostos de maneira tricomponente, possibilitando uma oportunidade de aplicar e explorar esta técnica para o desenvolvimento de uma metodologia de simples reprodutibilidade e seguindo os princípios da Química Verde para a obtenção de moléculas mais complexas estruturalmente. Destaca-se de forma significante que a reação tricomponente para a obtenção de derivados de $4 H$-cromenos dentre várias as vantagens existentes, a economia atômica, visto que todos os átomos dos reagentes são incorporados no produto final.

Sendo assim, baseado nas condições otimizadas da síntese dos adutos de Knoevenagel (Tabela 10, p. 60), estas foram aplicadas para a síntese one-pot tricomponente de derivados de $4 H$-cromenos. Inicialmente, o primeiro $4 H$-cromeno sintetizado $\mathbf{3 g}$, utilizou como aldeído a vanilina (3-metoxi-4-hidroxibenzaldeído), $\mathbf{1 j}$.

Nesta primeira tentativa o EtOH foi utilizado como solvente da reação, visto sua eficiência já observada previamente na síntese dos adutos de Knoevenagel (Tabela 10, p. 62). O 4Hcromeno $\mathbf{3 g}$ foi sintetizado e durante seu processo de purificação por cromatografia em coluna, o qual utilizou uma mistura de hexano e acetato de etila (7:3) como fase móvel isocrática, foi observado a presença de 2 manchas muito próximas em frações subsequentes na placa de CCD. 
A primeira mancha (mais apolar) eluiu nas frações 12-15 e a segunda mancha (mais polar) estava presente nas frações 16-30. Pela diferença de fator de retenção, pode-se afirmar inicialmente que não se tratava dos reagentes (aldeído ou até mesmo o aduto de Knoevenagel).

Estas frações foram analisadas por CG-EM (IE, $70 \mathrm{eV}$ ) e foram observados três picos para ambos os compostos isolados. Isto ocorreu provavelmente pela força do método de ionização utilizado, acarretando fragmentações na molécula do derivado de $4 H$-cromeno $3 \mathrm{~g}$ antes mesmo da separação. Os cromatogramas destes dois produtos estão contidos na Figura 13.

Quando os íons moleculares destes picos foram analisados, observou-se que o primeiro pico (8 minutos) correspondeu a massa molecular da dimedona 3' e o terceiro pico (30 minutos) correspondeu a massa possivelmente do derivado de $4 H$-cromeno $\mathbf{3 g}(373 \mathrm{~g} / \mathrm{mol})$ com 100 unidades de massa atômica a menos (Figura 13), nomeado como 3g'. Já o segundo pico (25 minutos), nas frações 16-30 correspondeu a massa do aduto de Knoevenagel $\mathbf{2} \mathbf{j}$ e nas frações 12-15 correspondeu a massa do aduto de Knoevenagel $\mathbf{2} \mathbf{j}$ com 15 unidades de massa atômica a mais. Baseado nestas diferenças de unidades de massas atômicas, foi observado que o EtOH, solvente da reação, poderia estar reagindo com o cianoacetato de metila 2', por meio de uma substituição nucleofílica à carbonila do grupo éster, gerando o aduto $\mathbf{2} \mathbf{j}$ etoxilado, bem como, ao reagir com a dimedona 3 ', podendo formar o derivado de $4 H$-cromeno $\mathbf{3 g}$ etoxilado, o $\mathbf{3 g}$ ' justificando assim o aparecimento de 2 compostos com fatores de retenção muitos próximos no processo de purificação. Os respectivos espectros de massas também estão contidos na Figura 13. 
Figura 13. (A) Cromatograma da fração 12 (em azul) e da fração 17 (em rosa). (B) Espectro de massas do aduto de Knoevenagel 2j etoxilado referente ao pico eluído em 25 min. (C) Espectro de massas do aduto de Knoevenagel $\mathbf{2 j}$ referente ao pico eluído em $24 \mathrm{~min}$. (D) Espectro de massas referente ao pico eluído em 30 min (3g').

(A)

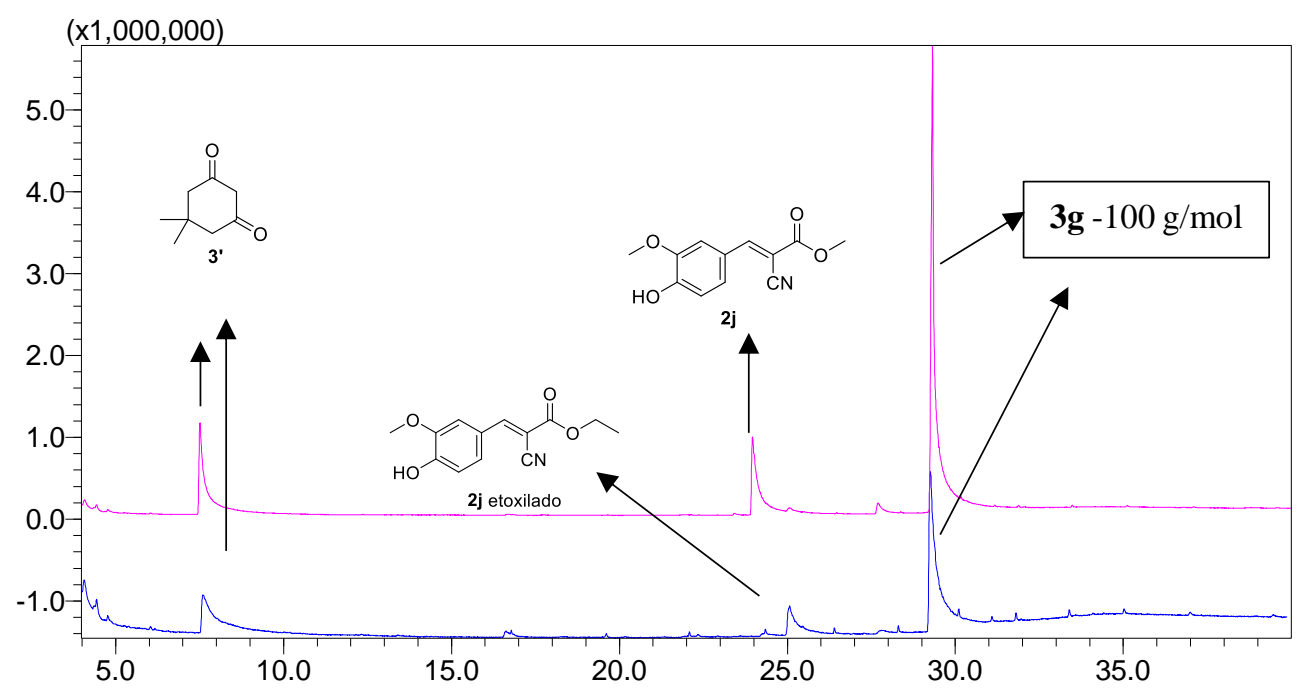

(B)

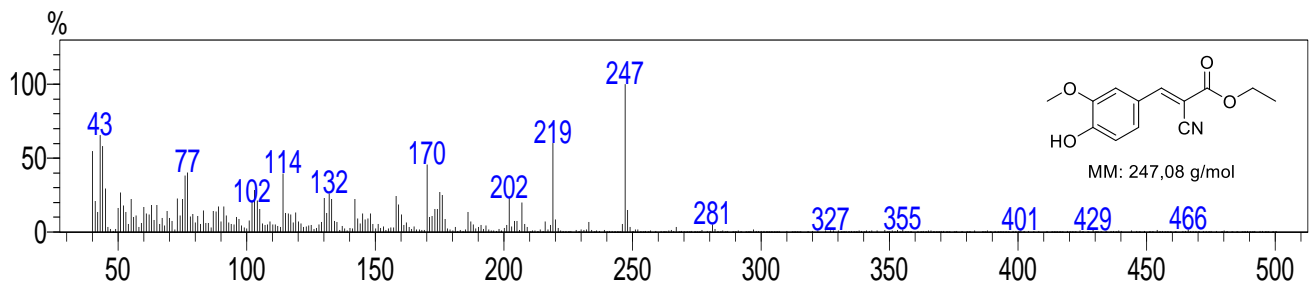

(C)

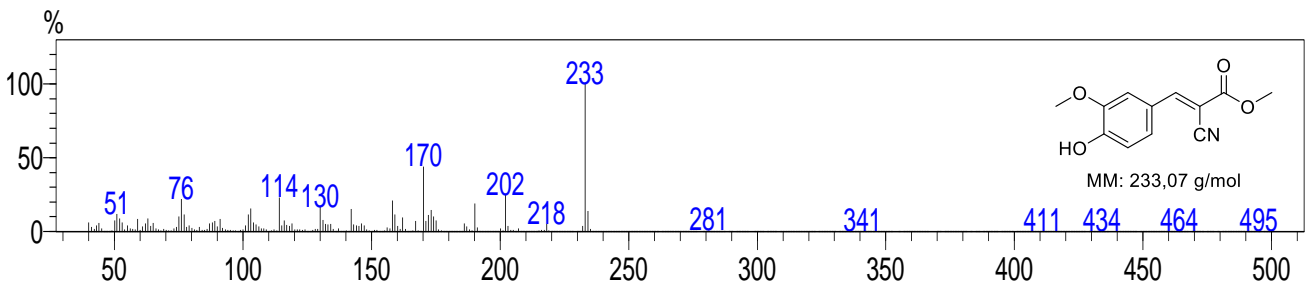

(D)

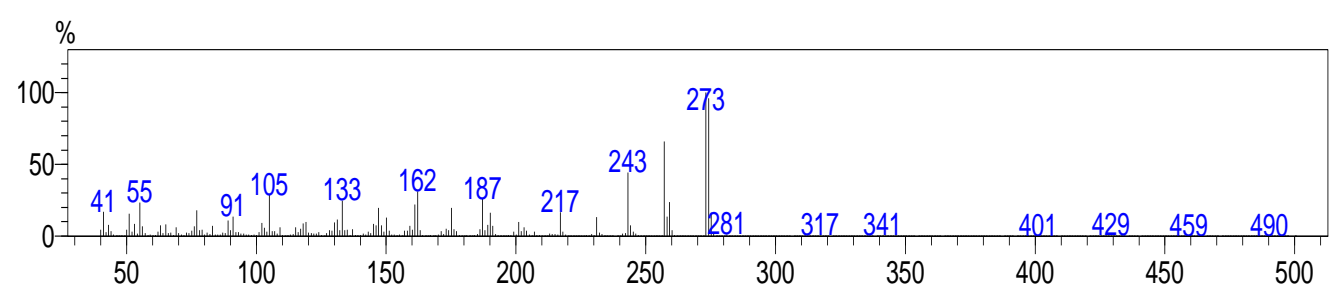

Todos os $4 H$-cromenos 3a-j sintetizados apresentaram este perfil de fragmentação quando foram analisados por CG-EM (IE, $70 \mathrm{eV}$ ), o qual apresentou 3 picos, sendo o primeiro pico referente a estrutura da dimedona 3', o pico intermediário correspondente com a massa do 
respectivo aduto de Knoevenagel e o último pico com 100 unidades de massa atômica a menos que o derivado de $4 H$-cromeno esperado. Contudo, não foi possível apresentar uma proposta de fragmentação plausível para a formação do íon do pico base $m / z$ 273, nem para os demais $4 H$-cromenos.

Esta reação de substituição nucleofílica com o EtOH à carbonila poderia estar ocorrendo neste momento, ou seja, no reagente cianoacetato de metila 2' para formar o cianoacetato de etila e não na formação dos adutos de Knoevenagel, provavelmente devido ao maior tempo reacional e pela maior quantidade de base adicionada ao meio $(30 \mu \mathrm{L})$ que foi o dobro da quantidade utilizada na síntese dos adutos 2a-l. A proposta mecanística desta reação está descrita no Esquema 23.

Esquema 23. Reação do EtOH com o cianoacetato de metila seguida da síntese do derivado de $4 H$ cromeno $3 g$.

1)

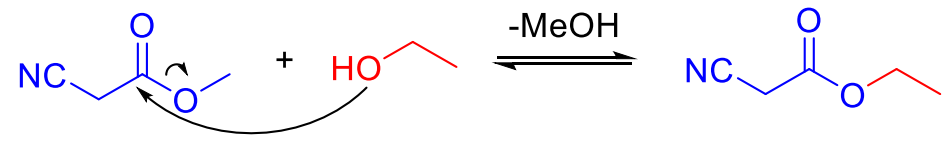

2)

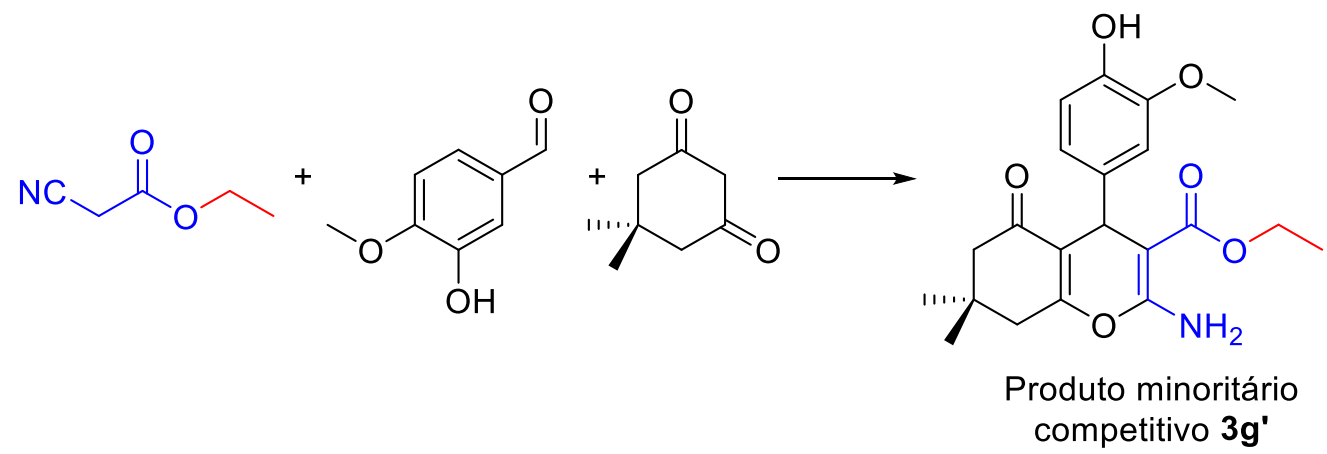

$\mathrm{Na}$ tentativa de impedir esta reação competitiva, a síntese foi realizada utilizando a $\mathrm{H}_{2} \mathrm{O}$ como solvente, um solvente com poder nucleofílico menor em relação ao EtOH. Durante o processo de purificação não foram mais observadas as duas manchas próximas na placa de CCD e também foi observada apenas a massa referente ao aduto metoxilado via CG-EM, evidenciando, assim, que o EtOH estava sendo responsável pela síntese do produto indesejado, interferindo no processo reacional.

Não foram observadas diferenças significantes nos rendimentos isolados $(\mathrm{EtOH}-49 \% \mathrm{e}$ $\mathrm{H}_{2} \mathrm{O}-42 \%$ ) e por apresentar maior facilidade na etapa de purificação, a $\mathrm{H}_{2} \mathrm{O}$ foi utilizada como solvente para realizar uma série sintética de dez derivados de $4 H$-cromenos. Esta metodologia utilizou o dobro da quantidade de TEA devido a necessidade de gerar dois ânions: o ânion do cianoacetato de metila 2' e o ânion da dimedona 3' (como mostrado pelo mecanismo descrito na Introdução. Todos os $4 H$-cromenos 3a-j foram sintetizados com rendimentos moderados 
(40-60\%) e foram purificados por cromatografia em coluna utilizando misturas de hexano e acetato de etila, em diferentes gradientes de polaridade, como fase móvel. Os rendimentos obtidos estão descritos na Tabela 14.

A Figura 14 ilustra as estruturas de todos os derivados de $4 H$-cromenos sintetizados por irradiação MO via reação tricomponente.

Tabela 14. Síntese one-pot tricomponente de derivados de $4 H$-cromenos 3a-j por irradiação MO.

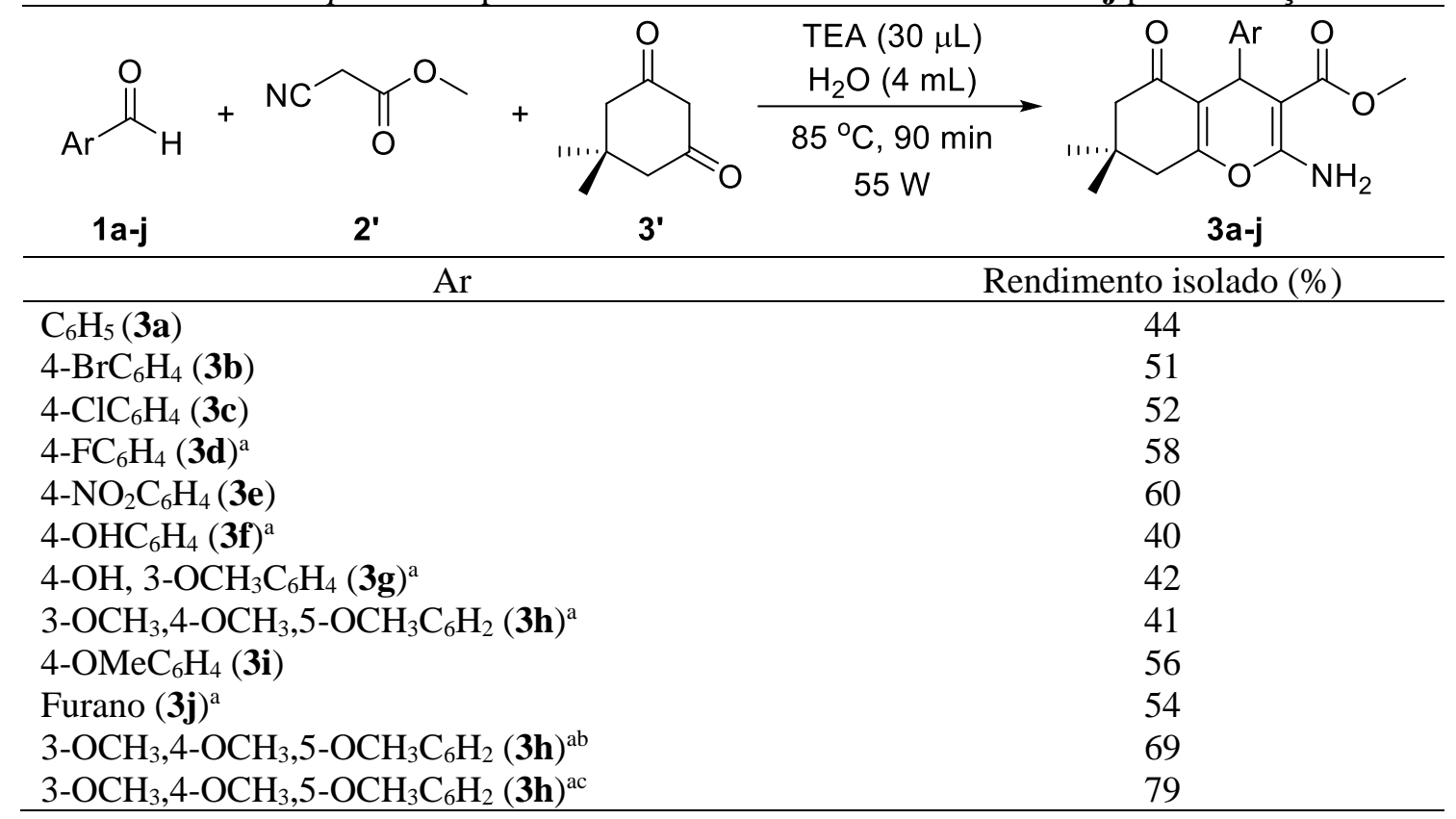

aProdutos inéditos;

${ }^{b}$ Reação realizada em reator MO durante $3 \mathrm{~h}$;

'Reação realizada em chapa de aquecimento durante $24 \mathrm{~h}$. 
Figura 14. Estruturas dos derivados de $4 H$-cromenos 3a-j sintetizados por irradiação $\mathrm{MO}$ via reação tricomponente.

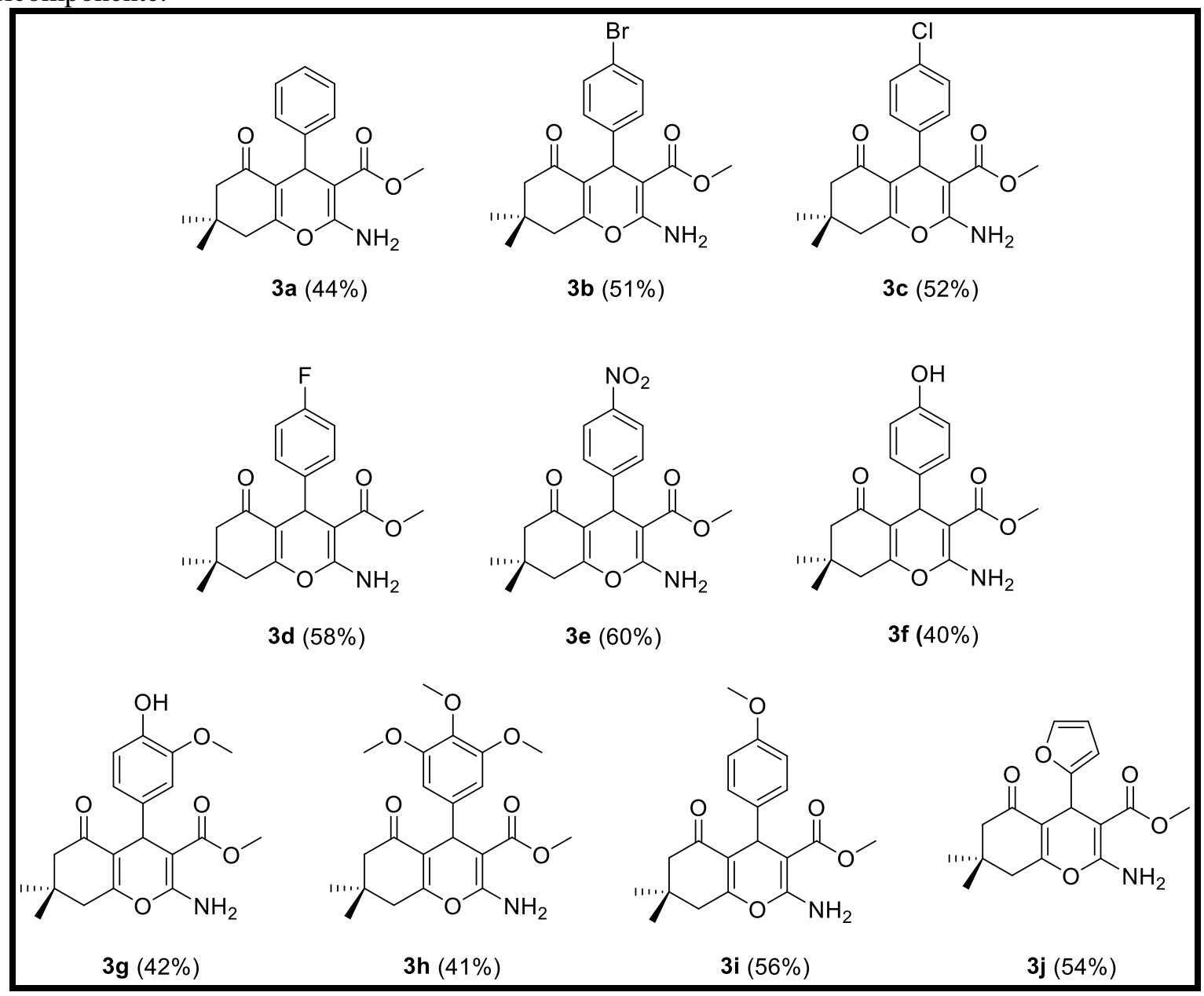

Todos os derivados de $4 H$-cromenos $\mathbf{3 a - j}$ foram caracterizados por técnicas espectrométricas e espectroscópicas (IV, $\mathrm{RMN}$ de ${ }^{1} \mathrm{H} \mathrm{e}{ }^{13} \mathrm{C}$ ), bem como foi determinado o ponto de fusão dos produtos sólidos. Os $4 H$-cromenos $\mathbf{3 d}$, $\mathbf{3 f}, \mathbf{3 g}$, $\mathbf{3 h}$ e $\mathbf{3 j}$ são inéditos e seus dados de HRMS também foram adquiridos. O $4 H$-cromeno $\mathbf{3 b}$ foi selecionado para exemplificar o processo de caracterização realizada para todos compostos da série.

No espectro de infravermelho $\left(\mathrm{KBr}, \mathrm{cm}^{-1}\right)$ foram observadas 7 bandas relevantes, as quais são referentes as deformações axiais das ligações N-H em 3408 e $3305 \mathrm{~cm}^{-1}$ do grupo amino, das ligações C-H do anel ciclo-hexano em $2957 \mathrm{~cm}^{-1}$, das ligações $\mathrm{C}=\mathrm{O}$ em $1690 \mathrm{~cm}^{-1}$ do grupo éster e em $1658 \mathrm{~cm}^{-1}$ da cetona conjugada, das ligações C-O fora do plano em $1364 \mathrm{~cm}^{-1}$ do grupo éster e em 1201 e $1162 \mathrm{~cm}^{-1}$ do anel pirano, das ligações $\mathrm{C}=\mathrm{C}$ aromática em $1525 \mathrm{~cm}^{-1}$ e do grupo funcional $\mathrm{CH}_{2}$ adjacente a carbonila em $1438 \mathrm{~cm}^{-1}$. Outras bandas também foram observadas no espectro em 3305, 1735, 1617, 1485, 1294, 1246, 1201, 1162, 1088, 1036, 1009 , $840 \mathrm{~cm}^{-1}$. Todos esses sinais podem ser observados na Figura 15. 
Figura 15. Espectro de absorção na região do infravermelho (puro, $\mathrm{cm}^{-1}$ ) do $4 H$-cromeno $\mathbf{3 b}$.

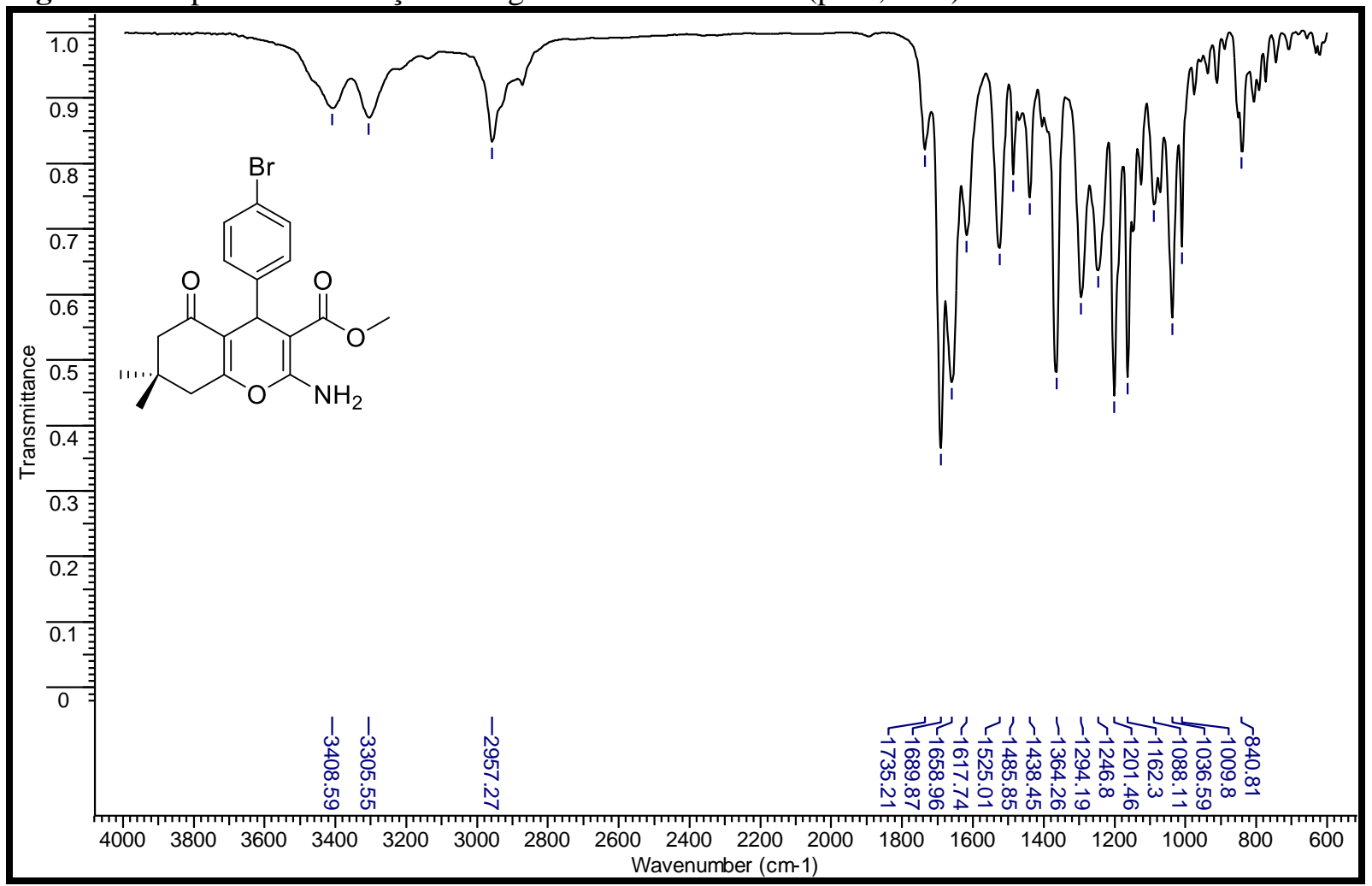

A atribuição dos sinais do espectro de RMN de ${ }^{1} \mathrm{H}$ foi baseada no modelo ORTEP de um $4 H$-cromeno $3 \mathbf{k}$ muito similar ao $4 H$-cromeno $\mathbf{3 g}$, diferenciando apenas no grupo éster, que em seu lugar está ligado um grupo ciano e no substituinte do anel aromático que ao invés de um átomo de bromo é o grupo hidroxila. Na Figura 16 está ilustrado o modelo ORTEP e a estrutura do derivado de $4 H$-cromeno 3k utilizado como referência, bem como os hidrogênios e a metila em posições pseudo-equatoriais, em cunha preenchida $\left(\mathrm{H}_{\mathrm{a}}, \mathrm{H}_{\mathrm{c}}\right.$ e $\left.\mathrm{C}_{2}\right)$, os hidrogênios e a metila em posições pseudo-axiais, em cunha tracejada $\left(\mathrm{H}_{\mathrm{b}}, \mathrm{H}_{\mathrm{d}}\right.$ e $\left.\mathrm{C}_{1}\right)$, neste núcleo cicloexanona que se assemelha a uma pseudo-cadeira. 
Figura 16. Modelo ORTEP e a estrutura do derivado de $4 H$-cromeno 3k utilizado como referência para as atribuições dos sinais de $\mathrm{RMN}{ }^{1} \mathrm{H} \mathrm{e}{ }^{13} \mathrm{C}$.

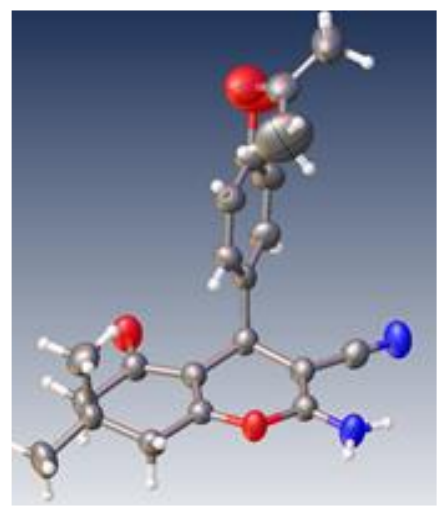

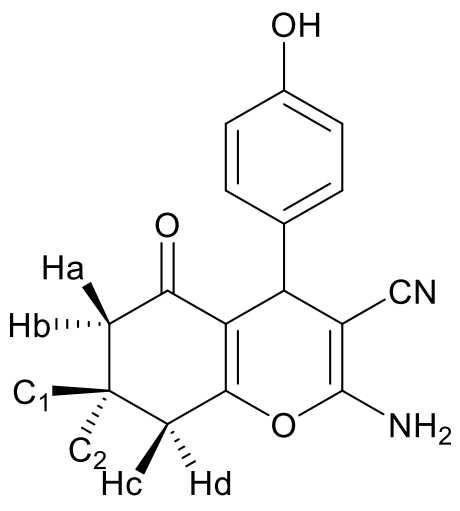

3k

O espectro de RMN de ${ }^{1} \mathrm{H}$ (400 MHz, DMSO- $d_{6}$ ) apresentou um singleto largo em 7,59 ppm (s, 2H) referente aos hidrogênios do grupo amino; um dubleto em em 7,39 ppm (d, $J=8,4$ $\mathrm{Hz}, 2 \mathrm{H}$ ) referente aos hidrogênios do anel aromático na posição meta em relação ao substituinte bromo; um dubleto em 7,09 ppm $(\mathrm{d}, J=8,4 \mathrm{~Hz}, 2 \mathrm{H})$ referente aos hidrogênios do anel aromático na posição orto em relação ao substituinte bromo. Também foi observado um singleto em 4,48 ppm $(\mathrm{s}, 1 \mathrm{H})$ referente ao hidrogênio ligado ao centro estereogênico; um singleto em 3,50 ppm $(\mathrm{s}, 3 \mathrm{H})$ referente aos hidrogênios da metila do grupo éster.

Sequencialmente, foi observado um dubleto em $2,55 \mathrm{ppm}(\mathrm{d}, J=17,6 \mathrm{~Hz}, 1 \mathrm{H})$ referente ao hidrogênio $\mathbf{H}_{\mathbf{a}}$ geminal do carbono metilênico $\alpha$-carbonílico na posição pseudo-equatorial e um dubleto em 2,45 ppm (d, $J=17,6 \mathrm{~Hz}, 1 \mathrm{H})$ referente ao hidrogênio $\mathbf{H}_{\mathbf{b}}$ geminal do carbono metilênico $\alpha$-carbonílico na posição pseudo-axial;

Outro dubleto foi observado em 2,26 ppm $(\mathrm{d}, J=16,1 \mathrm{~Hz}, 1 \mathrm{H})$ referente ao hidrogênio $\mathbf{H}_{\mathbf{c}}$ geminal ligado ao carbono metilênico adjacente à ligação $\alpha, \beta$-insaturada na posição pseudoequatorial e um dubleto em 2,06 ppm $(\mathrm{d}, J=16,1 \mathrm{~Hz}, 1 \mathrm{H})$ referente ao hidrogênio $\mathbf{H d}_{\mathbf{d}}$ geminal do carbono metilênico na posição adjacente à ligação $\alpha, \beta$-insaturada na posição pseudo-axial.

Por fim, um singleto em 1,03 ppm (s,3H) referente aos hidrogênios do grupo metila na posição pseudo-axial e um singleto em $0,88 \mathrm{ppm}(\mathrm{s}, 3 \mathrm{H})$ referente aos hidrogênios do grupo metila na posição pseudo-equatorial. Todos estes sinais podem ser observados na Figura 17. 
Figura 17. Espectro de RMN ${ }^{1} \mathrm{H}\left(400 \mathrm{MHz}\right.$, DMSO- $\left.d_{6}\right)$ do derivado de $4 H$-cromeno $3 \mathbf{b}$.

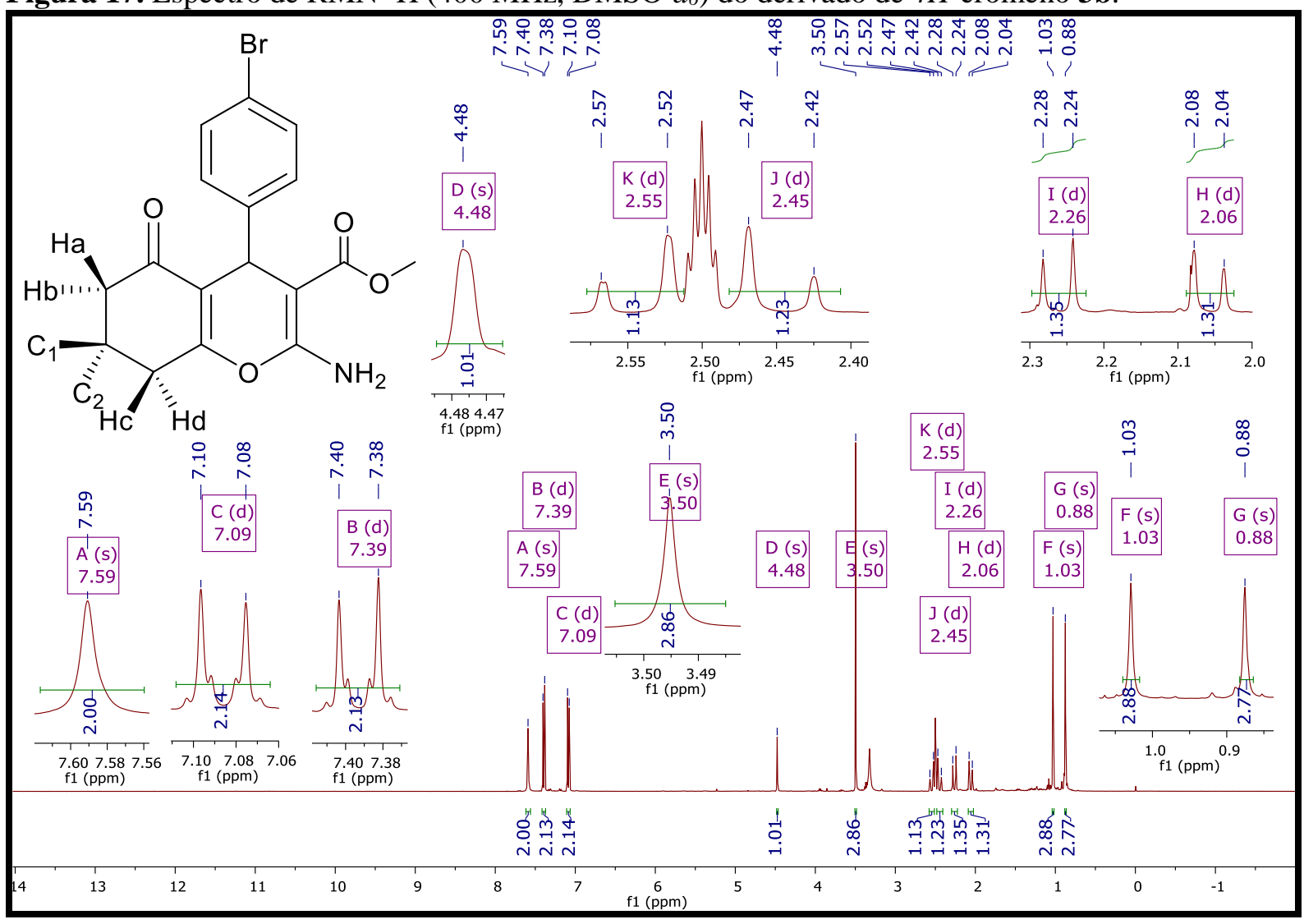

O espectro de RMN de ${ }^{13} \mathrm{C}$ (100 MHz, DMSO- $d_{6}$ ) apresentou um sinal em 195,78 ppm característico de carbono carbonílico do grupo cetona; um sinal em 168,13 ppm referente ao carbono carbonílico do grupo éster; um sinal em 162,30 ppm referente ao carbono insaturado ligado ao grupo amino e ao átomo de oxigênio do anel pirano; um sinal em 159,23 ppm referente ao carbono insaturado adjacente ao oxigênio do anel pirano e ao carbono metilênico do núcleo cicloexanona; um sinal em 145,74 ppm referente ao carbono aromático ligado ao centro estereogênico; um sinal em 130,68 ppm referente aos hidrogênios aromáticos na posição orto em relação ao bromo; um sinal em 129,79 ppm referente aos carbonos do anel aromático na posição meta em relação ao bromo.

Também foram observados no espectro de RMN de ${ }^{13} \mathrm{C}$ um sinal em 118,81 ppm referente ao carbono do anel aromático ligado ao átomo de bromo; um sinal em 115,10 ppm referente ao carbono insaturado $\alpha$-carbonílico; um sinal em 77,04 ppm referente ao carbono insaturado $\alpha$ adjacente ao grupo éster; um sinal em 50,52 ppm referente ao carbono do grupo metila ligado ao grupo éster; um sinal em 49,90 ppm referente ao carbono metilênico na posição $\alpha$-carbonila do grupo cetona; um sinal em 39,78 ppm referente ao carbono metilênico adjacente ao núcleo pirano; um sinal em 32,91 referente ao carbono do centro estereogênico; um sinal em 31,86 
ppm referente ao carbono metilênico $\alpha$-carbonila; um sinal em 28,59 ppm referente ao carbono $\mathbf{C}_{1}$ do grupo metila na posição pseudo-axial; um sinal em 26,46 ppm referente ao carbono $\mathbf{C}_{2}$ do grupo metila na posição pseudo-equatorial. Todos estes sinais podem ser observados na Figura 18.

Todas estas atribuições de RMN foram também confirmadas com o modelo teórico obtido no programa MestreNova versão 9.0.

Figura 18. Espectro de $\mathrm{RMN}{ }^{13} \mathrm{C}\left(100 \mathrm{MHz}, \mathrm{DMSO}-d_{6}\right)$ do derivado de $4 H$-cromeno $3 \mathbf{b}$.

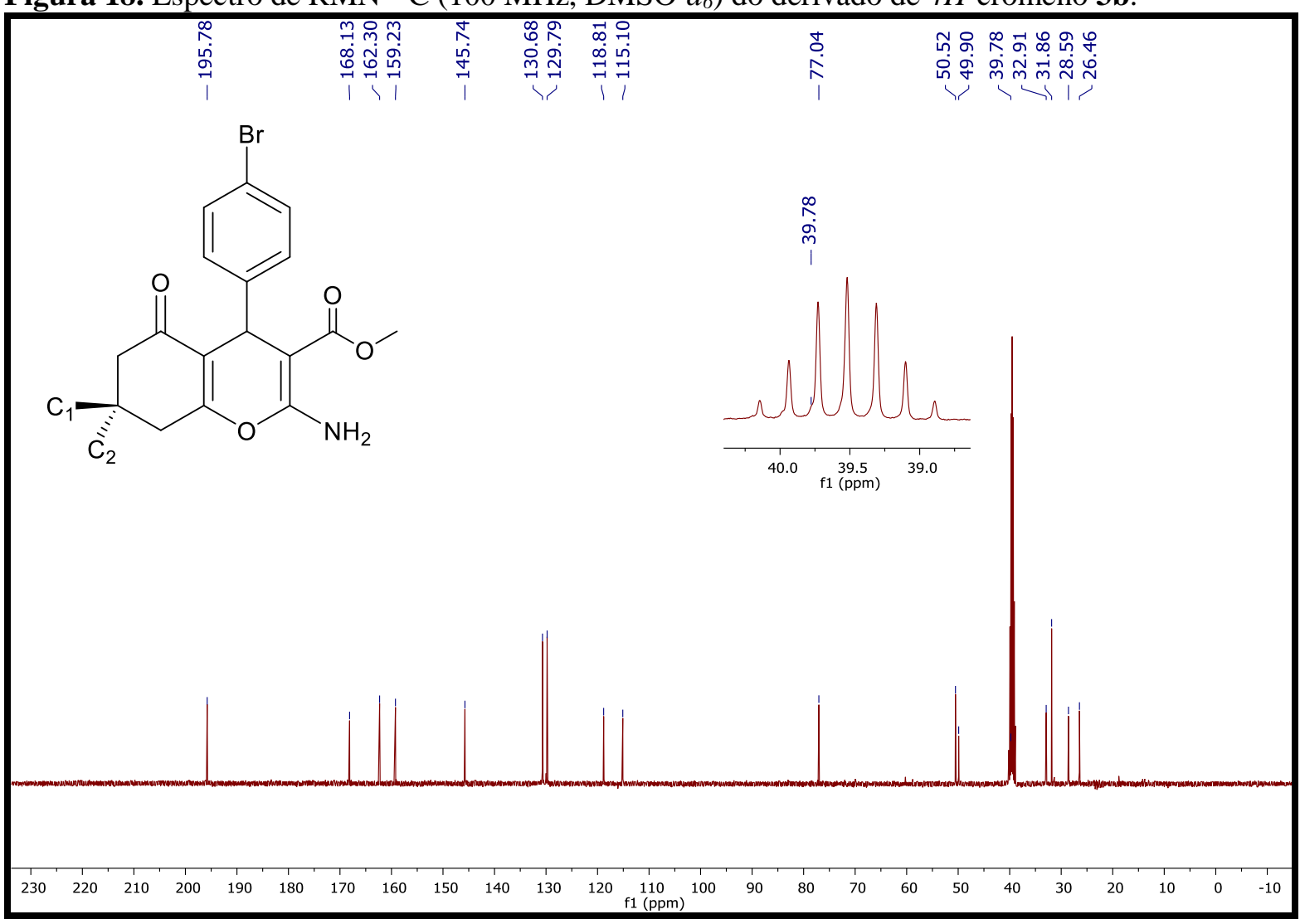

Como já descrito, não foi possível analisar os derivados de $4 H$-cromenos pelo CG-EM (IE, $70 \mathrm{eV}$ ), provavelmente devido ao método de ionização utilizado não ser brando. Bem como, devido as moléculas serem polifuncionalizadas e conjugadas, e a fragmentação possivelmente ocorreu durante a ionização. Sendo assim, as análises de espectrometria de massas foram realizadas em um equipamento com fonte de ionização mais branda, a eletronspray, em modo positivo com obtenção do íon $[\mathrm{M}+\mathrm{H}]^{+}$. Foi possível identificar o íon molecular $m / z, 406,07495$ $\left(\mathrm{MH}^{+}, 100 \%\right)$, com um erro de 24 ppm em relação ao íon molecular teórico calculado $\mathrm{m} / \mathrm{z}$ 406,06485. O espectro de massas pode ser observado na Figura 19. 
Figura 19. Espectro de massas do derivado de $4 H$-cromeno 3b realizado em um espectrômetro de massas LTQ-Orbitrap Velos (Thermo Scientific) com fonte de ionização eletronspray em modo positivo $[\mathrm{M}+\mathrm{H}]^{+}$.

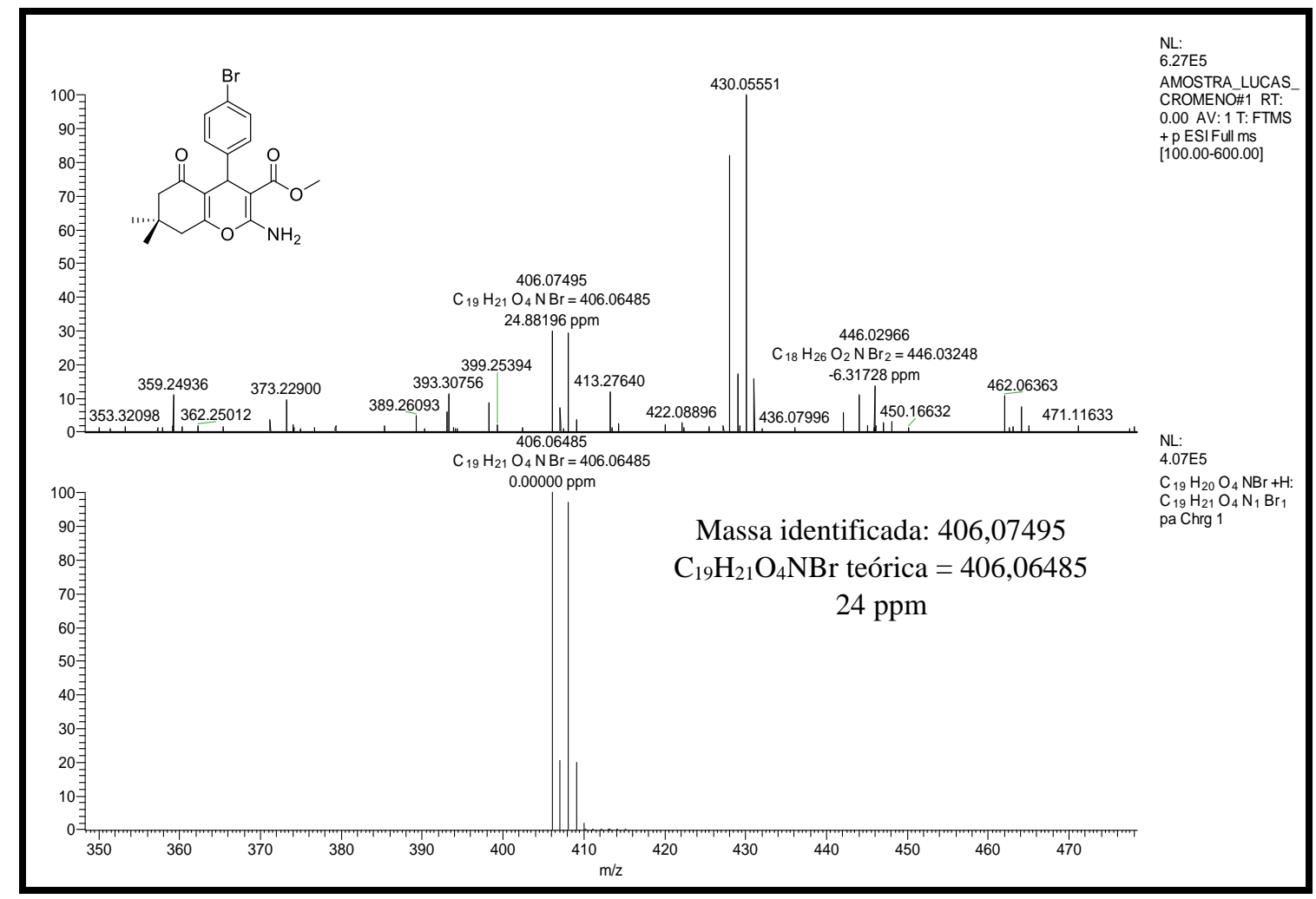

Com a técnica da radiação MO foi possível desenvolver uma metodologia sintética alternativa one-pot, tricomponente e eficiente, que segue alguns dos princípios da Química Verde em um tempo relativamente curto, na obtenção de compostos com potenciais bioativos devido a seu esqueleto derivado de $4 H$-cromeno.

Os compostos com substituintes eletrorretiradores, 3b-e, ligados ao anel aromático na posição para, $\mathrm{Br}(51 \%), \mathrm{Cl}(52 \%), \mathrm{F}(58 \%)$ e $\mathrm{NO}_{2}(60 \%)$ apresentaram valores de rendimentos condizentes com as suas respectivos propriedades eletrorretiradores de densidade eletrônica do anel aromático, pois, o composto $3 \mathbf{e}$ que contém o substituinte mais eletronegativo, o grupo nitro, apresentou o maior valor de rendimento (60\%) enquanto o composto $\mathbf{3 b}$ que contém um átomo de bromo como substituinte, o menos eletronegativo em comparação aos demais grupos, apresentou o menor valor de rendimento (51\%).

Já os compostos 3f-e com substituintes eletrodoadores no anel aromático, com exceção de 3e que apresenta um grupo metoxila na posição para e forneceu $56 \%$ de rendimento, os demais apresentaram os menores valores de rendimentos observados na série (40-42\%). Tal observação é coerente visto que os grupos hidroxila e metoxila são fortes doadores de densidade eletrônica 
e tornam tanto o aldeído, na etapa de condensação, quanto o aduto de Knoevenagel, na adição de Michael, menos reativos para o progresso da reação.

Quanto a natureza do núcleo aromático presente (benzenoide ou furano) foi constatado um aumento no valor de rendimento isolado para o composto contendo o anel furano (54\% para $\mathbf{3 j}$ ) em relação ao núcleo benzênico ( $44 \%$ para 3a). Este aumento no rendimento pode ser justificado devido ao menor efeito de ressonância observado no anel furano em comparação ao anel benzeno, devido a presença do oxigênio como heteroátomo, o qual por sua vez é altamente eletronegativo e não disponibiliza facilmente seu par de elétrons para realizar ressonância por toda molécula. Ao observar o aduto precursor do derivado de $4 H$-cromeno 3a, pode-se notar que devido a esse menor efeito conjugativo, o átomo de carbono que sofre a adição de Michael se encontra mais eletrofílico e suscetível a este tipo de ataque.

Através desta metodologia one-pot tricomponente via irradiação MO foram sintetizadas 10 moléculas das quais 5 são inéditas.

\subsection{Condensação de Knoevenagel entre cetonas aromáticas e a malononitrila}

As cetonas são uma classe de compostos carbonílicos pouco reativos frente às reações de adição nucleofílica em comparação aos aldeídos, devido a três fatores dominantes: o impedimento estérico, o efeito indutivo doador de elétrons e a hiperconjugação (Figura 20).

Figura 20. Ilustração da reatividade de cetonas e aldeídos por efeitos eletrônicos.

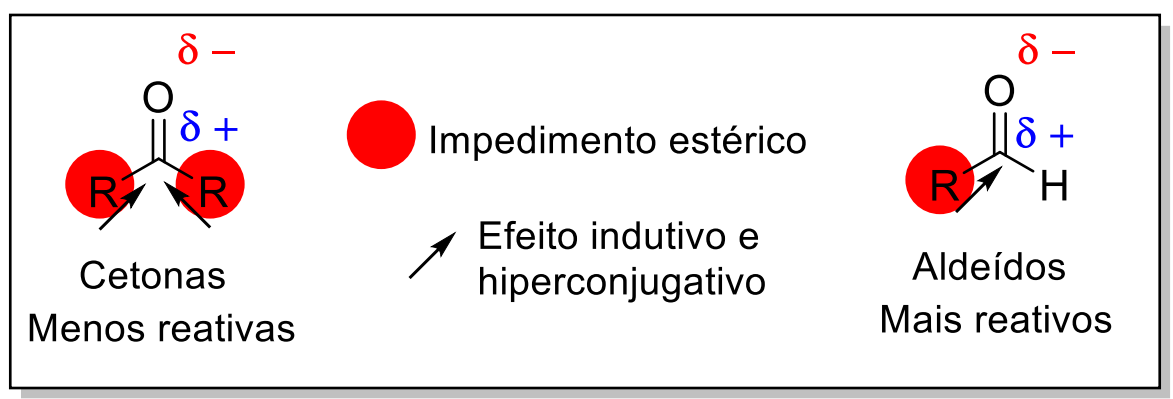

O efeito de impedimento estérico é causado devido à carbonila estar localizada entre dois átomos de carbono como grupos substituintes. Tal fato, dificulta espacialmente o ataque de um nucleófilo ao carbono carbonílico, pois o mesmo está circundado de átomos que possuem um volume relevante que promovem interações repulsivas de van der Waals durante a aproximação do nucleófilo. Já os aldeídos, possuem apenas um átomo de carbono adjacente ao carbono 
carbonílico, sendo o outro substituinte sempre um átomo de hidrogênio, de menor volume espacial, facilitando assim o ataque de um nucleófilo à carbonila do aldeído em relação a cetona.

O carbono carbonílico de uma cetona é menos positivo ou elétron-deficiente em comparação a de um aldeído, pois os dois carbonos adjacentes funcionam como doadores de densidade eletrônica por efeito indutivo e hiperconjugativo. Já nos aldeídos, esse efeito de doação eletrônica é menos efetivo, pois existe apenas um grupo doador, já que o átomo de hidrogênio não possui esta propriedade. A partir de tais descrições, pode-se inferir que a carbonila de uma cetona é menos reativa que a de um aldeído frente a um ataque nucleofílico. Este ataque possui uma angulação de $107^{\circ}$ (trajetória de Bürgi-Dunitz) em relação à carbonila devido a uma compensação entre a máxima sobreposição entre os elétrons do nucleófilo e o orbital $\pi^{*}$ (antiligante) e a repulsão entre orbital $\pi$ preenchido frente ao nucleófilo [86]. A Figura 21 ilustra esta angulação observada.

Figura 21. Trajetória de Bürgi-Dunitz observada em ataques nucleofílicos a carbonila.

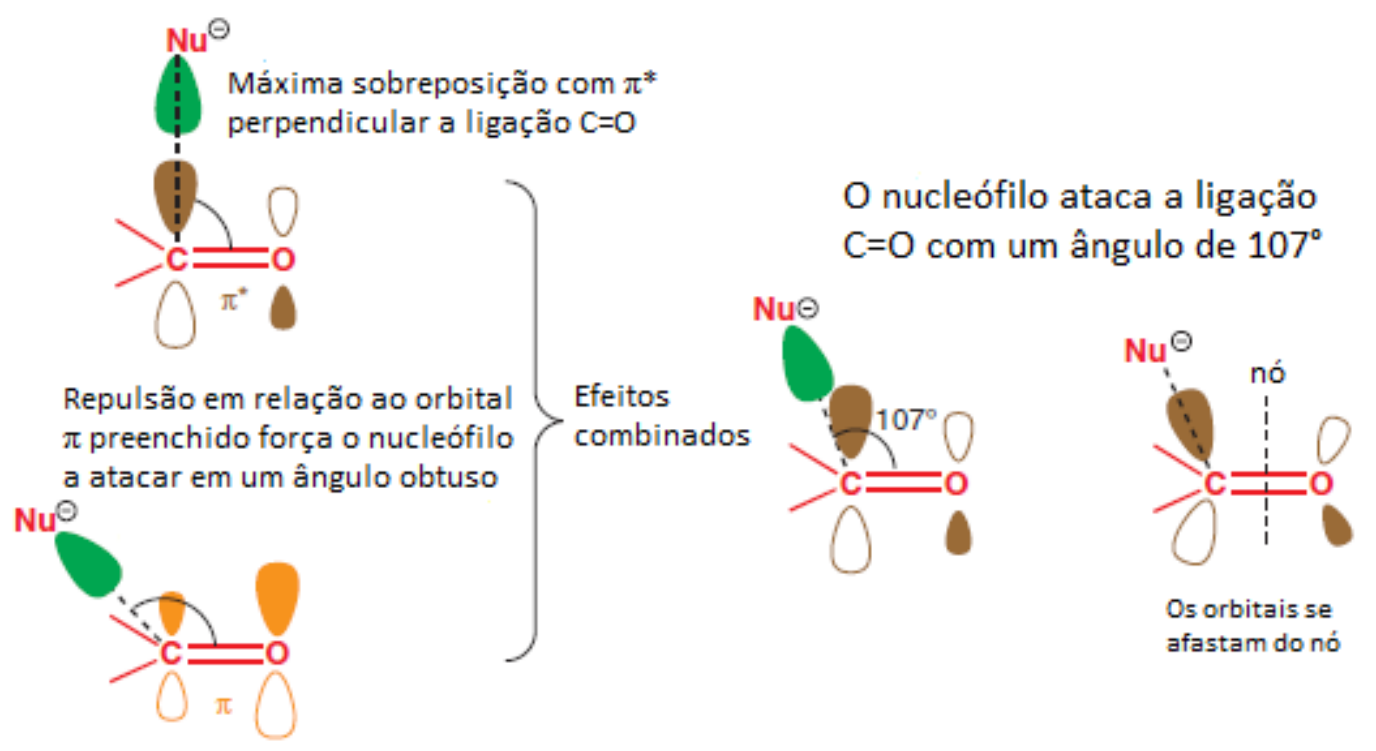

Figura adaptada do livro Organic Chemistry [86].

Partindo-se destas limitações de que as cetonas em comparação aos aldeídos são menos reativas frente a condensação de Knoevenagel, a metodologia testada foi nomeada síntese em meio básico $(\mathrm{NaOH})$. A proposta desta metodologia foi desprotonar os hidrogênios ácidos da malononitrila 5', com uma base forte, previamente à adição da cetona ao sistema reacional. A formação do ânion previamente favorece o caráter nucleofílico do ânion da malononitrila e com isso, torna o ataque à carbonila mais efetivo. 
$\mathrm{O} \mathrm{NaOH}$ (5M, $p K a$ 15,7 do seu ácido conjugado) foi escolhido como a base a ser utilizada, pois pela análise de acidez e basicidade, o $\mathrm{NaOH}$ tem capacidade para desprotonar os hidrogênios ácidos da malononitrila ( $p K a$ 11). Sendo assim, inicialmente foram testados diferentes solventes para a realização desta metodologia: $\mathrm{H}_{2} \mathrm{O}$, THF e EtOH (Tabela 15). A acetofenona 4a foi utilizada como reagente modelo para a otimização das condições reacionais. Todos valores de conversões foram realizados integrando as áreas dos picos dos reagentes e produtos (análises realizadas em CG-EM).

Tabela 15. Reação de Knoevenagel entre a malononitrila 2' e a acetofenona 1a, utilizando diferentes solventes pela metodologia por base forte $(\mathrm{NaOH}, 5 \mathrm{M})$.

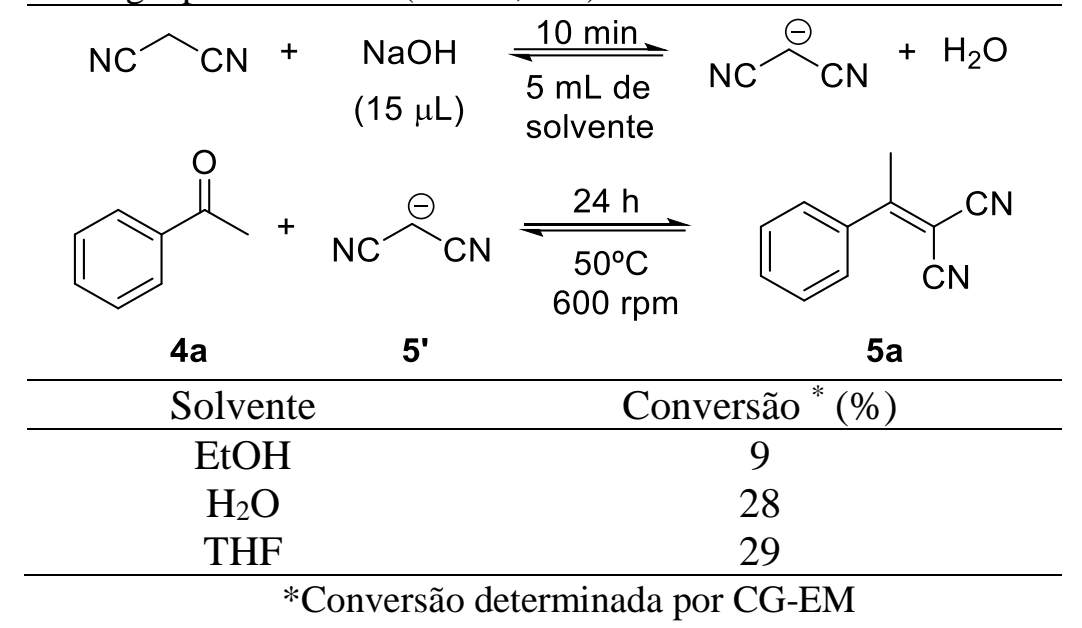

Os maiores valores de conversão na formação do aduto 5a foram observados quando o THF foi utilizado. Tal resultado é justificável, pois trata-se de um solvente polar aprótico. Este solvente não tem a capacidade de solvatar ânions, sendo assim, deixando o ânion da malononitrila livre em solução para promover o ataque nucleofílico à carbonila. Bem como, o THF não possui hidrogênios ácidos suficientes $(p K a>30)$ para serem desprotonados pelo $\mathrm{NaOH}$, o que garantiu que toda base adicionada desprotonasse apenas a malononitrila 5'. Contudo, a conversão observada quando a $\mathrm{H}_{2} \mathrm{O}$ foi utilizada como solvente prótico foi similar. Este resultado pode ser justificado pelo fato de que os reagentes são poucos solúveis em $\mathrm{H}_{2} \mathrm{O}$, sendo assim, o efeito de solvatação não foi prejudicial no andamento da reação, embora este solvente tenha capacidade de solvatar os cátions e ânions em solução.

Sequencialmente, foi realizada uma série sintética com diferentes cetonas aromáticas utilizando THF como solvente, com o intuito de observar a influência de grupos eletrodoadores e eletrorretiradores nos valores de conversão. A Tabela 16 ilustra os resultados obtidos de conversão para estas reações adquiridos por CG-EM. 
Tabela 16. Síntese de adutos de Knoevenagel em meio básico $(\mathrm{NaOH})$ utilizando diferentes cetonas em THF.

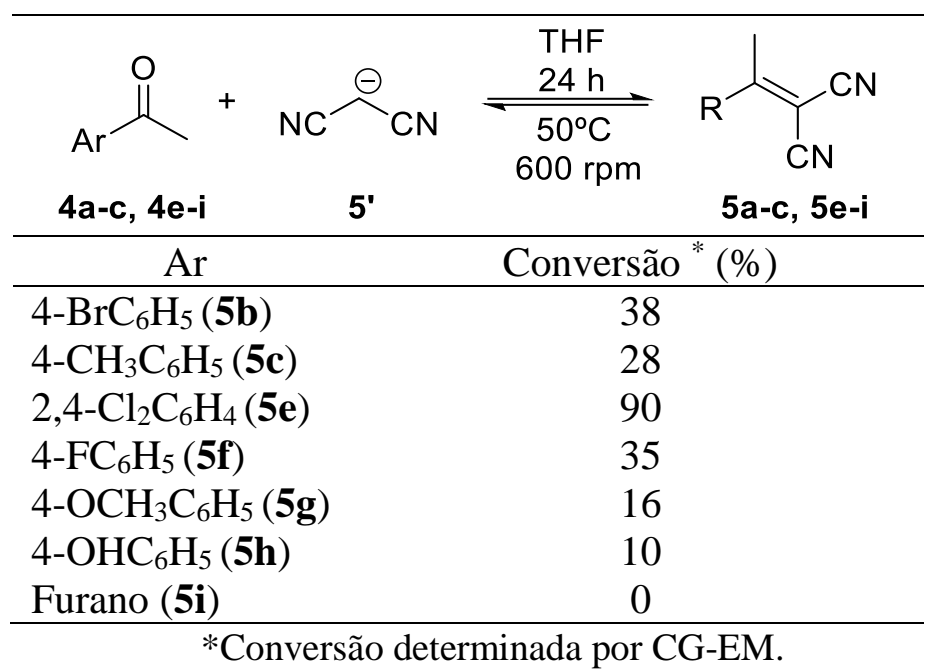

Foi observado que a presença de grupos doadores de elétrons (metoxila, hidroxila e metila) diminuíram ainda mais a reatividade da cetona, pois torna o carbono carbonílico menos eletrodeficiente especialmente por efeito de ressonância. Baseando-se neste fato, pode-se constatar as conversões abaixo de $28 \%$ obtidas nestas reações. Já em cetonas substituídas por grupos eletrorretiradores (bromo, cloro e flúor) foram observadas conversões mais elevadas (acima de $35 \%$ ), devido a maior reatividade do carbono carbonílico, pois o mesmo encontra-se mais deficiente de elétrons e mais suscetível ao ataque nucleofílico do ânion da malononitrila. Nestes casos os efeitos eletrônicos (ressonância e indutivo) favorecem o progresso da reação devido a presença de grupos eletrorretiradores.

A massa molecular esperada para o aduto de Knoevenagel $5 \mathbf{i}$ era de $158 \mathrm{~g} / \mathrm{mol}$. O composto formado apresentou a massa molecular de $224 \mathrm{~g} / \mathrm{mol}$ e foi nomeado como 6a. A proposta estrutural para este produto envolveu a inserção de 2 moléculas de malononitrila 5': a primeira via condensação de Knoevenagel com a molécula de cetona e a segunda via adição de Michael com o aduto de Knoevenagel 5i já formado. Esta reação ocorreu somente neste caso provavelmente devido ao menor tamanho e consequentemente menor impedimento estérico do anel furano em relação ao anel benzeno, o que facilitou o ataque nucleofílico de outro ânion de malononitrila 5' no aduto de Knoevenagel 5i já formado. E também devido a força da base $(\mathrm{NaOH})$, pois garantiu uma formação dos ânions de malononitrila 5' em excesso na solução e resultou na formação de uma espécie de produto cinético. O Esquema 24 ilustra esta proposta de formação do produto 6a que possui massa molecular condizente ao íon molecular observado no espectro de massas. 
Esquema 24. Proposta de formação do produto 6a via reação de Michael entre a malononitrila 5' e o aduto de Knoevenagel $\mathbf{5 i}$.

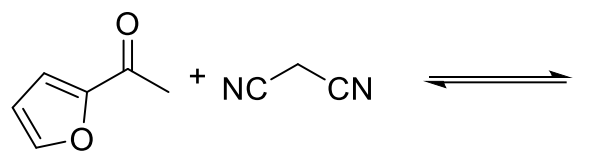

MM: $158,05 \mathrm{~g} / \mathrm{mol}$

Aduto $5 \mathbf{i}$<smiles>N#CC(N)C(c1ccco1)(C(C#N)C#N)C(C#N)C#N</smiles>

MM: $224,07 \mathrm{~g} / \mathrm{mol}$

Produto obtido, $6 \mathbf{a}$

A Figura 22 apresenta o cromatograma e o respectivo espectro de massas referente a reação à reação de Knoevenagel para a formação do produto $\mathbf{6 a}$.

Figura 22. Síntese do aduto 5i que resultou no produto 6a. (A) Cromatograma obtido da síntese (B) Espectro de massas do produto identificado como $\mathbf{6 a}$.

(A)

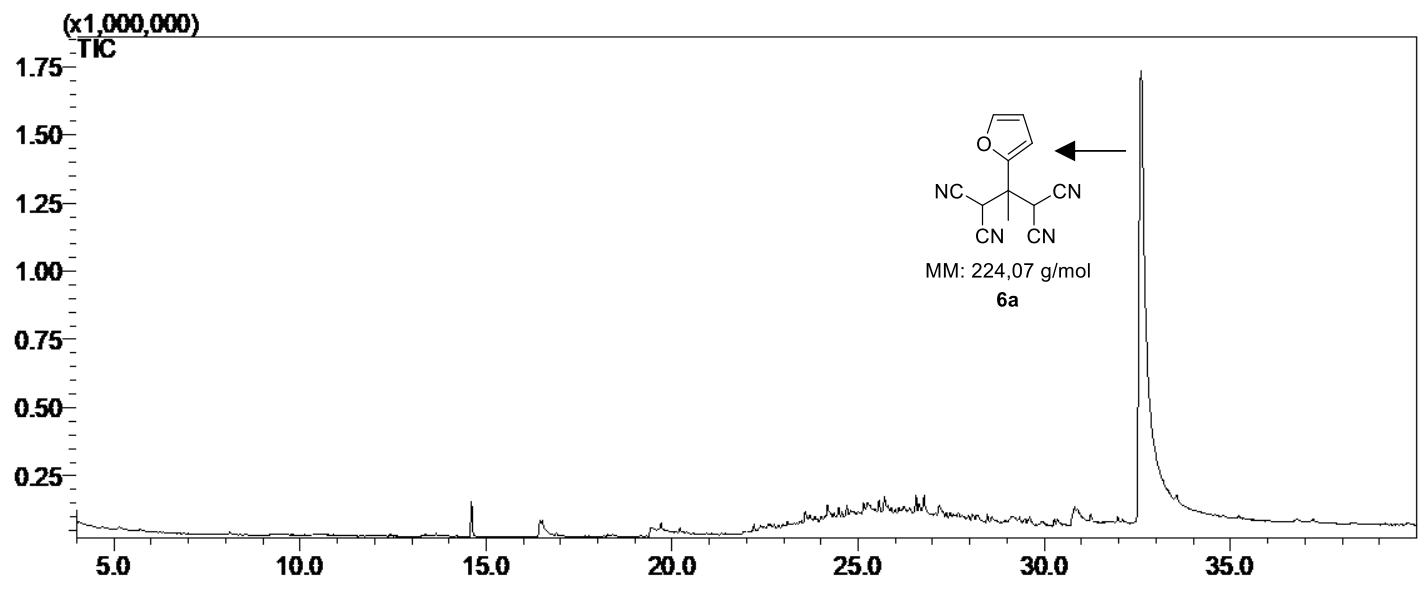

(B)

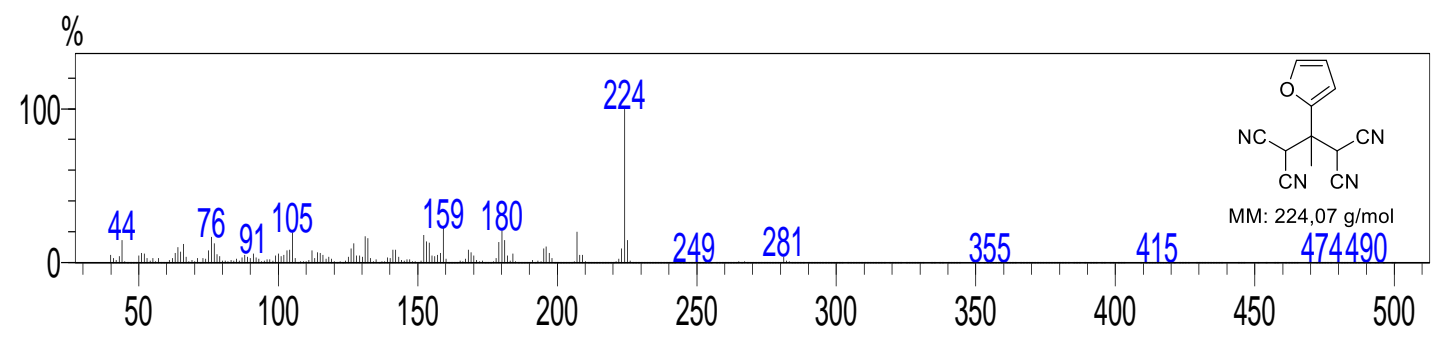

A Figura 23 contém o cromatograma de todas reações realizadas, seguida do espectro de massas dos respectivos adutos de Knoevenagel (5a-c e 5e-h). Nestes casos, não foram obtidos os valores de rendimentos isolados devido aos baixos valores de conversão encontrados na maioria dos casos estudados. Os baixos valores de conversão também podem estar relacionados 
às reações de retro-Knoevenagel uma vez que estas facilmente ocorrem durante o equilíbrio reacional.

Figura 23. Cromatogramas referentes as reações realizadas pela metodologia base forte $(\mathrm{NaOH})$ e o espectro de massas (IE, $70 \mathrm{eV}$ ) do respectivo aduto de Knoevenagel, 5a-c e 5e-h. (A) aduto 5b (B) aduto $\mathbf{5 c}(\mathrm{C})$ aduto $5 \mathbf{e}(\mathrm{D})$ aduto $\mathbf{5 f}(\mathrm{E})$ aduto $\mathbf{5 g}(\mathrm{F})$ aduto $\mathbf{5 h}$.

(A) Síntese do aduto $\mathbf{5 b}$.
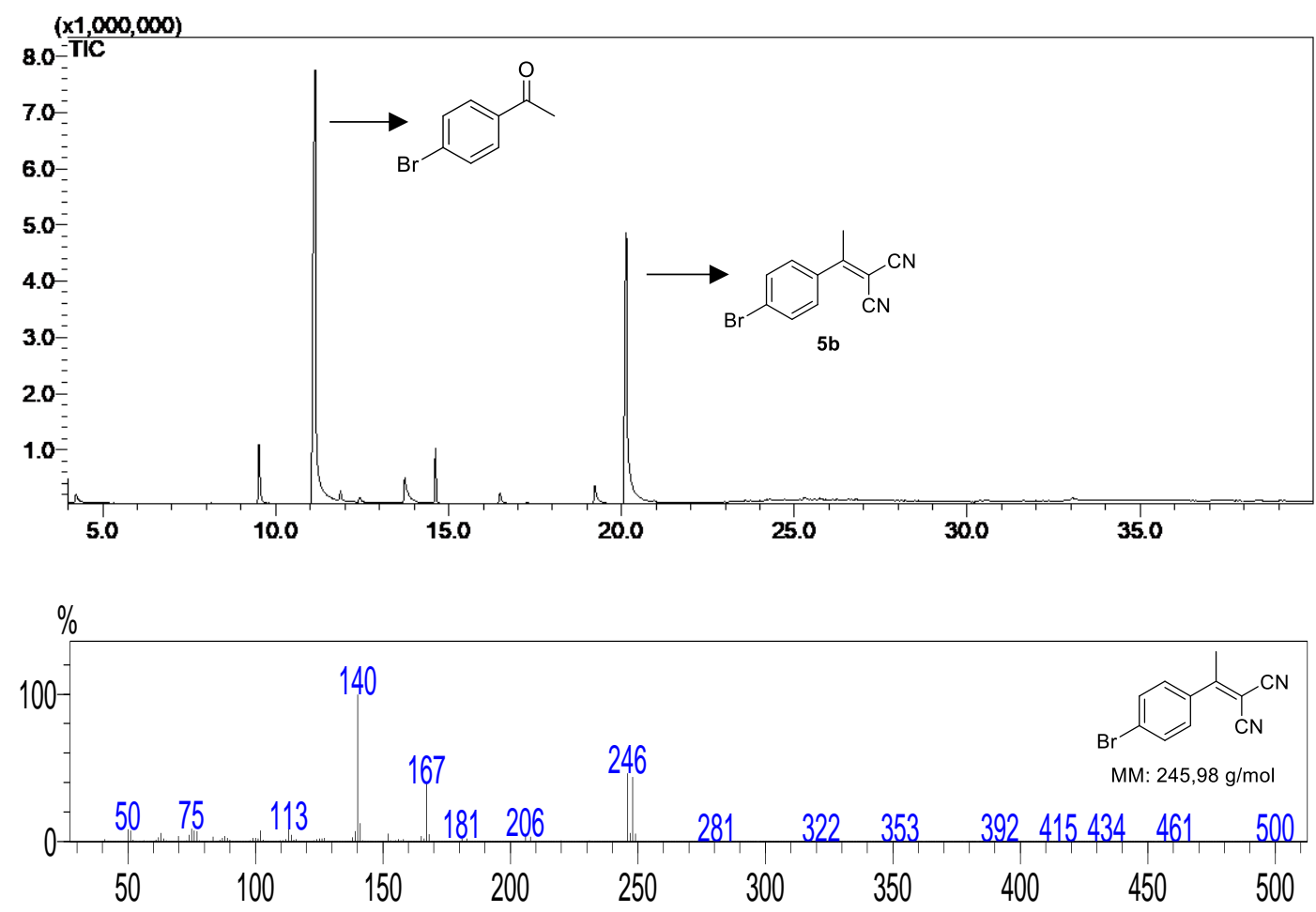

(B) Síntese do aduto $\mathbf{5 c}$.

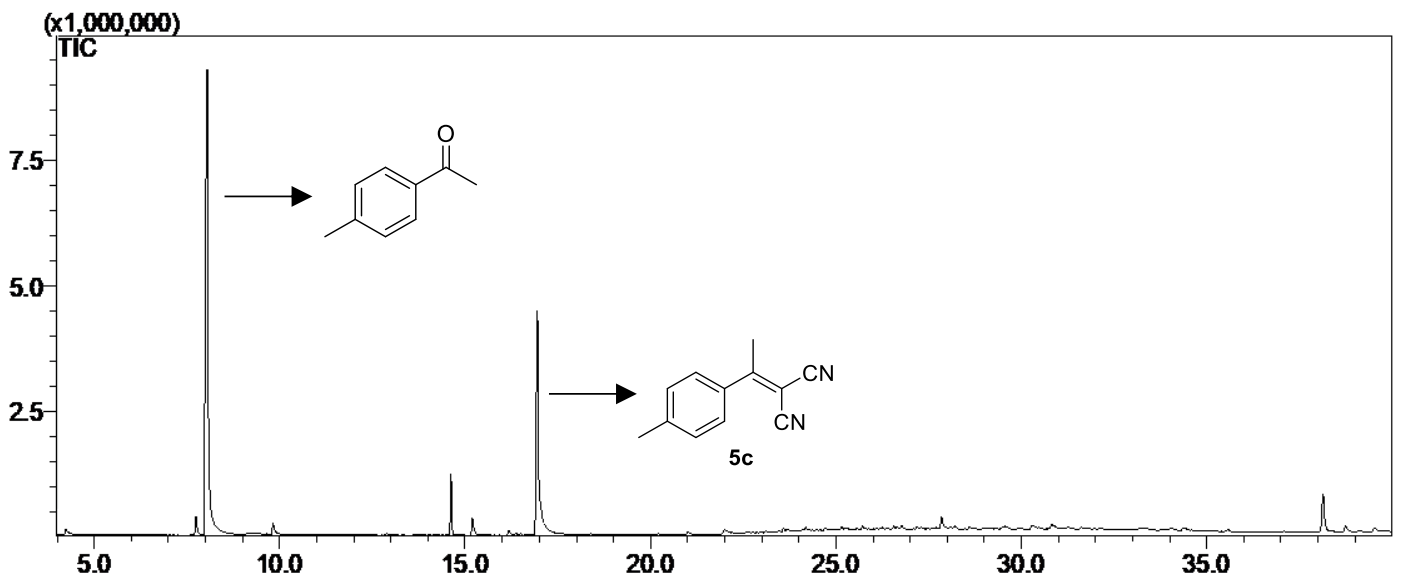




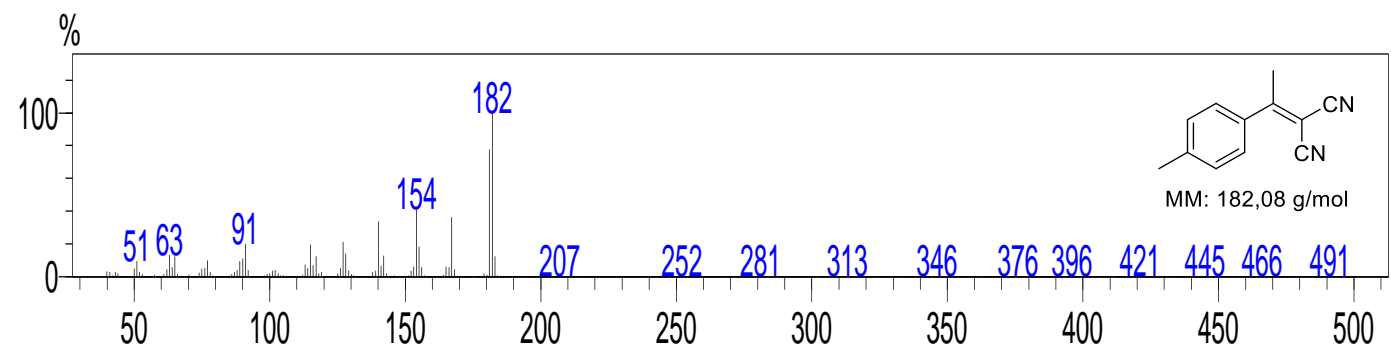

(C) Síntese do aduto 5 e.
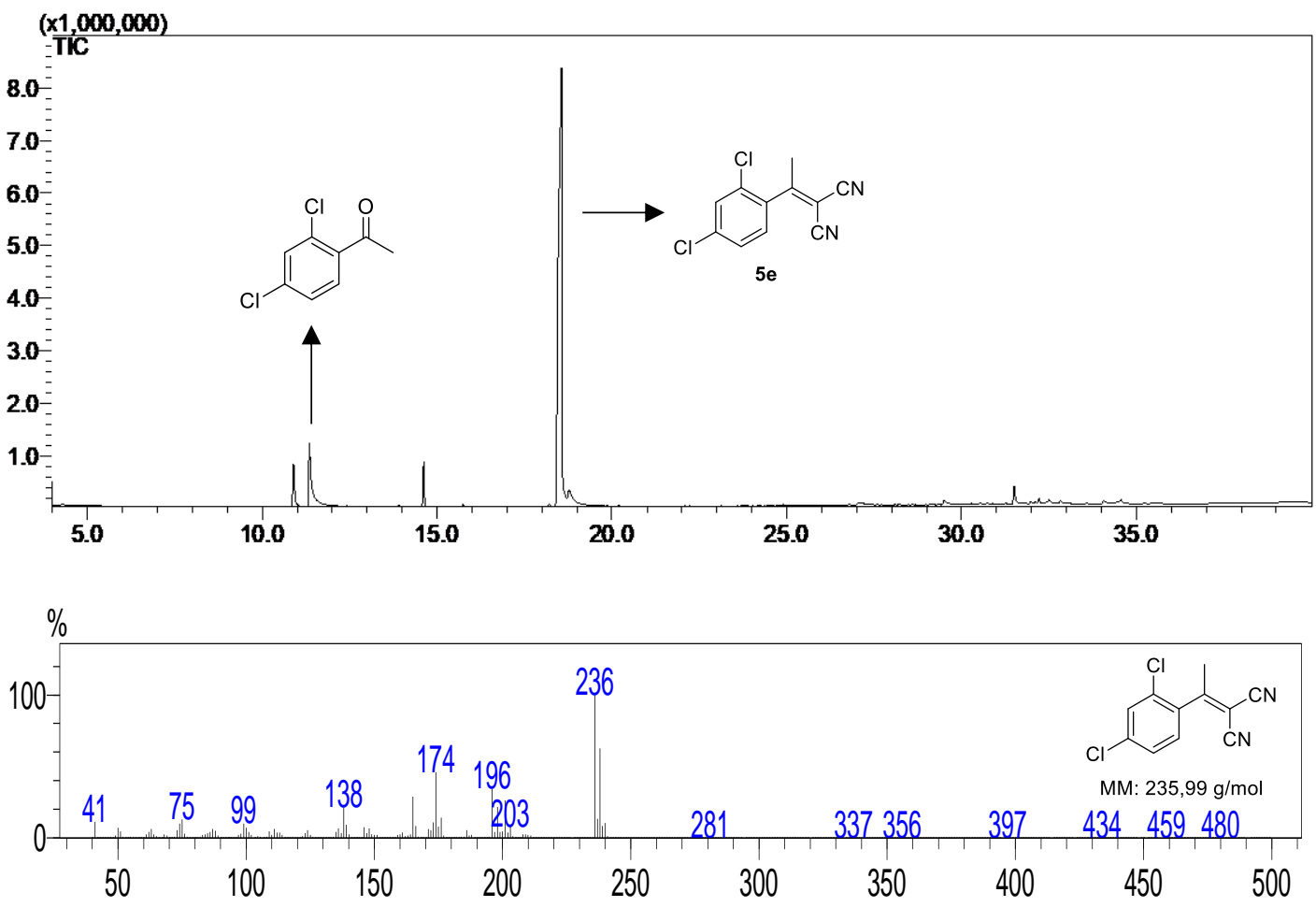

(D) Síntese do aduto $\mathbf{5 f}$.

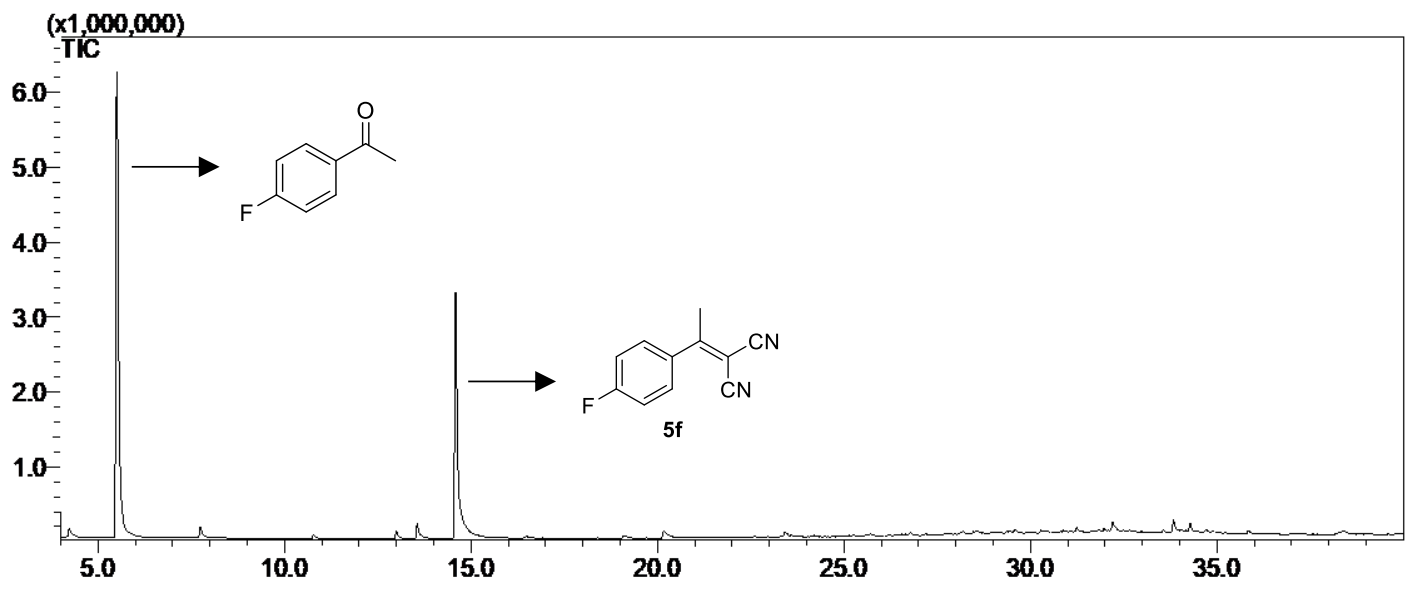




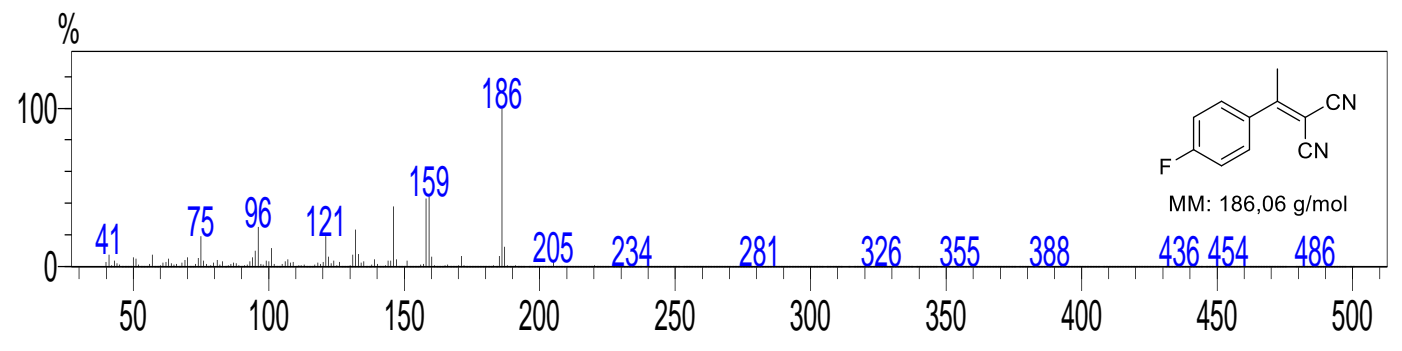

(E) Síntese do aduto 5g.
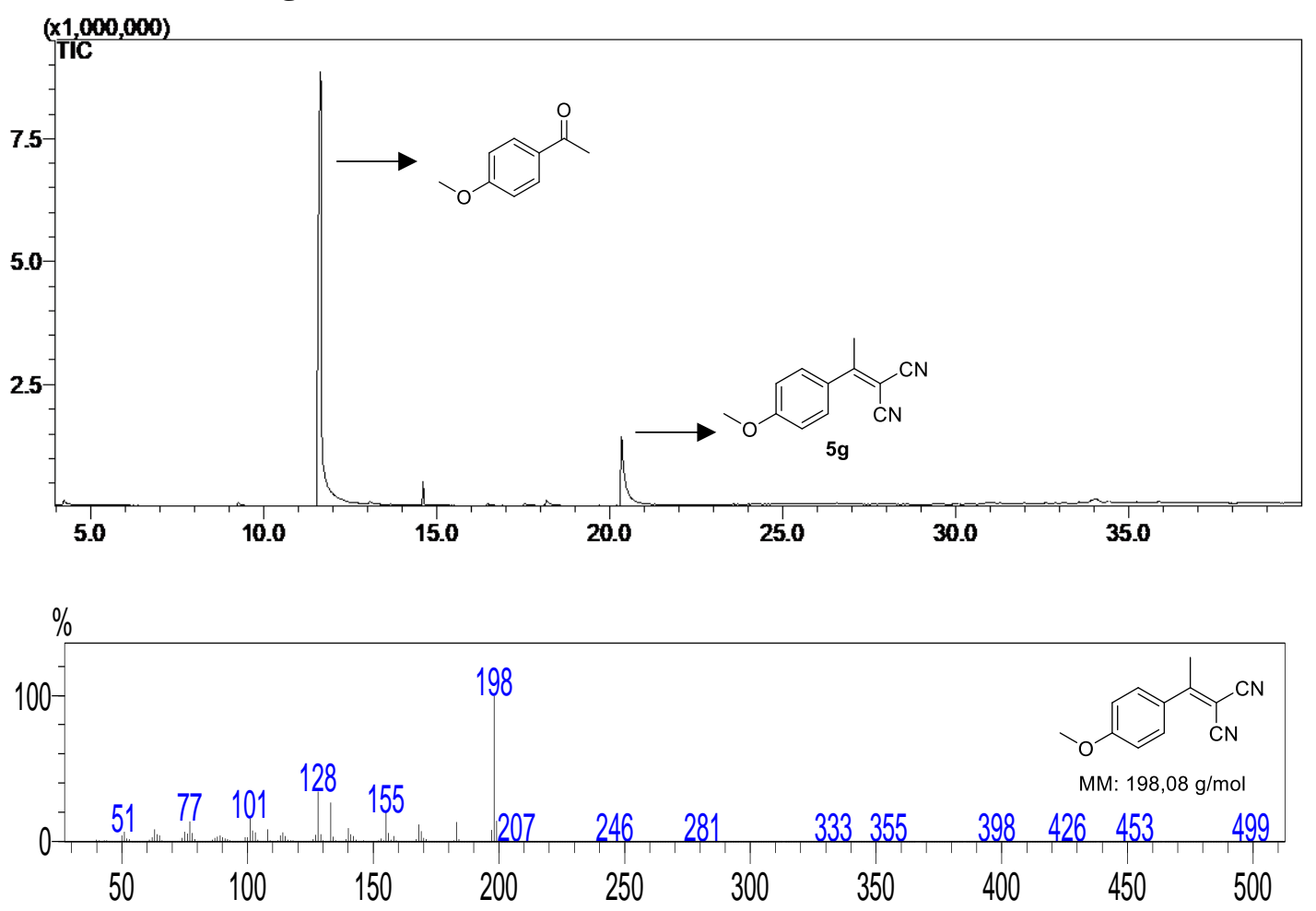

(F) Síntese do aduto $\mathbf{5 h}$.

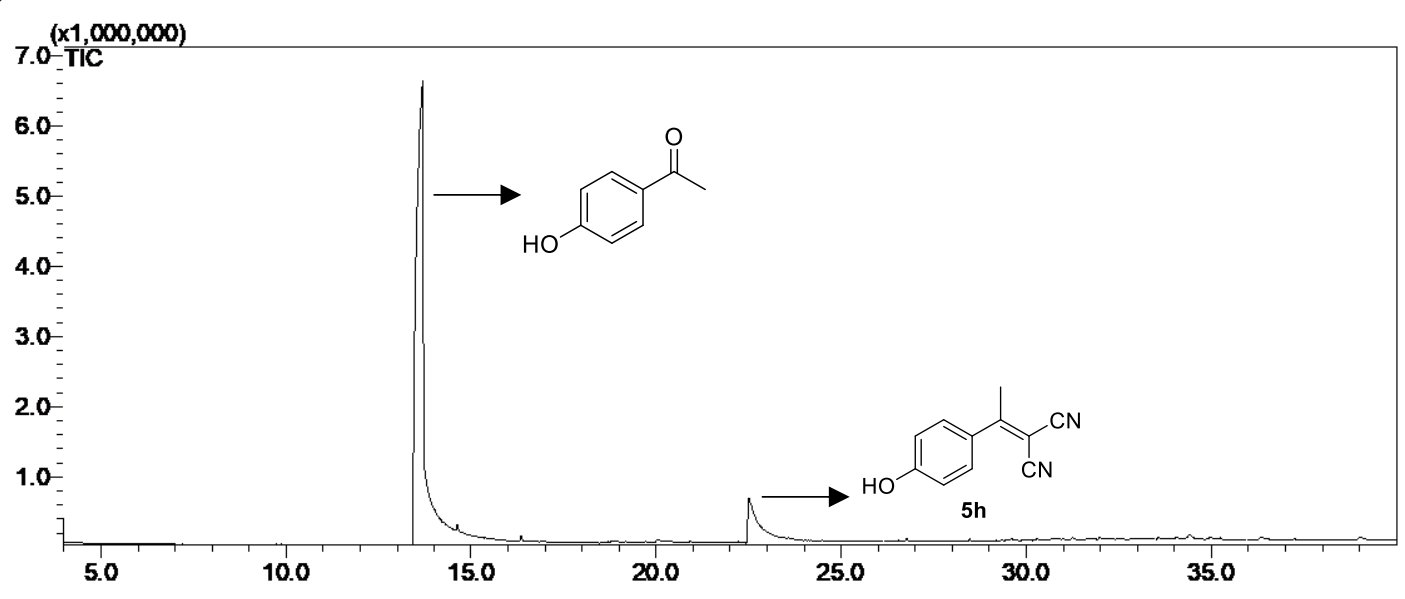




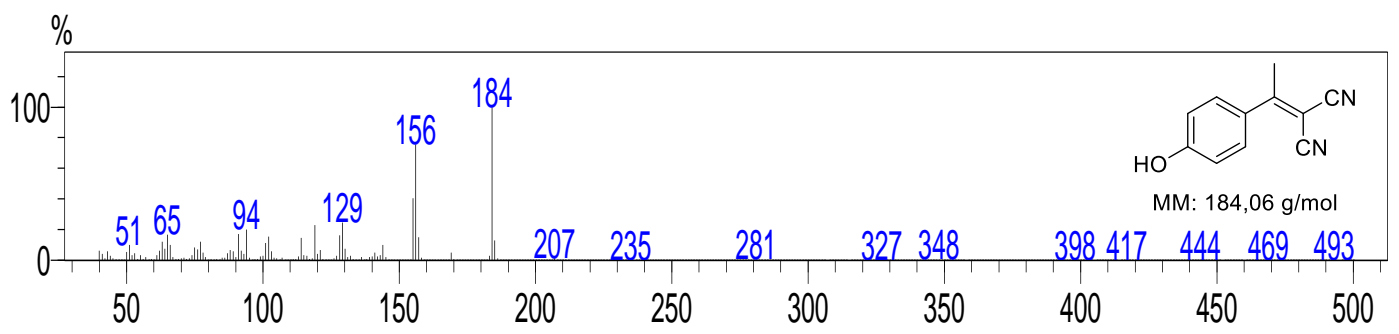

Visto que a preparação do ânion da malononitrila 5' em meio básico com $\mathrm{NaOH}$ não foi eficiente para promover valores elevados de conversão para os adutos de Knoevenagel, foi avaliada uma metodologia one-pot em meio básico, na presença de trietilamina (TEA), similar a utilizada para sintetizar os adutos de Knoevenagel provenientes de aldeídos aromáticos (Tabela 10, p. 62). Assim, diferentes solventes com polaridades distintas $\left(\mathrm{MeOH}, \mathrm{EtOH}, \mathrm{H}_{2} \mathrm{O}\right.$, THF, hexano) foram testados na síntese do aduto 5a, utilizando TEA como base. Contudo, o melhor resultado ocorreu quando a reação foi conduzida na ausência de solvente, onde em apenas $1 \mathrm{~h}$ de reação foi obtido 55\% de conversão na síntese do aduto 5a. Todos os resultados estão descritos na Tabela 17.

Tabela 17. Uso de diferentes solventes na síntese one-pot do aduto 2a utilizando TEA.

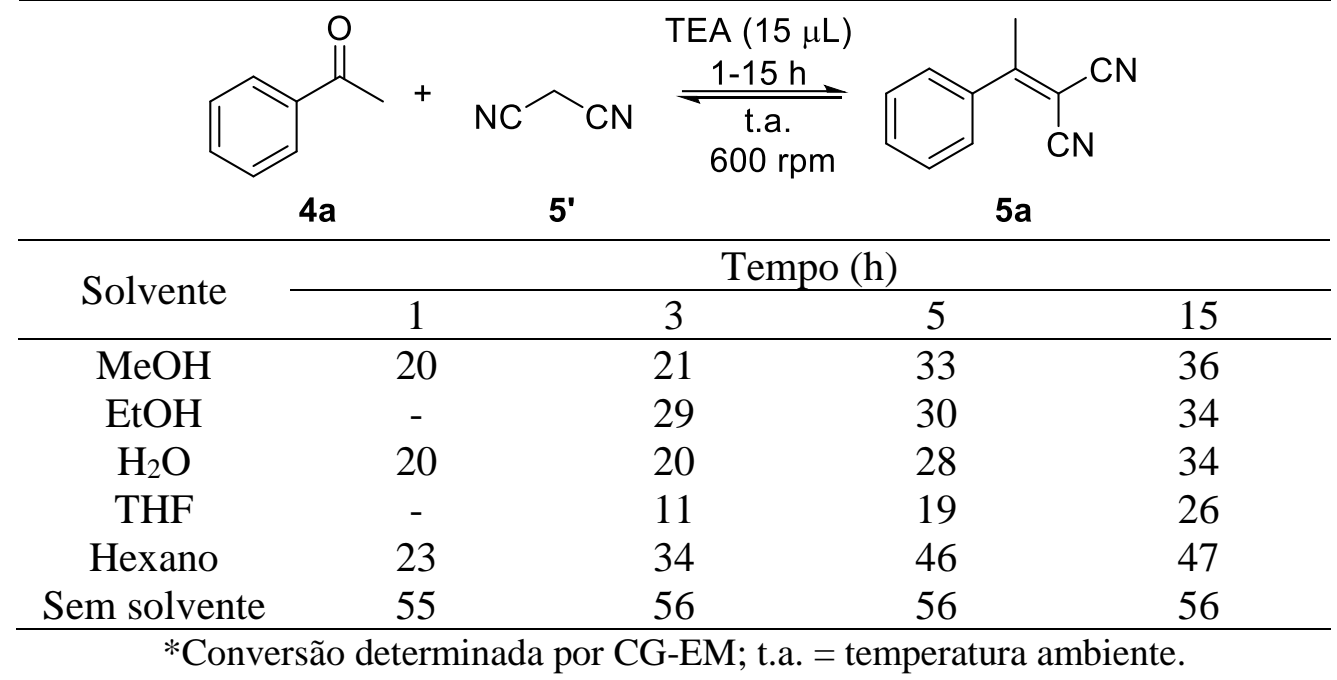

Na busca por maiores valores de conversão e a partir dos resultados obtidos anteriormente, foi realizada uma série sintética em reator MO, na qual foram selecionadas apenas as cetonas contendo grupos eletrorretiradores ligados ao anel aromático e também contendo o anel furano, baseado em suas maiores reatividades, em reator MO. Estas reações foram conduzidas na ausência de solvente, durante $60 \mathrm{~min}$, a $85^{\circ} \mathrm{C}$ e a $10 \mathrm{~W}$ de potência. 
Em geral, foram obtidos valores moderados de conversão dos respectivos adutos de Knoevenagel, na faixa de $41-58 \%$ e novamente o aduto 5e apresentou o maior valor de conversão (58\%). Todos os resultados obtidos estão descritos na Tabela 18. Como já discutido anteriormente, o aduto 5e foi formado em maior proporção que os demais adutos, possivelmente, devido a maior reatividade da cetona $4 \mathbf{e}$, que apresenta 2 átomos de cloro eletronegativos ligados ao anel aromático, fato que aumenta a reatividade do carbono carbonílico.

Tabela 18. Síntese de adutos de Knoevenagel entre cetonas aromáticas e a malononitrila 5' utilizando TEA por irradiação MO.

\begin{tabular}{|c|c|c|c|}
\hline $\begin{array}{c}\text { Ar } \\
\text { 4a, 4b, 4d, } \\
4 \mathrm{e}, 4 \mathrm{f}, 4 \mathrm{i}\end{array}$ & $\mathrm{NC}_{\mathbf{5}^{\prime}} \overbrace{\mathrm{CN}}^{\mathrm{TE}}$ & $\begin{array}{l}\mathrm{A}(15 \mu \mathrm{L}) \\
\frac{1 \mathrm{~h}}{85^{\circ} \mathrm{C}} \\
10^{\mathrm{W}}\end{array}$ & $\begin{array}{c}\mathrm{CN} \\
\mathbf{5 a}, \mathbf{5 b}, \mathbf{5 d} \text {, } \\
\mathbf{5 e , 5 f , 5 i}\end{array}$ \\
\hline $\mathrm{Ar}$ & Conversão (\% & & Rendimento isolado (\%) \\
\hline $\mathrm{C}_{6} \mathrm{H}_{6}(\mathbf{4 a})$ & 52 & & $(-)$ \\
\hline $4-\mathrm{BrC}_{6} \mathrm{H}_{5}(\mathbf{4 b})$ & 41 & & 3 \\
\hline $4-\mathrm{ClC}_{6} \mathrm{H}_{5}(\mathbf{4 d})$ & 42 & & $(-)$ \\
\hline $2,4-\mathrm{Cl}_{2} \mathrm{C}_{6} \mathrm{H}_{5}(\mathbf{4 e})$ & 58 & & 10 \\
\hline $4-\mathrm{FC}_{6} \mathrm{H}_{5}(\mathbf{4 f})$ & 45 & & 5 \\
\hline Furano (4i) & $\mathrm{a}$ & & 6 \\
\hline
\end{tabular}

*Conversão determinada por CG-EM;

${ }^{a}$ Não calculada, pois o reagente não foi identificado nas condições de análise;

(-) Não foi possível isolar o produto.

A Figura 24 contém os cromatogramas das sínteses realizadas pela metodologia em meio básico, utilizando a TEA, bem como, os espectros de massas condizentes com as massas moleculares calculadas para os adutos $5 \mathbf{a}, \mathbf{5 d}$ e $\mathbf{5 i}$. 
Figura 24. Cromatogramas referente as reações realizadas pela metodologia em meio básico (TEA) e o espectro de massas (IE, $70 \mathrm{eV}$ ) dos respectivos adutos de Knoevenagel, 5a, 5d e 5i. (A) aduto 5a (B) aduto $5 \mathbf{d}(\mathrm{C})$ aduto $\mathbf{5 i}$.

(A) Síntese do aduto 5a.
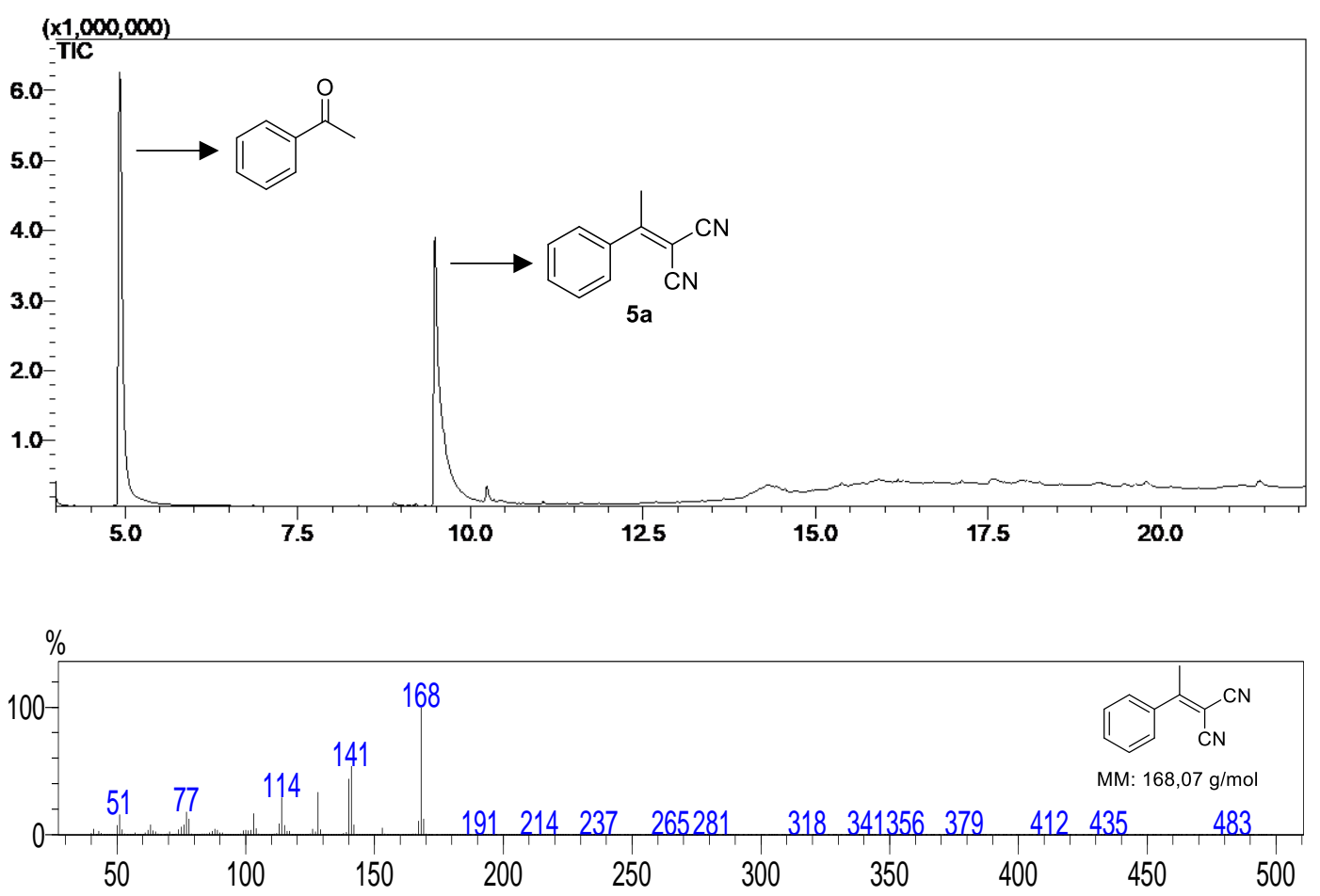

(B) Síntese do aduto 5d.
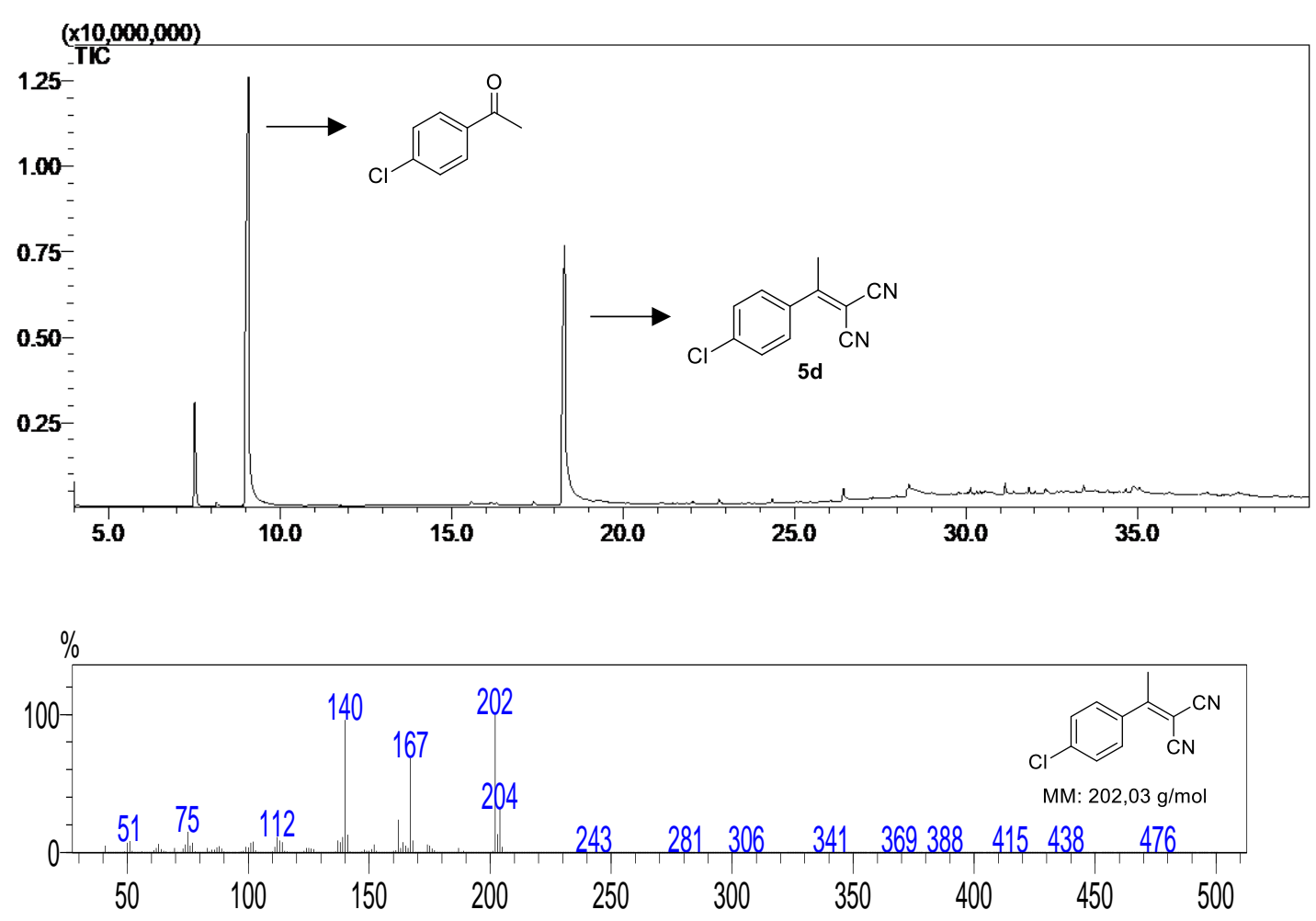
(C) Síntese do aduto 5i.
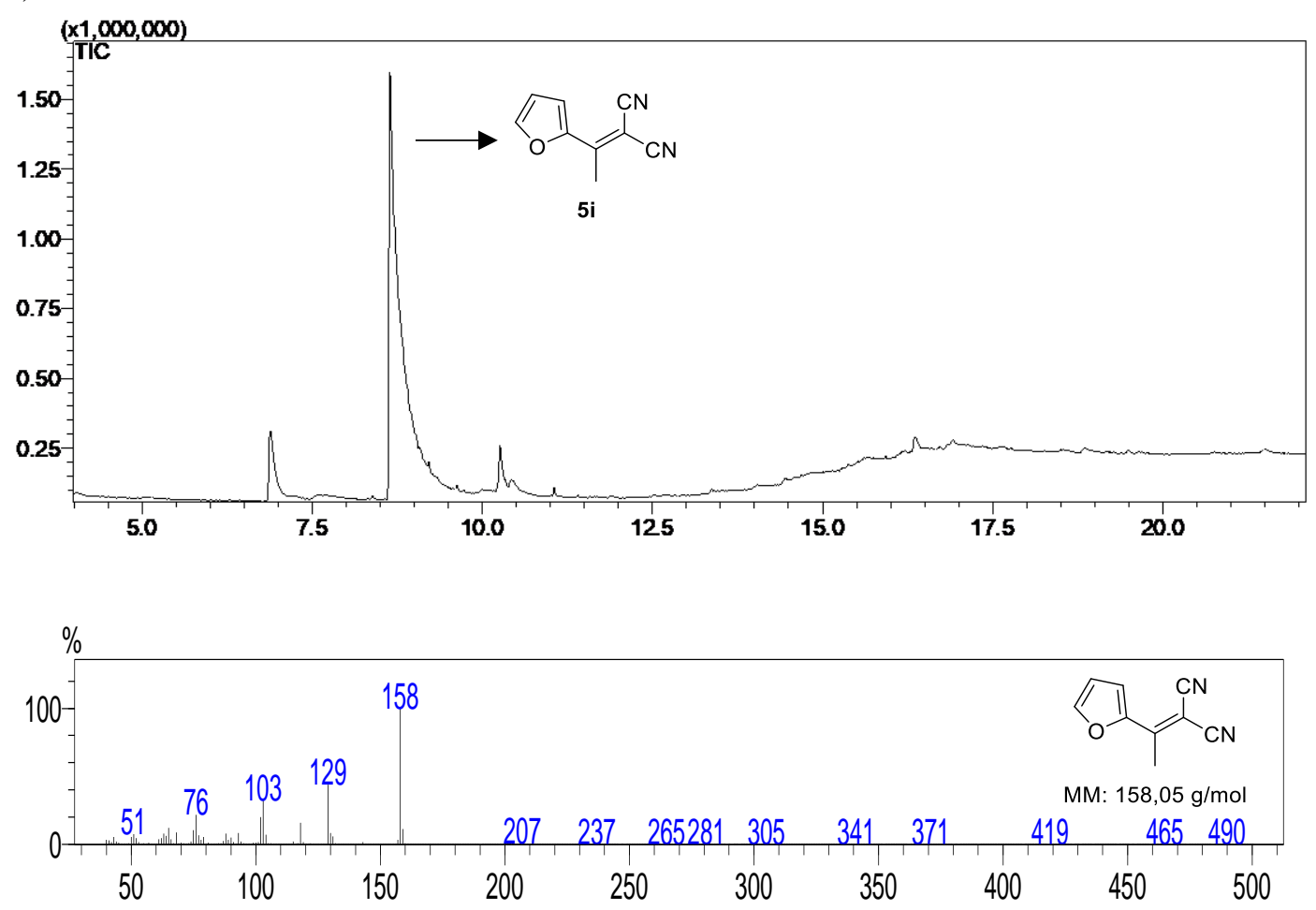

Contudo, ao comparar os valores de conversão da síntese do aduto 5a em chapa de aquecimento (55\%, Tabela 17) e em reator MO (52\%, Tabela 18), pode-se inferir que os efeitos da radiação MO não foram significativos para contribuir com a cinética desta reação, verificando que os impedimentos eletrônicos e estéricos possivelmente foram predominantes e garantiram que os valores de conversão não fossem superiores quando a reação foi realizada em um reator MO.

Em contraponto, é notável que a metodologia one-pot em meio básico utilizando TEA na ausência de solvente foi mais eficiente em comparação à metodologia em meio básico utilizando $\mathrm{NaOH}$. Na presença de TEA, em apenas $1 \mathrm{~h}$ de reação, todos os valores de conversão se aproximaram de 50\%, enquanto no procedimento em que se utilizou $\mathrm{NaOH}$, os valores ficaram na faixa de 0-38\% em 24 h de reação, com exceção do aduto $\mathbf{5 e}(\mathrm{c}=58 \%)$.

Os adutos de Knoevenagel 5a, 5b, 5d, 5e, 5f e 5i foram purificados por cromatografia em coluna utilizando misturas de hexano e acetato de etila, porém apenas os adutos $\mathbf{5 b}$, $\mathbf{5} \mathbf{f}$ e $\mathbf{5 i}$ foram isolados. Nesta etapa foram encontradas dificuldades para isolar os compostos devido à similaridade entre a polaridade do reagente e do produto, bem como o baixo valor de rendimento encontrado. Após esta etapa, estes os compostos foram caracterizados por técnicas espectroscópicas (RMN ${ }^{1} \mathrm{H} \mathrm{e}^{13} \mathrm{C}$ ) e espectrométrica (CG-EM). 
O aduto de Knoevenagel $5 \mathbf{i}$ foi selecionado para exemplificar o processo de caracterização realizada para alguns compostos desta série.

No espectro de infravermelho $\left(\mathrm{KBr}, \mathrm{cm}^{-1}\right)$, ilustrado na Figura 25 , foram observadas quatro bandas mais relevantes referentes as deformações axiais características da ligação C-H de anéis aromático em 3124 e $3041 \mathrm{~cm}^{-1}$, das duas ligações $\mathrm{C} \equiv \mathrm{N}$ em 2231 e $2223 \mathrm{~cm}^{-1}$ do grupo ciano, da ligação $\mathrm{C}=\mathrm{C}$ do anel aromático furano em $1745 \mathrm{~cm}^{-1}$, da ligação $\mathrm{C}=\mathrm{C}$ conjugada ao anel aromático em $1606 \mathrm{~cm}^{-1}$. Também foi observada a deformação angular das ligações C-H do grupo $\mathrm{CH}_{3}$ em $1394 \mathrm{~cm}^{-1}$. Outras bandas também foram observadas, em 2922, 1529, 1456, $1330,1296,1230,1151,1070,1022,943,935,883,767,605,584 \mathrm{~cm}^{-1}$.

Figura 25. Espectro de absorção na região do infravermelho (puro, $\mathrm{cm}^{-1}$ ) do aduto $\mathbf{5 i}$.

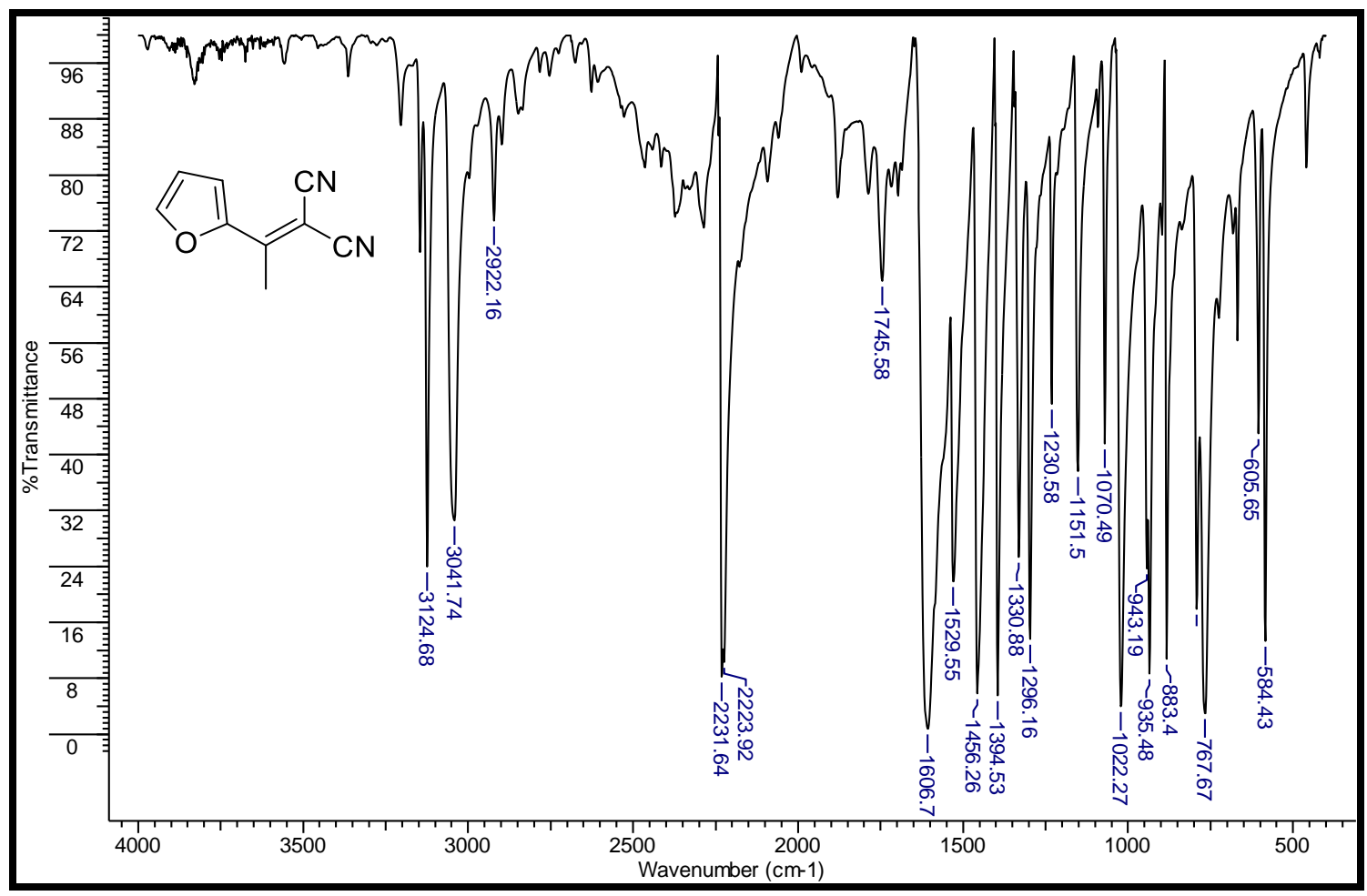

O espectro de RMN de ${ }^{1} \mathrm{H}\left(400 \mathrm{MHz}, \mathrm{DMSO}-d_{6}\right)$ apresentou um duplo dubleto em 8,24 ppm (dd, $J=1,7$ e $0,7 \mathrm{~Hz}, 1 \mathrm{H})$ referente ao hidrogênio $\alpha$-metínico em relação ao átomo de oxigênio; um duplo dubleto em 7,67 ppm (dd, $J=3,8$ e $0,7 \mathrm{~Hz}, 1 \mathrm{H})$ referente ao hidrogênios $\alpha$ em relação ao carbono ipso do anel aromático; um duplo dubleto em 6,92 ppm (dd, $J=3,8$ e $1,7 \mathrm{~Hz}, 1 \mathrm{H})$ referente ao hidrogênio $\beta$ em relação ao carbono ipso do anel aromático; um singleto em 2,52 ppm (s, $3 \mathrm{H}$ ) referente ao grupo metila ligado ao carbono insaturado adjacente ao anel aromático. Todos estes sinais podem ser observados na Figura 26. 
Figura 26. Espectro de RMN ${ }^{1} \mathrm{H}\left(400 \mathrm{MHz}, \mathrm{DMSO}-d_{6}\right)$ do aduto de Knoevenagel 5i.

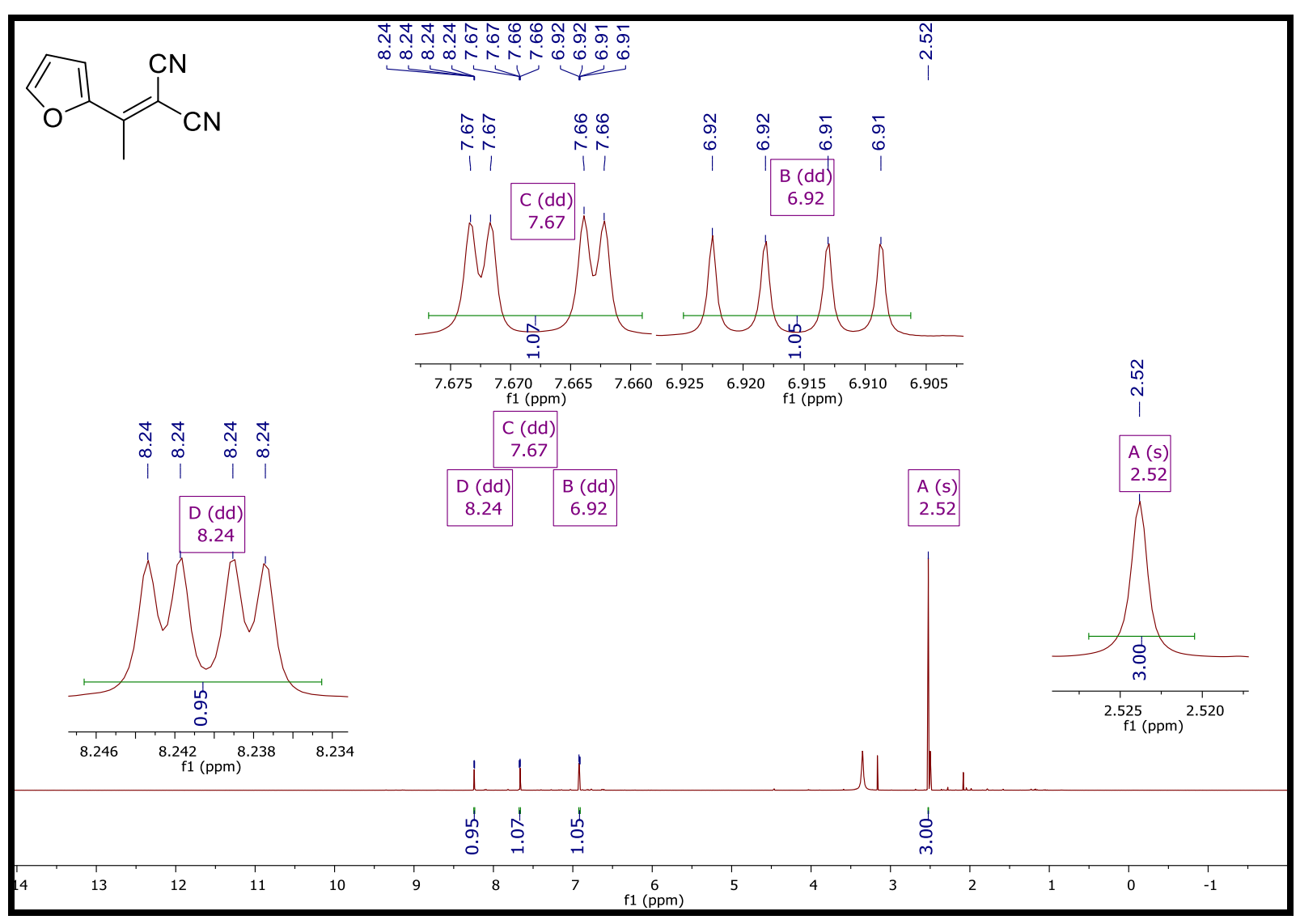

O espectro de RMN de ${ }^{13} \mathrm{C}$ (100 MHz, DMSO- $d_{6}$ ) apresentou um sinal em 156,13 ppm referente ao carbono olefínico ligado ao anel aromático; um sinal em 149,51 ppm referente ao carbono aromático $\alpha$ ao carbono olefínico; um sinal em 148,85 ppm referente ao carbono metínico aromático ligado ao átomo de oxigênio; um sinal em 122,60 ppm referente ao carbono $\alpha$ em relação ao carbono ipso do anel aromático; um sinal em 114,51 ppm referente ao carbono $\beta$ em relação ao carbono ipso do anel aromático; um sinal em 114,15 ppm referente ao carbono do grupo cian cis em relação ao grupo metila; um sinal em 113,89 ppm referente carbono do grupo ciano trans em relação ao grupo metila; um sinal em 75,02 ppm referente ao carbono ligado aos grupos ciano e um sinal em 19,45 ppm referente a metila ligada ao carbono olefínico. Todos estes sinais podem ser observados na Figura 27. 
Figura 27. Espectro de RMN ${ }^{13} \mathrm{C}\left(100 \mathrm{MHz}, \mathrm{DMSO}-d_{6}\right)$ do aduto de Knoevenagel 5i.

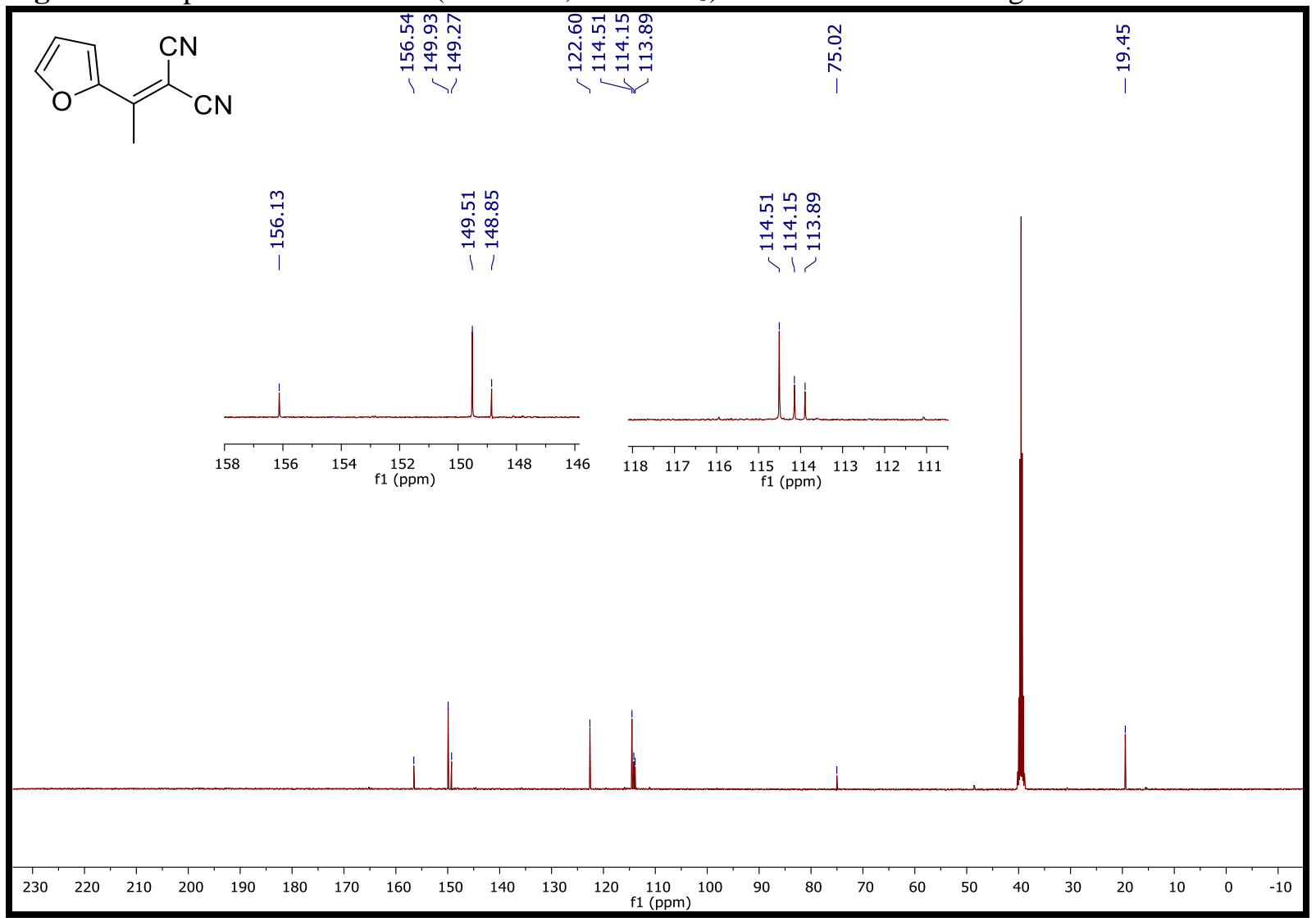

Como previsto, as cetonas apresentaram-se como reagentes mais limitados que os aldeídos para serem utilizados nas condensações de Knoevenagel devido aos fatores eletrônicos e estéricos. Ainda assim, a partir de algumas tentativas e mudanças de condições reacionais foi verificado que a reação se comportou melhor na ausência de solventes orgânicos, destacando principalmente os polares, os quais desaceleram a reação devido aos efeitos de solvatação do nucleófilo (ânion malononitrila) e do eletrófilo (cetona).

Ainda na presença de etanol e metanol respectivamente, pode ocorrer a formação de hemicetais e acetais. Bem como, na presença de água, a formação de hidratos ou gem-diol é favorecida. Esses fatores contribuem para os baixos valores de conversões, pois, quando as cetonas estão nas respectivas formas descritas, o carbono carbonílico deixa de atuar como eletrófilo, fato que dificulta a condensação de Knoevenagel de ocorrer. Estas reações estão ilustradas no Esquema 25. 
Esquema 25. Formação de dióis, hemicetais e acetais a partir de cetonas em solventes nucleofílicos próticos.

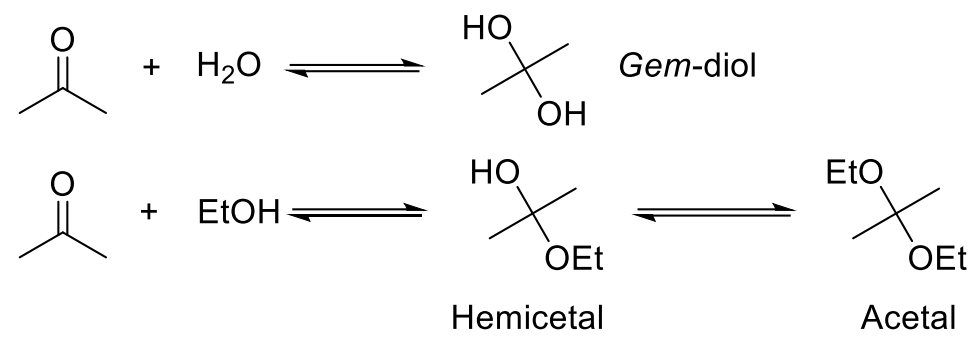

Mesmo utilizando diferentes metodologias, dificuldades no processo de isolamento e purificação foram constantementes observadas. Somado ao fato da baixa reatividade das cetonas, uma polimerização da malononitrila provavelmente ocorreu em todos os sistemas planejados, visto que, de acordo com Kawabata e colaboradores [87] esta se polimeriza com certa facilidade em meio básico. Esta hipótese não foi comprovada experimentalmente, porém, pela análise do conteúdo final das reações, os quais continham sempre um sólido negro pouco solúvel em solventes apolares (hexano) e em alguns polares $\left(\mathrm{H}_{2} \mathrm{O}\right.$ e THF) foi possível inferir que a reação competitiva de polimerização ocorreu. Vale ressaltar que, quando foi possível isolar os produtos, os mesmos possuíam colocaração completamente distinta do sólido negro citado, o possível produto de polimerização.

Por fim, pode-se concluir que foi possível sintetizar adutos de Knoevenagel a partir de cetonas aromáticas, os quais possuem poucos relatos na literatura, seguindo os princípios da Química Verde, pois não foi utilizado solvente e nem catalisadores tóxicos em larga escala, em valores de conversão moderados para os adutos de Knoevenagel que possuíam substituintes eletrorretiradores no anel aromático $\mathbf{5 b}$ e 5d-i ou que não possuíam substituintes 5a (42-58\%). Contudo, a purificação destes compostos foi exaustiva e pouco eficiente, visto os baixos valores de rendimentos isolados obtidos e em alguns casos não foi possível isolar os produtos.

\subsection{Biotransformação de adutos de Knoevenagel obtidos a partir de aldeídos e cianoacetato de metila}

Baseado no trabalho de Jimenez et al. [29] o fungo de ambiente marinho Penicillium citrinum CBMAI 1186 possui a enzima ene-redutase, a qual é capaz de realizar reações de adição trans de hidrogênios em sistemas $\alpha, \beta$-insaturados. Esta enzima foi muito eficiente na 
redução de adutos de Knoevenagel sintetizados entre aldeídos aromáticos e a malononitrila, formando os respectivos produtos bio-hidrogenados com excelentes rendimentos.

O mecanismo da redução catalisada por ene-redutases tem sido elucidado na literatura, onde um íon hidreto, derivado da flavina mononucleotídica reduzida $\left(\mathrm{FMN}_{\mathrm{red}}\right)$, é estereosseletivamente transferido para o carbono- $\alpha$ ao grupo éster do aduto de Knoevenagel. Subsequentemente, um resíduo de tirosina transfere um próton, para o carbono- $\beta$ a partir do lado oposto do ataque do íon hidreto que foi transferido para o carbono $\alpha$ do substrato (Figura 28). Como consequência, a estereoquímica global deste mecanismo ocorre via adição trans$\left[\mathrm{H}_{2}\right][88]$.

Figura 28. Proposta de adição do íon hidreto pela ene-redutase contida no fungo $P$. citrinum CBMAI 1186.

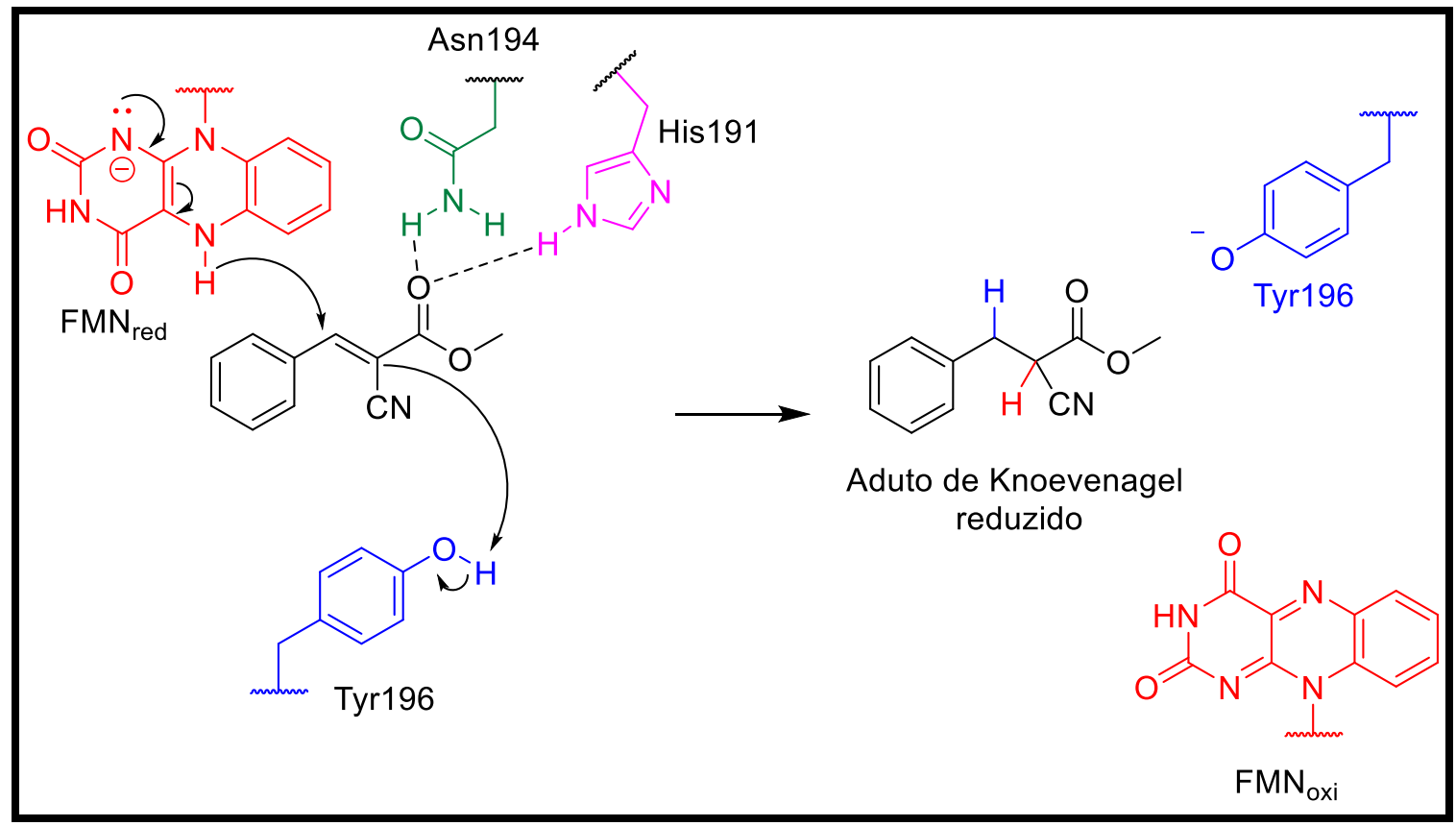

Adaptada do estudo de Toogood et al. [87]

Desta forma, alguns adutos sintetizados neste trabalho foram submetidos ao processo de biotransformação com o fungo $P$. citrinum CBMAI 1186. Foram selecionados dois adutos contendo grupos eletrorretiradores ( $\mathbf{2} \mathbf{d}$ e $\mathbf{2 g}$ ) e dois adutos contendo grupos eletrodoadores ( $\mathbf{2} \mathbf{j}$ e 2k) com intuito de avaliar a interferência destes substituintes nas biotransformações. $\mathrm{O}$ interesse nestas reduções foi estudar uma possível hidrogenação enantiosseletiva, pois a estrutura dos adutos selecionados eram próquirais e ao serem reduzidos poderiam formar um centro estereogênico quaternário altamente funcionalizado, como descrito no Esquema 26. 
Esquema 26. Proposta de biorredução do aduto 2d pelo fungo $P$. citrinum CBMAI 1186.<smiles>COC(=O)C(C#N)=Cc1ccc(Cl)cc1</smiles>

O comportamento em função do tempo das biotransformações foi estudada, realizando as reações em um, dois, três e cinco dias. Todas as reações foram analisadas por CG-EM (IE, 70 eV). Para todos os adutos selecionados não foi constatado como produto majoritário o aduto reduzido via ene-redutase como foi proposto inicialmente (Esquema 26) e em alguns casos a formação deste produto nem sequer foi identificada. Como não ocorreu uma tendência, a biotransformação de cada aduto foi discutida individualmente.

Destaca-se que todas as reações foram extraídas individualmente, de acordo com o tempo reacional realizado, para posterior análise via CG-EM. Todos os compostos também foram confirmados na base de dados WILEY do espectrômetro de massas e apresentaram similaridade acima de $90 \%$.

Na biotransformação do aduto $\mathbf{2 d}$, em 1 dia de reação foi observado que o material de partida ainda era o composto majoritário. Contudo, foi constatado um produto de biotransformação, o qual pode ser descrito como um aduto biorreduzido e com a perda do grupo éster.

Embora não foi verificada a formação do produto reduzido, sugere-se que primeiramente ocorreu uma bio-hidrogenação da olefina, subsequentemente uma reação de hidrólise do grupo éster seguida de uma descarboxilação do aduto hidrogenado, formando o composto 3-(4clorofenil)propanonitrila (Figura 19, A). Para comprovar esta reação, como sugestão, seria necessário preparar o aduto hidrogenado via $\mathrm{H}_{2} / \mathrm{Pd}$ e adicionar ao meio de cultura com o fungo P. citrinum CBMAI 1186. Neste trabalho esta reação não foi realizada.

Foi observado que a 3-(4-clorofenil)propanonitrila, teve sua concentração aumentada quanto maior o tempo das reações (1-5 dias). Um outro produto de biotransformação também foi observado, porém apenas no $5^{\circ}$ dia de reação, o qual foi identificado como sendo o ácido 4clorobenzóico. Este ácido pode ter sido gerado após a reação de retro-Knoevenagel ter ocorrido, gerando o aldeído, o qual foi oxidado por enzimas oxidases para o respectivo ácido carboxílico. Esta proposta de rota de biotransformação está demonstrada no Esquema 27. Todos os cromatogramas das reações realizadas de 1 a 5 dias e os espectros de massas dos produtos de biotransformação, identificados na biblioteca Wiley os quais apresentaram $>90 \%$ de similaridade, estão contidos na Figura 29. 
Os picos destacados com a letra "M" referem-se aos possíveis metabólitos extraídos dos fungos, majoritariamente derivados da membrana celular, composta comumente por ácidos graxos e esteroides.

Figura 29. Cromatogramas das biotransformações do aduto $\mathbf{2 d}$ com o fungo P. citrinum CBMAI 1186 e os espectros de massas dos produtos de biotransformações.

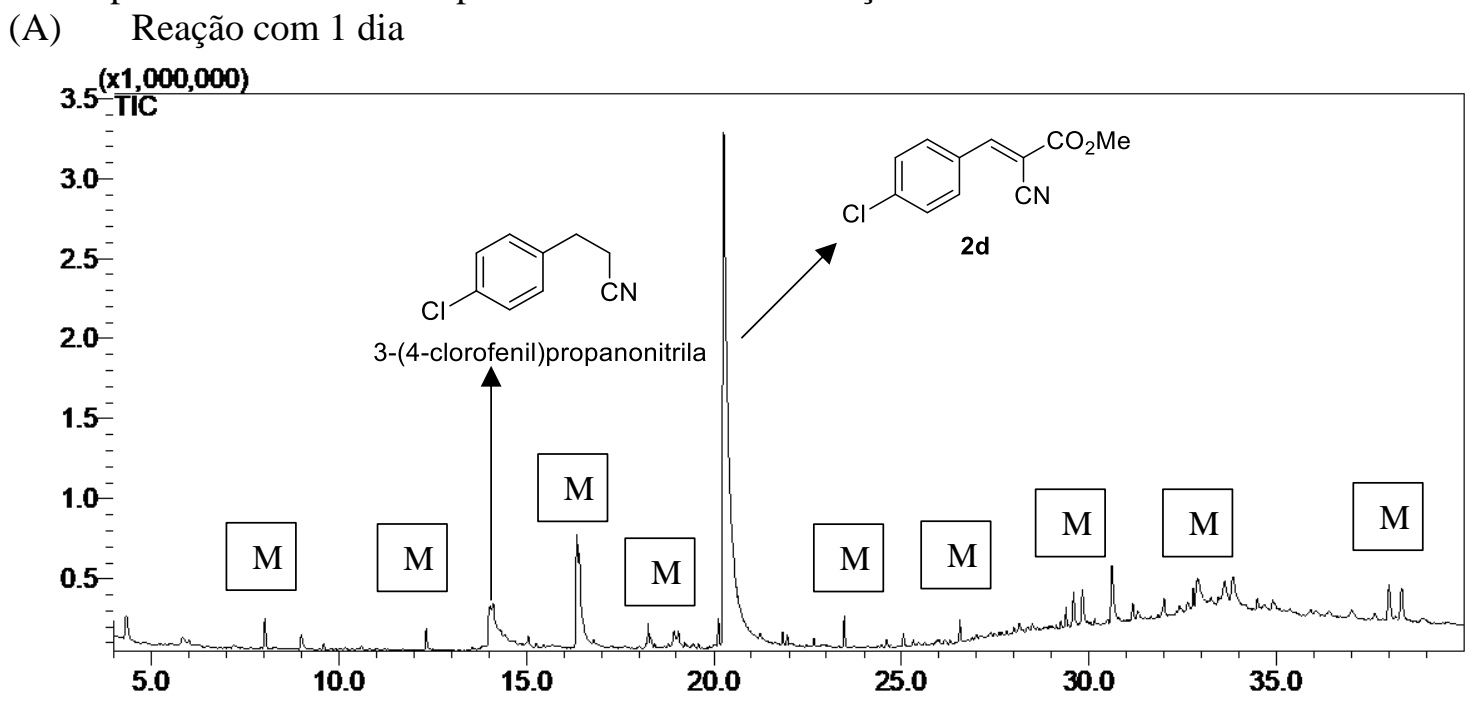

(B) Reação com 2 dias.

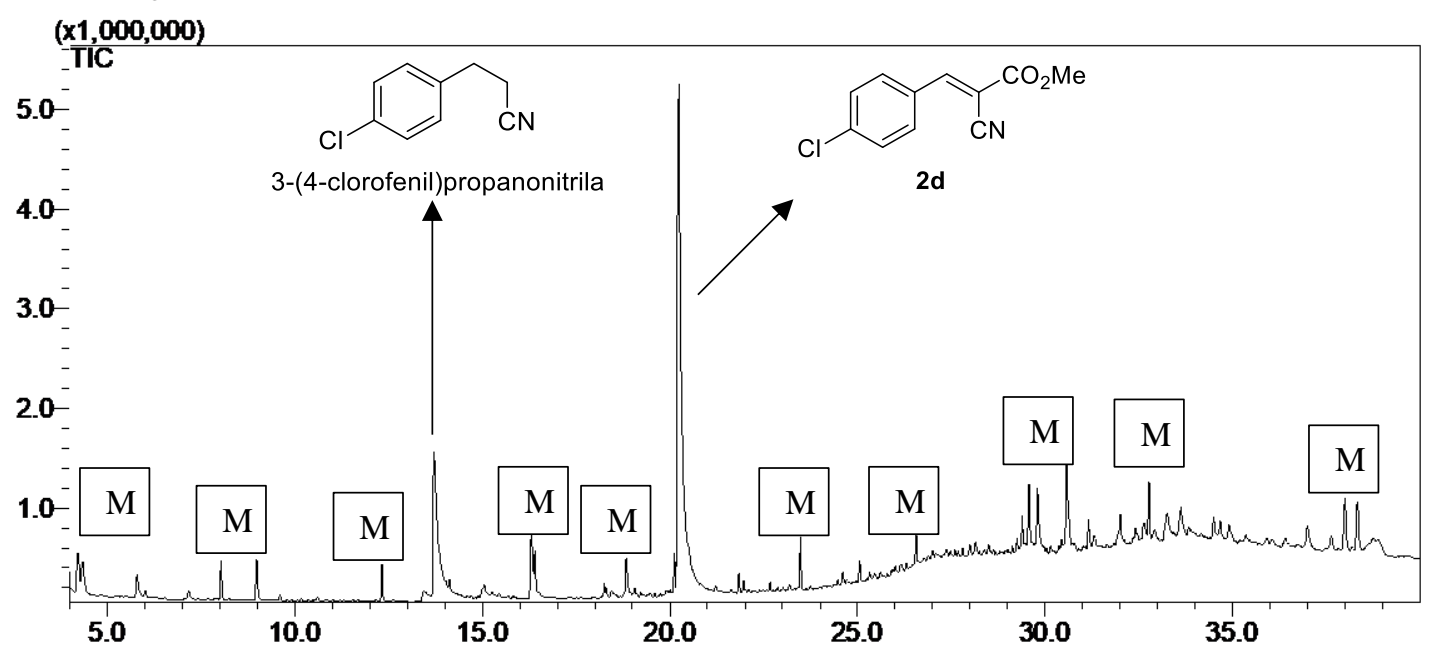


(C) Reação com 3 dias.

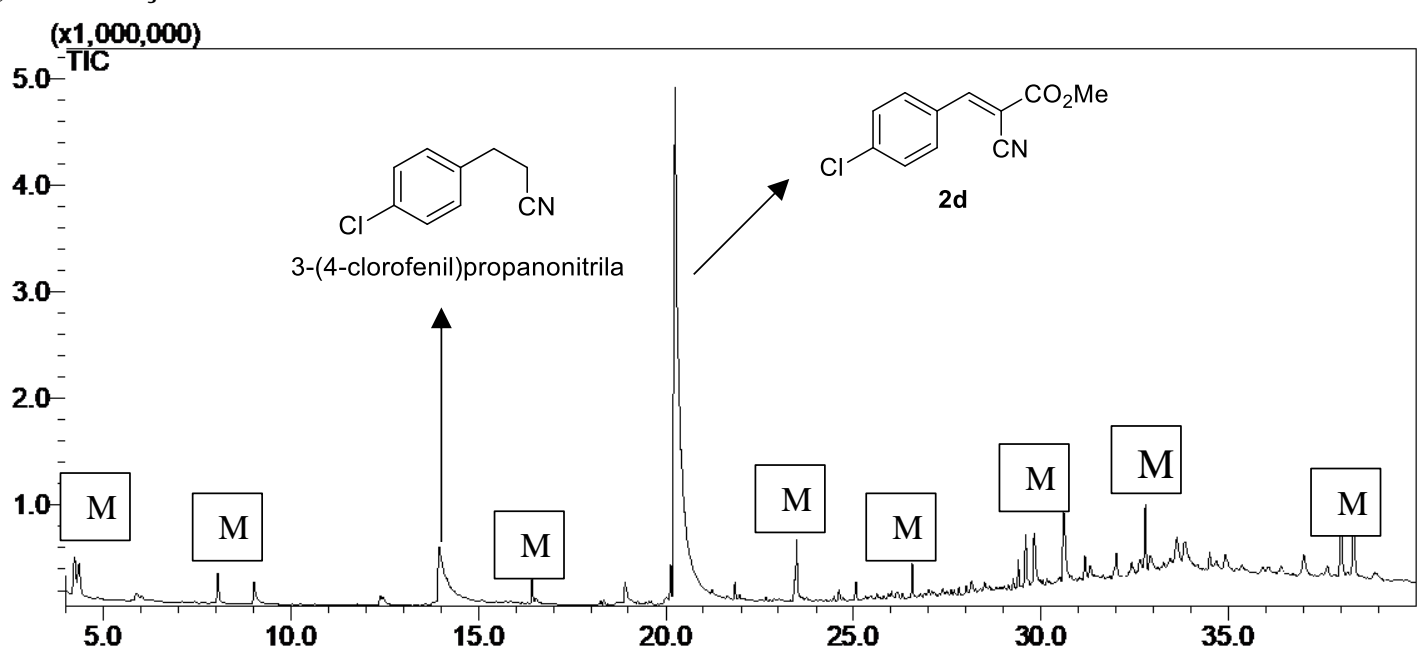

(D) Reação com 5 dias.

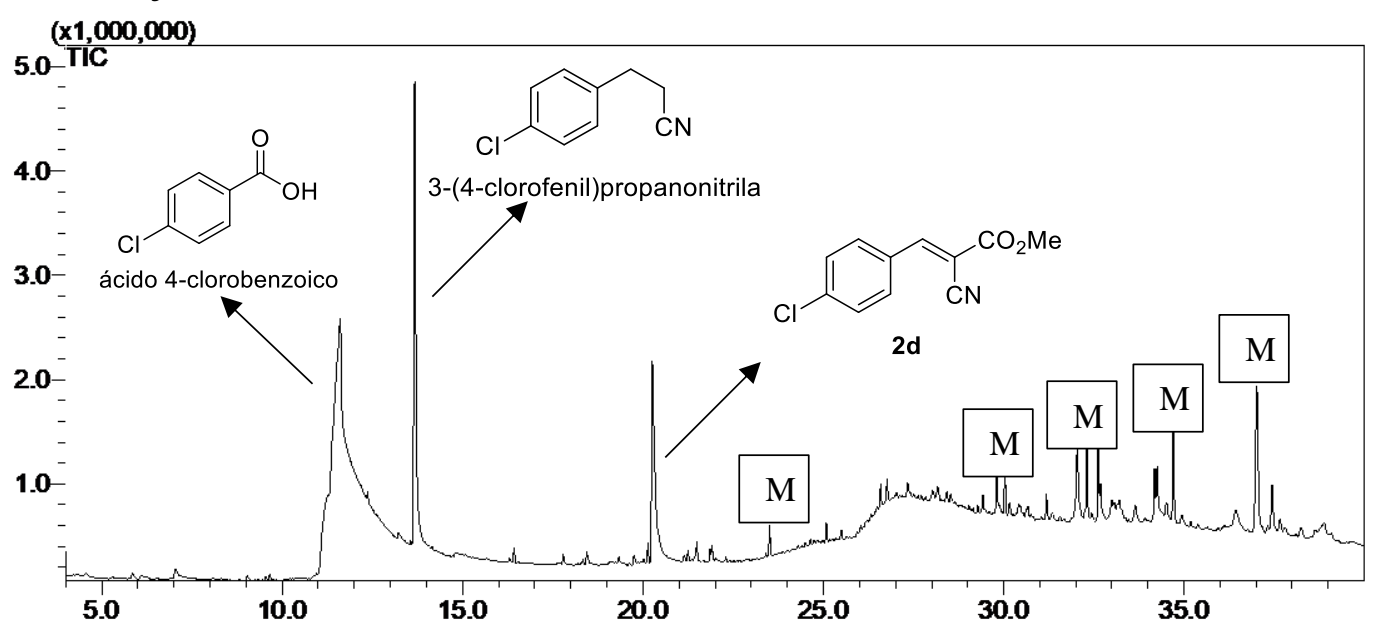

(E) Espectro de massas do 3-(4-clorofenil)propanonitrila.

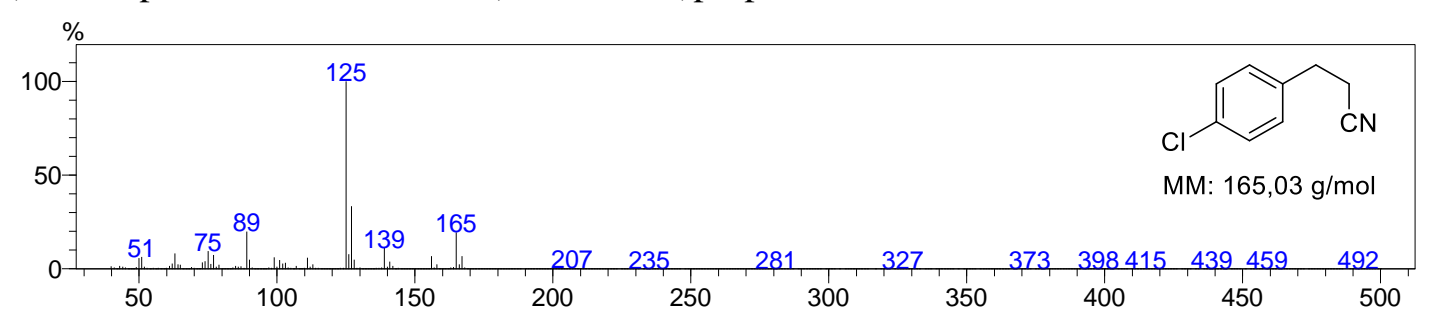

(F) Espectro de massas do ácido 4-clorobenzoico.

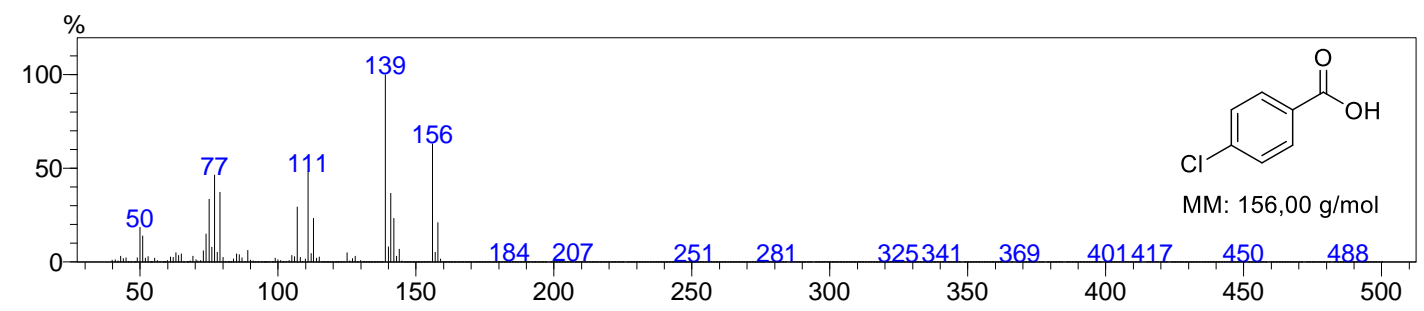


Esquema 27. Proposta de rotas de biotransformações do aduto $\mathbf{2 d}$ pelo fungo $P$. citrinum CBMAI 1186. (A) Formação do 3-(4-clorofenil)propanonitrila<smiles>COC(=O)C(C=Cc1ccc(Cl)cc1)=CC(C)Cc1ccc(Cl)cc1</smiles>

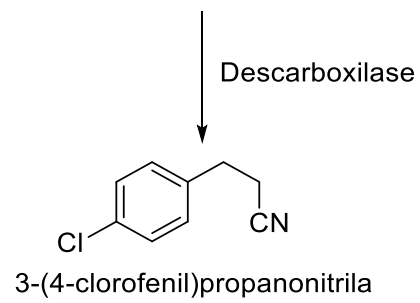

(B) Formação do ácido 4-clorobenzóico

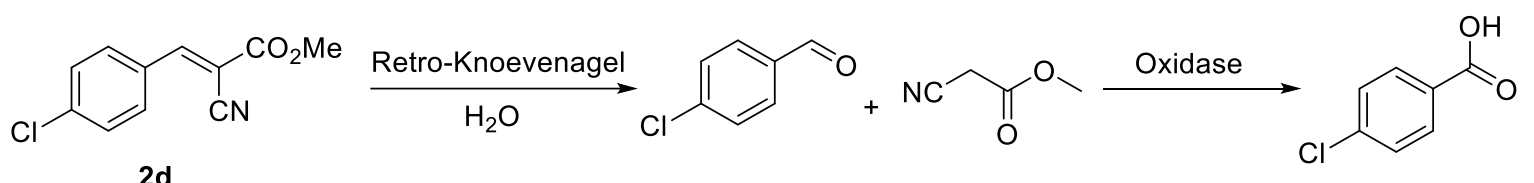

2d

Ácido 4-clorobenzoico

Na biotransformação do aduto $\mathbf{2 g}$ não foram constatados produtos de biotransformação até 3 dias de reação. Porém, após 5 dias foram identificados dois compostos, o 4-nitrobenzaldeído e o seu respectivo álcool reduzido, o (4-nitrofenil)metanol. A formação destes compostos evidenciou que a reação retro-Knoevenagel ocorreu e também a presença de enzimas hidrolases e oxidorredutases que promoveram a biotransformação dos compostos formados. Esta proposta de rota de biotransformação está demonstrada no Esquema 28. Todos os cromatogramas das reações realizadas de 1 a 5 dias estão demonstradas na Figura 30, bem como os espectros de massas dos produtos identificados na biblioteca Wiley, os quais apresentaram $>90 \%$ de similaridade.

Figura 30. Biotransformação do aduto $2 \mathrm{~g}$ realizada pelo fungo P. citrinum CBMAI 1186.

(A) Reação com 1 dia.

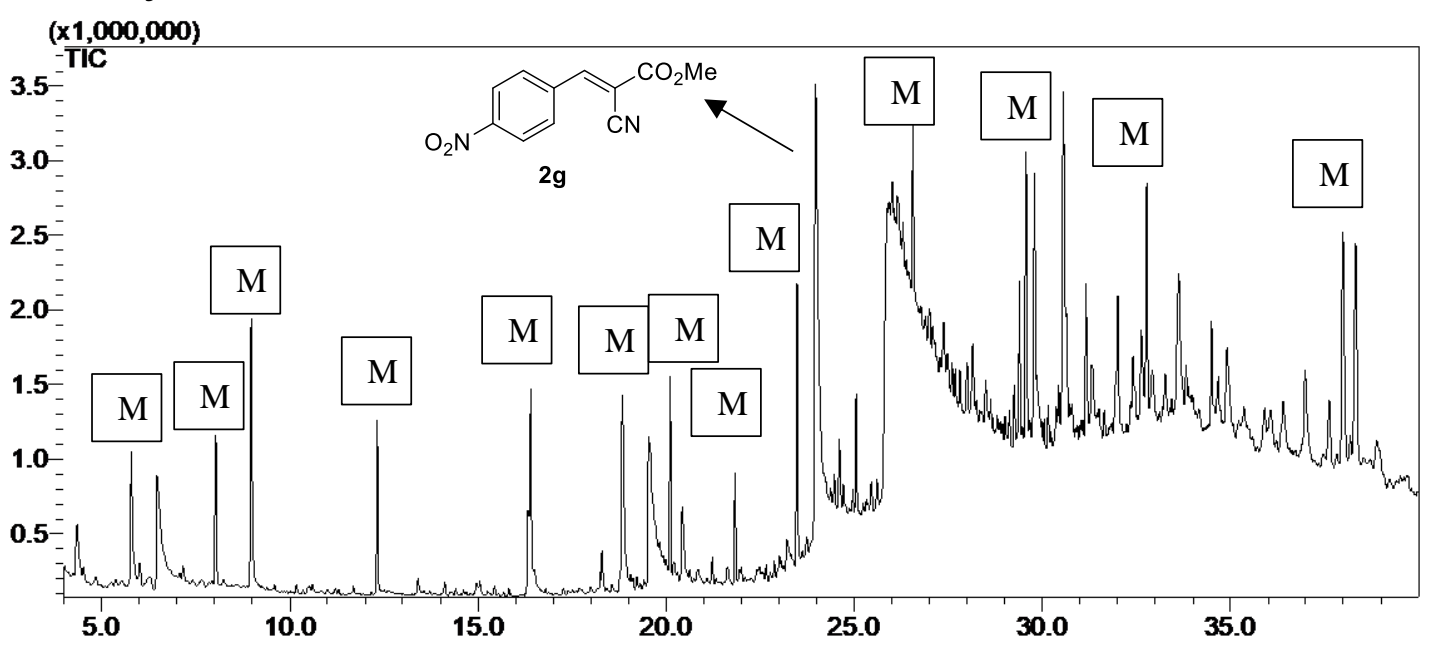


(B) Reação com 2 dias.

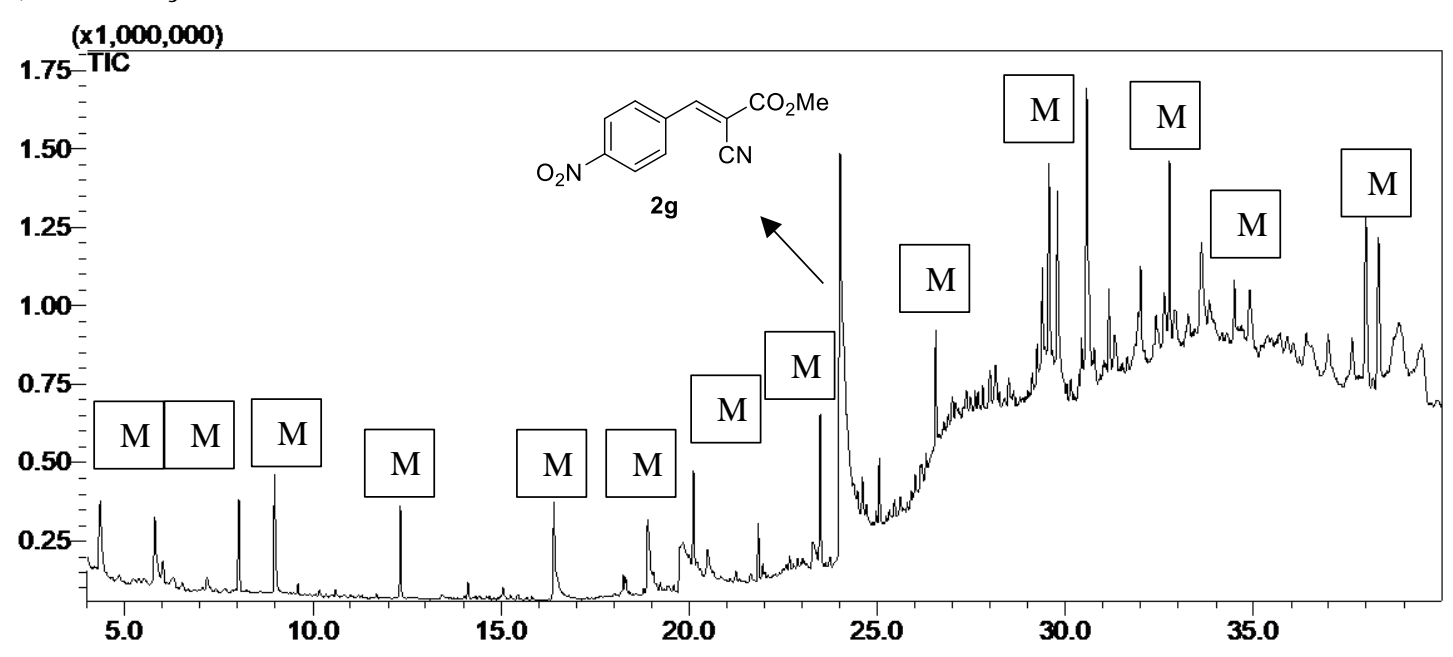

(C) Reação com 3 dias.

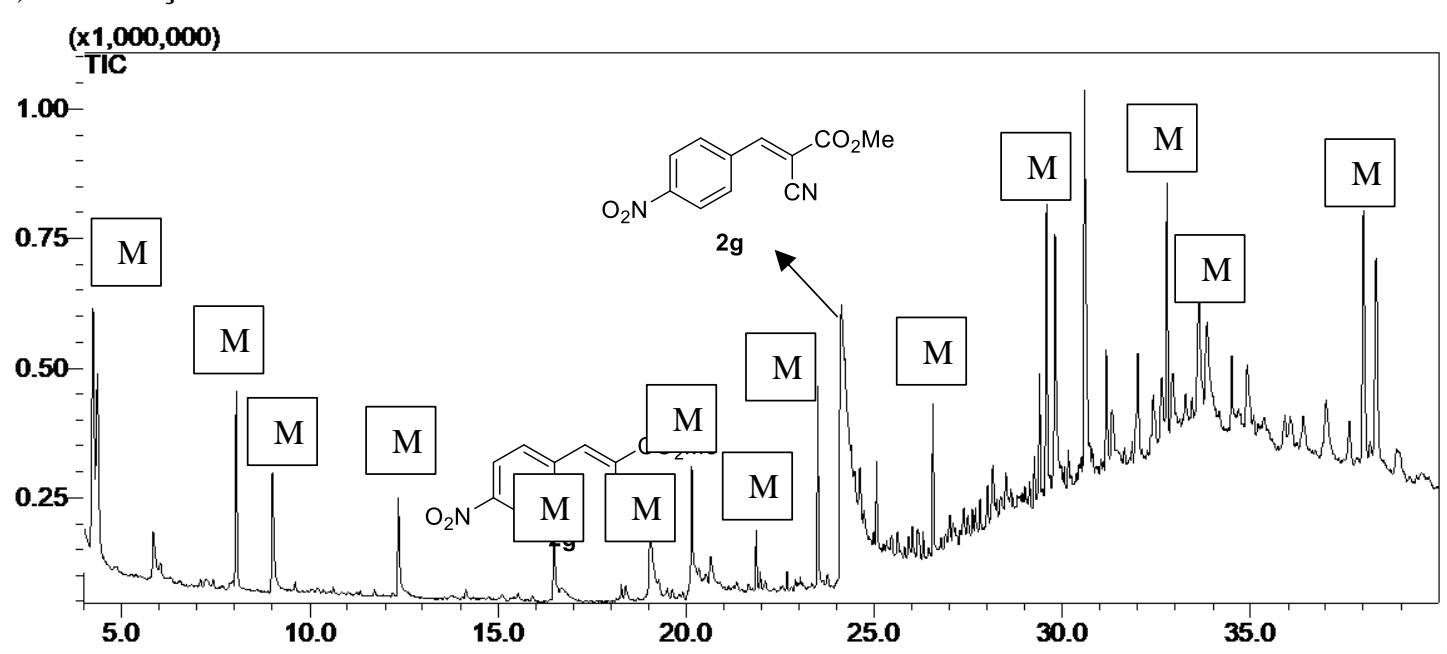

(D) Reação com 5 dias.

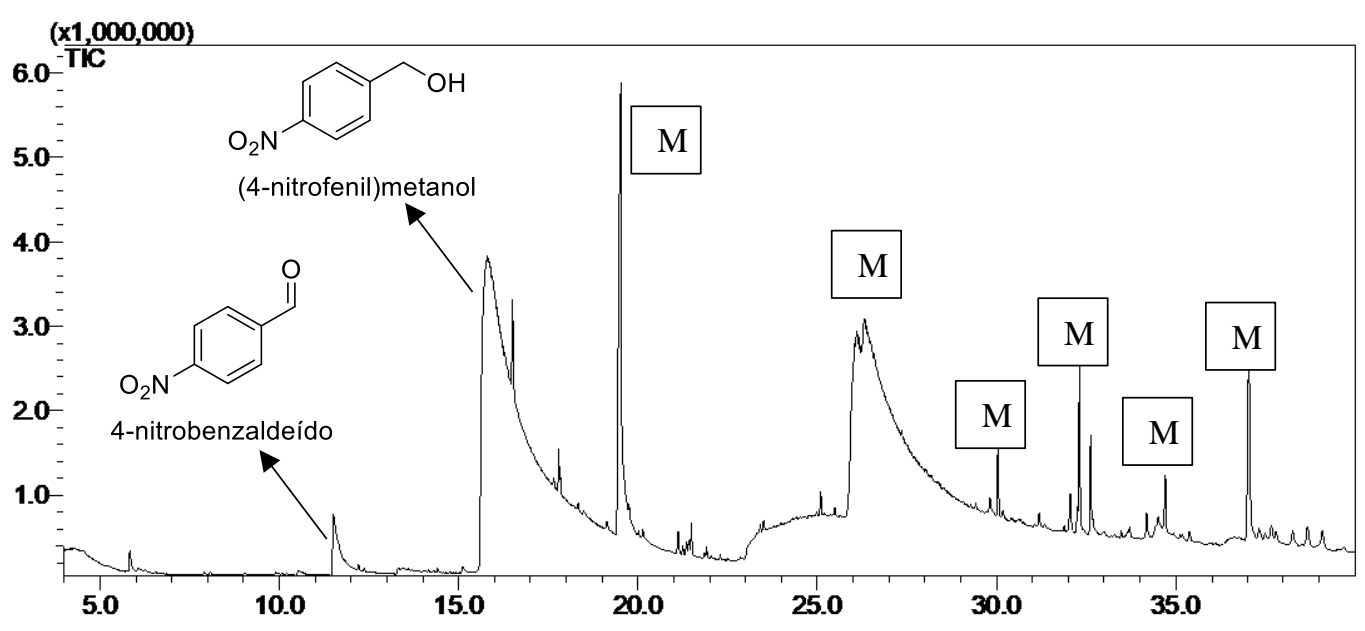


(E) Espectro de massas do (4-nitrofenil)metanol.

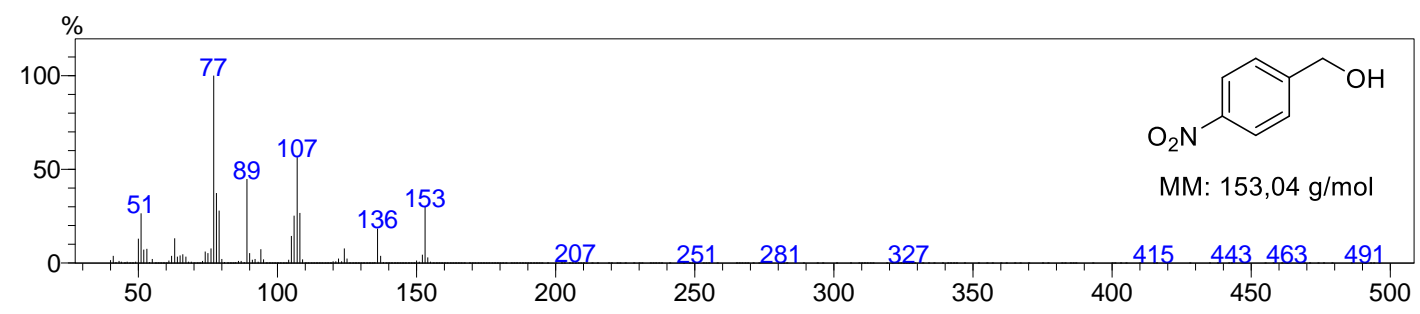

(F) Espectro de massas do ácido 4-nitrobenzaldeído.

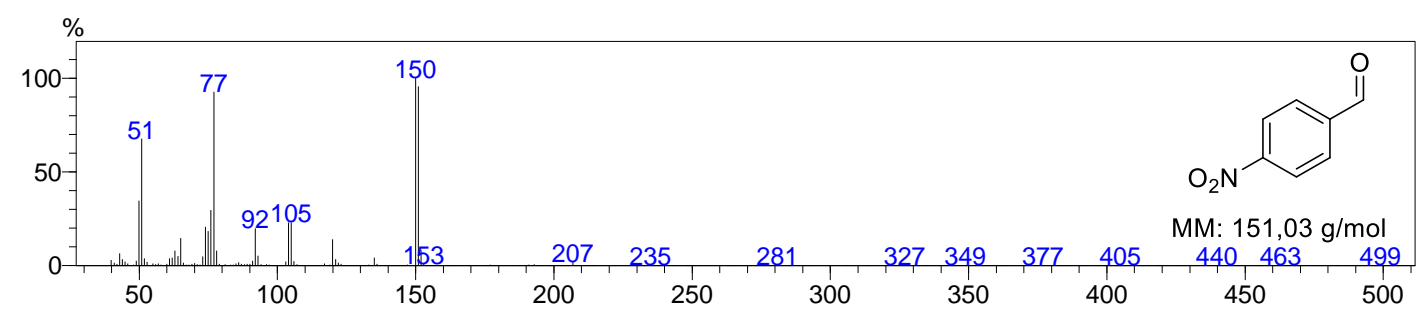

Esquema 28. Proposta de rota de biotransformação do aduto 2 g pelo fungo $P$. citrinum CBMAI 1186.<smiles>COC(=O)/C(C#N)=C/c1ccc([N+](=O)[O-])cc1</smiles>

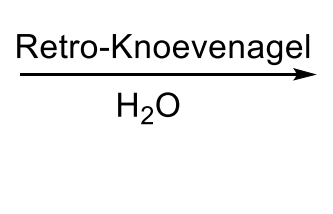<smiles>COC(=O)CC#N</smiles><smiles>[R20]CCCCCCc1ccc([N+](=O)[O-])cc1CO</smiles>

(4-nitrofenil)metanol

$\mathrm{Na}$ biotransformação do aduto $\mathbf{2} \mathbf{j}$, também não foram constatados produtos de biotransformação até 3 dias de reação. Contudo, após 5 dias de reação foram obtidos três produtos (Figura 19) que evidenciam que a reação retro-Knoevenagel ocorreu, sendo um deles o respectivo álcool, o 4-metil-hidroxi-2-metoxifenol, produto da redução do aldeído $\mathbf{1 j}$ por uma enzima redutase.

Quanto ao produto majoritário 2-metoxifenol, o que contém o anel aromático com seus substituintes, hidroxila e metoxila, pode ser formado por uma reação de oxidação da vanilina 1j ao correspondente ácido carboxílico, o ácido 4-hidroxi-3-metoxifenil benzoico, por uma oxidase que, sequencialmente, pode também promover uma reação de descarboxilação promovida por uma descarboxilase para formar o 2-metoxifenol como produto majoritário. Destaca-se que o ácido 4-hidroxi-3-metoxi benzoico não foi observado nas análises das reações. Esta proposta de rota de biotransformação está demonstrada no Esquema 29 (p. 101). Todos os 
cromatogramas das reações realizadas de 1 a 5 dias e os espectros de massas dos produtos de biotransformação, identificados na biblioteca Wiley, os quais apresentaram $>90 \%$ de similaridade, estão contidos na Figura 31.

Figura 31. Biotransformação do aduto $2 \mathbf{j}$ realizada pelo fungo $P$. citrinum CBMAI 1186.

(A) Reação em 1 dia.

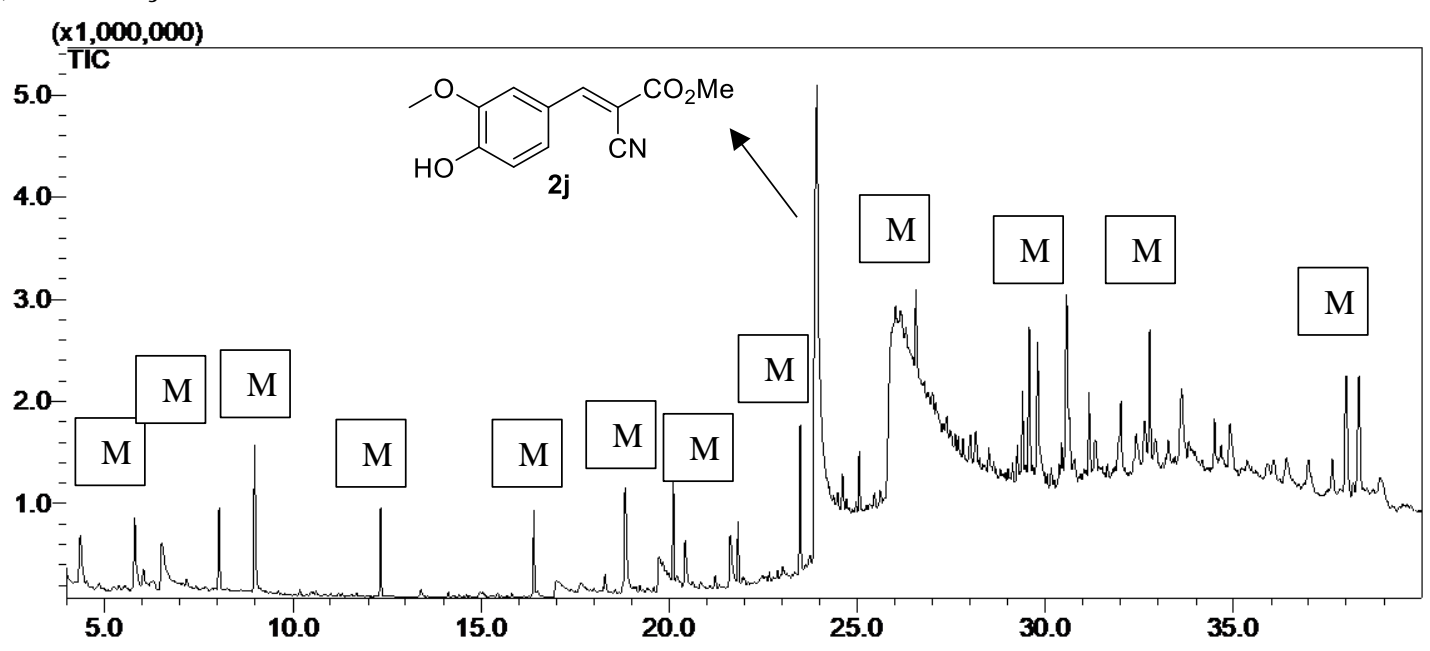

(B) Reação em 2 dias.

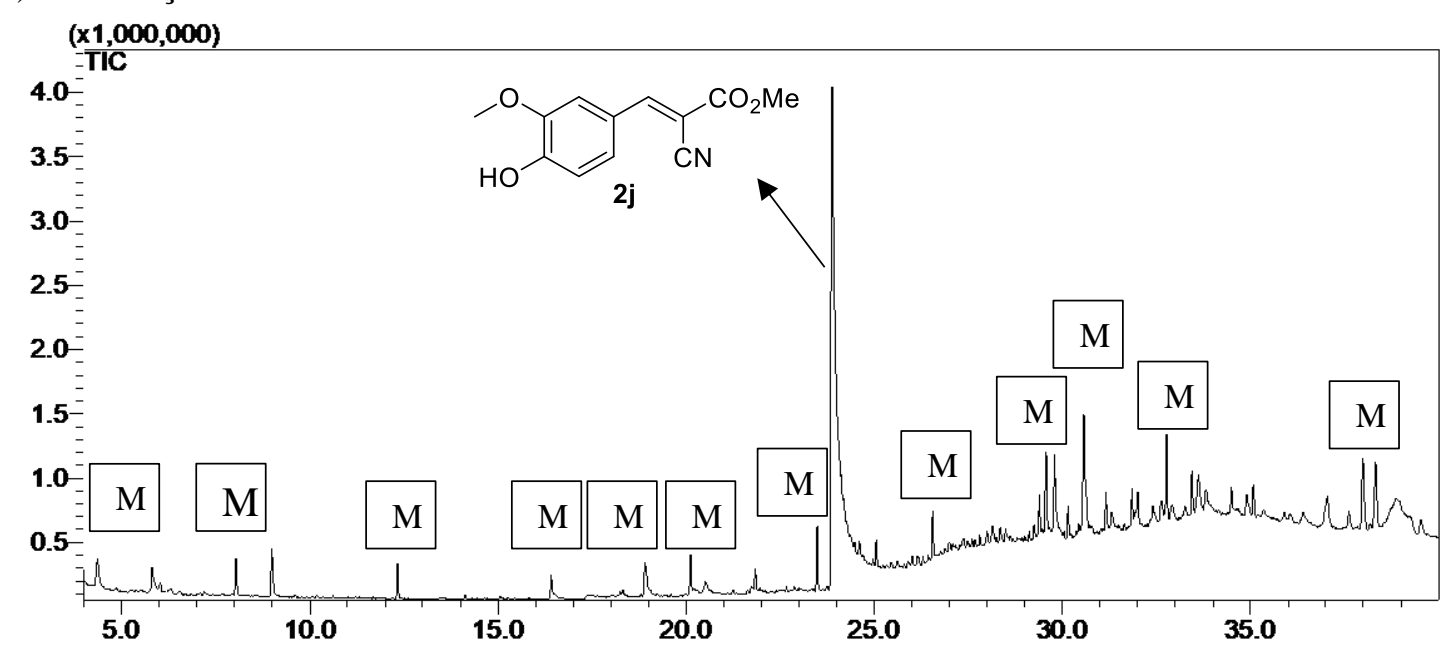


(C) Reação em 3 dias.

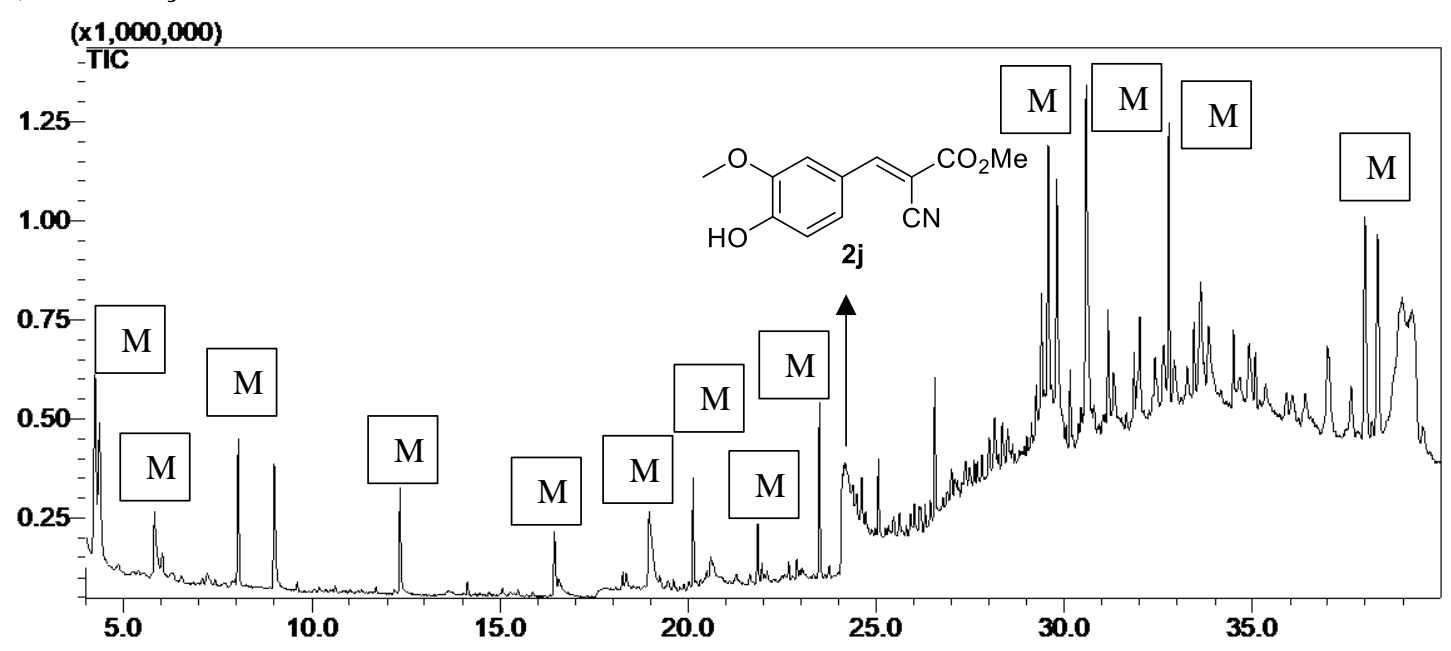

(D) Reação em 5 dias.

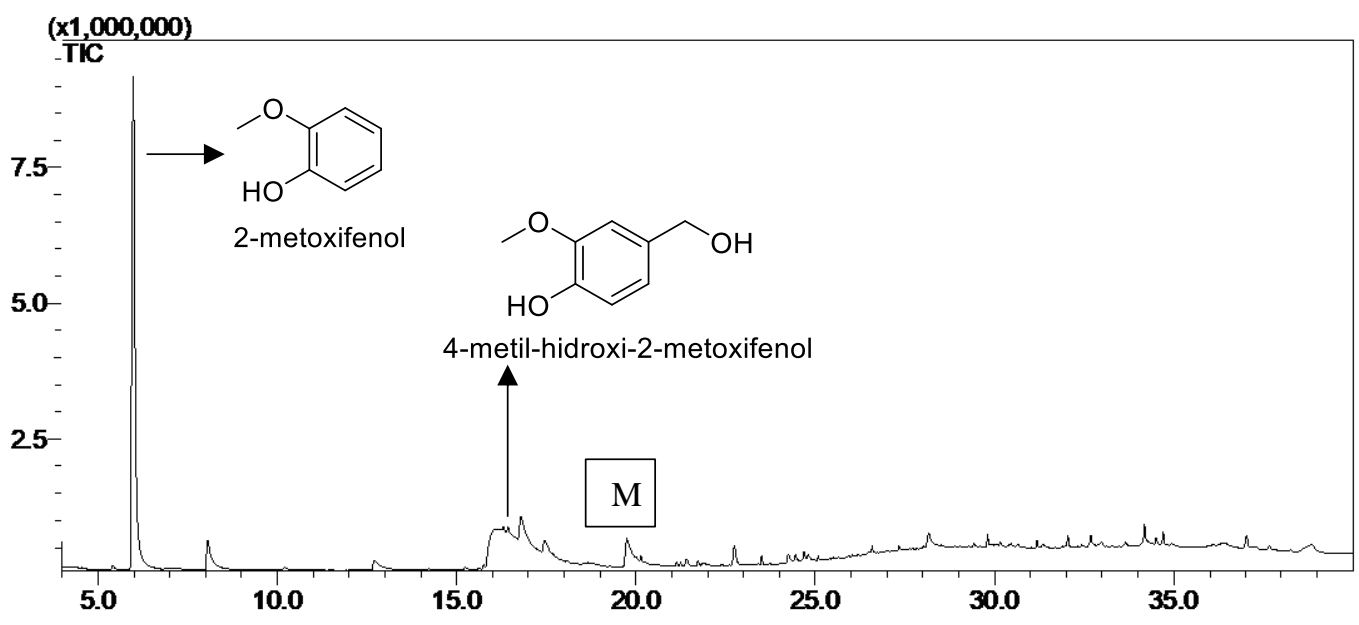

(E) Espectro de massas do 4-metil-hidroxi-2-metoxifenol

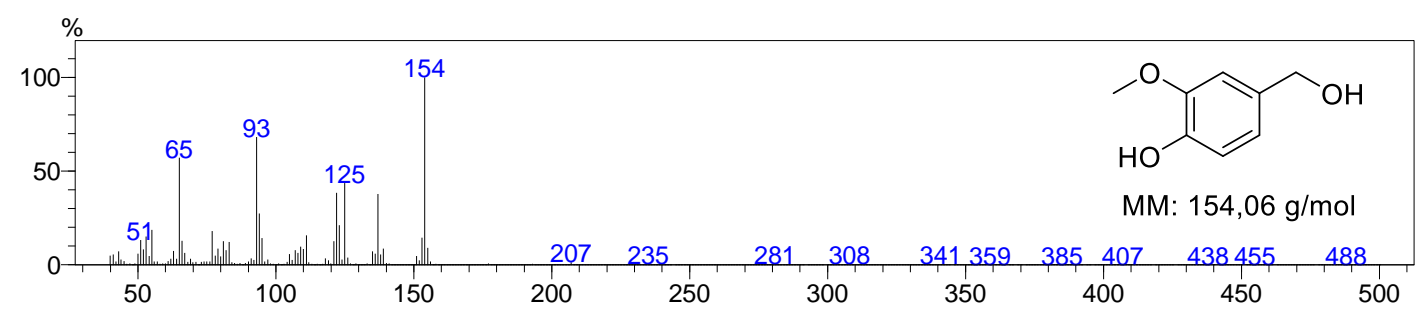

(F) Espectro de massas do 2-metoxifenol.

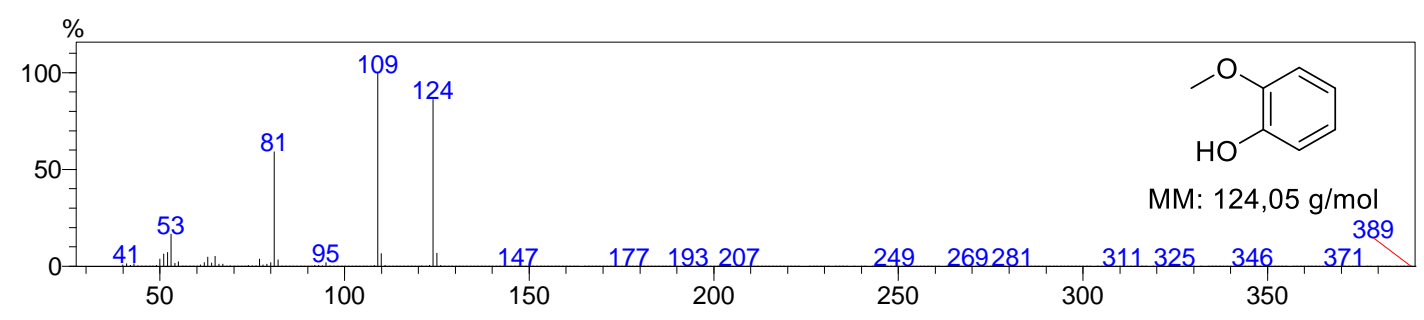


Esquema 29. Proposta de rota de biotransformação do aduto $2 \mathbf{j}$ pelo fungo $P$. citrinum CBMAI 1186.

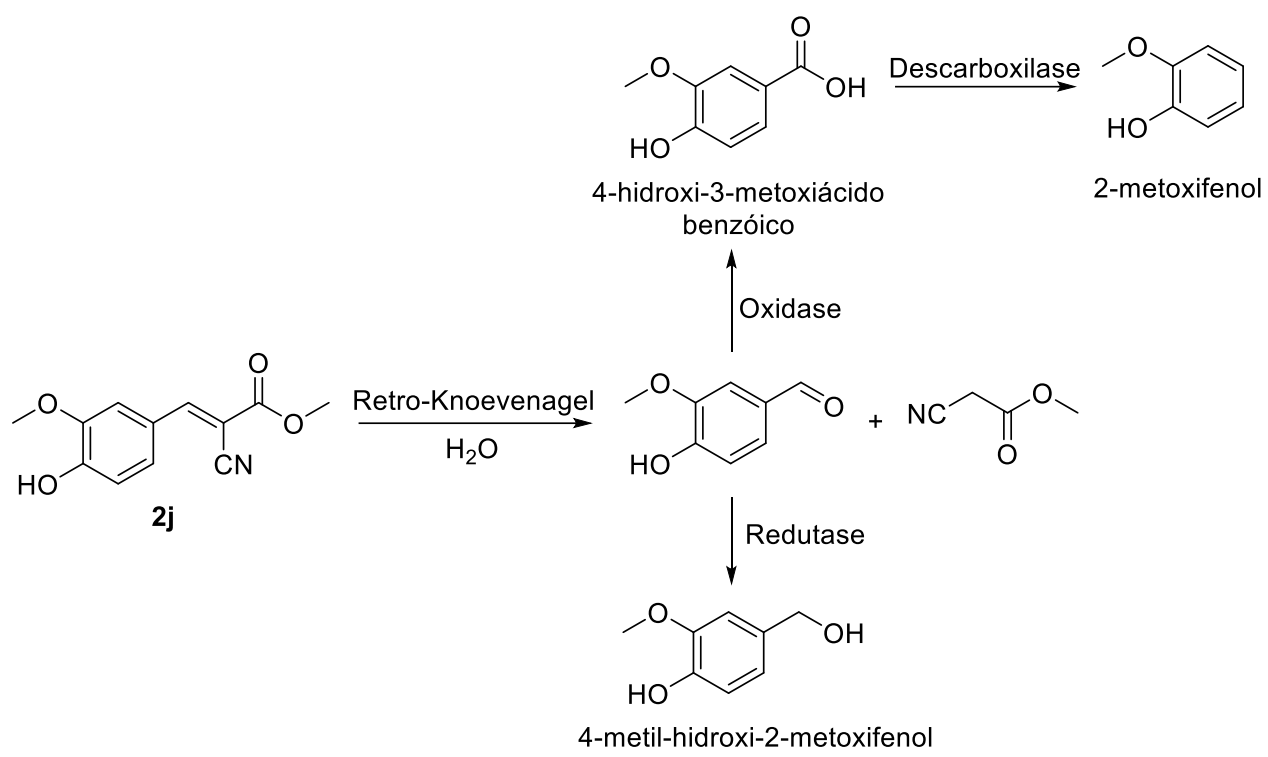

$\mathrm{Na}$ biotransformação do aduto $\mathbf{2 k}$ foi observado exclusivamente a formação do aduto reduzido, o 2-ciano-3-(3,4,5-trimetoxifenil)propanoato de metila, inicialmente desejado em até 3 dias de reação. Contudo, em 5 dias de reação, este produto foi consumido e foi notado a formação de 3 produtos distintos, que sugerem novamente que a reação retro-Knoevenagel ocorreu. Neste caso pode-se inferir a presença de enzimas tanto oxidativos quanto redutivas, pois foi constatada a presença do álcool (3,4,5-trimetoxifenil)metanol, produto reduzido do aldeído $\mathbf{2 k}$, bem como o ácido (3,4,5-trimetoxi)benzoico, produto oxidado do aldeído 1k. Esta proposta de rota de biotransformação está descrita no Esquema 30. Todos os cromatogramas das reações realizadas de 1 a 5 dias e os espectros de massas dos produtos de biotransformação, identificados na biblioteca Wiley os quais apresentaram $>90 \%$ de similaridade, estão demonstradas na Figura 32. 
Figura 32. Biotransformação do aduto 2k realizada pelo fungo $P$. citrinum CBMAI 1186.

(A) Reação em 1 dia.

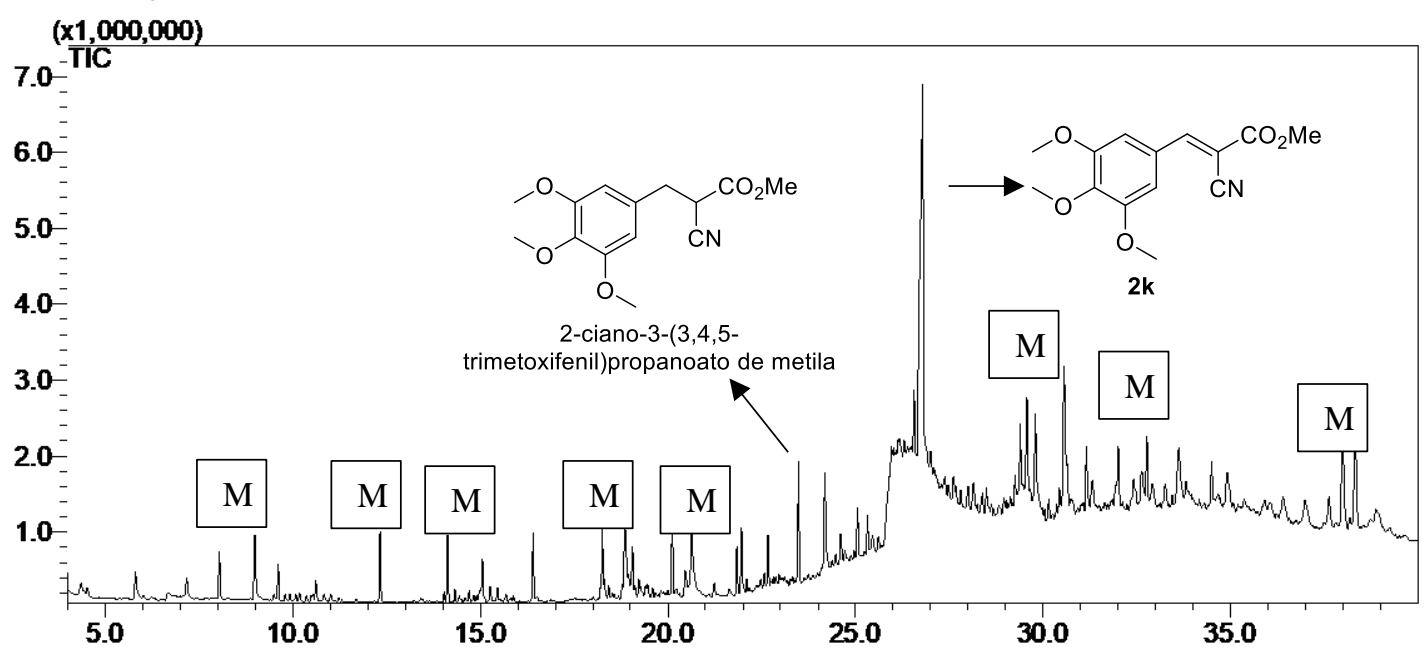

(B) Reação em 2 dias.

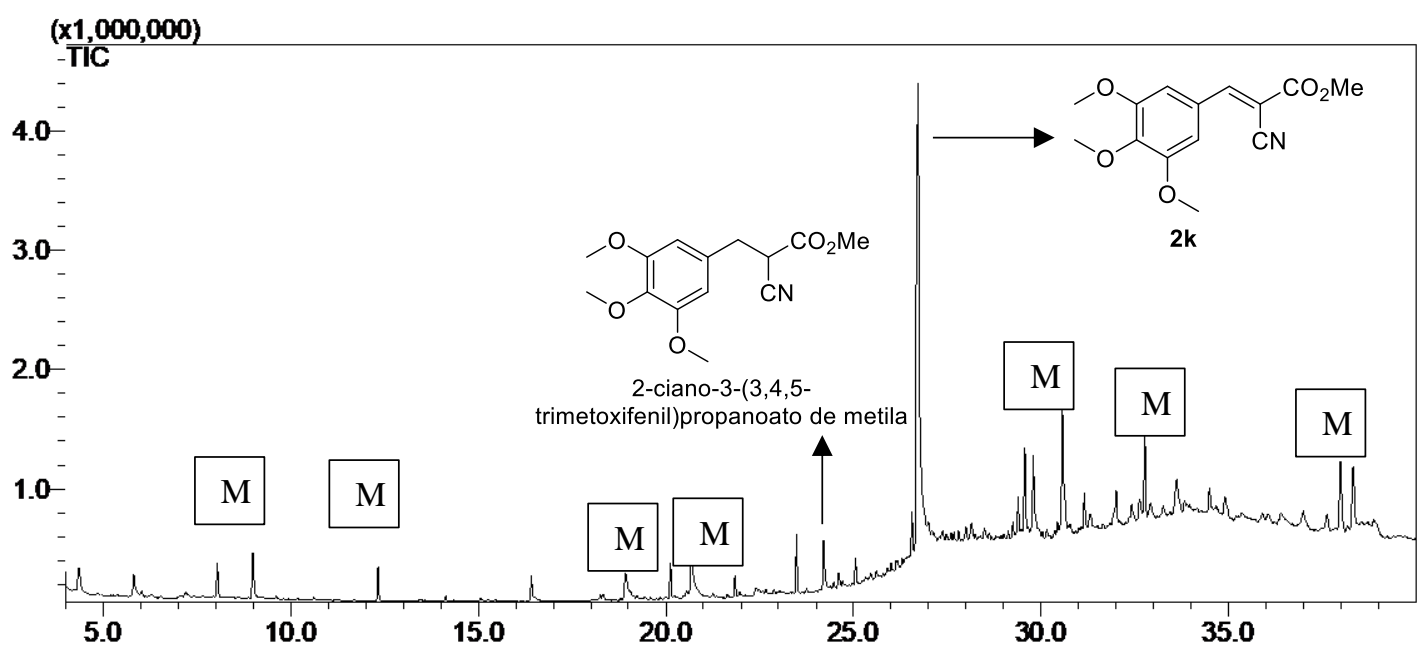

(C) Reação em 3 dias.

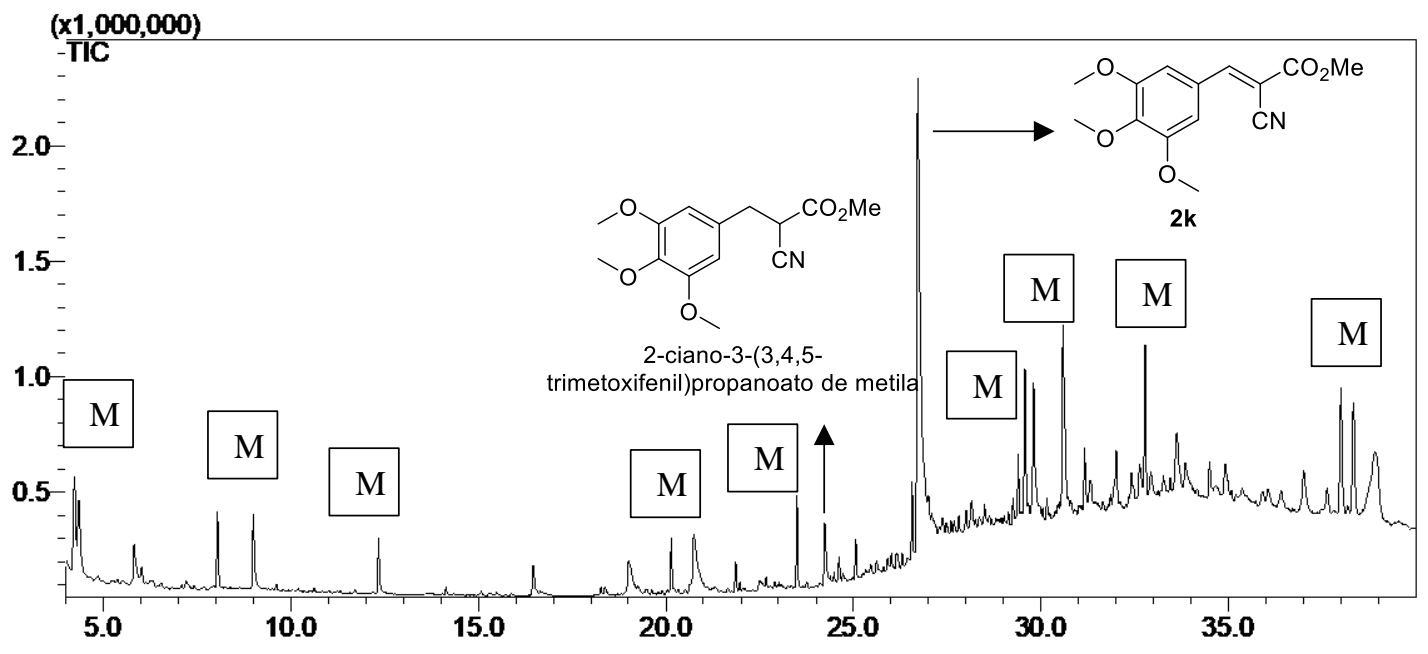


(D) Reação em 5 dias.

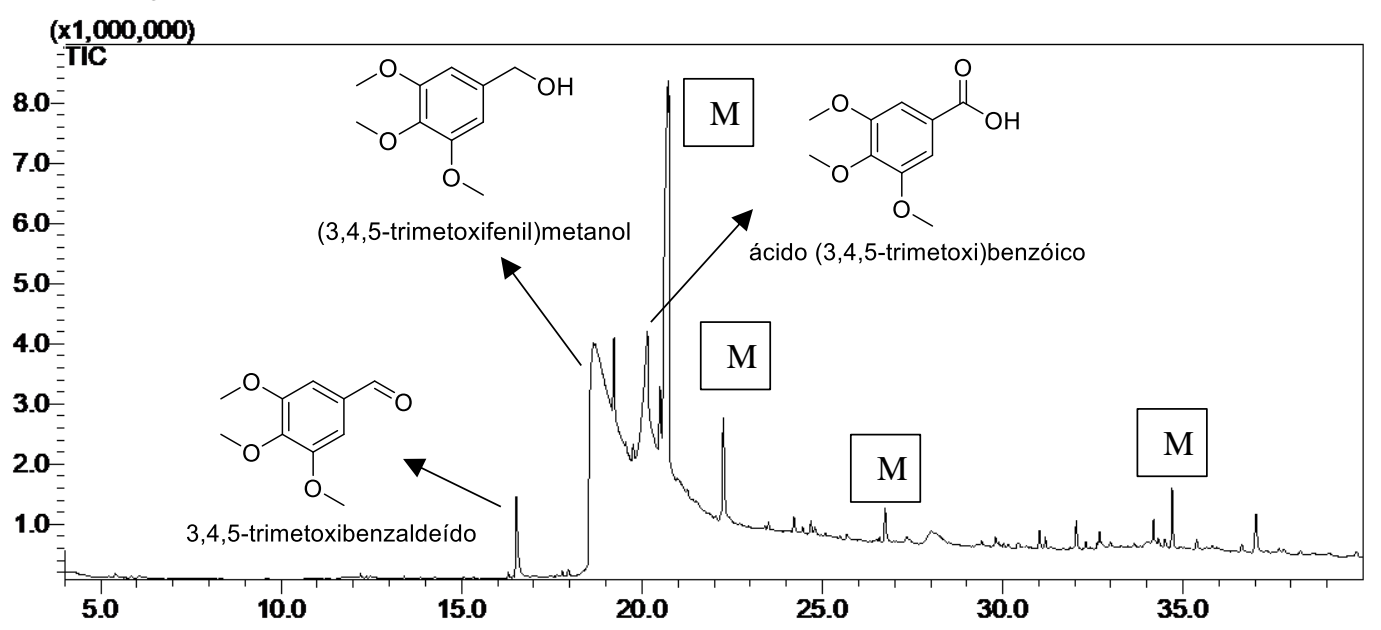

(E) Espectro de massas do (3,4,5-trimetoxifenil)metanol.

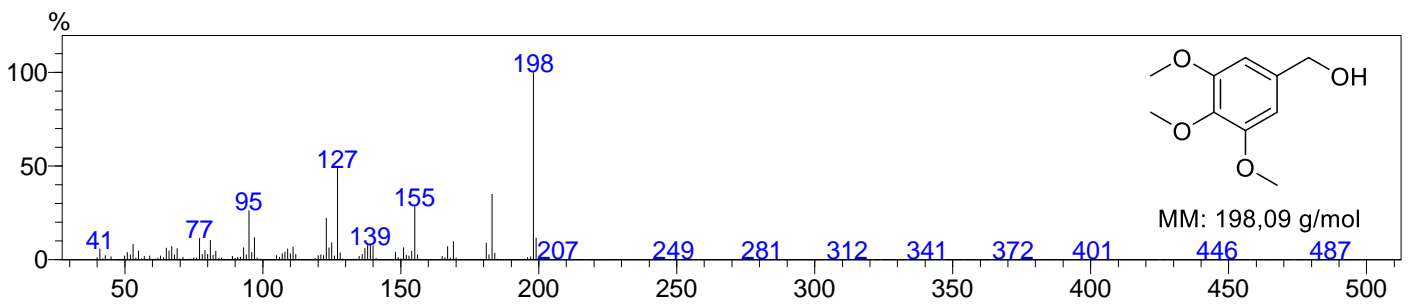

(F) Espectro de massas do 3,4,5-trimetoxibenzaldeído.

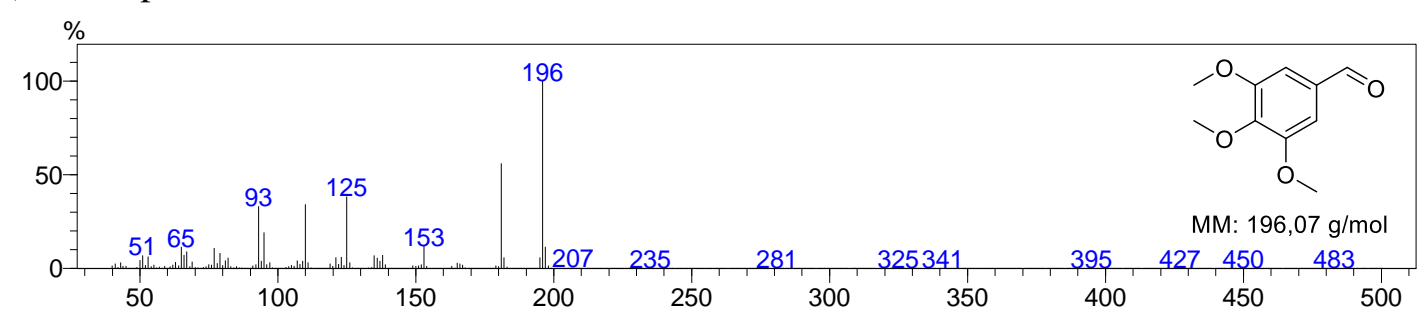

(G) Espectro de massas do ácido (3,4,5-trimetoxi)benzóico.

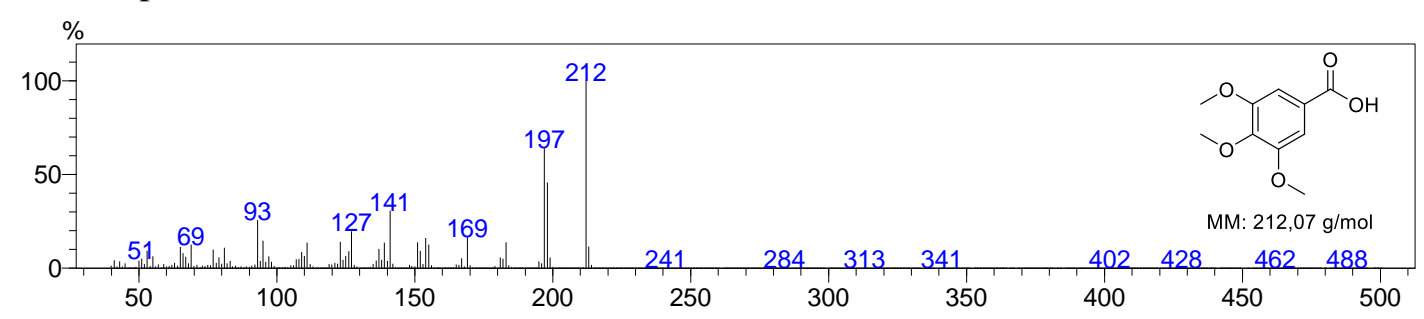


Esquema 30. Proposta de rota de biotransformação do aduto 2k pelo fungo P. citrinum CBMAI 1186.

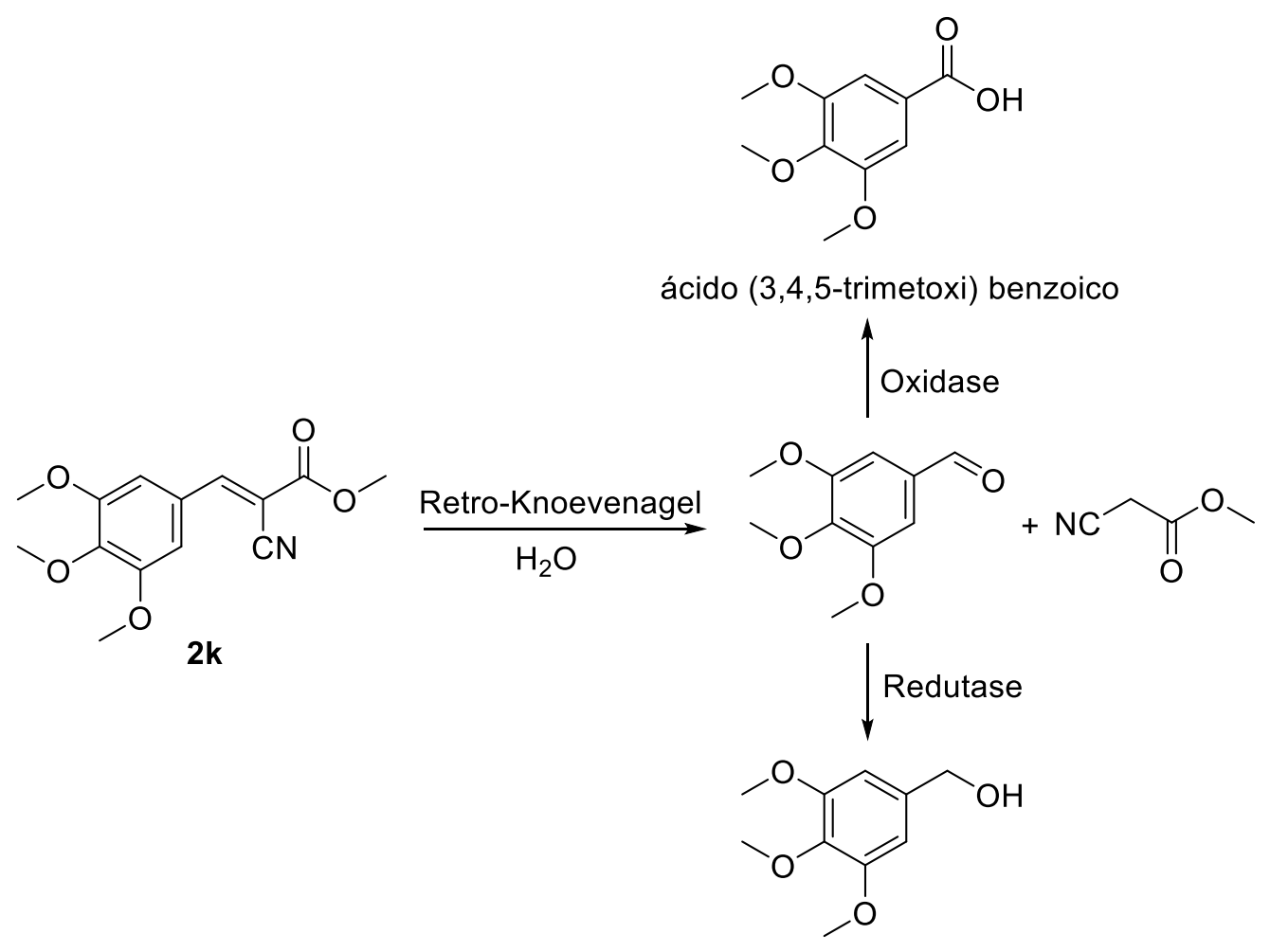

(3,4,5-trimetoxifenil)metanol

A reação controle realizada em tampão fosfato $(\mathrm{pH}=7)$ do aduto $\mathbf{2 d}$ foi realizada durante 5 dias e foi observado a formação do 4-clorobenzaldeído 1d (Figura 33). Observou-se que a reação de retro-Knoevenagel ocorreu parcialmente de maneira espontânea no meio reacional. Contudo, pode também ter ocorrido a reação por enzimas hidrolases, uma vez que na maioria dos casos observou-se a formação dos produtos de retro-Knoevenagel desde $01^{\circ}$ dia de reação. Este comportamento do aduto $\mathbf{2 d}$ pode se extrapolado também para os adutos $\mathbf{2 g}, \mathbf{2} \mathbf{j}$ e $\mathbf{2 k}$ biotransformados o que pode ter dificultado a formação dos adutos reduzidos apenas em suas ligações duplas carbono-carbono para formar o centro estereogênico. A ocorrência da reação de retro-Knoevenagel de maneira expontânea ou enzimática produziu no meio reacional o respectivo aldeído, o qual foi biotransformado nos respectivos álcoois e ácidos carboxílicos via enzimas oxidorredutases. 
Figura 33. Reação controle do aduto $\mathbf{2 d}$ realizada em 5 dias.

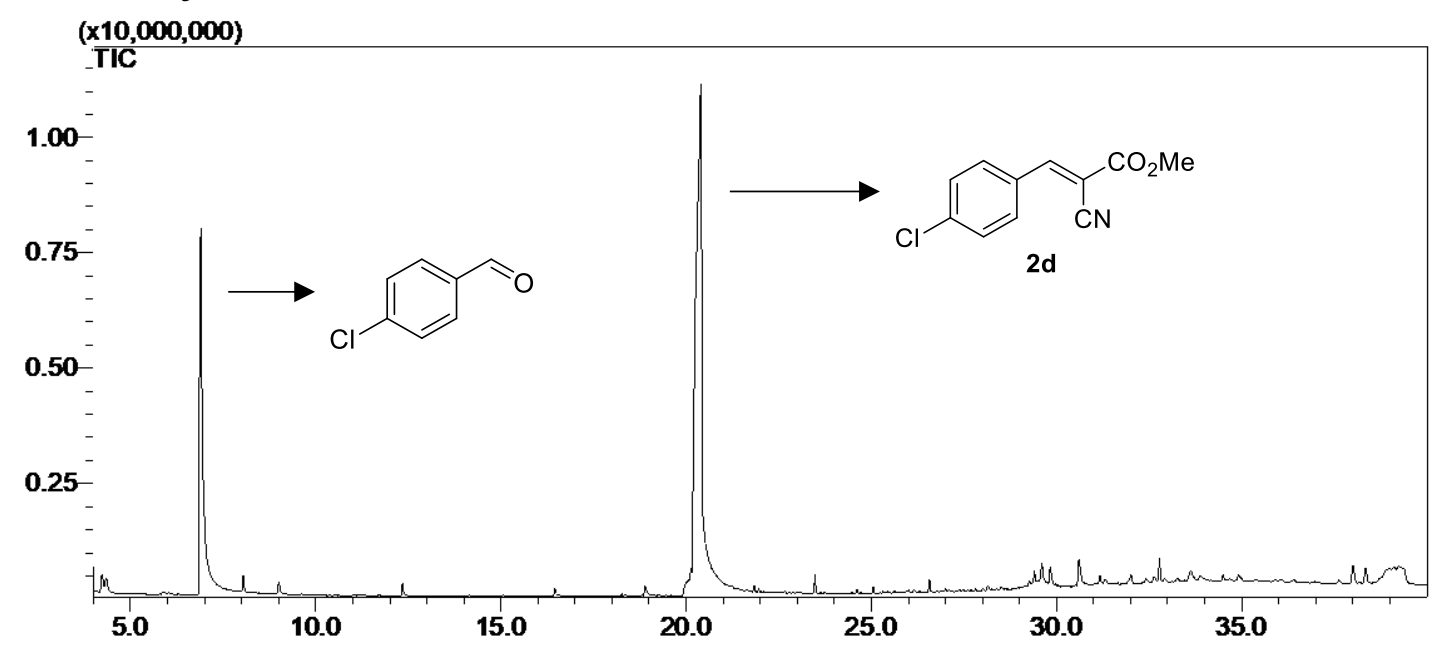

Através destes estudos pode-se concluir que na biotransformação que o grupo éster adjacente a insaturação foi um fator que dificultou a obtenção dos adutos de Knoevenagel apenas com sua ligação dupla reduzida, devido a sua alta reatividade frente a reações de hidrólise espontâneas e/ou enzimáticas.

Sendo assim, baseado nos produtos identificados, o fungo demonstrou maior capacidade de biodegradar este tipo de adutos de Knoevenagel do que efetivamente biorreduzí-los de forma seletiva a ligação dupla carbono-carbono para a criação de um centro estereogênico quaternário. 
CONCLUSÃO 


\section{CONCLUSÃO}

Através da assistência do aquecimento via irradiação MO foi possível desenvolver uma metodologia para a síntese de adutos de Knoevenagel entre aldeídos aromáticos e o cianoacetato de metila 2' através de reações com curtos períodos reacionais de 30 minutos, utilizando solventes verdes como água ou etanol e atingindo bons rendimentos na faixa de 70-90\%. Destacou-se também o fácil procedimento de purificação utilizado, o qual envolveu a lavagem da reação "bruta" com hexano a quente resultando nos adutos de Knoevenagel 2a-l puros. Foram sintetizados doze compostos dos quais, com exceção do aduto 2a, para nosso conhecimento, foram sintetizados pela primeira vez utilizando este tipo de radiação eletromagnética.

Com a finalidade de garantir uma aplicabilidade para os adutos de Knoevenagel sintetizados 2a-l, através do auxílio da irradiação MO como método de aquecimento foi desenvolvida uma metodologia para síntese de $4 H$-cromenos a partir de reações tricomponente entre aldeídos aromáticos, o cianoacetato de metila 2' e a dimedona 3'. Os 4H-cromenos 3a-h foram obtidos com rendimentos na faixa de 40-60\% em 90 minutos de reação. Destacou-se nesta metodologia o seu caráter sustentável, pois o solvente utilizado foi a água e também a facilidade na síntese de moléculas mais complexas a partir de reações one-pot e tricomponente, as quais envolvem o princípio de economia atômica, para a síntese de moléculas cuja estrutura possui potencial bioativo já comprovado. Foram sintetizados dez $4 H$-cromenos dos quais cinco, para nosso conhecimento, são inéditos na literatura.

Também foram realizadas condensações de Knoevenagel utilizando cetonas aromáticas como compostos carbonílicos e a malononitrila 5' a partir de duas metodologias distintas. A primeira metodologia utilizou $\mathrm{NaOH}$ como base em uma reação do tipo cascata. Após 24 h de reação, em chapa de aquecimento convencional foram observados baixos valores de conversão na síntese dos adutos 5a-c e 5f-i na faixa de 0-38\%. A segunda metodologia foi realizada via reação one-pot e utilizou TEA como base. Foi observado que a reação tinha uma melhor efetividade na ausência de qualquer tipo de solvente e também que a baixa reatividade das cetonas devido aos efeitos eletrônicos e estéricos foram predominantes ao aquecimento via irradiação MO que não se mostrou efetiva para acelerar a reação ou resultar em valores de conversão elevados. Contudo, foram realizadas as sínteses dos adutos $\mathbf{5 a}, \mathbf{5 b}, \mathbf{5 d}, \mathbf{5 f}$ e $\mathbf{5 i}$ em reator MO por uma de reação e valores de conversões na faixa de 41-52\% foram alcançados. Destaca-se neste estudo que foi possível alcançar valores moderados de conversão em apenas uma hora de reação utilizando compostos pouco reativos como as cetonas. Os adutos $\mathbf{5 b}, \mathbf{5 e}, \mathbf{5 f}$ 
e $5 \mathbf{i}$ foram sintetizados e isolados, para o nosso conhecimento, pela primeira vez utilizando este tipo de radiação eletromagnética.

Por fim, reações de biotransformação foram realizadas utilizando os adutos de Knoevenagel 2d, 2g, 2j e 2k com o fungo de ambiente marinho P. citrinum CBMAI 1186. Foram realizadas reações de um, dois, três e cinco dias e não foram observados produtos de bio-hidrogenação, mas sim, produtos de biotransformação oxidados, reduzidos em relação aos respectivos aldeídos formadores dos adutos. Também foram observados produtos descarboxilados nestas reações. A partir da reação de controle abiótico de $\mathbf{2 d}$, foi notado que a reação tende parcialmente a realizar a reação de retro-Knoevenagel de maneira espontânea. Sendo assim, a partir dos produtos identificados, pode-se concluir que o fungo possui enzimas oxidases e redutases em suas células e que elas atuaram preferencialmente nos produtos de retro-Knoevenagel, os aldeídos, que também podem ter sido obtidos por uma via enzimática. Portanto, foi avaliado neste estudo que o fungo P. citrinum CBMAI 1186 possui em suas células além de enzimas ene- redutases, enzimas oxidases, redutases e descarboxilases, as quais foram predominantemente ativas frente aos substratos utilizados, os adutos de Knoevenagel.

Sendo assim, a partir de metodologias ambientalmente sustentáveis, foram obtidos 31 compostos, sendo 5 inéditos na literatura. e a grande maioria dos restantes foram sintetizados pela primeira vez sob efeito da irradiação micro-ondas. Este trabalho proporcionou um desenvolvimento sintético e enzimático frente às reações de Knoevenagel e seus derivados $4 \mathrm{H}$ cromenos. 
REFERÊNCIAS 


\section{REFERÊNCIAS}

[1]LARHED, M.; HALLBERD, A. Microwave-assisted high-speed chemistry: A new technique in drug discovery. Drug Discovery Today, v. 6, n. 8, p. 406-416, 2001.

[2]DE SOUZA, R. O. M. A.; MIRANDA, L. S. M. Irradiação de micro-ondas aplicada à síntese orgânica: Uma história de sucesso no Brasil, Química Nova, v. 34, n. 3, p. 497-506, 2011.

[3]JONES, G. Knoevenagel condensation. In: ORGANIC reactions. New York: John Wiley, 1964 v. 15 p. $204-273$.

[4]ZANIN, L. L.; JIMENEZ, D. E. Q.; PORTO, A. L. M.; FONSECA, L. P. Knoevenagel condensation reactions of cyano malononitrile-derivatives under microwave radiation. Current Organic Chemistry, v. 22, p. 519-532, 2018.

[5]SMITH, M. B.; MARCH, J. March's advanced organic chemistry: reactions, mechanisms and structure. New York: John Wiley, 2001. 2374 p.

[6]KUMAR, D.; REDDY, V. B.; SHARAD, S.; DUBE, U.; KAPUR, S. A facile one-pot green synthesis and antibacterial activity of 2-amino- $4 \mathrm{H}$-pyrans and 2-amino-5-oxo-5,6,7,8-tetrahydro-4Hchromenes. European Journal of Medicinal Chemistry, v. 44, n. 9, p. 3805-3809, 2009.

[7]BEHBEHANI, H.; IBRAHIM, H. M.; MAKHSEED, S.; ELNAGDI, M. H.; MAHMOUD, H. 2Aminothiophenes as building blocks in heterocyclic synthesis: Synthesis and antimicrobial evaluation of a new class of pyrido[1,2-a]thieno[3,2-e] pyrimidine, quinoline and pyridin-2-one derivatives.

European Journal of Medicinal Chemistry, v. 52, p. 51-65, 2012.

[8]AL-MOUSAWI, S. M.; MOUSTAFA, M. S.; AL-SALEH, E. Antimicrobial activities of some novel thiazoles. Russian Journal of Bioorganic Chemistry, v. 42, n. 4, p. 428-433, 2016.

[9]KASHTOH, H.; MUHAMMAD, M. T.; KHAN, J. J. A.; RASHEED, S.; KHAN, A.; PERVEEN, S. JAVAID, K.; WAHAB, A. T.; KHAN, K. M.; CHOUDHARY, M. I. Dihydropyrano [2,3-c] pyrazole: Novel in vitro inhibitors of yeast $\alpha$-glucosidase. Bioorganic Chemistry, v. 65, p. 61-72, 2016.

[10]MISHRA, S.; HAJRA, A. Copper-catalyzed oxidative annulation between 2-aminopyridine and arylidenemalononitrile leading to 4-oxo-pyrido[1,2-a]pyrimidine-3-carbonitrile. Tetrahedron Letters, v. 56, n. 41, p. 5651-5655, 2015.

[11]RAMESH, R.; LALITHA, A. Synthesis of pyran annulated heterocyclic scaffolds: A highly convenient protocol using dimethylamine. Research on Chemical Intermediates, v. 41, n. 10, p. 8009-8017, 2015. 
[12]KASIBHATLA, S.; GOURDEAU, H.; MEEROVITCH, K.; DREWE, J.; REDDY, S.; QIU, L.; ZHANG, H.; BERGERON, F.; BOUFFARD, D.; YANG, Q.; HERICH, J.; LAMOTHE, S.; CAI, S. X.; TSENG, B. Discovery and mechanism of action of a novel series of apoptosis inducers with potential vascular targeting activity. Molecular Cancer Therapeutics, v. 3, n. 11, p. 1365-74, 2004.

[13]GIRGIS, A. S.; ISMAIL, N. S. M.; FARAG, H. Facile synthesis, vasorelaxant properties and molecular modeling studies of 2-amino-8a-methoxy-4H-pyrano[3,2-c]pyridine-3-carbonitriles.

European Journal of Medicinal Chemistry, v. 46, n. 6, p. 2397-2407, 2011.

[14]CASTRO, F. Alternativa para fármaco mais vendido. São Paulo, 2011. Disponível em: <http://agencia.fapesp.br/alternativa_para_farmaco_mais_vendido/13313/.> Acesso em: 10 abr. 2018.

[15]LI, J. J.; JOHNSON, D. S.; SLISKOVIC, D. R.; ROTH, B. D. Contemporary drug synthesis. New York: Wiley-Interscience, 2004. 416 p.

[16]WEI, Y. S.; ZHANG, S.; YIN, S.; ZHAO, C.; LUO, S.; AU, C. Solid superbase derived from lanthanum-magnesium composite oxide and its catalytic performance in the condensation under solvent-free condition. Catalysis Communication, v. 12, n. 14, p. 1333-1338, 2011.

[17]RAO, P. S.; VENKATARATNAM, R. V. Zinc chloride as a new catalyst for Knoevenagel condensation. Tetrahedron Letters, v. 32, n. 41, p. 5821-5822, 1991.

[18]SCHNEIDER, E. M.; ZELTNER, M.; KRÄNZLIN, N.; GRASS, R. N.; STARK, W. J. Base-free Knoevenagel condensation catalyzed by copper metal surfaces. Chemical Communications, v. 51, n. 53, p. 10695-10698, 2015.

[19]LI, G.; XIAO, J.; ZHANG, W. Knoevenagel condensation catalyzed by a tertiary-amine functionalized polyacrylonitrile fiber. Green Chemistry, v. 13, n. 7, p. 1828, 2011.

[20]AMMAR, H. B.; CHTOUROU, M.; FRIKHA, M. H.; TRABELSI, M. Green condensation reaction of aromatic aldehydes with active methylene compounds catalyzed by anion-exchange resin under ultrasound irradiation. Ultrasonics Sonochemistry, v. 22, p. 559-564, 2015.

[21]OHASHI, M.; KAPOOR, M. P.; INAGAKI, S. Chemical modification of crystal-like mesoporous phenylene-silica with amino group. Chemical Communications, n. 7, p. 841-843, 2008.

[22]TROTZKI, R.; HOFFMANN, M. M.; ONDRUSCHKA, B. The Knoevenagel condensation at room temperature. Green Chemistry, v. 10, n. 8, p. 873-878, 2008.

[23]KRISHNAN, G. R.; THOMAS, J.; SREEKUMAR, K. Organocatalysis by poly(amidoamine) dendrimers; Knoevenagel and Mannich reactions catalyzed in water. Arkivoc, n. 10, p. 106-120, 2009. 
[24]BASSYOUNI, F. A.; ABU-BAKR, S. M.; REHIM, M. A. Evolution of microwave irradiation and its application in green chemistry and biosciences. Research on Chemical Intermediates. v. 38, n. 2, p. 283-322, 2012.

[25]GEDYE, R.; SMITH, F.; WESTAWAY, K.; ALI, H.; BALDISERA, L.; LABERGE, L.; ROUSELL, J. The use of microwave ovens for rapid organic synthesis. Tetrahedron Letters, v. 27, n. 3, p. 279-282, 1986.

[26]GIGUERE, R. J.; BRAY, T. L.; DUNCAN, S. M.; MAJETICH, G. Application of commercial microwave ovens to organic synthesis. Tetrahedron Letters, v. 27, n. 41, p. 4945-4948, 1986.

[27]YADAV, J. S.; REDDY, B. V. S.; BASAK, A. K.; VISALI, B.; NARSAIAH, A. V.; NAGAIAH, K. Phosphane-catalyzed Knoevenagel condensation: a facile synthesis of $\alpha$-cyanoacrylates and $\alpha$ cyanoacrylonitriles. European Journal of Organic Chemistry, v. 2004, n. 3, p. 546-551, 2004.

[28]RAI, S. K.; KHANAM, S.; KHANNA, R. S.; TEWARI, A. K. Cascade synthesis of 2-pyridones using acrylamides and ketones. RSC Advances, v. 4, n. 83, p. 44141-44145, 2014.

[29]JIMENEZ, D. E. Q.; FERREIRA, I. M.; BIROLLI, W. G.; FONSECA, L. P.; PORTO, A. L. M. Synthesis and biocatalytic ene-reduction of Knoevenagel condensation compounds by the marinederived fungus Penicillium citrinum CBMAI 1186. Tetrahedron, v. 72, n. 46, p. 7317-7322, 2016.

[30]SANSEVERINO, A. M. Microondas em síntese orgânica. Química Nova, v. 25, n. 4, p. 660-667, 2002.

[31]GUPTA, P.; KOUR, M.; PAUL, S.; CLARK, J. H. Ionic liquid coated sulfonated carbon/silica composites: novel heterogeneous catalysts for organic syntheses in water. RSC Advances, v. 4, p. 7461-7470, 2014.

[32]KRISHNAN, G. R.; SREEKUMAR, K. First example of organocatalysis by polystyrenesupported PAMAM dendrimers: Highly efficient and reusable catalyst for knoevenagel condensations. European Journal of Organic Chemistry, v. 2008, p. 4763-4768, 2008.

[33]ROBICHAUD, B. A.; LIU, K. G. Titanium isopropoxide/pyridine mediated Knoevenagel reactions. Tetrahedron Letters, v. 52, n. 51, p. 6935-6938, 2011.

[34]FAVRE, H. A.; POWELL, W. H. Nomenclature of organic chemistry: IUPAC

recommendations and preferred names 2013. Cambridge: The Royal Society of Chemistry, 2014. 1568 p.

[35]PRATAP, R.; RAM, V. J. Natural and synthetic chromenes, fused chromenes, and versatility of dihydrobenzo[h]chromenes in organic synthesis. Chemical Reviews, v. 114, n. 20, p. 10476-10526, 2014. 
[36]ITOKAWA, H.; IBRAGEIM, Z. Z.; QIAO, Y. F.; TAKEYA, K. Anthraquinones, naphthohydroquinones and naphthohydroquinone dimers from Rubia cordifolia and their cytotoxic activity. Chemical and Pharmaceutical Bulletin, v. 41, n. 10, p. 1869-1872, 1993.

[37]BALDOQUI, D. C.; KATO, M. J.; CAVALHEIRO, A. J.; BOLZANI, V. D. S.; YOUNG, M. C. M.; FURLAN, M. A chromene and prenylated benzoic acid from Piper aduncum. Phytochemistry, v. 51, n. 7, p. 899-902, 1999.

[38]LAGO, J. H. G.; RAMOS, C. S.; CASANOVA, D. C. C.; MORANDIM, A. A.; BERGAMO, D. C. B.; CAVALHEIRO, A. J.; BOLZANI, V. D. S.; FURLAN, M.; GUIMARÃES, E. F.; YOUNG, M. C. M.; KATO, M. J. Benzoic acid derivatives from Piper species and their fungitoxic activity against Cladosporium cladosporioides and C. sphaerospermum. Journal of Natural Products, v. 67, n. 11, p. 1783-1788, 2004.

[39]PARRA, J. E.; PATIÑO, O. J.; PRIETO, J. A.; DELGADO, W. A.; CUCA, L. E. A new benzoic acid derivative isolated from Piper $c f$. cumanense Kunth (Piperaceae). Phytochemistry Letters, v. 6, n. 4, p. 590-592, 2013.

[40]TANAKA, H.; ATSUMI, I.; SHIROTA, O.; SEKITA, S.; SAKAI, E.; SATO, M.; MURATA, J.; MURATA, H.; DARNAEDI, D.; CHEN, I. S. Three new constituents from the roots of Erythrina variegata and their antibacterial activity against methicillin-resistant Staphylococcus aureus.

Chemistry and Biodiversity, v. 8, n. 3, p. 476-482, 2011.

[41]APPENDINO, G.; GIBBONS, S.; GIANA, A.; PAGANI, A.; GRASSI, G.; STAVRI, M.; SMITH, E.; RAHMAN, M. M. Antibacterial cannabinoids from Cannabis sativa: A structure-activity study. Journal of Natural Products, v. 71, n. 8, p. 1427-1430, 2008.

[42]IL'INA, I.; MIKHALCHENKO, O.; PAVLOVA, A.; KORCHAGINA, D.; TOLSTIKOVA, T.; VOLCHO, K.; SALAKHUTDINOV, N.; POKUSHALOV, E. Highly potent analgesic activity of monoterpene-derived $(2 S, 4 a R, 8 R, 8 a R)$-2-aryl-4,7-dimethyl-3,4,4a, 5,8,8a-hexahydro-2H-chromene4,8-diols. Medicinal Chemistry Research, v. 23, n. 12, p. 5063-5073, 2014.

[43]JANG, K. H.; LEE, B. H.; CHOI, B. W.; LEE, W. S.; SHIN, J. Chromenes from the brown alga Sargassum s iliquastrum. Journal of Natural Products, v. 68, n. 5, p. 716-723, 2005.

[44]WANG, Y.; XU, K.; LIN, L.; PAN, Y.; ZHENG, X. Geranyl flavonoids from the leaves of Artocarpus altilis. Phytochemistry, v. 68, n. 9, p. 1300-1306, 2007.

[45]LEE, Y. R.; KIM, Y. M. A novel method for the synthesis of substituted benzochromenes by ethylenediamine diacetate-catalyzed cyclizations of naphthalenols to $\alpha, \beta$-unsaturated aldehydes. Concise synthesis of the natural products. Helvetica Chimica Acta, v. 90, p. 2401-2413, 2007. 
[46]BODAGHIFARD, M. A.; SOLIMANNEJAD, M.; ASADBEGI, S.; DOLATABADIFARAHANI, S. Mild and green synthesis of tetrahydrobenzopyran, pyranopyrimidinone and polyhydroquinoline derivatives and DFT study on product structures. Research on Chemical Intermediates, v. 42, n. 2, p. 1165-1179, 2016.

[47]KHARBANGAR, I.; ROHMAN, R.; MECADON, H.; MYRBOH, B. KF- $\mathrm{Al}_{2} \mathrm{O}_{3}$ as an efficient and recyclable basic catalyst for the synthesis of $4 H$-pyran-3-carboxylates and 5-acetyl- $4 H$-pyrans. International Journal of Organic Chemistry, v. 2, p. 282-286, 2012.

[48]NASSERI, M. A.; SADEGHZADEH, S. M. A highly active $\mathrm{FeNi}_{3}-\mathrm{SiO}_{2}$ magnetic nanoparticles catalyst for the preparation of $4 H$-benzo[b]pyrans and spirooxindoles under mild conditions. Journal of the Iranian Chemical Society, v. 10, n. 5, p. 1047-1056, 2013.

[49]KHURANA, J. M.; NAND, B.; SALUJA, P. 1,8-Diazabicyclo[5.4.0]undec-7-ene: A highly efficient catalyst for one-pot synthesis of substituted tetrahydro- $4 H$-chromenes, tetrahydro[b] pyrans, pyrano[d]pyrimidines, and $4 H$-pyrans in aqueous medium. Journal of Heterocyclic Chemistry, v. 51, p. 618-624, 2013.

[50]THANGAMANI, A. Grindstone chemistry : an efficient and green synthesis of 2-amino- $4 \mathrm{H}$ benzo[b] pyrans. Journal of Applied and Advanced Research, v. 2, n. 2, p. 78-85, 2017.

[51]BALALAIE, S.; BARARJANIAN, M.; SHEIKH-AHMADI, M.; HEKMAT, S.; SALEHI, P. Diammonium hydrogen phosphate: An efficient and versatile catalyst for the one-pot synthesis of tetrahydrobenzo[b]pyran derivatives in aqueous media. Synthetic Communications, v. 37, n. 7, p. 1097-1108, 2007.

[52]HAGIWARA, H.; ISOBE, K.; NUMAMAE, A.; HOSHI, T.; SUZUKI, T. Microwave-promoted sequential three-component synthesis of tetrahydrobenzo[b]pyran in water catalyzed by heterogeneous amine grafted on silica. Heterocycles, v. 68, n. 5, p. 889-895, 2006.

[53]DEVI, I.; BHUYAN, P. J. Sodium bromide catalysed one-pot synthesis of tetrahydrobenzo[b]pyrans via a three-component cyclocondensation under microwave irradiation and solvent free conditions. Tetrahedron Letters, v. 45, n. 47, p. 8625-8627, 2004.

[54]SAINI, A.; S. KUMAR, S.; SANDHU, J. S. A new LiBr-catalyzed , facile and efficient method for the synthesis of 14-alkyl or aryl-14H-dibenzo [a,j] xanthenes and tetrahydrobenzo[b] pyrans under solvent-free conventional and microwave heating. Synlett, n. 12, p. 1928-1932, 2006.

[55]TU, S. J.; GAO, Y.; GUO, C.; SHI, D.; LU, Z. A convenient synthesis of 2-amino-5,6,7,8tetrahydro-5-oxo-4-aryl-7,7-dimethyl-4H-benzo-[b]-pyran-3 -carbonitrile under microwave irradiation. Synthetic Communications, v. 32, n. 14, p. 2137-2141, 2002.

[56]ABD EL-RAHMAN, N. M.; EL-KATEB, A. A.; MADY, M. F. Simplified approach to the uncatalyzed Knoevenagel condensation and Michael addition reactions in water using microwave irradiation. Synthetic Communications, v. 37, n. 22, p. 3961-3970, 2007. 
[57]FABER, K. Biotransformations in organic chemistry. 5th ed. Berlin: Springer, 2004. 454 p.

[58]BIROLLI, W. G.; VACONDIO, B.; ALVARENGA, N.; SELEGHIM, M. H. R.; PORTO, A. L. M. Enantioselective biodegradation of the pyrethroid ( \pm )-lambda-cyhalothrin by marine-derived fungi. Chemosphere, v. 197, p. 651-660, 2018.

[59]LIMA, R. N.; PORTO, A. L. M. Biocatalytic aminolysis of ethyl (S)-mandelate by lipase from Candida antarctica. Catalysis Communications, v. 100, p. 157-163, 2017.

[60]MÜLLER, M. Chemical diversity through biotransformations. Current Opinion in Biotechnology, v. 15, n. 6, p. 591-598, 2004.

[61]RICCI, L. C.; COMASSETO, J. V.; ANDRADE, L. H.; CAPELARI, M.; CASS, Q. B.; PORTO, A. L. M. Biotransformations of aryl alkyl sulfides by whole cells of white-rot Basidiomycetes. Enzyme and Microbial Technology, v. 36, n. 7, p. 937-946, 2005.

[62]KEPPLER, A. F.; PORTO, A. L. M.; SCHOENLEIN-CRUSIUS, I. H.; COMASSETO, J. V.; ANDRADE, L. H. Enzymatic evaluation of different Aspergillus strains by biotransformation of cyclic ketones. Enzyme and Microbial Technology, v. 36, n. 7, p. 967-975, 2005.

[63]CHOI, J. M.; HAN, S. S.; KIM, H. S. Industrial applications of enzyme biocatalysis: Current status and future aspects. Biotechnology Advances, v. 33, n. 7, p. 1443-1454, 2015.

[64]PADMAKUMAR R.; ORIEL, P. Bioconversion of acrylonitrile to acrylamide using a thermostable nitrile hydratase. Applied Biochemistry and Biotechnology, v. 79, n. 1-3, p. 671-680, 1999.

[65]KHAN, F. A.; VALLAT, A.; SÜSS-FINK, G. Highly selective $\mathrm{C}=\mathrm{C}$ bond hydrogenation in $\alpha, \beta-$ unsaturated ketones catalyzed by hectorite-supported ruthenium nanoparticles. Journal of Molecular Catalysis A: Chemical, v. 355, p. 168-173, 2012.

[66]GALLETTI, A. M. R.; BERTOLDO, C. A. M.; PICCINELLI, F. Chitosan as biosupport for the MW-assisted synthesis of palladium catalysts and their use in the hydrogenation of ethyl cinnamate. Applied Catalysis A: General, v. 468, p. 95-101, 2013.

[67]LIU, Q.; LI, J.; SHEN, X. X.; XING, R. G.; YANG, J.; LIU, Z.; ZHOU, B. Hydrogenation of olefins using Hantzsch ester catalyzed by palladium on carbon. Tetrahedron Letters, v. 50, p. 10261028, 2009.

[68]NAHRA, F.; MACÉ, Y.; LAMBIN, D.; RIANT, O. Copper/palladium-catalyzed 1,4 reduction and asymmetric allylic alkylation of $\alpha, \beta$-unsaturated ketones: Enantioselective dual catalysis. Angewandte Chemie International Edition, v. 52, n. 11, p. 3208-3212, 2013. 
[69]SHIOMI, T.; ADACHI, T.; TORIBATAKE, K.; ZHOU, L.; NISHIYAMA, H. Asymmetric $\beta$ boration of $\alpha, \beta$-unsaturated carbonyl compounds promoted by chiral rhodium-bisoxazolinylphenyl catalysts. Chemical Communications, n. 40, p. 5987, 2009.

[70]SILVA, V. D.; CARLETTO, J. S.; CARASEK, E.; STAMBUK, B. U.; DA GRAÇA NASCIMENTO, M. Asymmetric reduction of (4S)-(+)-carvone catalyzed by baker's yeast: A green method for monitoring the conversion based on liquid-liquid-liquid microextraction with polypropylene hollow fiber membranes. Process Biochemistry, v. 48, n. 8, p. 1159-1165, 2013.

[71]SCHAEFER, C. A.; SILVA, V. D.; STAMBUKB, B. U.; DA G. NASCIMENTO, M. Use of saccharomyces cerevisiae yeasts in the chemoselective bioreduction of $(1 E, 4 E)$-1,5-bis(4methoxyphenyl)-1,4-pentadien-3-one in biphasic system. Journal of Brazilian Chemical Society, v. 24, n. 7, p. 1116-1122, 2013.

[72]BIZERRA, A. M. C.; GONZALO, G.; LAVANDERA, I.; GOTOR-FERNÁNDEZ, V.; MATTOS, M. C.; OLIVEIRA, M. C. F.; LEMOS T. L. G.; GOTOR, V. Reduction processes biocatalyzed by Vigna unguiculata. Tetrahedron Asymmetry, v. 21, p. 566-570, 2010.

[73]FERREIRA, I. M.; MEIRA, E. B.; ROSSET, I. G.; PORTO, A. L. M. Chemoselective biohydrogenation of $\alpha, \beta$ - and $\alpha, \beta, \gamma, \delta$-unsaturated ketones by the marine-derived fungus Penicillium citrinum CBMAI 1186 in a biphasic system. Journal of Molecular Catalysis B: Enzymatic, v. 115, p. 59-65, 2015.

[74]DE RESENDE FILHO, J. B. M.; PIRES, G. P.; DE OLIVEIRA FERREIRA, J. M. G.; TEOTONIO, E. E. S.; VALE, J. A. .Knoevenagel condensation of aldehydes and ketones with malononitrile catalyzed by amine compounds-tethered $\mathrm{Fe}_{3} \mathrm{O}_{4} @ \mathrm{SiO}_{2}$ nanoparticles. Catalysis Letters, v. 147, n. 1, p. 167-180, 2017.

[75]DEY, K. S.; DE SOUSA, A. N.; JANIAK, C. Microporous polyurethane material for size selective heterogeneous catalysis of the Knoevenagel reaction. Chemical Communications, v. 52, n. 50, p. 7834-7837, 2016.

[76]CAMERINO, M. A.; LIU, M.; MORIYA, S.; KITAHASHI, T.; MAHGOUB, A.; MOUNTFORD, S. J.; CHALMERS, D. K.; SOGA, T.; PARHAR, I. S.; THOMPSON, P. E. Beta amino acid-modified and fluorescently labelled kisspeptin analogues with potent KISS1R activity. Journal of Peptide Science, v. 22., p. 406-414, 2016.

[77]BENZEKRI, Z.; EL MEJDOUBI, K.; BOUKHRIS, S.; SALLEK, B.; LAKHRISSI, B.; SOUIZI, A. Dicalcium phosphate dehydrate DCPD as a highly efficient and reusable catalyst for Knoevenagel condensation. Synthetic Communications, v. 46, p. 442-451, 2016.

[78]FORD, L.; YLIJOKI, K. E.O.; GARCIA, M. T.; SINGER, R. D.; SCAMMELLS, P. J. Nitrogencontaining ionic liquids: Biodegradation studies and utility in base-mediated reactions. Australian Journal of Chemistry, v. 68, p. 849-857, 2015. 
[79]ZHAO, X.-L.; YANG, K.-F.; LIU, X.-G.; YE, C.-L.; XU, L.-W.; LAI, G.-Q. Polyguanidine as a highly efficient and reusable catalyst for Knoevenagel condensation reactions in water. Australian Journal of Chemistry, v. 66, p. 500-504, 2013.

[80]AYOUBI, S. A.;TEXIER-BOULLET, F.; HAMELIN, J. Minute synthesis of electrphilic alenes under microwave irradiation. Synthesis, p. 258-260, 1993.

[81]MELLO, P. A.; BARIN, J. S.; GUARNIERI, R. A. Microwave heating. In: FLORES, E. M. M. Microwave-assisted sample preparation for trace element determination. Amsterdan: Elsevier, 2014. cap. 2, p. 59-75.

[82]RONG, L.; LI, X.; WANG, H.; SHI, DAQING; T., S.; ZHUANG, Q. Efficient synthesis of tetrahydrobenzo[b]pyrans under solvent-free conditions at room temperature. Synthetic

Communications, v. 36, p. 2363-2369, 2006.

[83]WANG, X. S.; SHI, Q.; TU, S. J.; YAO, C. S. A convenient synthesis of 5-oxo-5,6,7,8-tetrahydro$4 H$-benzo-[b]-pyran derivatives catalyzed by KF-alumina. Synthetic Communications, v. 33, p. 119126, 2003.

[84]BANDGAR, S. B.; BANDGAR, B. P.; KORBAD, B. L.; TOTRE, J. V.; PATIL, S. Uncatalyzed reactions in aqueous media: Three-component, one-pot, clean synthesis of tetrahydrobenzo[b]pyran derivatives. Australian Journal of Chemistry, v. 60, p. 305-307, 2007.

[85]LI, J.-T.; XU, W.-Z.; YANG, L.-C.; LI, T.-S. One-Pot synthesis of 2-amino-4-aryl-3-carbalkoxy7,7-dimethyl-5,6,7,8-tetrahydrobenzo[b]pyran derivatives catalyzed by $\mathrm{KF} / \mathrm{Basic} \mathrm{Al}_{2} \mathrm{O}_{3}$ under ultrasound irradiation. Synthetic Communications, v. 34, p. 4565-4571, 2004.

[86]CLAYDEN, J.; GREEVES, N.; WARREN, S.; WOTHERS, P. Organic chemistry. Oxford: Oxford University, 2000. 1536p.

[87]KAWABATA, N.; CHEN, C. K.; YAMASHITA, S. Hidrogen transfer polymerization of malononitrile. Bulletin of the chemical society of Japan, v. 45, p. 1491-1493, 1972.

[88]TOOGOOD, H. S.; FRYSZKOWSKA, A.; HARE, V.; FISHER, K.; ROUJEINIKOVA, A.; LEYS, D.; GARDINER, J. M.; STEPHENS, G. M.; SCRUTTON, N. S. Structure-based insight into the asymmetric bioreduction of the $\mathrm{C}=\mathrm{C}$ double bond of $\alpha, \beta$-unsaturated nitroalkenes by pentaerythritol tetranitrate reductase. Advanced Synthesis and Catalysis, v. 350, p. 2789-2803, 2008 . 
APÊNDICE 


\section{APÊNDICE}

7.1. Espectros dos adutos 2a-l sintetizados entre aldeídos aromáticos e o cianoacetato de metila 2',

Espectro de RMN de ${ }^{1} \mathrm{H}\left(400 \mathrm{MHz}, \mathrm{CDCl}_{3}\right)$ do aduto 2a.

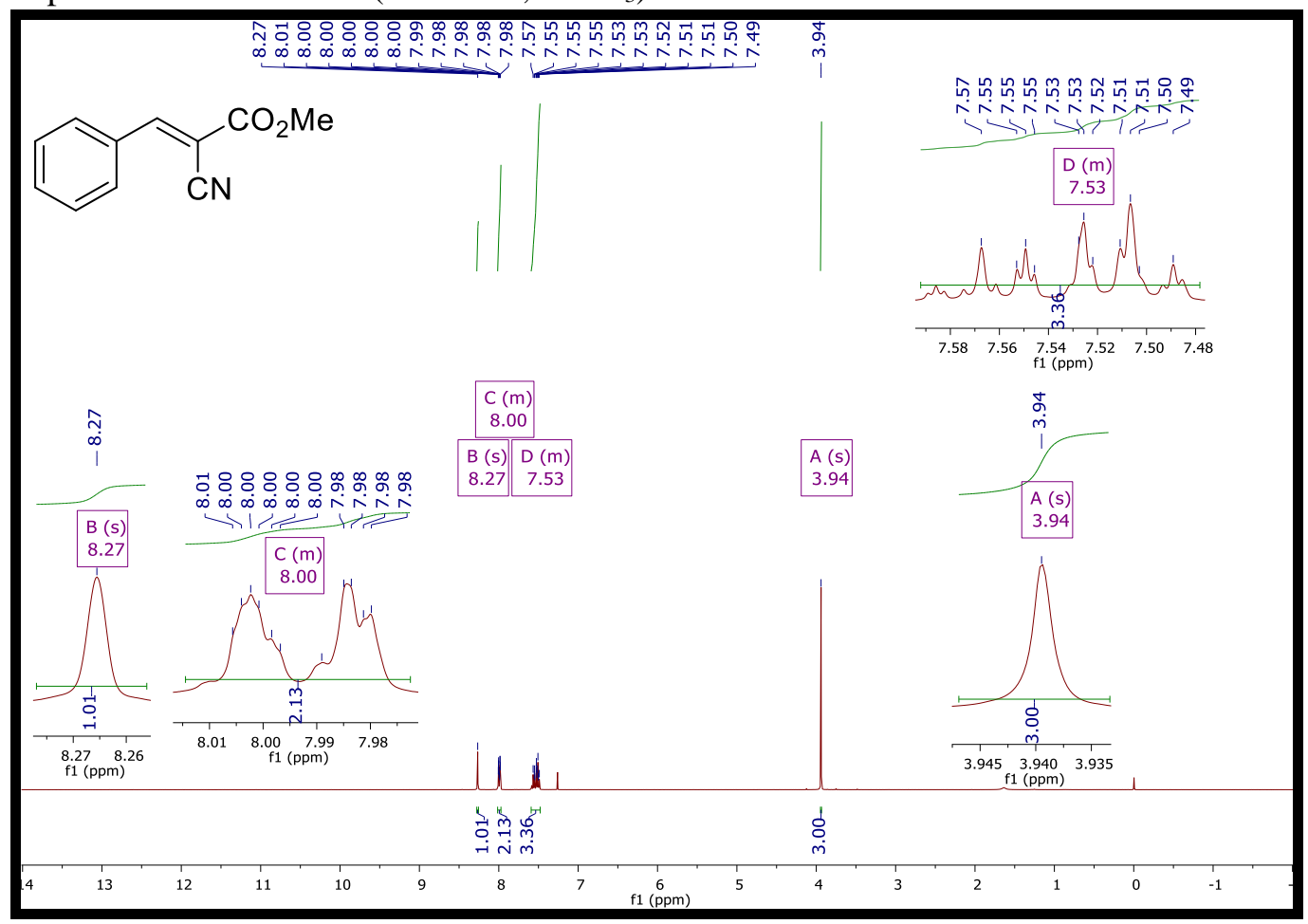

Espectro de RMN de ${ }^{13} \mathrm{C}\left(100 \mathrm{MHz}, \mathrm{CDCl}_{3}\right)$ do aduto 2a.

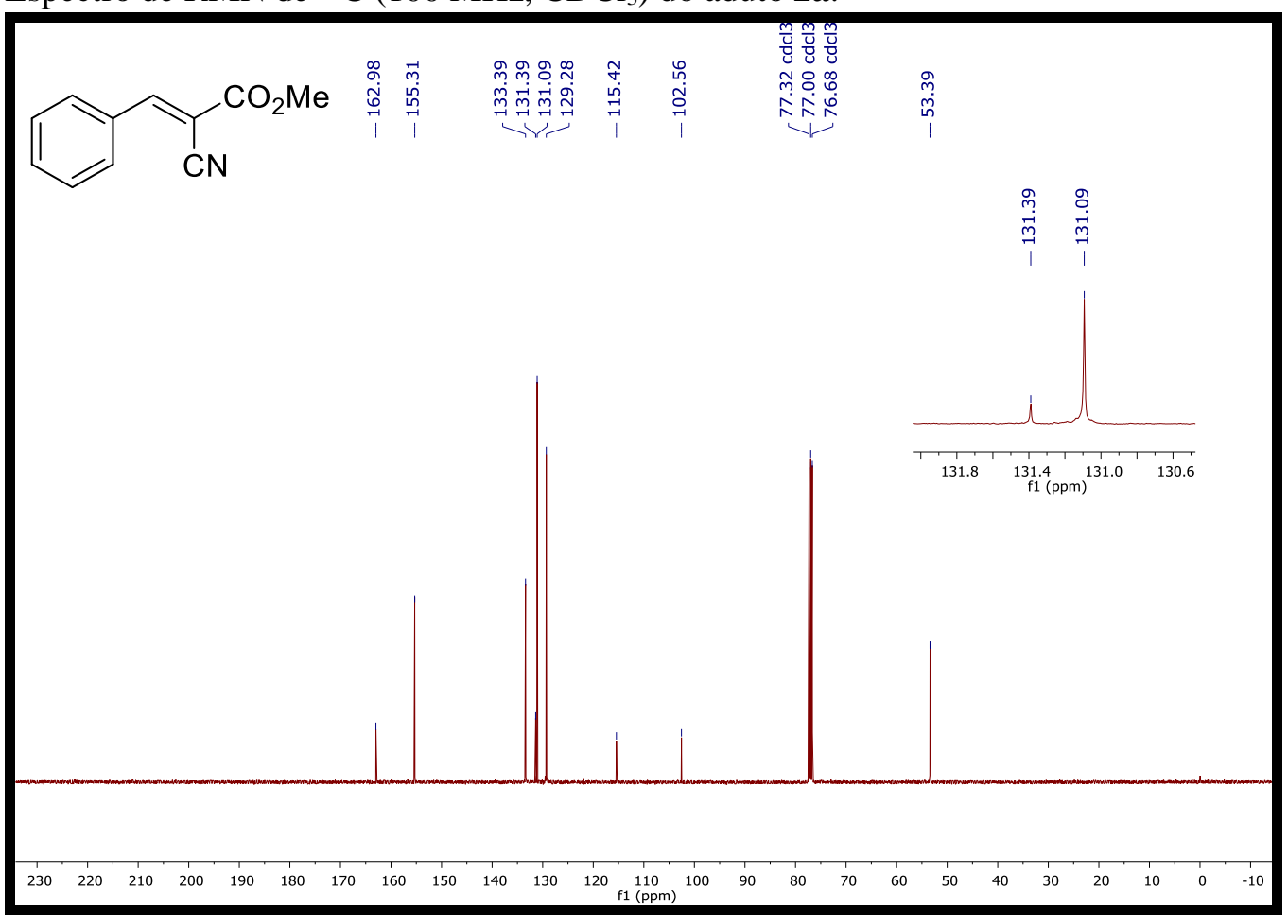


Espectro de absorção no infravermelho do aduto 2a

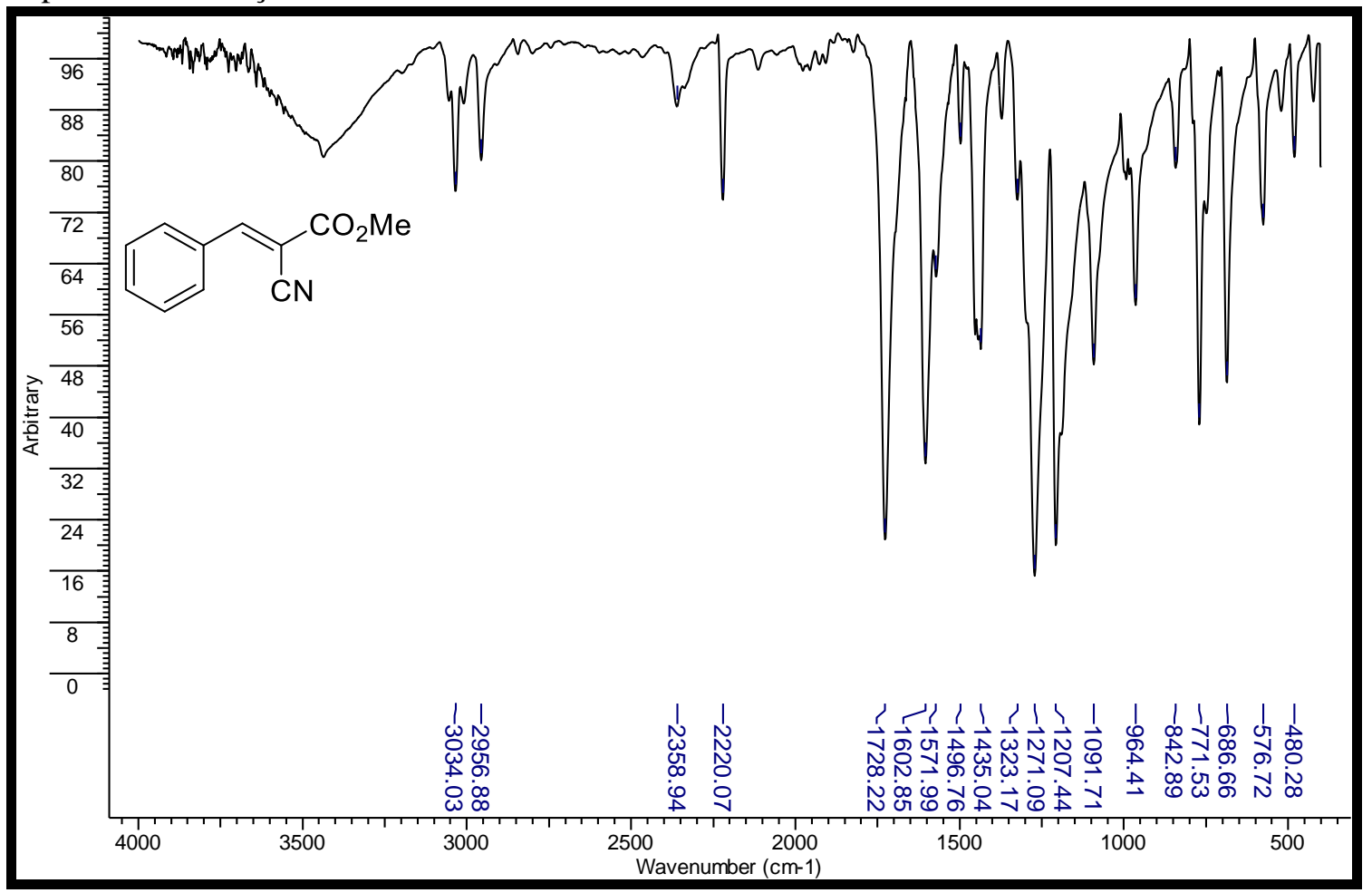

Espectro de massas (IE, $70 \mathrm{eV}$ ) do aduto $2 \mathbf{a}$.

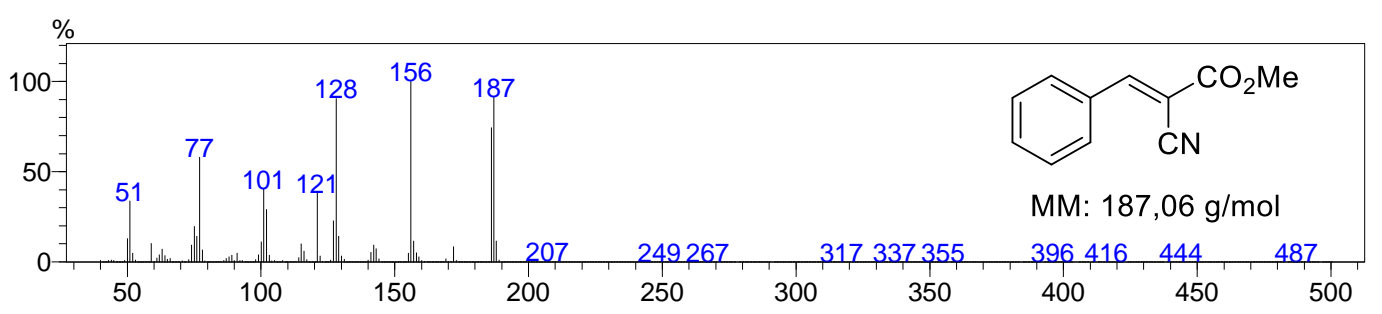


Espectro de RMN de ${ }^{1} \mathrm{H}\left(400 \mathrm{MHz}, \mathrm{CDCl}_{3}\right)$ do aduto $\mathbf{2 b}$.

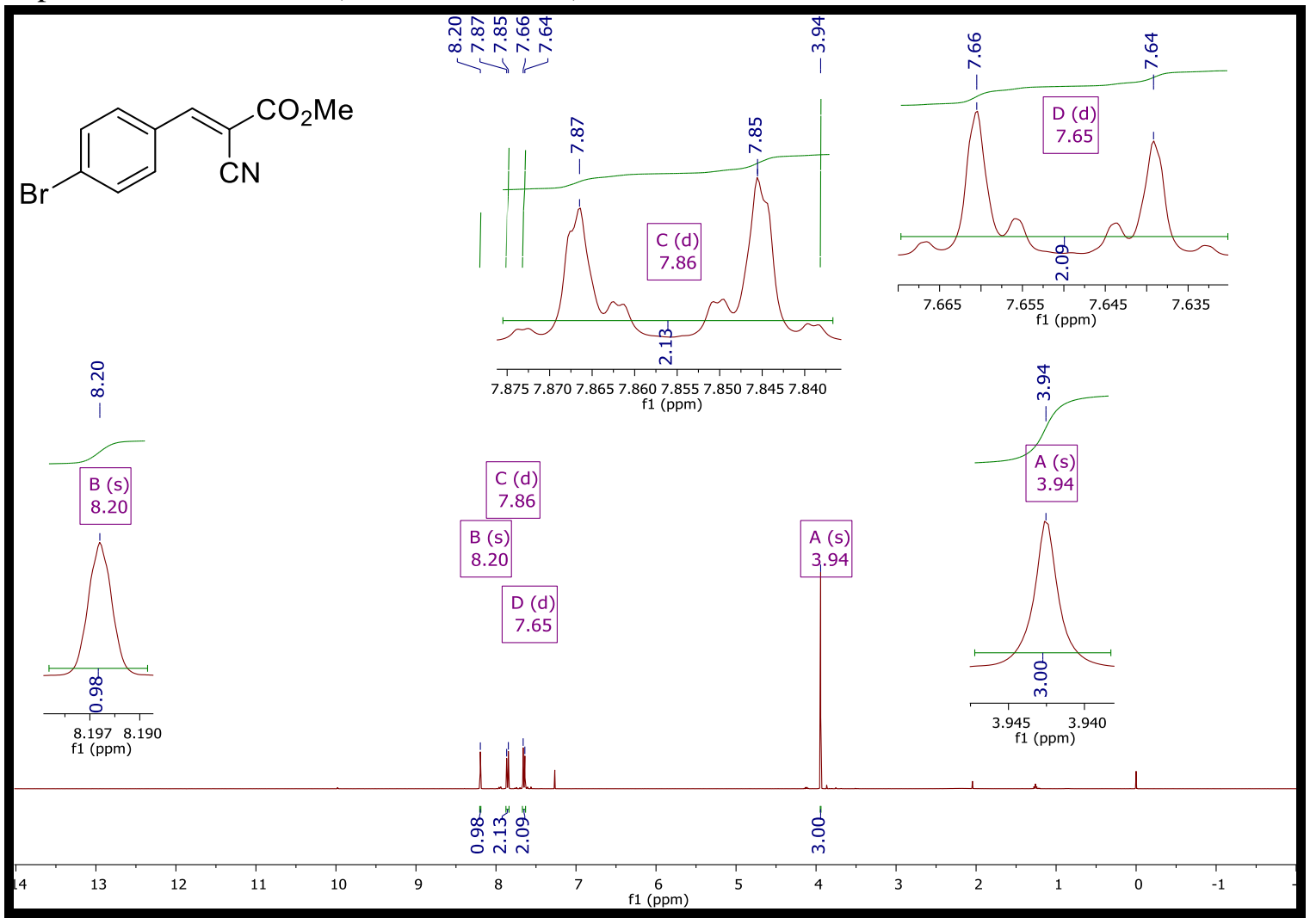

Espectro de $\mathrm{RMN}$ de ${ }^{13} \mathrm{C}\left(100 \mathrm{MHz}, \mathrm{CDCl}_{3}\right)$ do aduto $\mathbf{2 b}$.

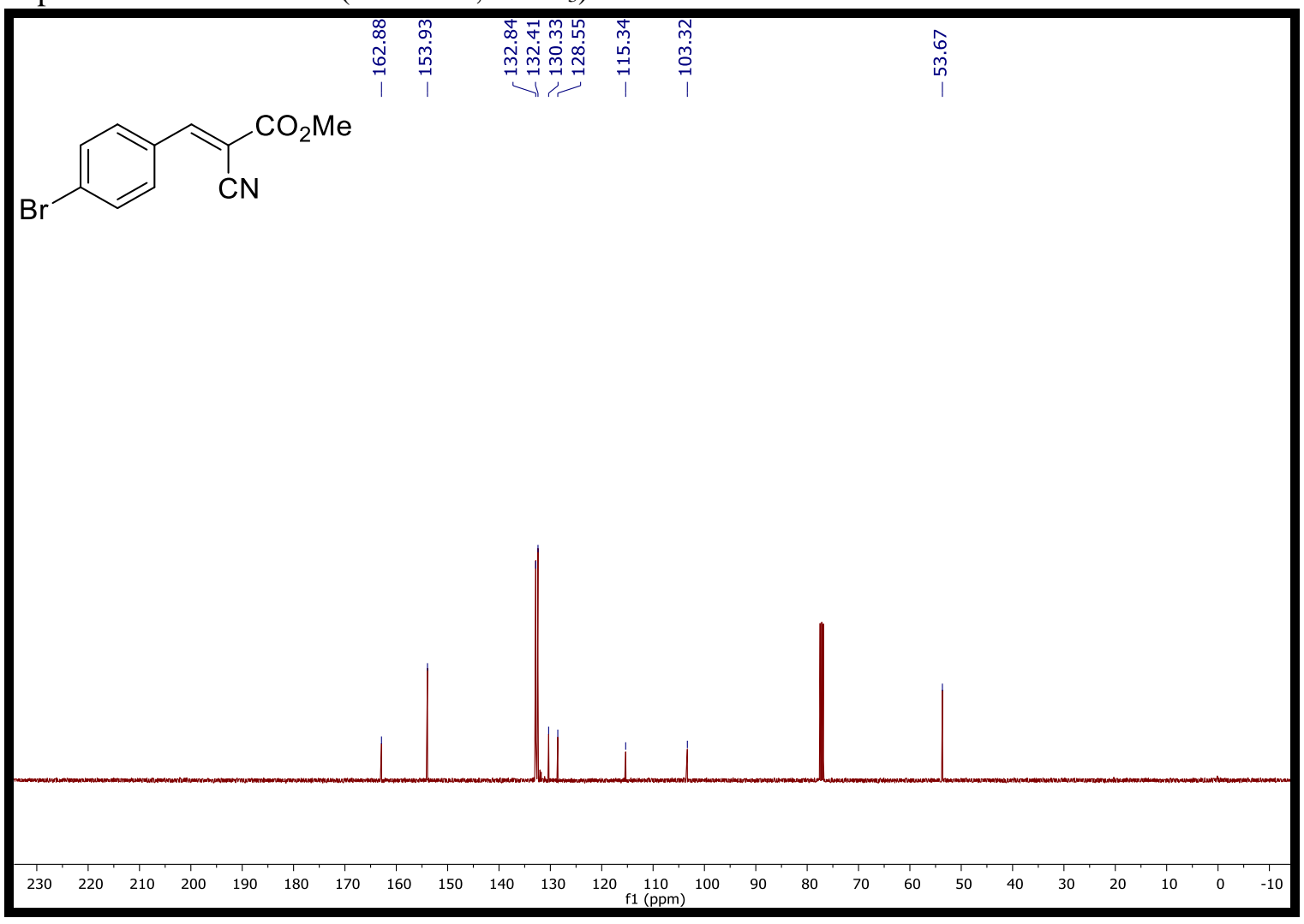


Espectro de absorção no infravermelho do aduto $\mathbf{2 b}$

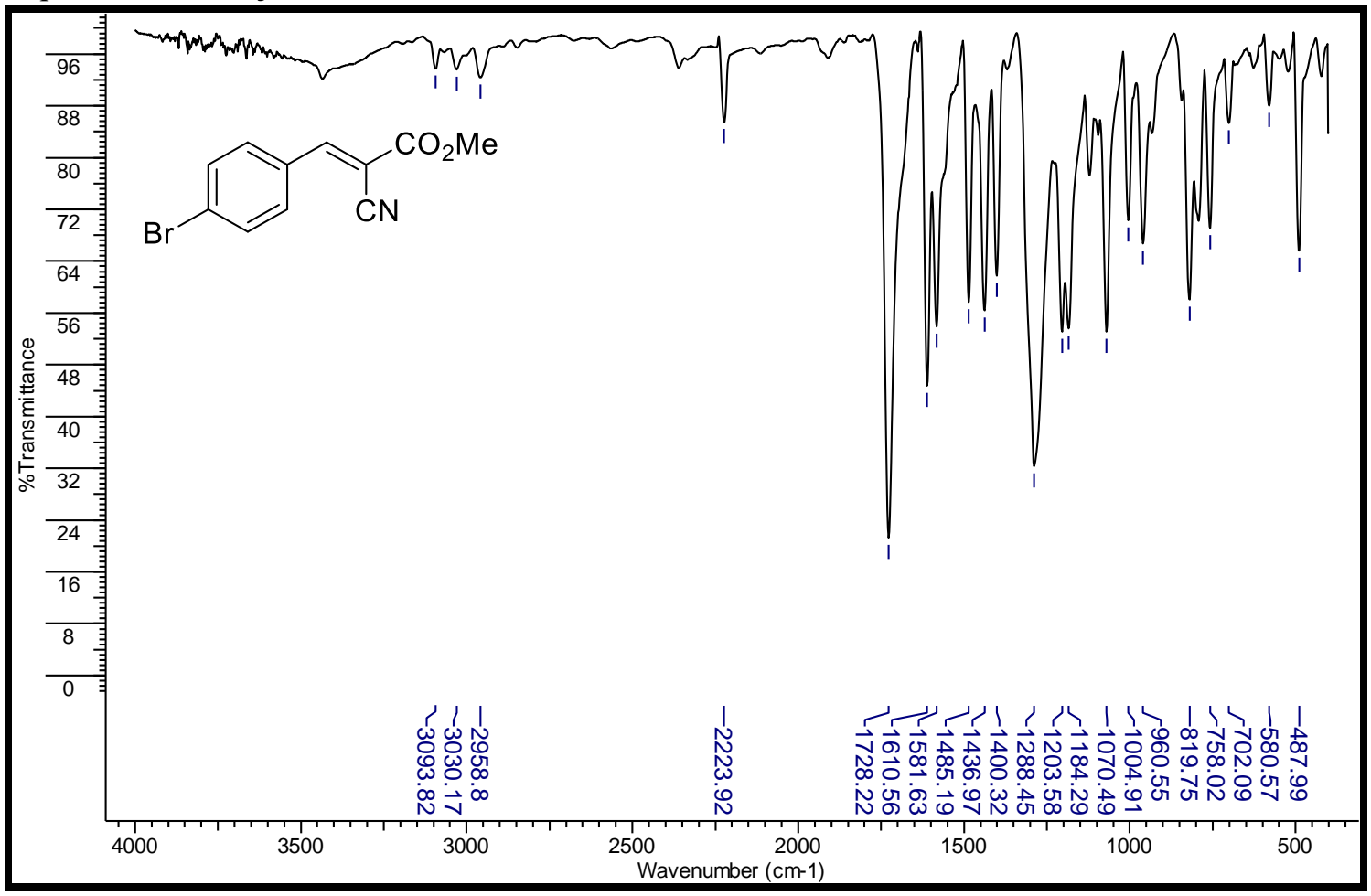


Espectro de RMN de ${ }^{1} \mathrm{H}\left(400 \mathrm{MHz}, \mathrm{CDCl}_{3}\right)$ do aduto 2c.

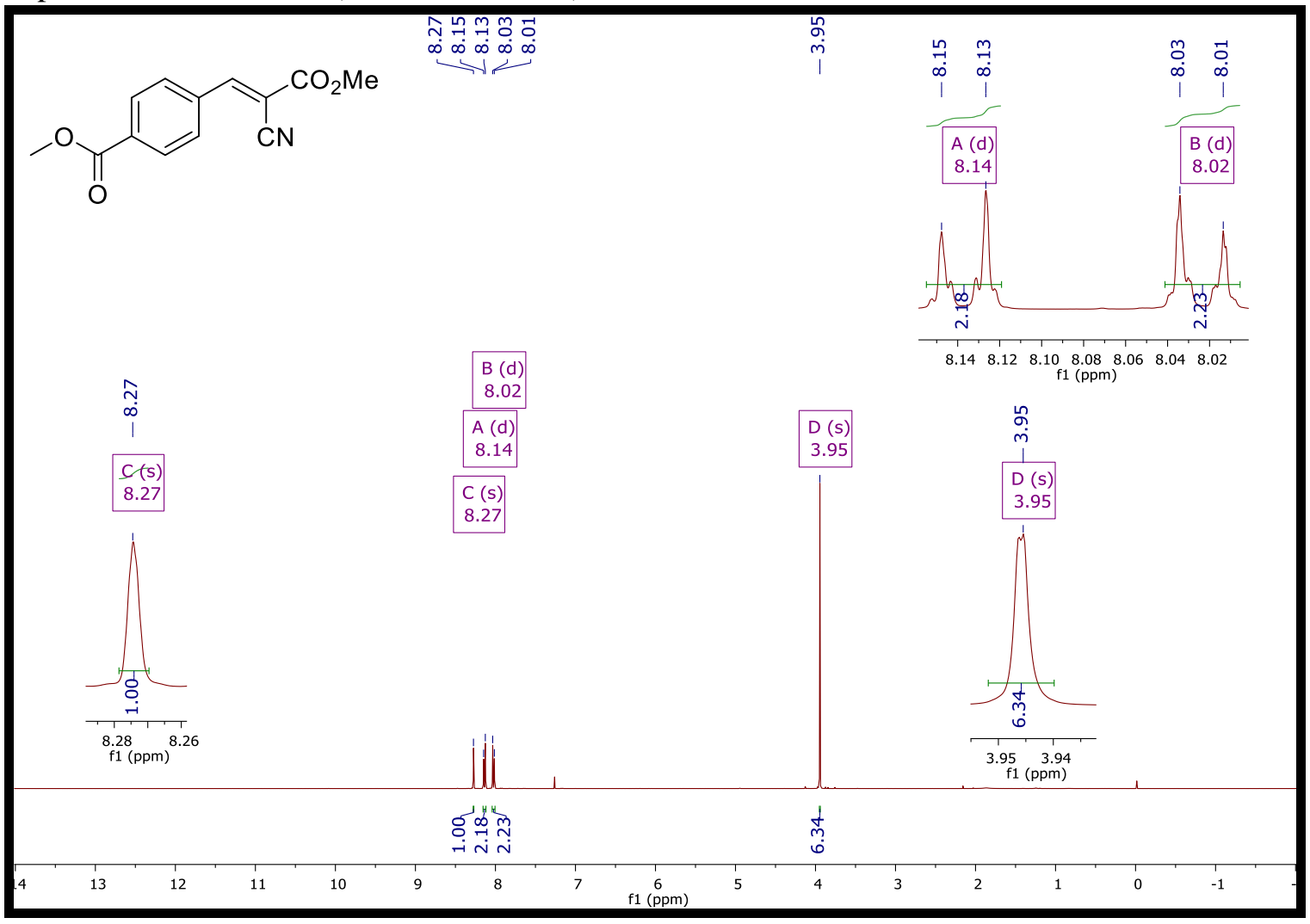

Espectro de RMN de ${ }^{13} \mathrm{C}\left(100 \mathrm{MHz}, \mathrm{CDCl}_{3}\right)$ do aduto $2 \mathbf{c}$.

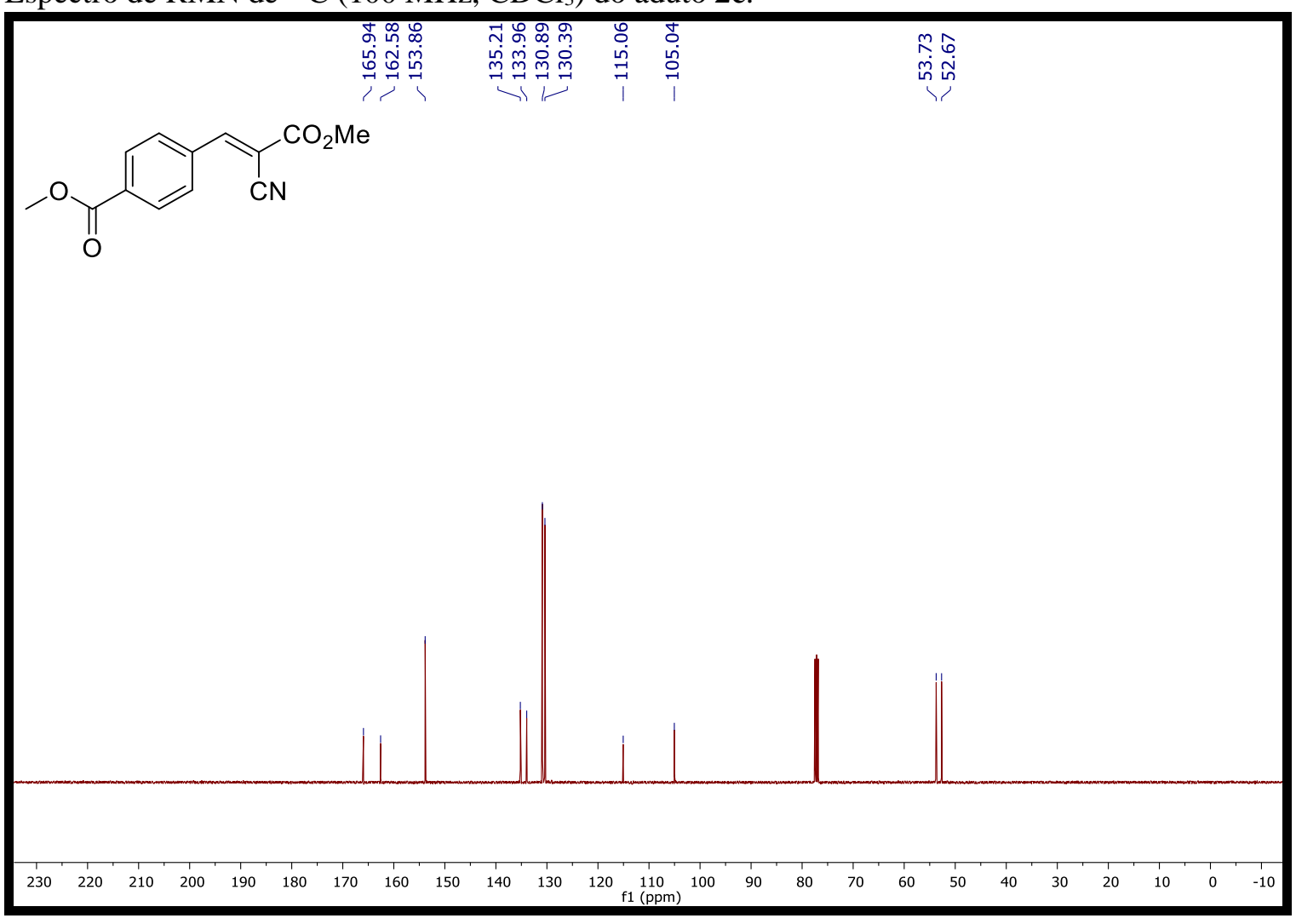


Espectro de absorção no infravermelho do aduto 2c.

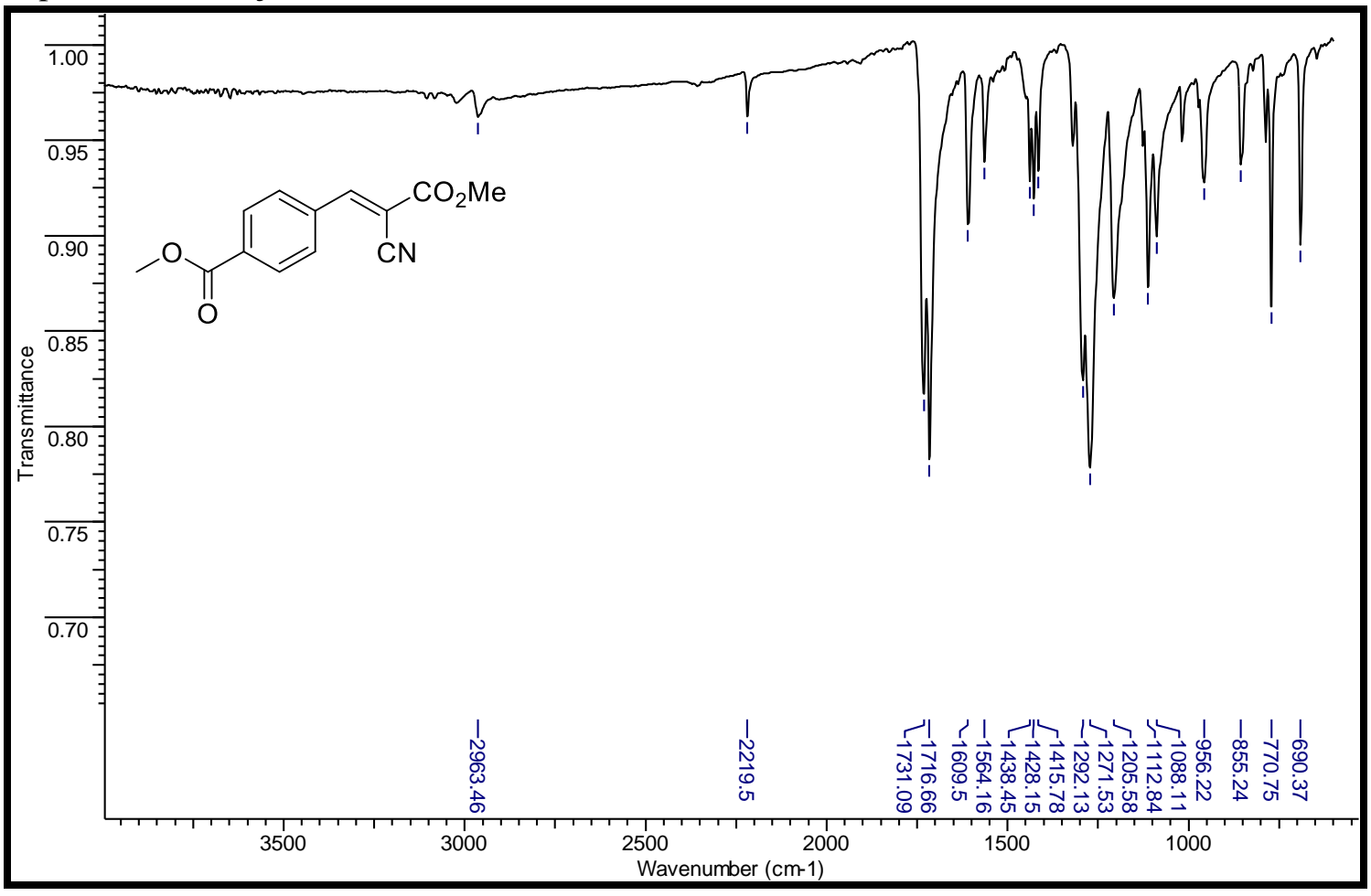

Espectro de massas (IE, $70 \mathrm{eV}$ ) do aduto 2c.

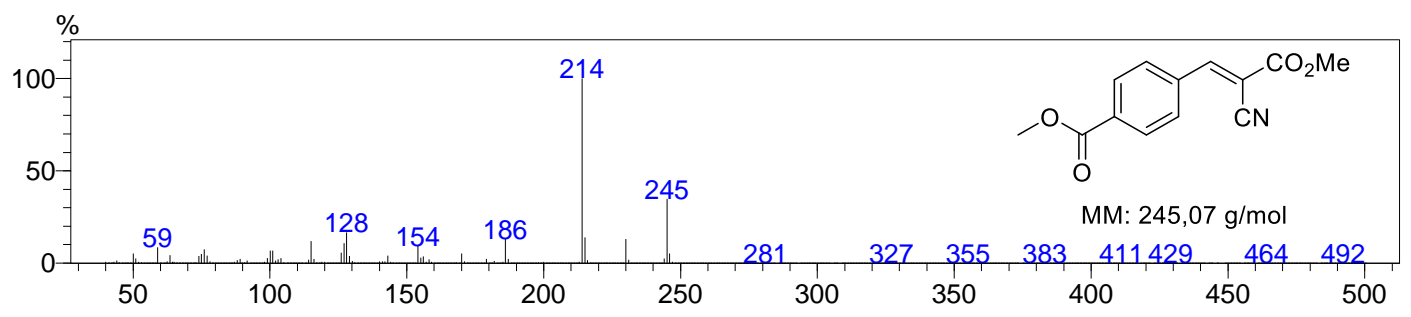


Espectro de RMN de ${ }^{1} \mathrm{H}$ (400 MHz, $\mathrm{CDCl}_{3}$ ) do aduto $2 d$.

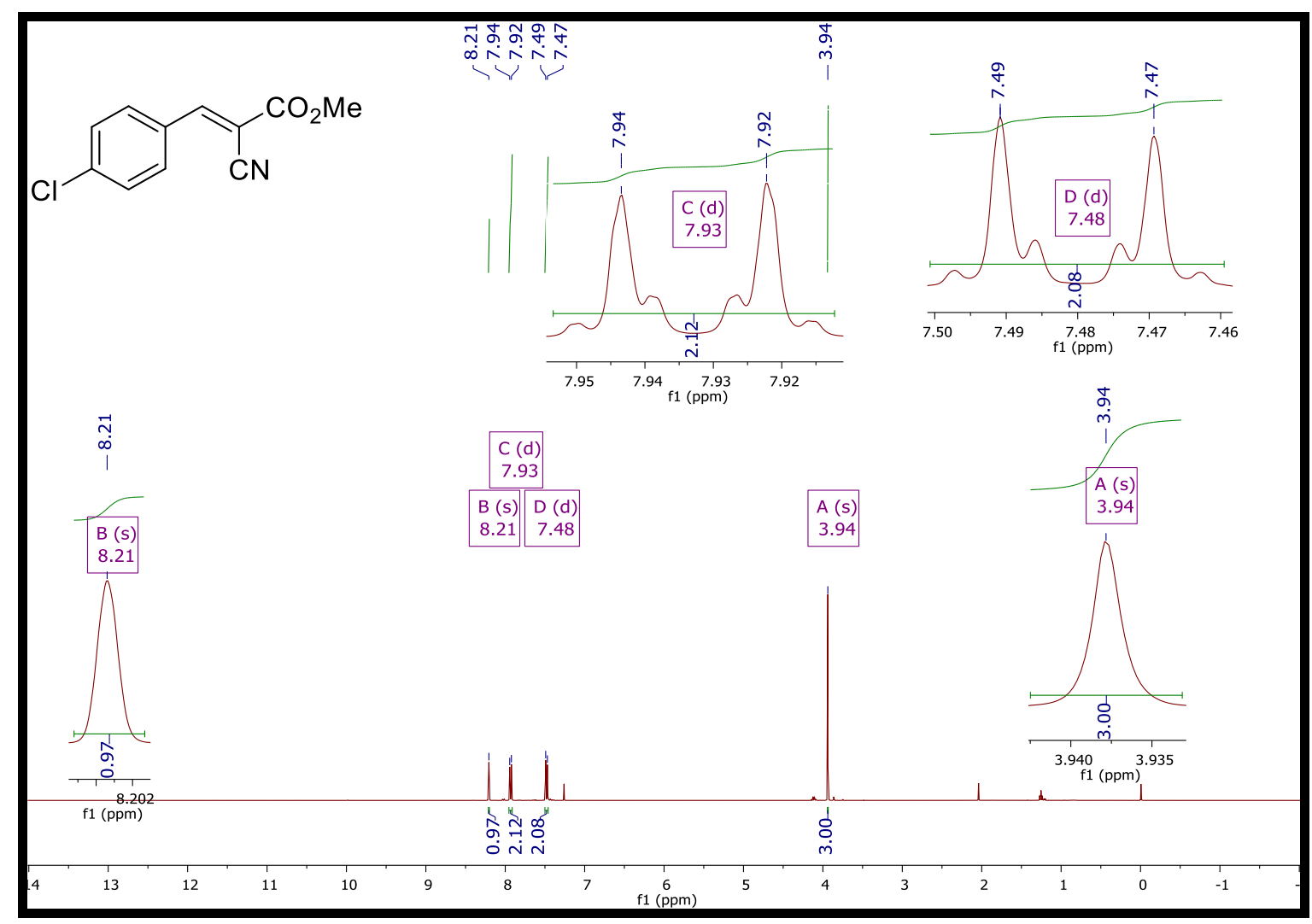

Espectro de RMN de ${ }^{13} \mathrm{C}\left(100 \mathrm{MHz}, \mathrm{CDCl}_{3}\right)$ do aduto $\mathbf{2 d}$.

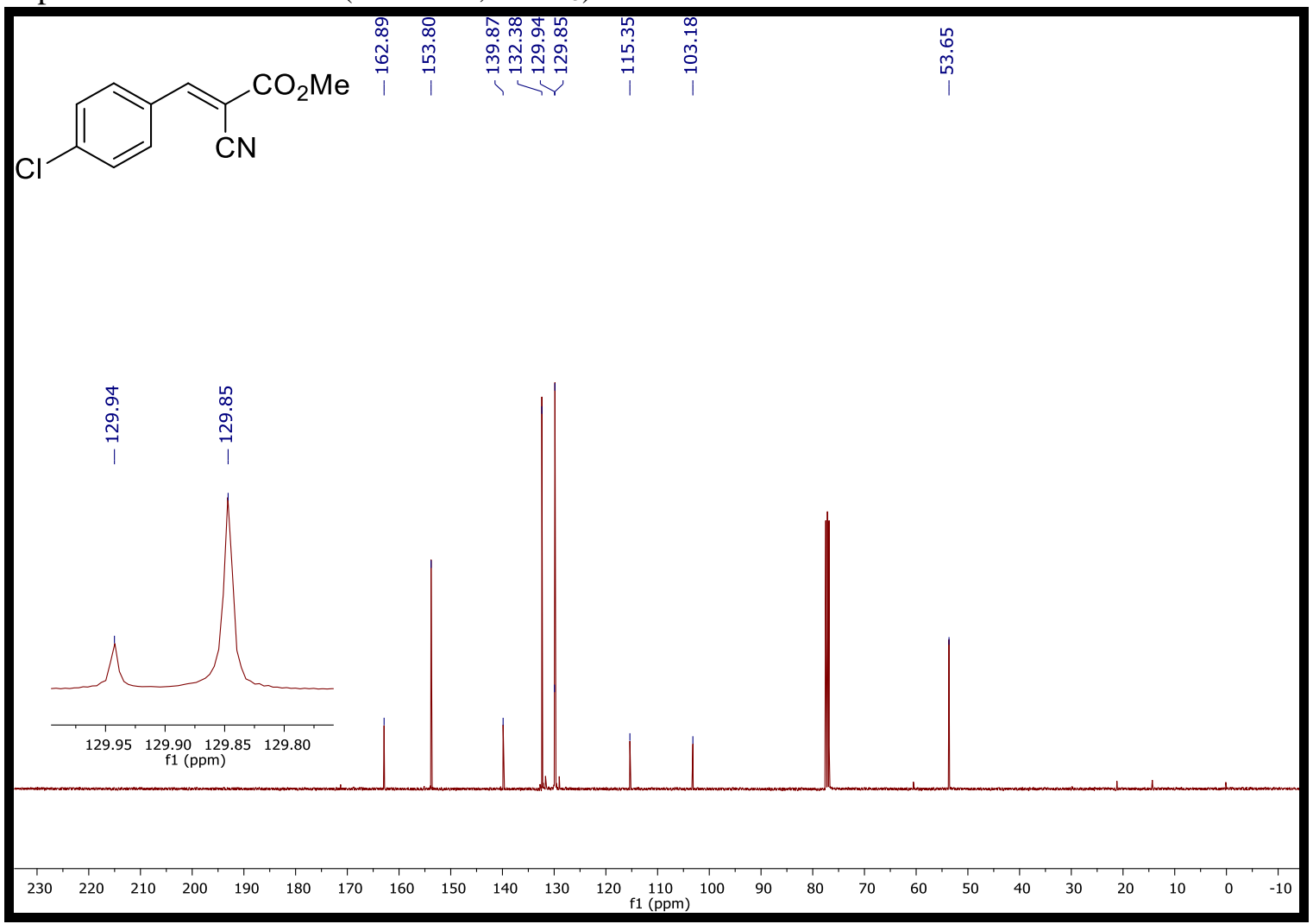


Espectro de absorção no infravermelho do aduto 2d

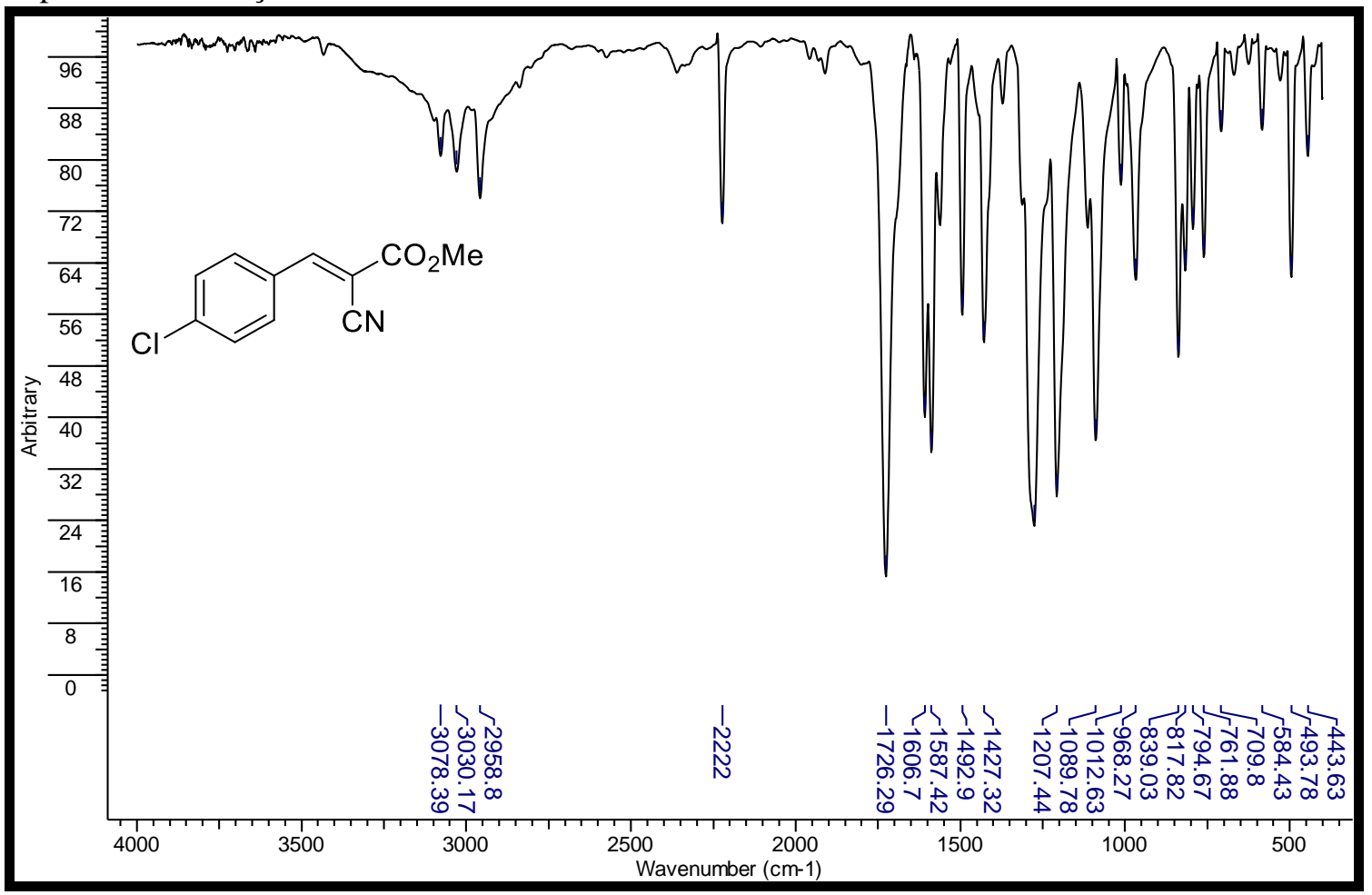

Espectro de massas (IE, $70 \mathrm{eV}$ ) do aduto $2 d$.

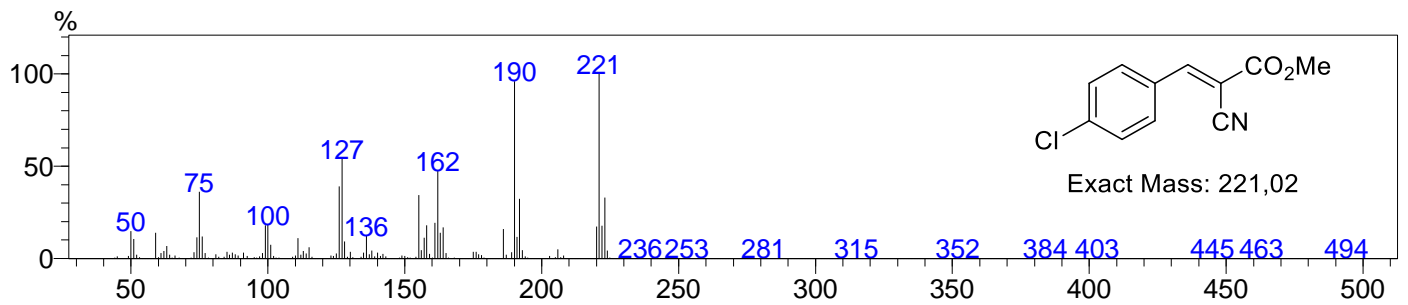


Espectro de RMN de ${ }^{1} \mathrm{H}\left(400 \mathrm{MHz}, \mathrm{CDCl}_{3}\right)$ do aduto $2 \mathbf{e}$.

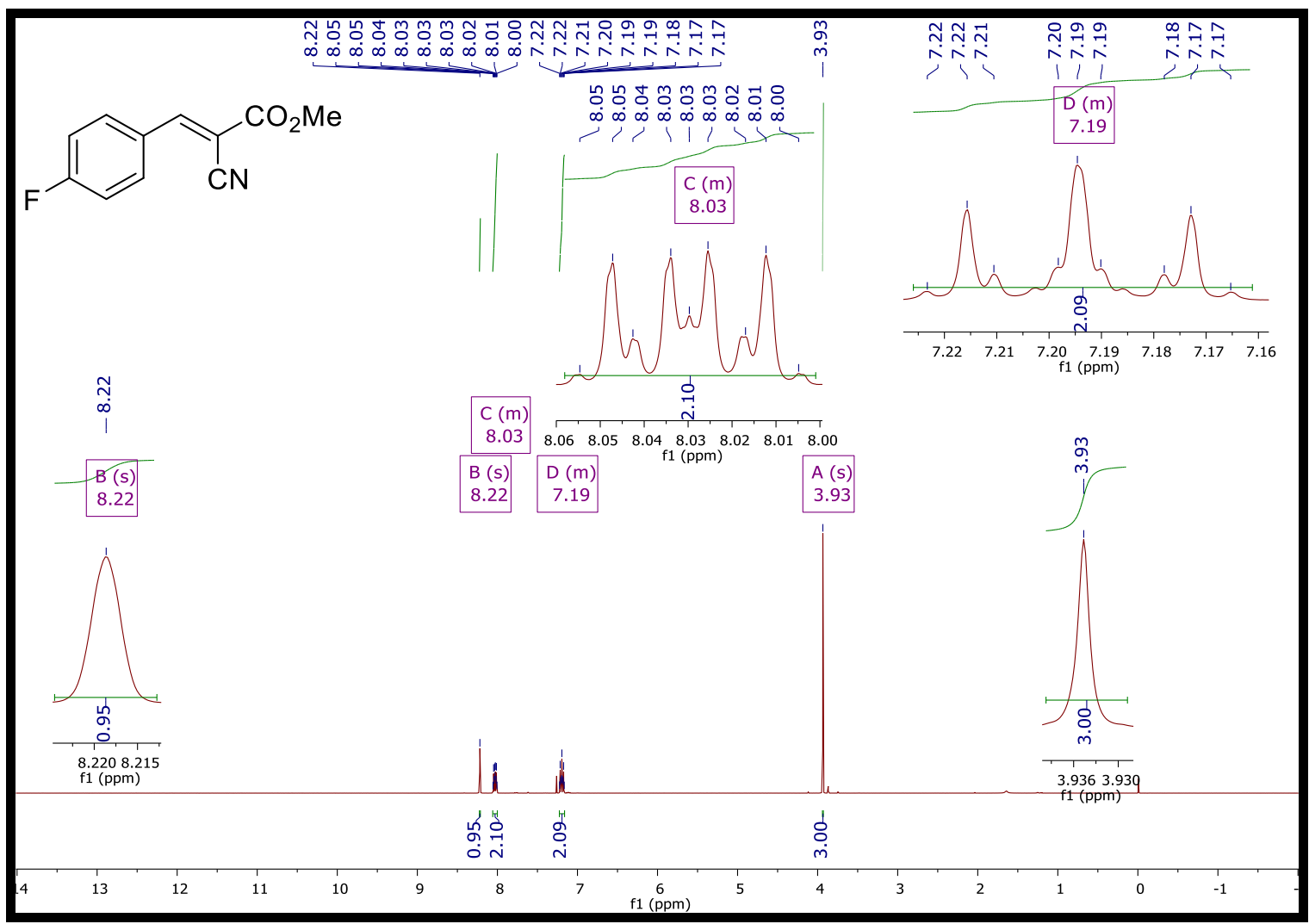

Espectro de $\mathrm{RMN}$ de ${ }^{13} \mathrm{C}\left(100 \mathrm{MHz}, \mathrm{CDCl}_{3}\right)$ do aduto $\mathbf{2 e}$.

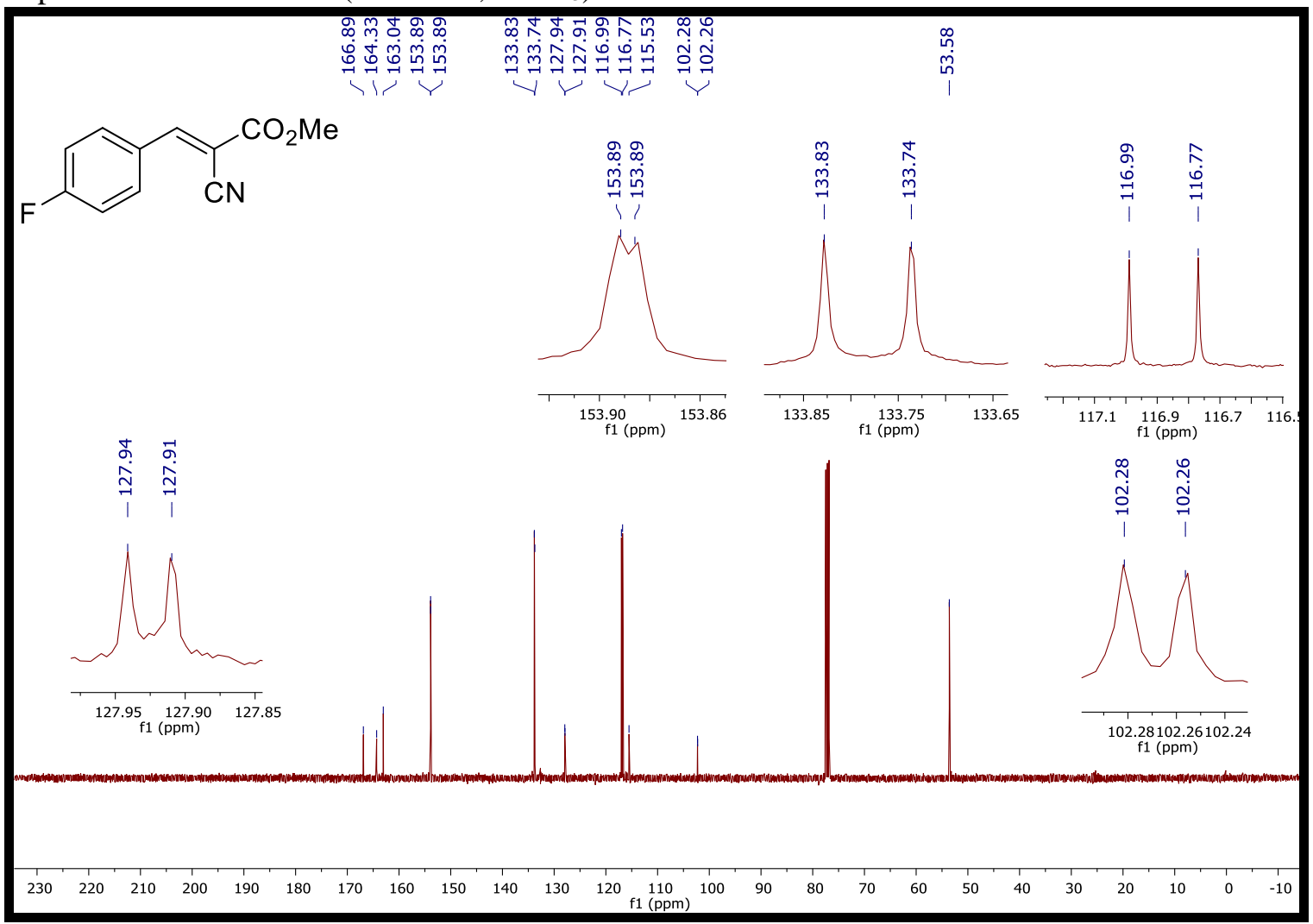


Espectro de absorção no infravermelho do aduto $2 \mathbf{e}$.

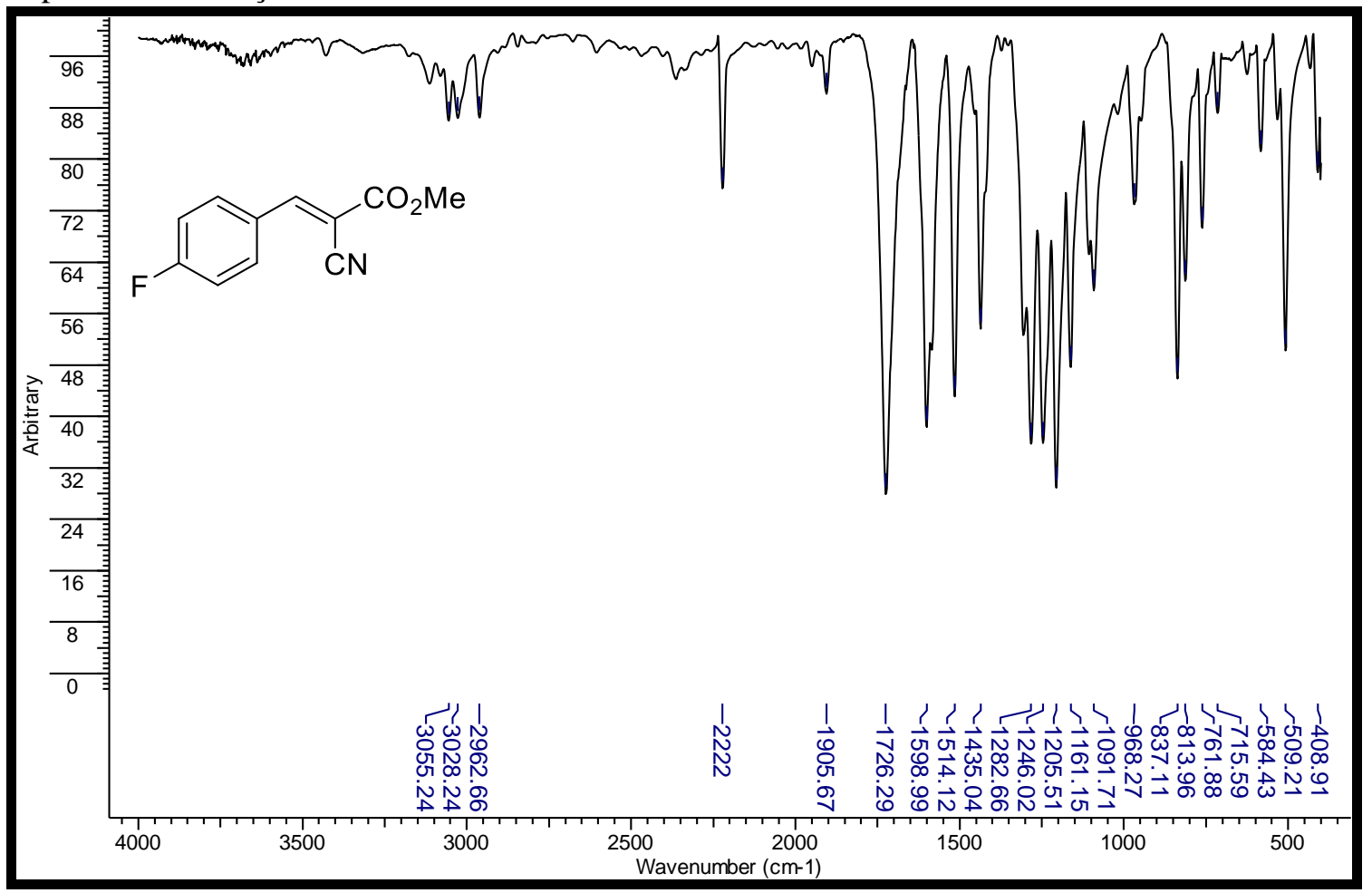

Espectro de massas (IE, $70 \mathrm{eV}$ ) do aduto $2 \mathbf{e}$.

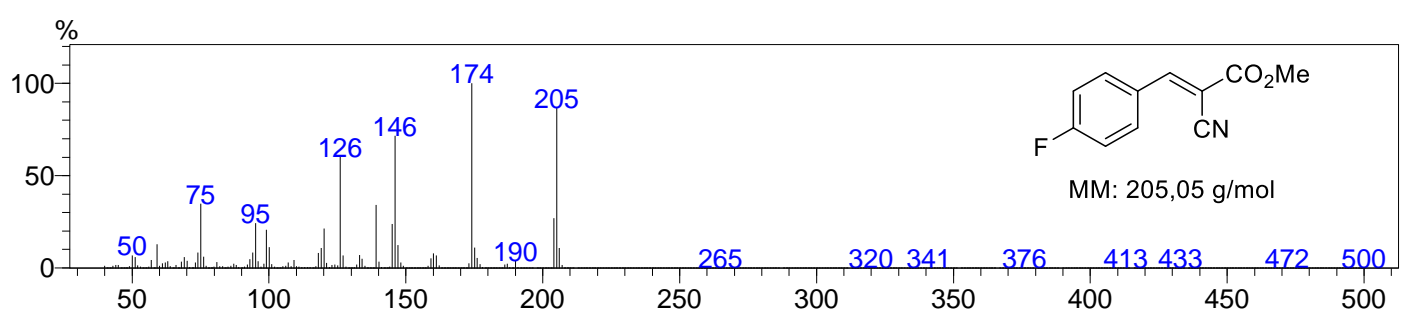


Espectro de RMN de ${ }^{1} \mathrm{H}\left(400 \mathrm{MHz}, \mathrm{CDCl}_{3}\right)$ do aduto $2 \mathrm{f}$.

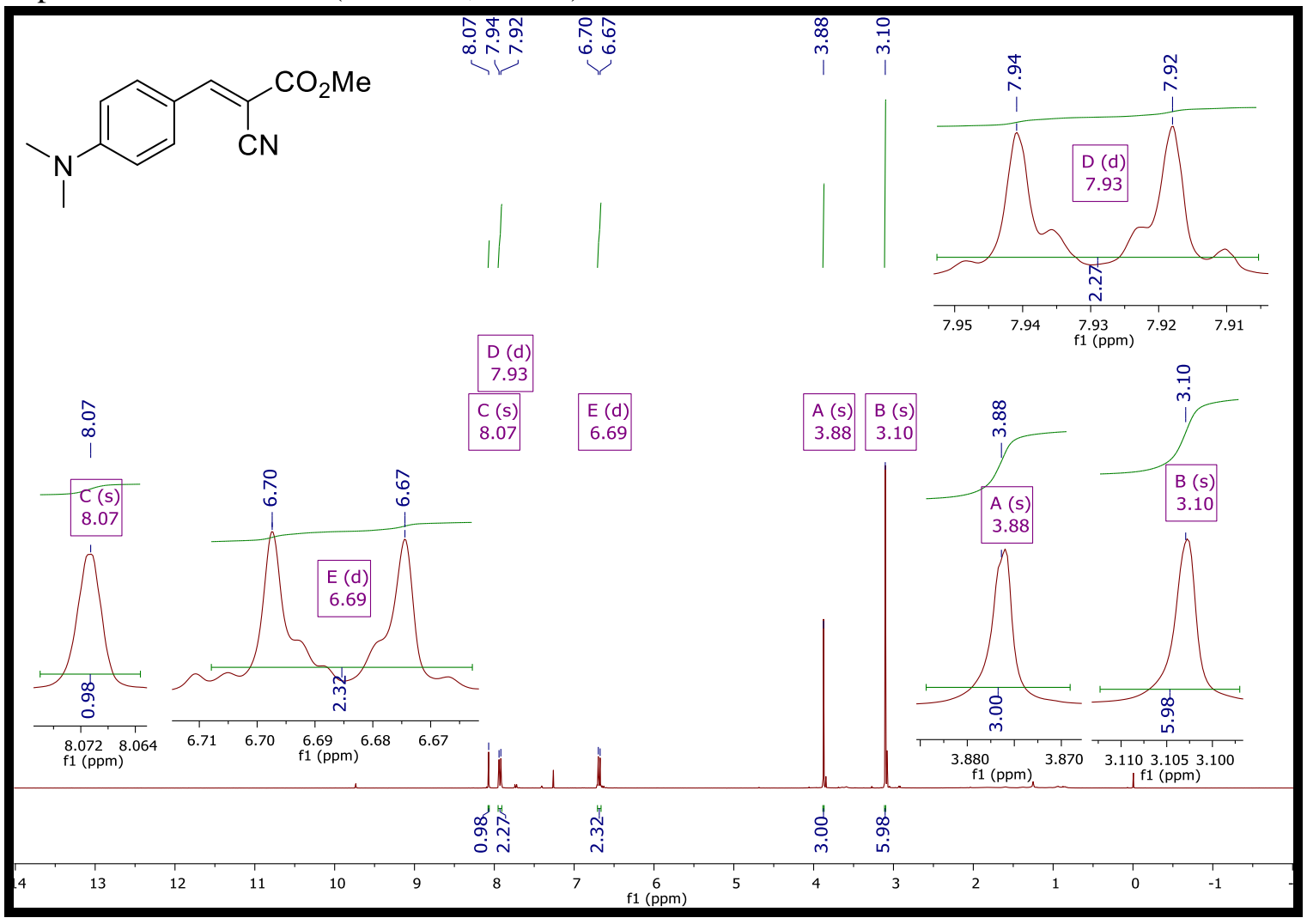

Espectro de RMN de ${ }^{13} \mathrm{C}\left(100 \mathrm{MHz}, \mathrm{CDCl}_{3}\right)$ do aduto $2 \mathrm{f}$.

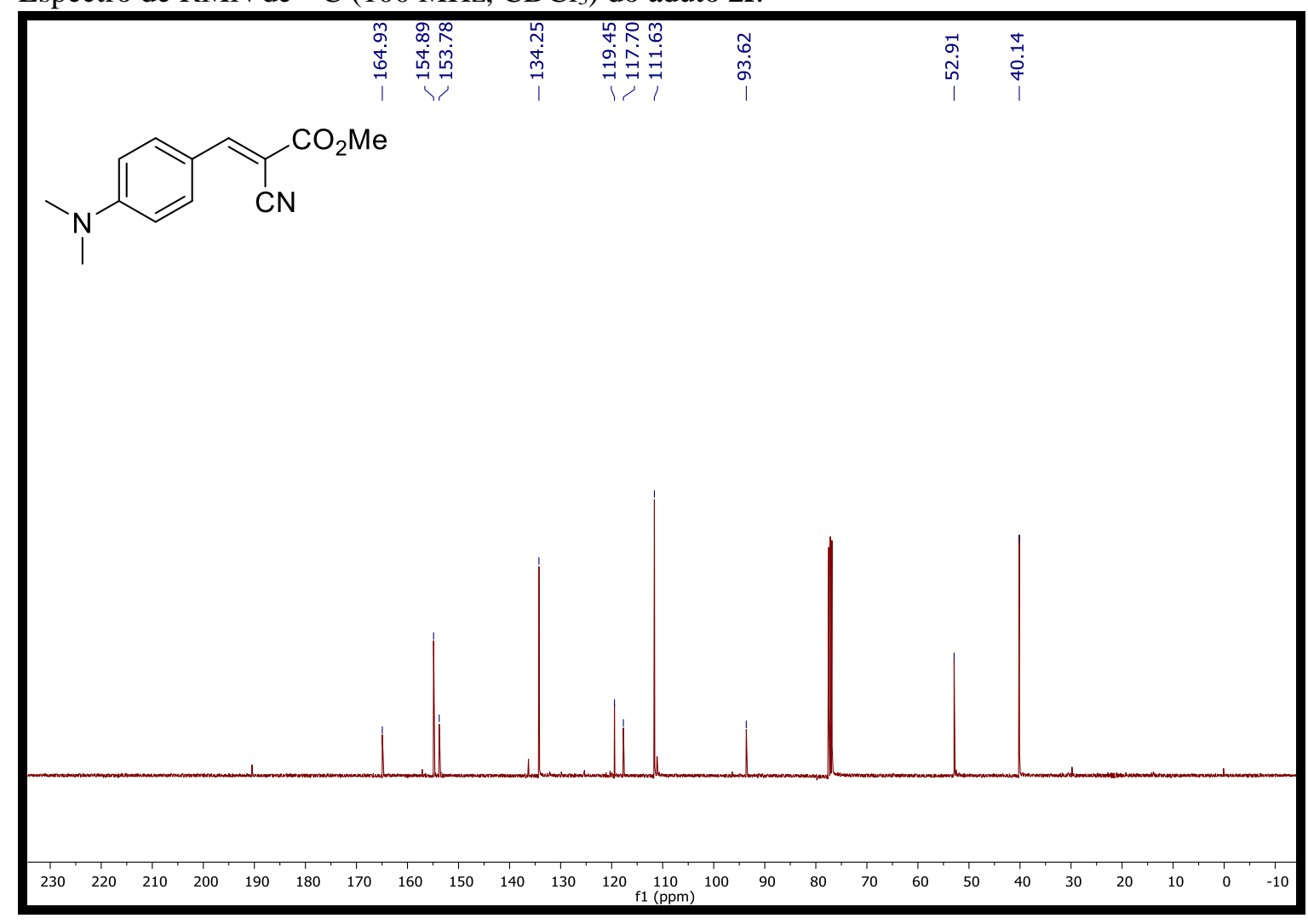


Espectro de absorção no infravermelho do aduto $2 \mathbf{f f}$.

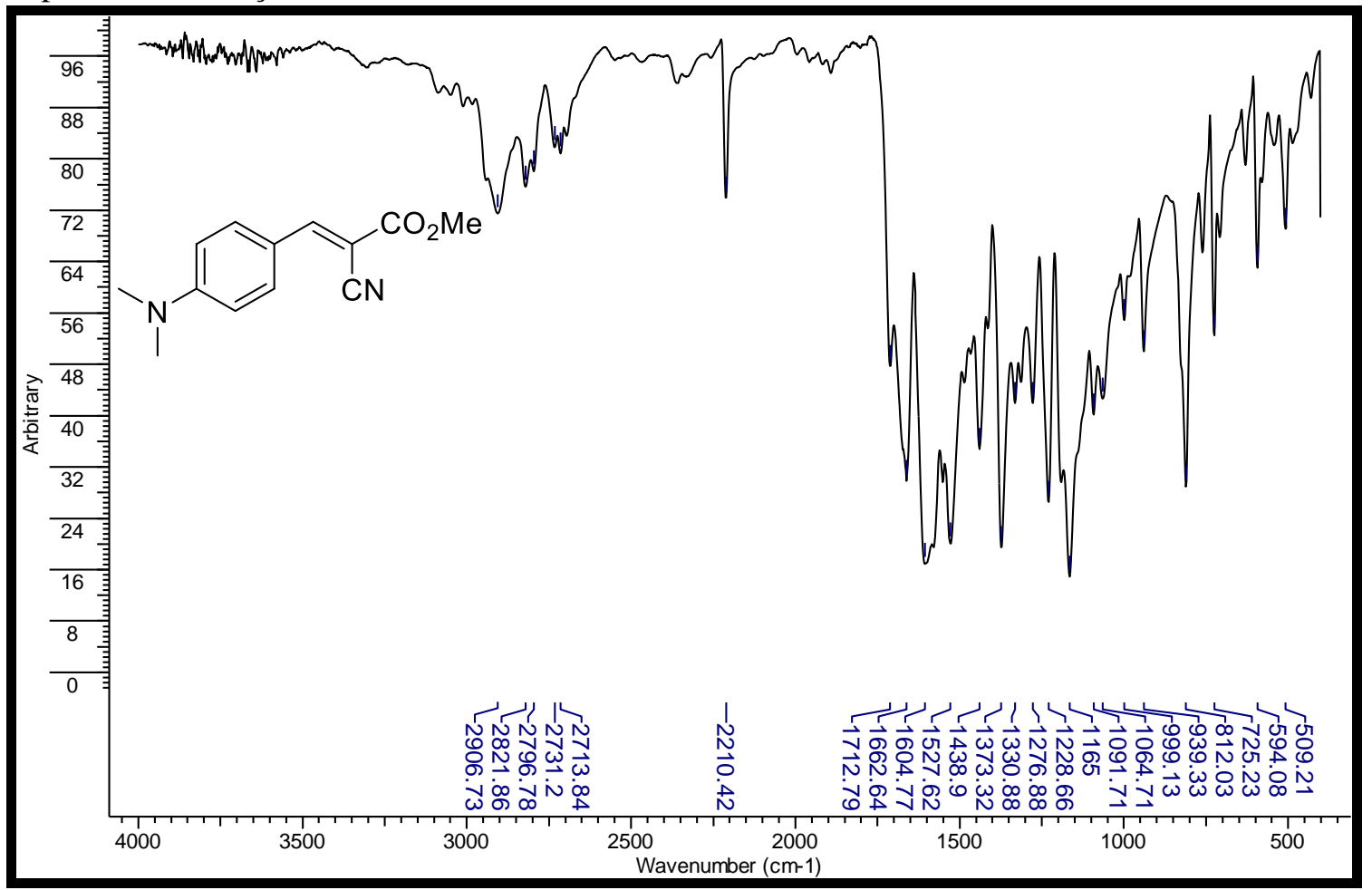

Espectro de massas (IE, $70 \mathrm{eV}$ ) do aduto $\mathbf{2 f}$.

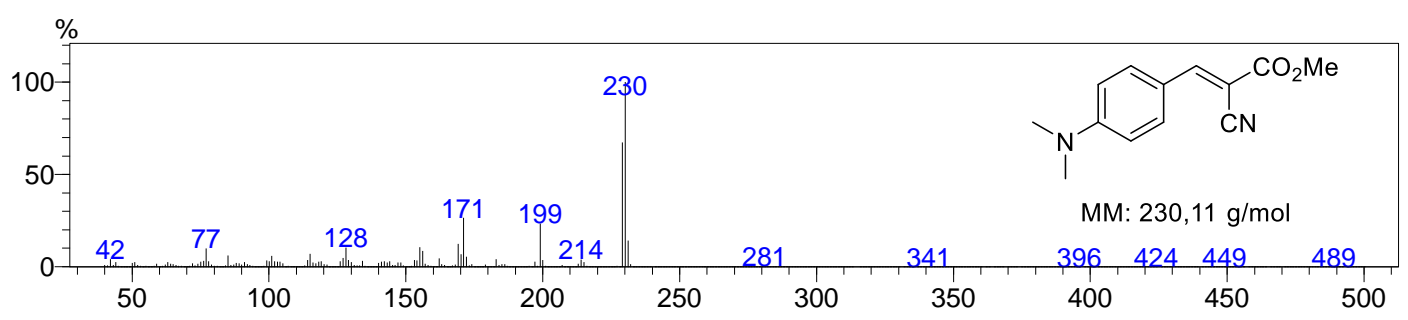


Espectro de RMN de ${ }^{1} \mathrm{H}\left(400 \mathrm{MHz}, \mathrm{CDCl}_{3}\right)$ do aduto $2 \mathrm{~g}$.

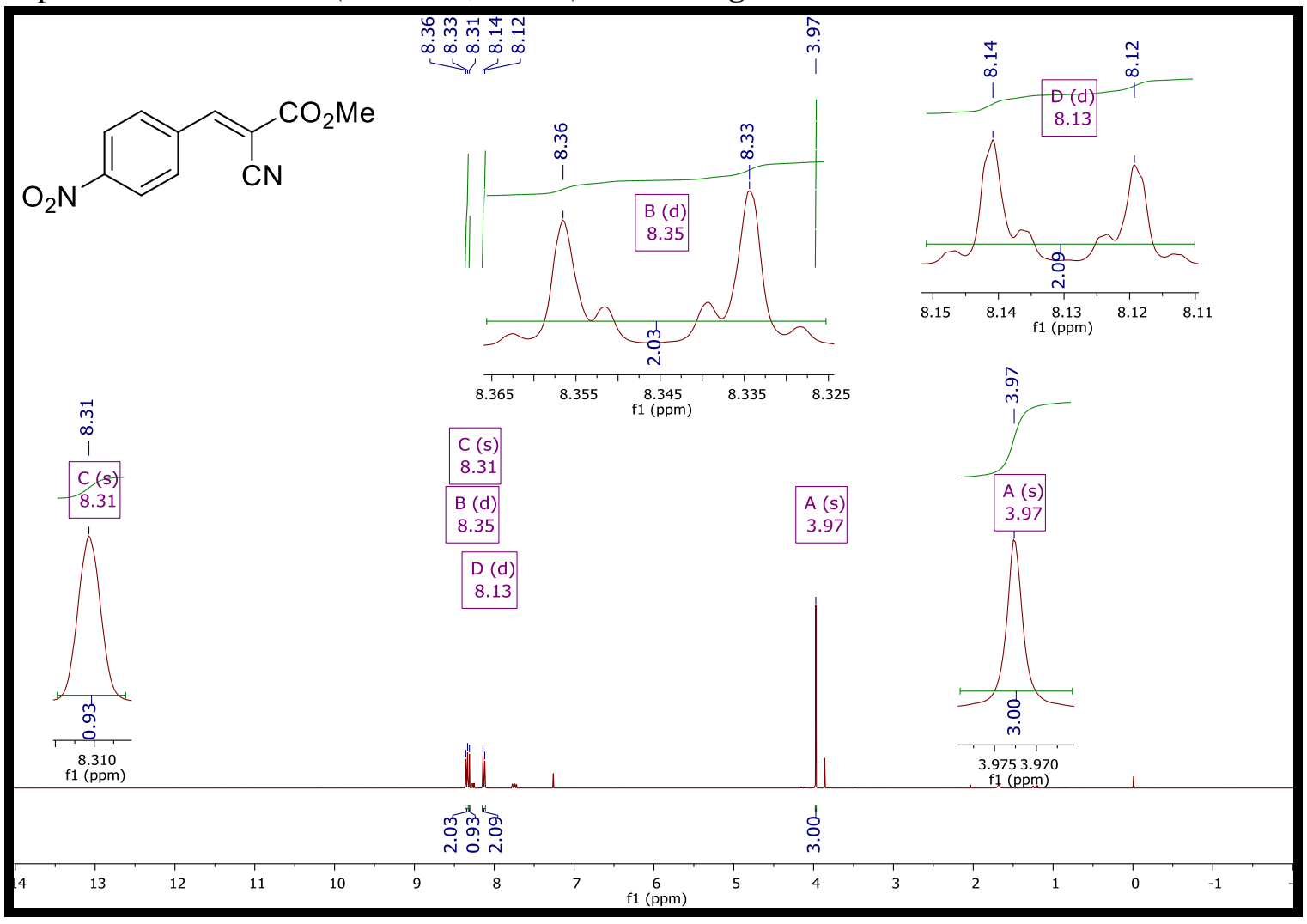

Espectro de $\mathrm{RMN}$ de ${ }^{13} \mathrm{C}\left(100 \mathrm{MHz}, \mathrm{CDCl}_{3}\right)$ do aduto $\mathbf{2 g}$.

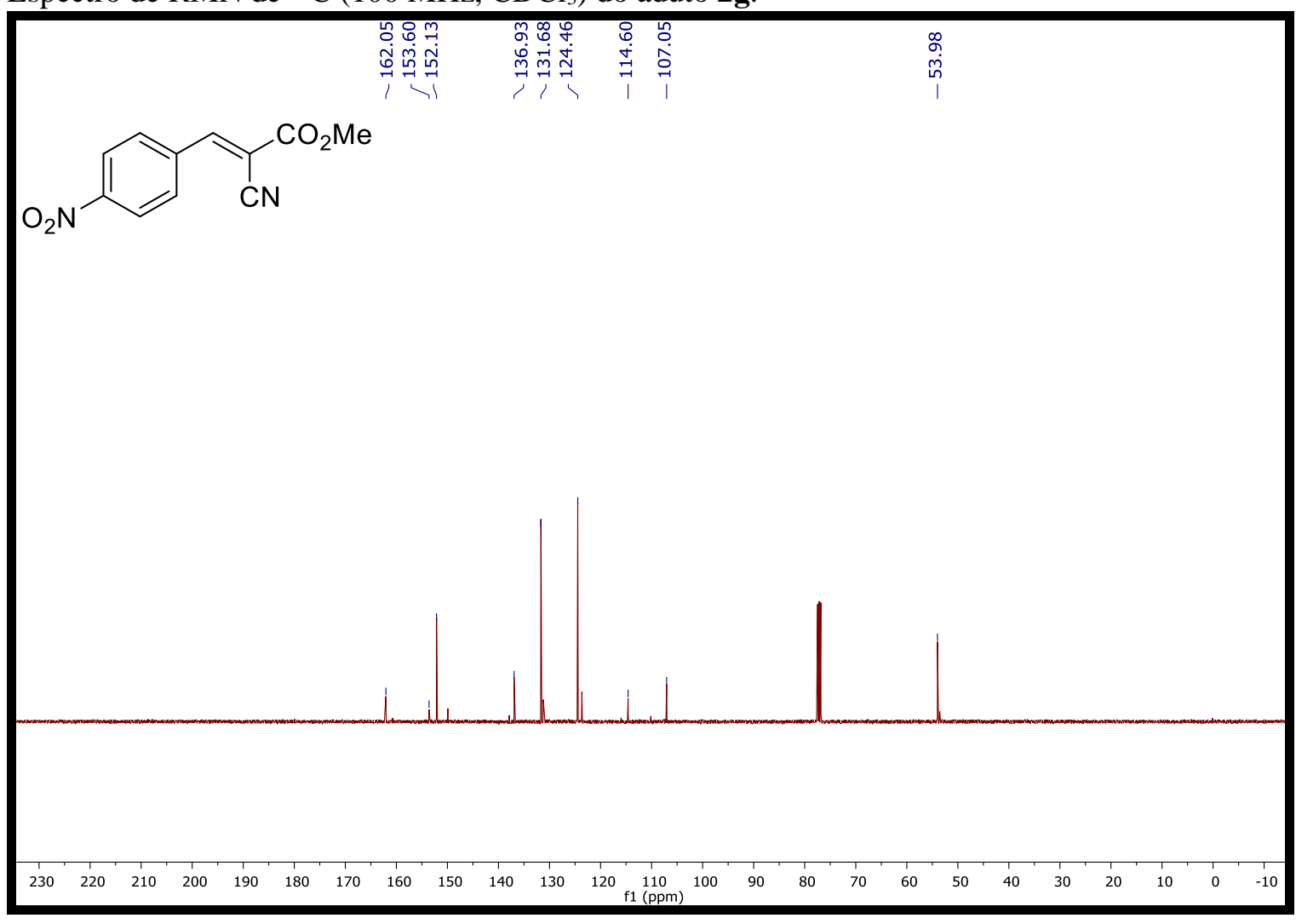


Espectro de absorção no infravermelho do aduto $\mathbf{2 g}$

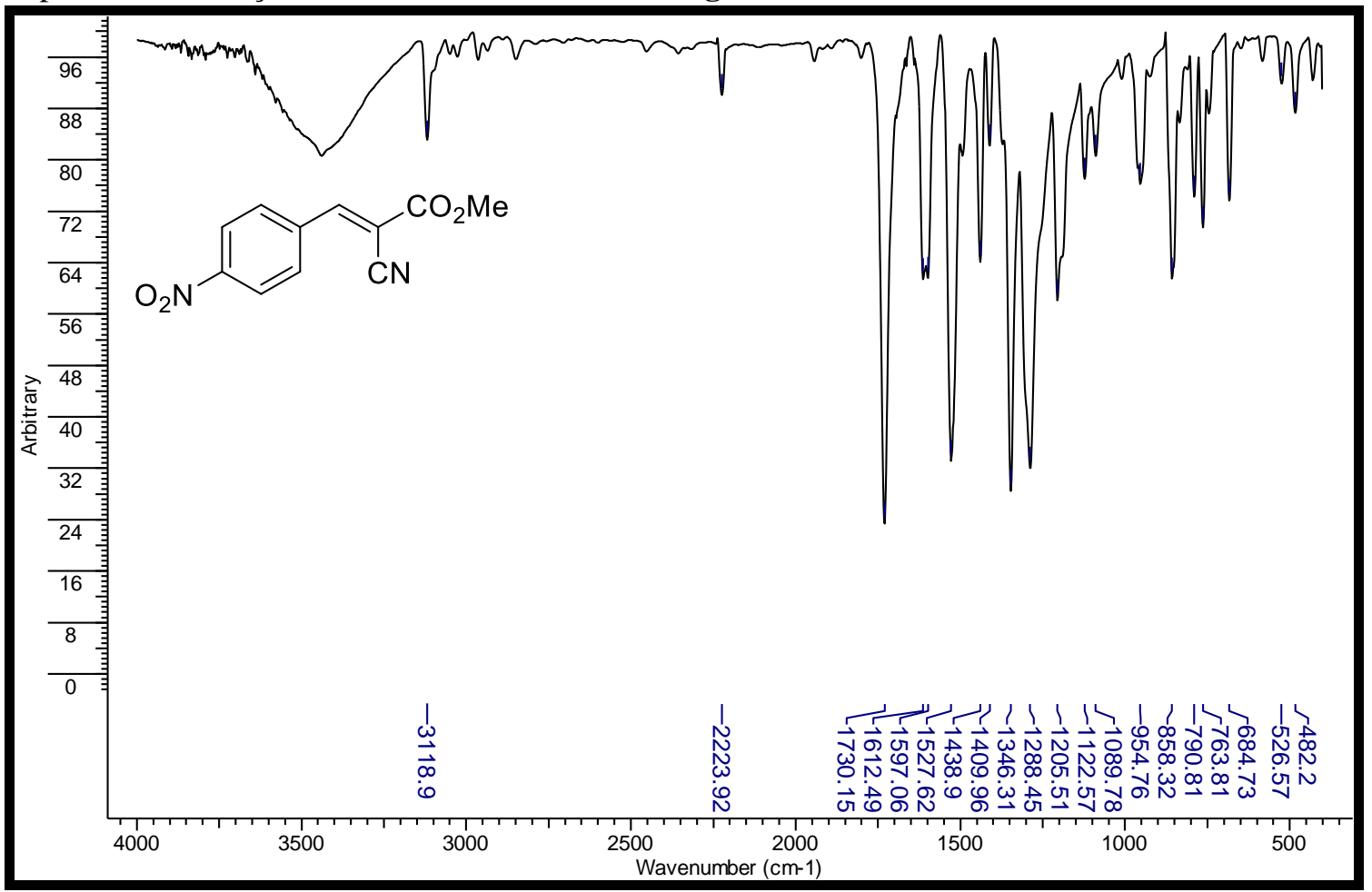

Espectro de massas (IE, $70 \mathrm{eV}$ ) do aduto $\mathbf{2 g}$.

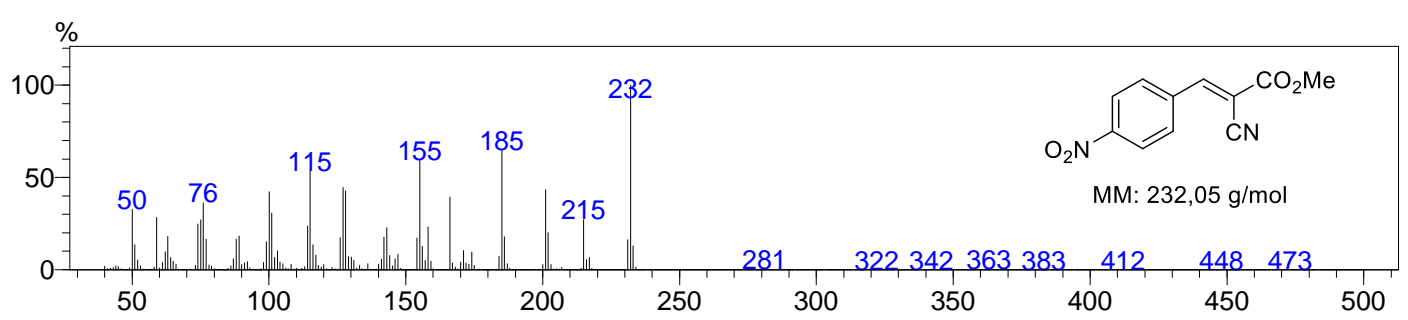


Espectro de RMN de ${ }^{1} \mathrm{H}\left(400 \mathrm{MHz}, \mathrm{CDCl}_{3}\right)$ do aduto $\mathbf{2 h}$.

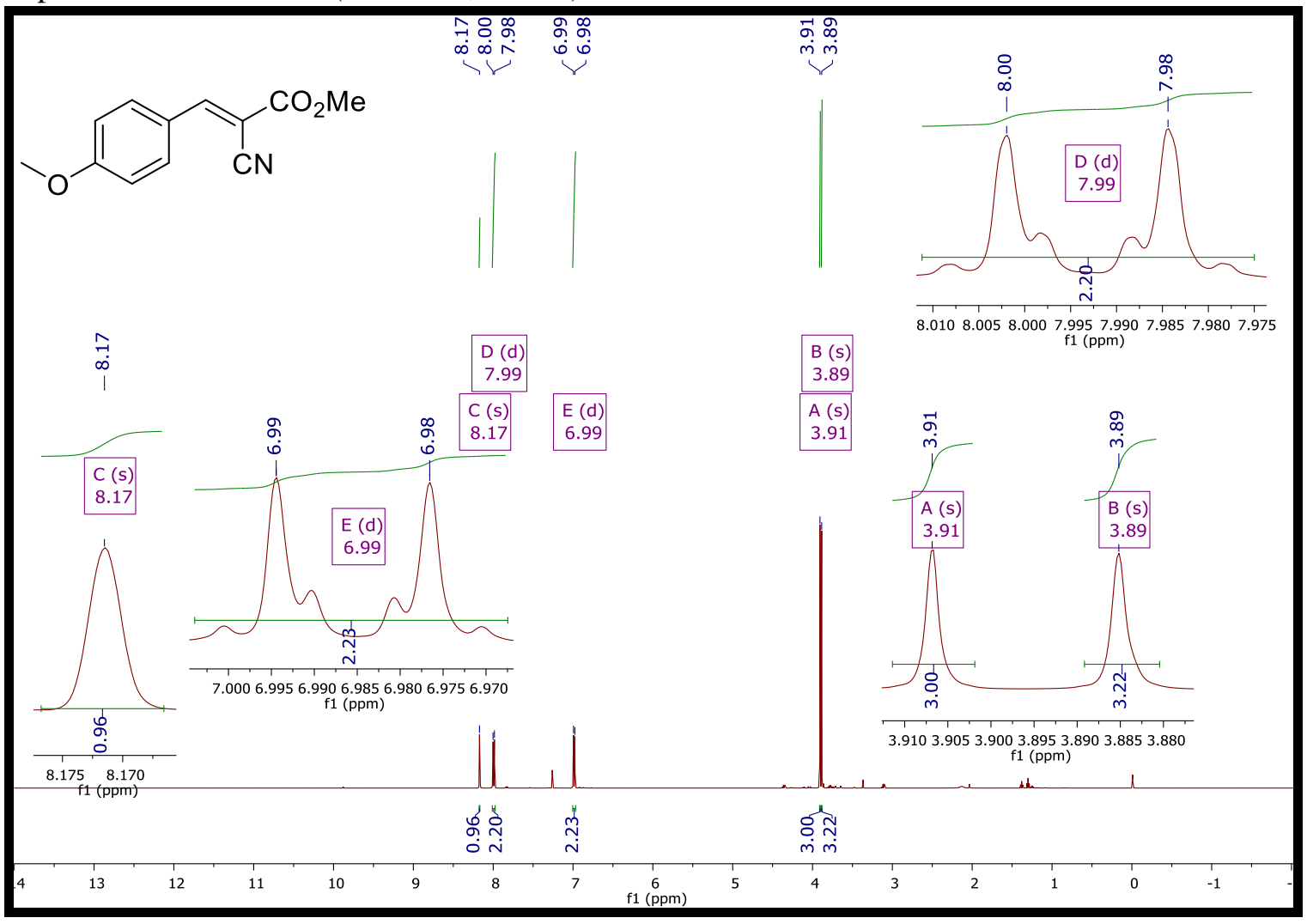

Espectro de $\mathrm{RMN}$ de ${ }^{13} \mathrm{C}\left(100 \mathrm{MHz}, \mathrm{CDCl}_{3}\right)$ do aduto $\mathbf{2 h}$.

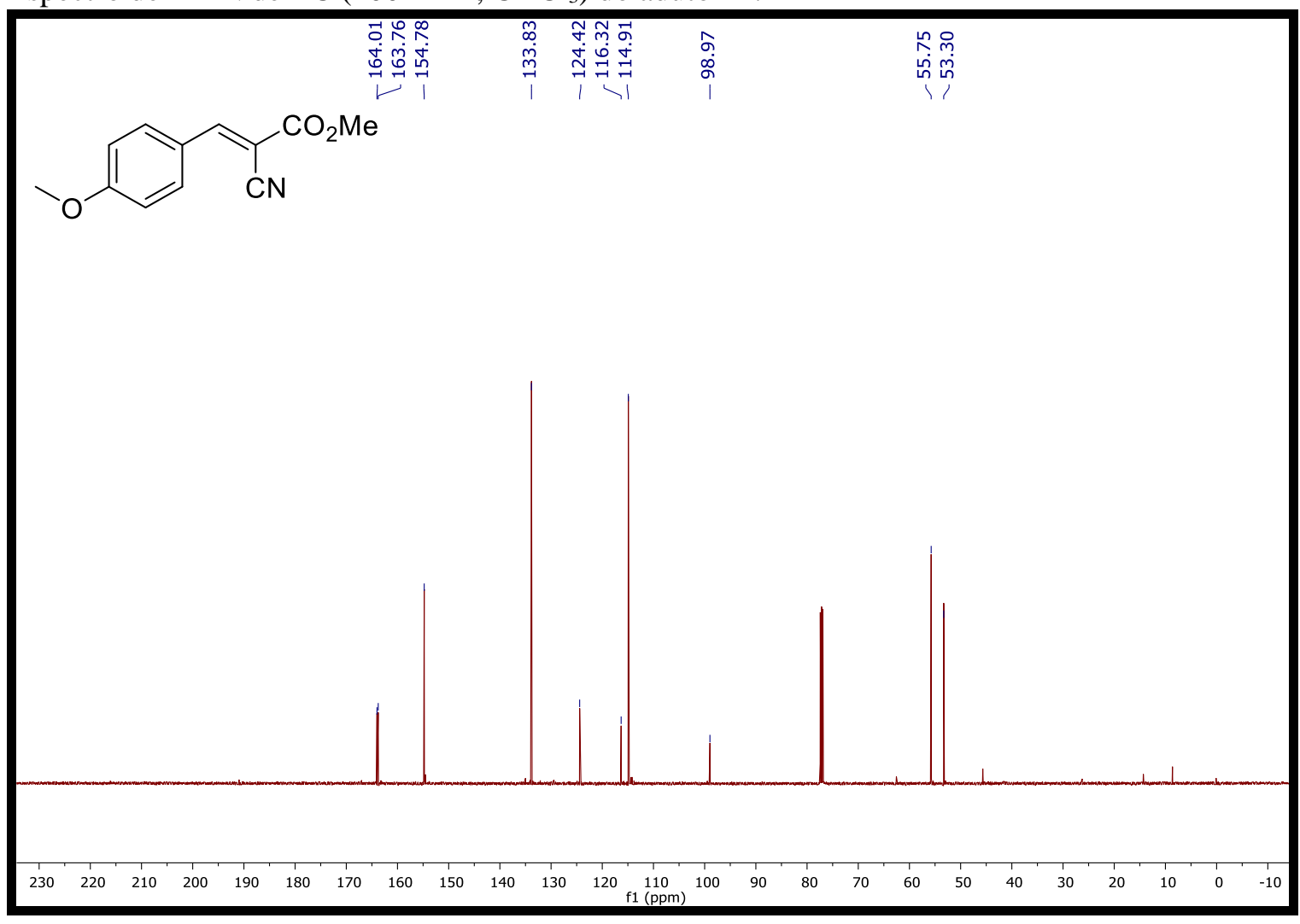


Espectro de absorção no infravermelho do aduto $\mathbf{2 h}$.

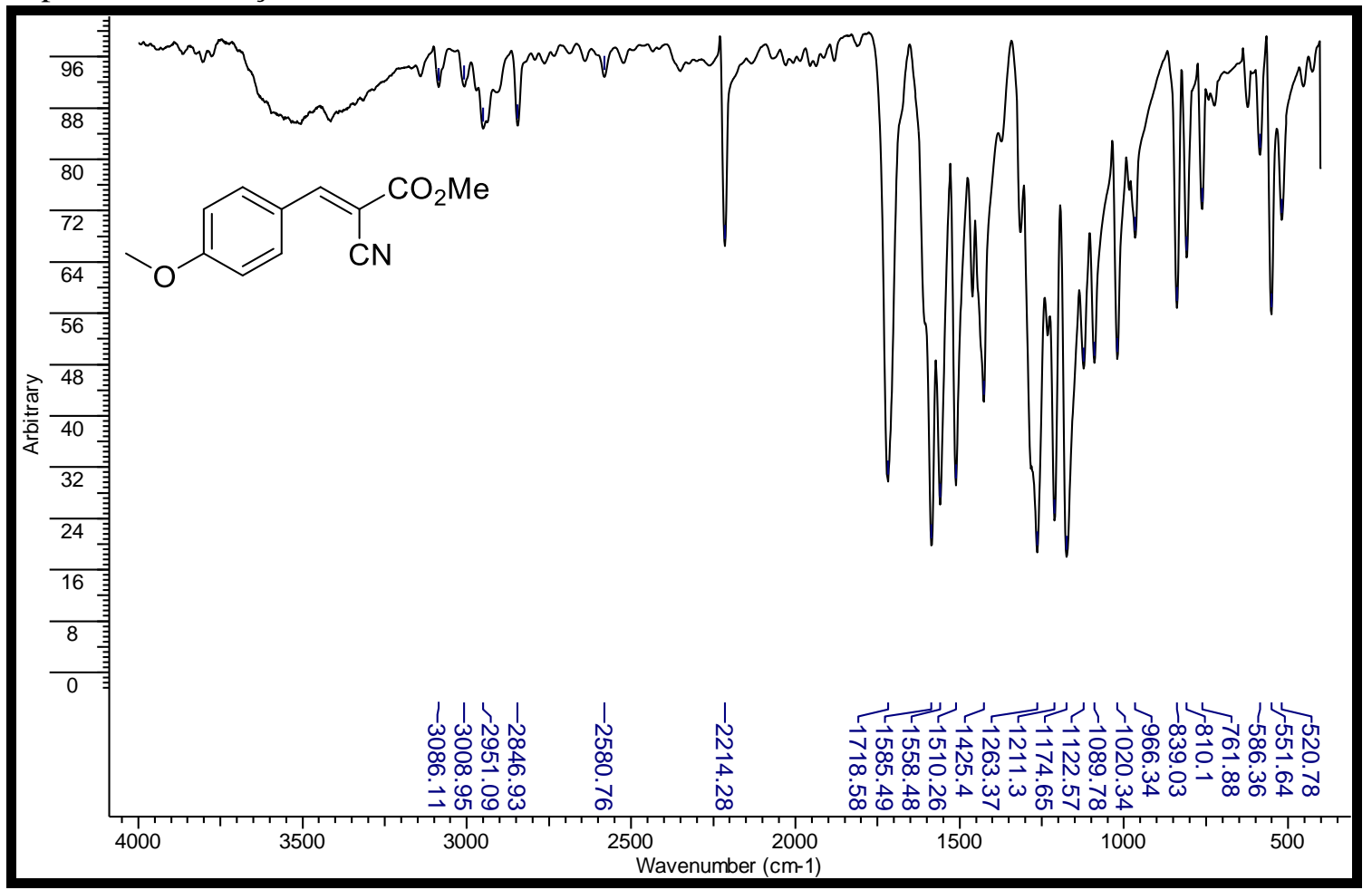

Espectro de massas (IE, $70 \mathrm{eV}$ ) do aduto $\mathbf{2 h}$.

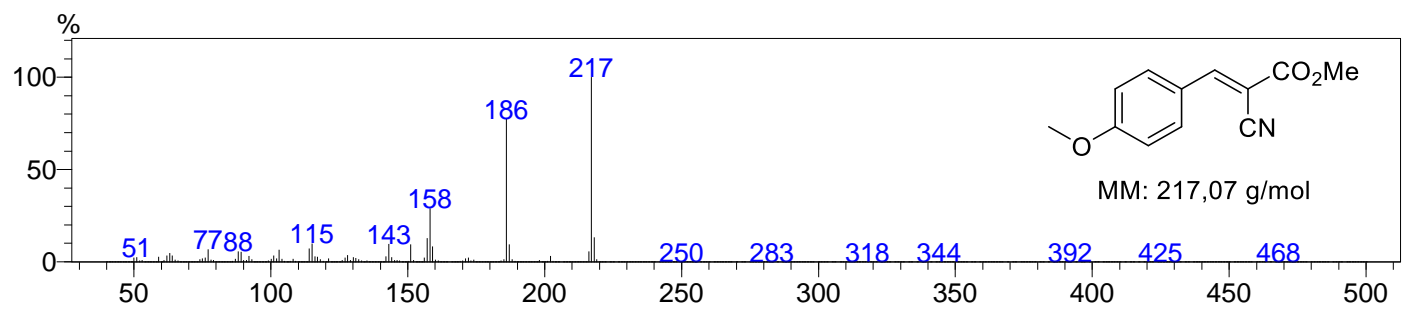


Espectro de RMN de ${ }^{1} \mathrm{H}$ (400 MHz, Acetona- $d_{6}$ ) do aduto $2 \mathbf{i}$.

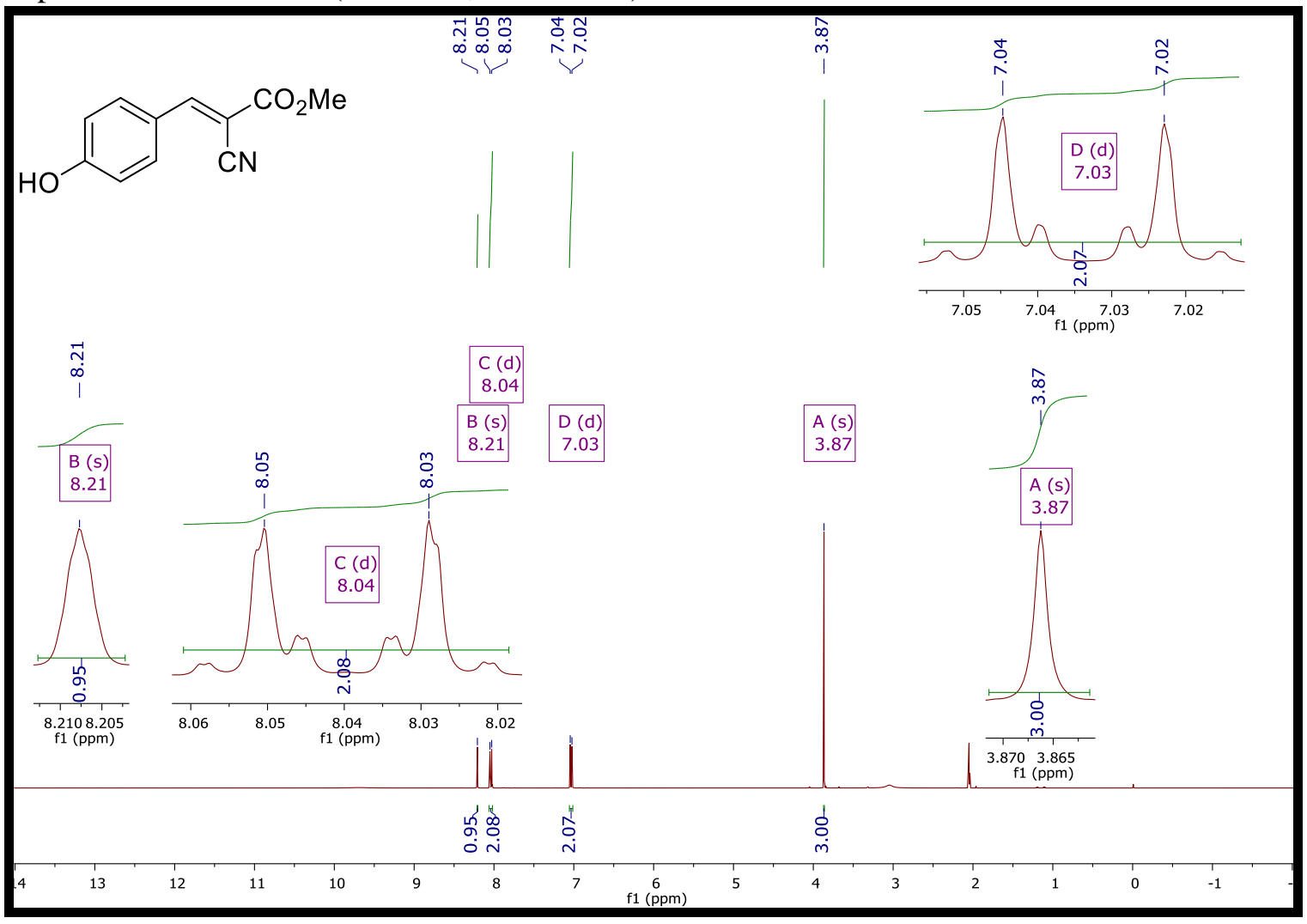

Espectro de RMN de ${ }^{13} \mathrm{C}$ (100 MHz, Acetona- $\left.d_{6}\right)$ do aduto $2 \mathbf{i}$.

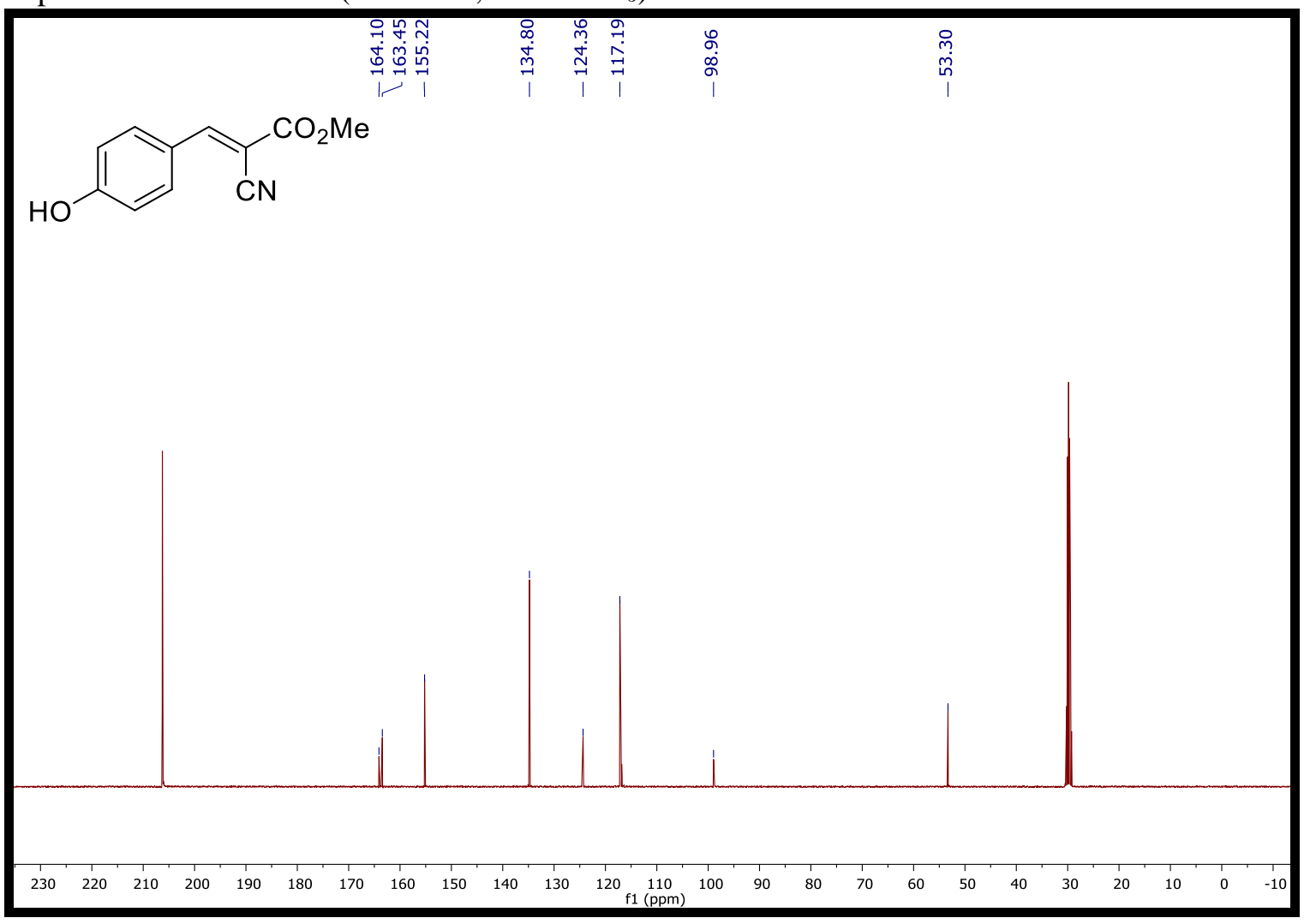


Espectro de absorção no infravermelho do aduto $\mathbf{2 i}$.

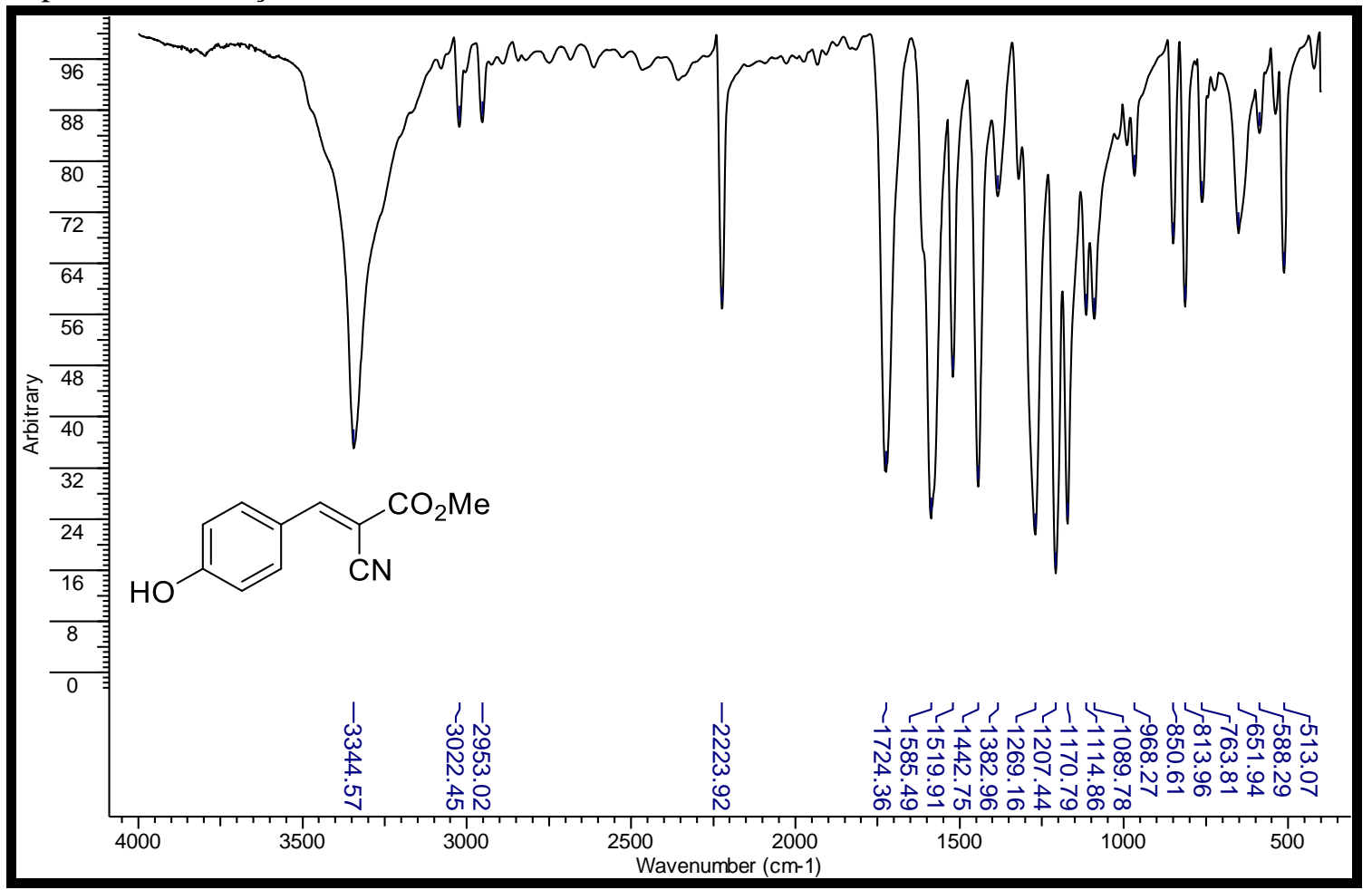

Espectro de massas (IE, $70 \mathrm{eV}$ ) do aduto $2 \mathbf{i}$.

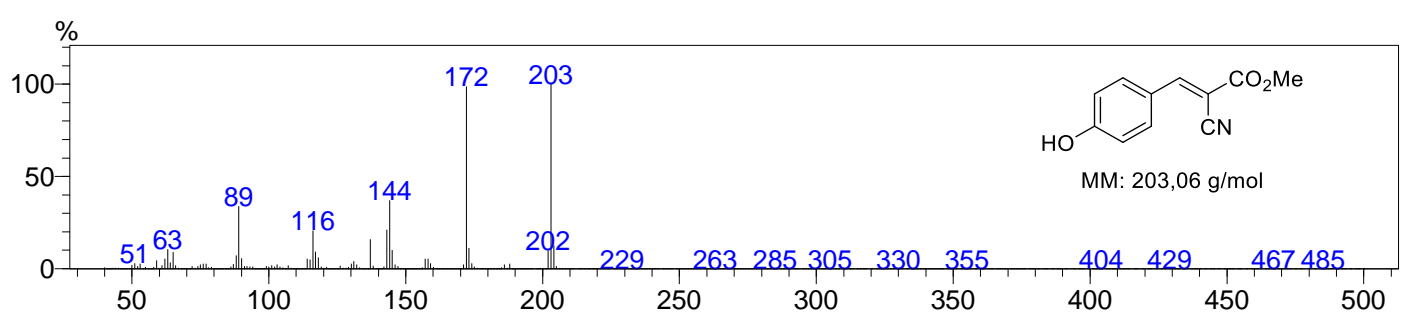


Espectro de RMN de ${ }^{1} \mathrm{H}\left(400 \mathrm{MHz}, \mathrm{CDCl}_{3}\right)$ do aduto $\mathbf{2 j}$.

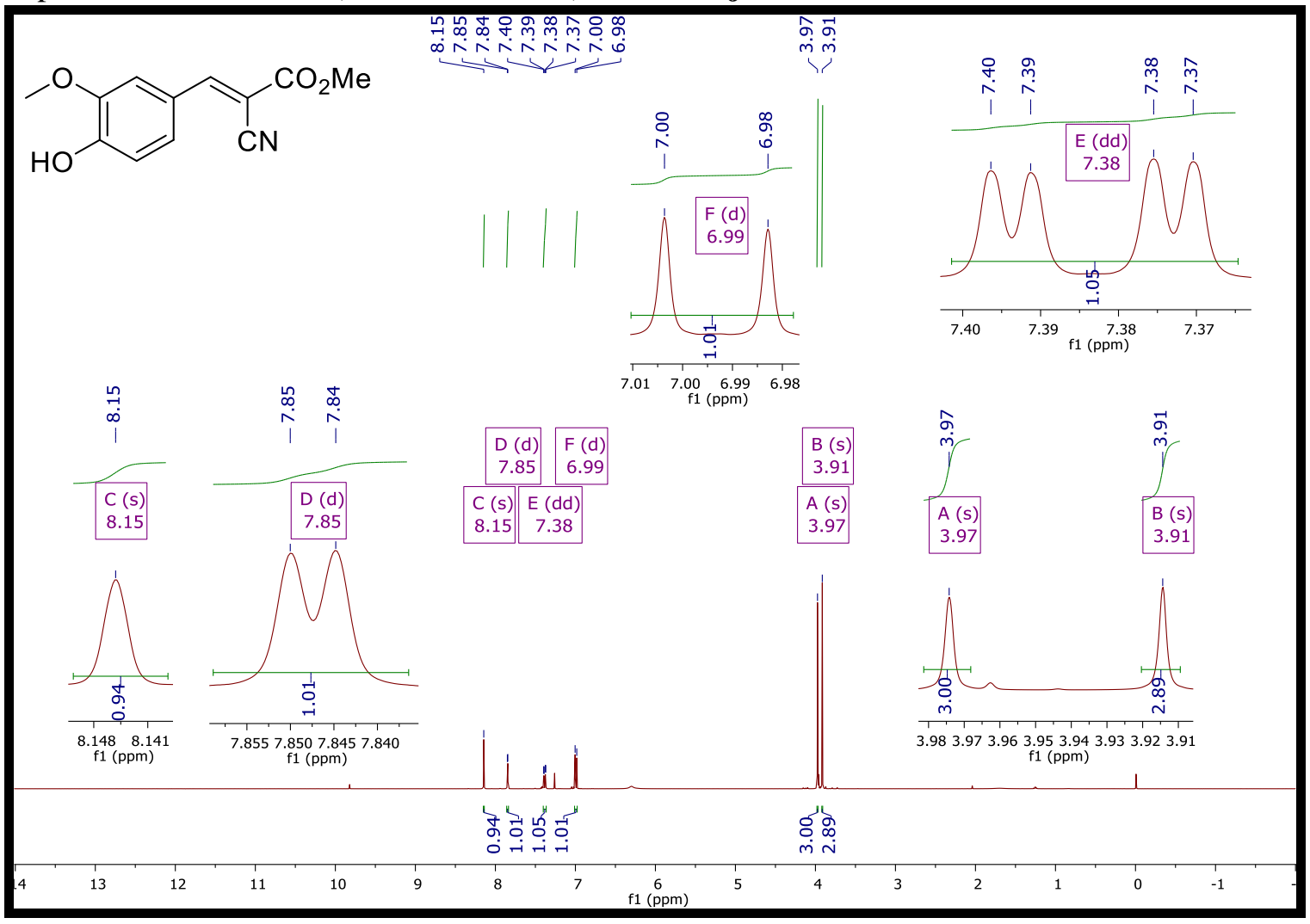

Espectro de RMN de ${ }^{13} \mathrm{C}\left(100 \mathrm{MHz}, \mathrm{CDCl}_{3}\right)$ do aduto $\mathbf{2 j}$.

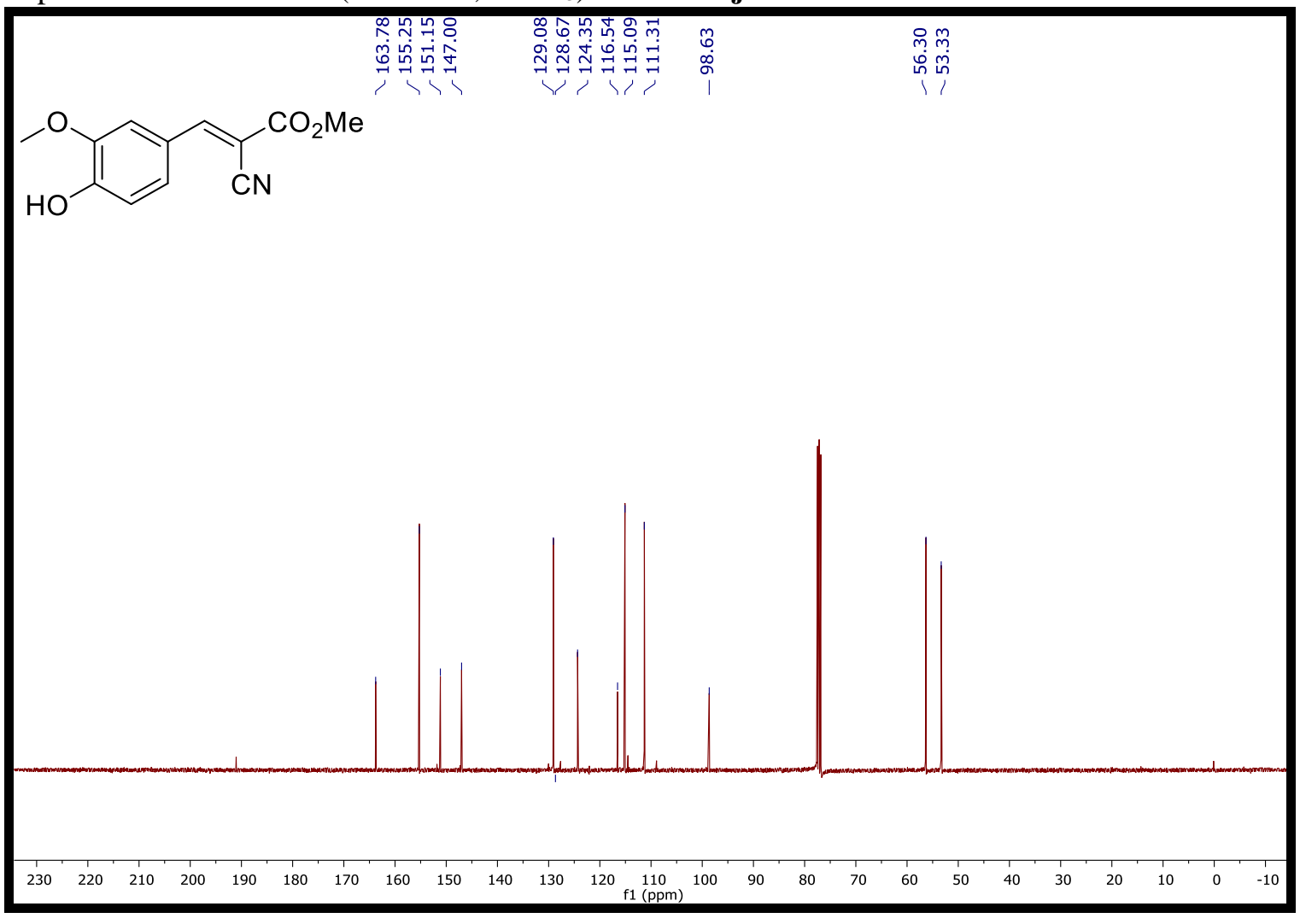


Espectro de absorção no infravermelho do aduto $\mathbf{2 j}$.

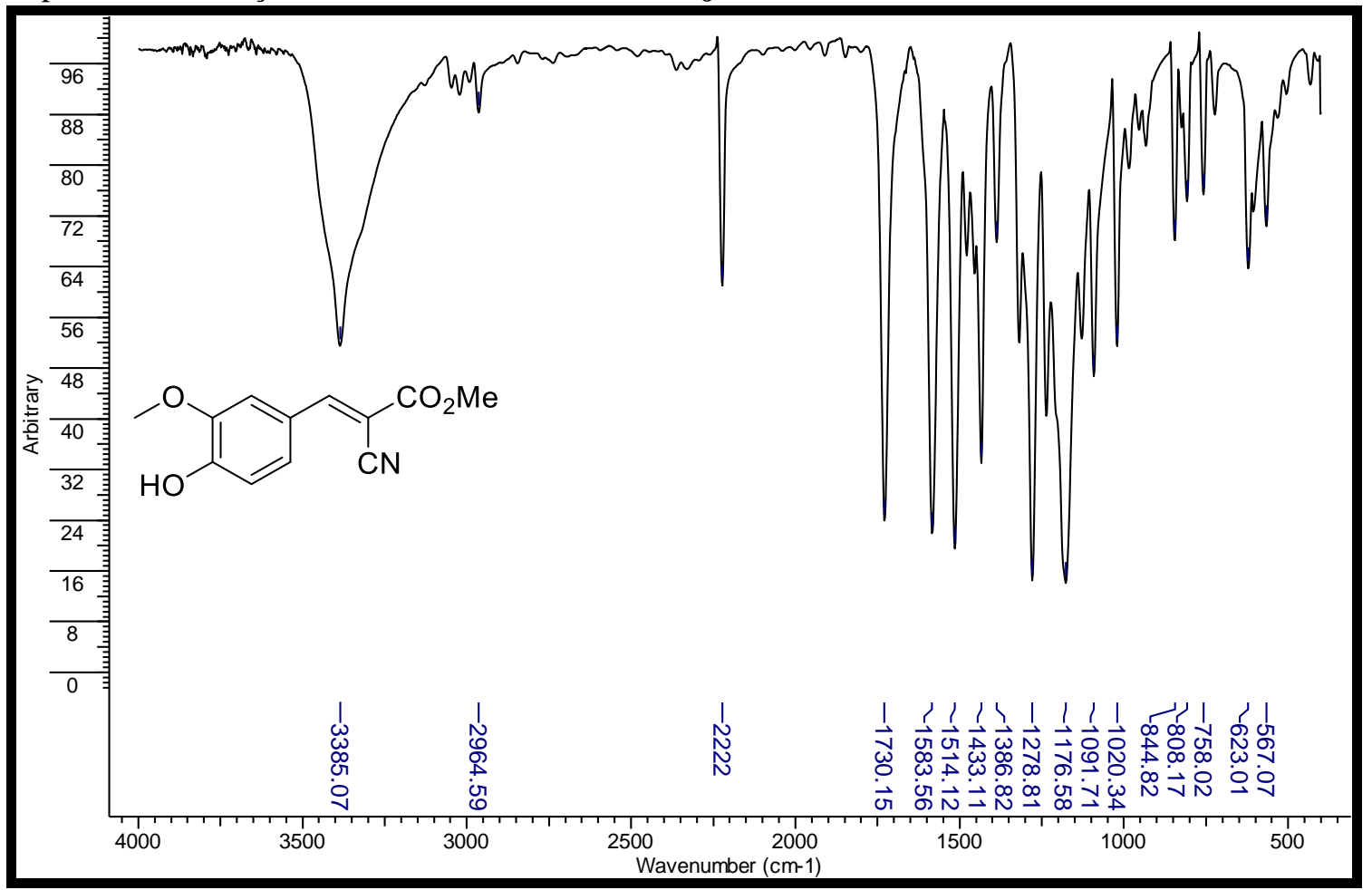

Espectro de massas (IE, $70 \mathrm{eV}$ ) do aduto $\mathbf{2} \mathbf{j}$.

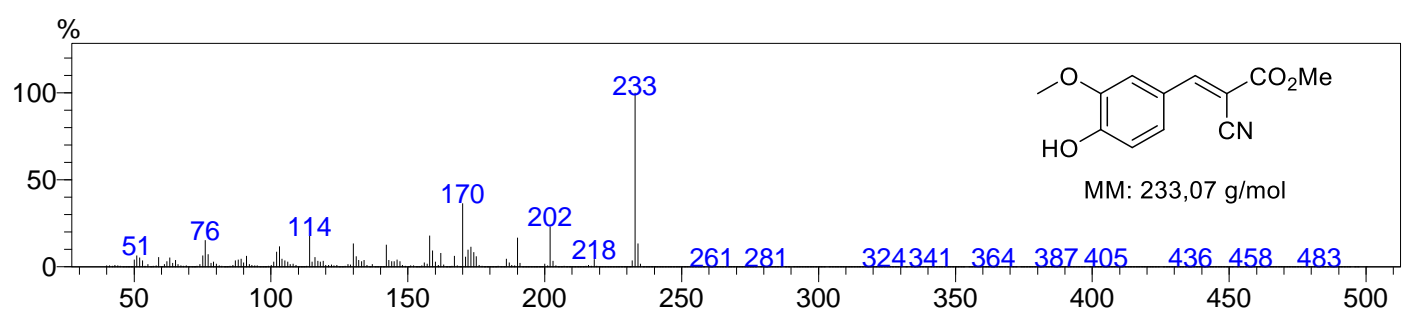


Espectro de RMN de ${ }^{1} \mathrm{H}\left(400 \mathrm{MHz}, \mathrm{CDCl}_{3}\right)$ do aduto $2 \mathbf{k}$.

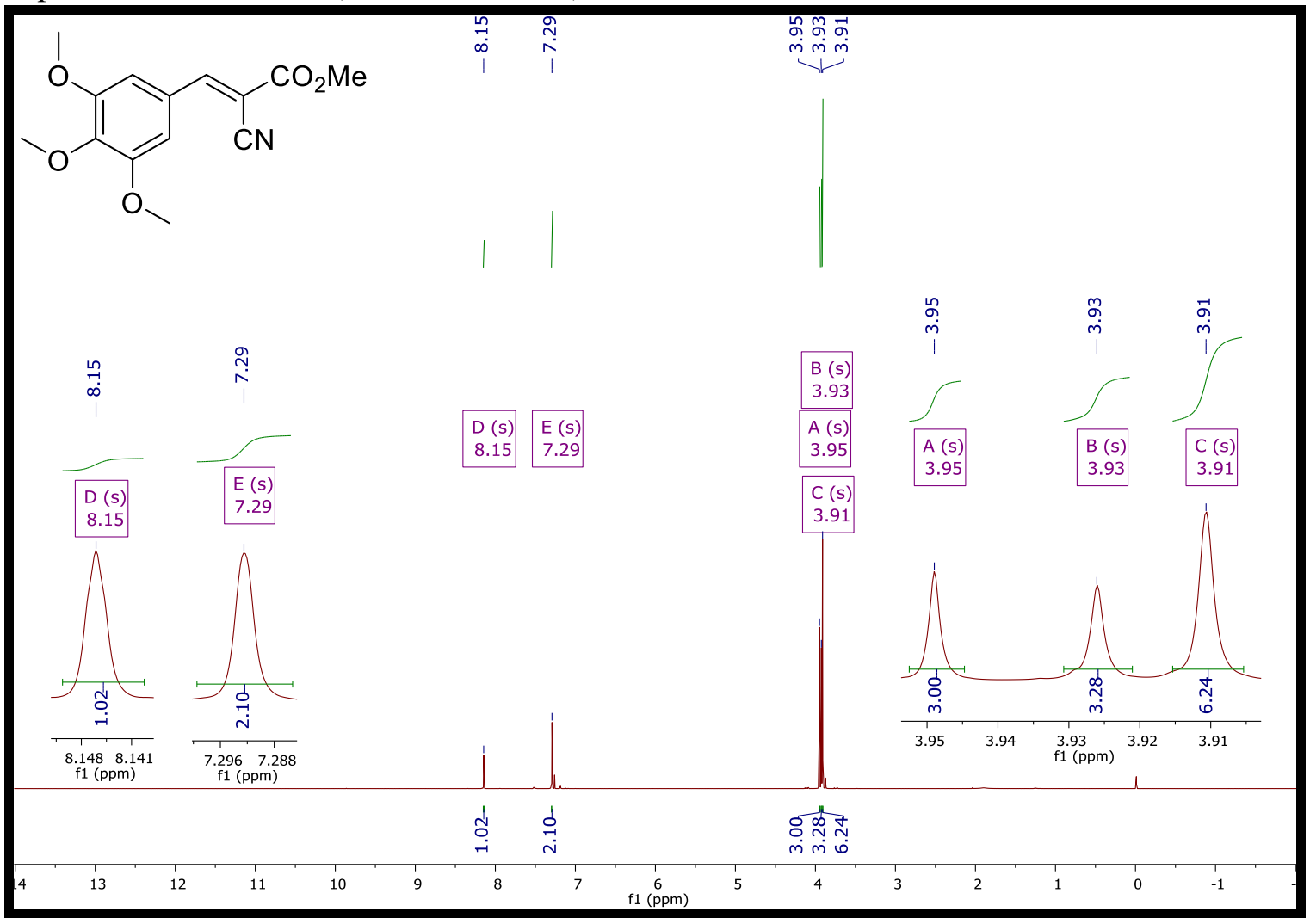

Espectro de RMN de ${ }^{13} \mathrm{C}\left(100 \mathrm{MHz}, \mathrm{CDCl}_{3}\right)$ do aduto $2 \mathbf{k}$.

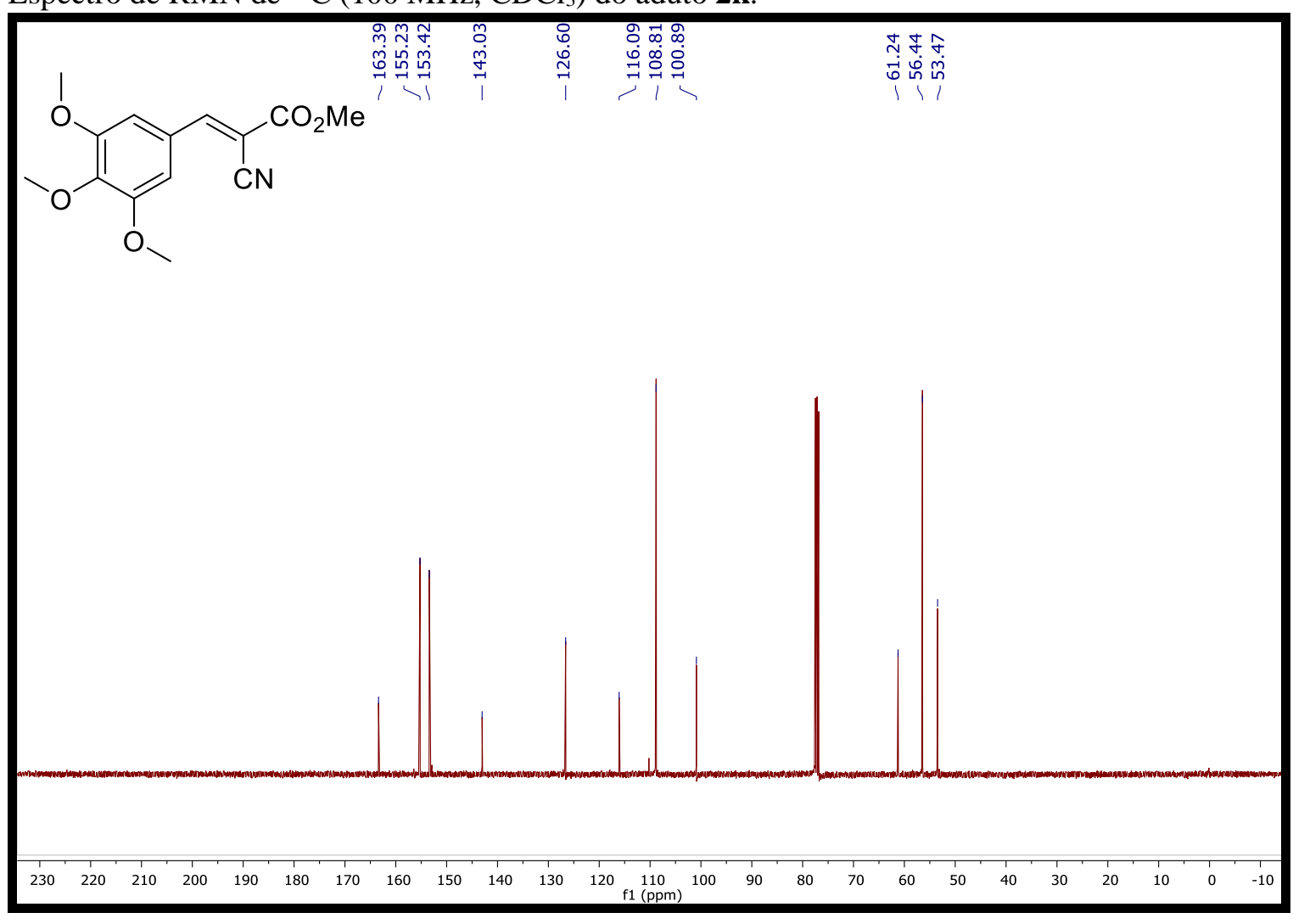


Espectro de absorção no infravermelho do aduto 2k.

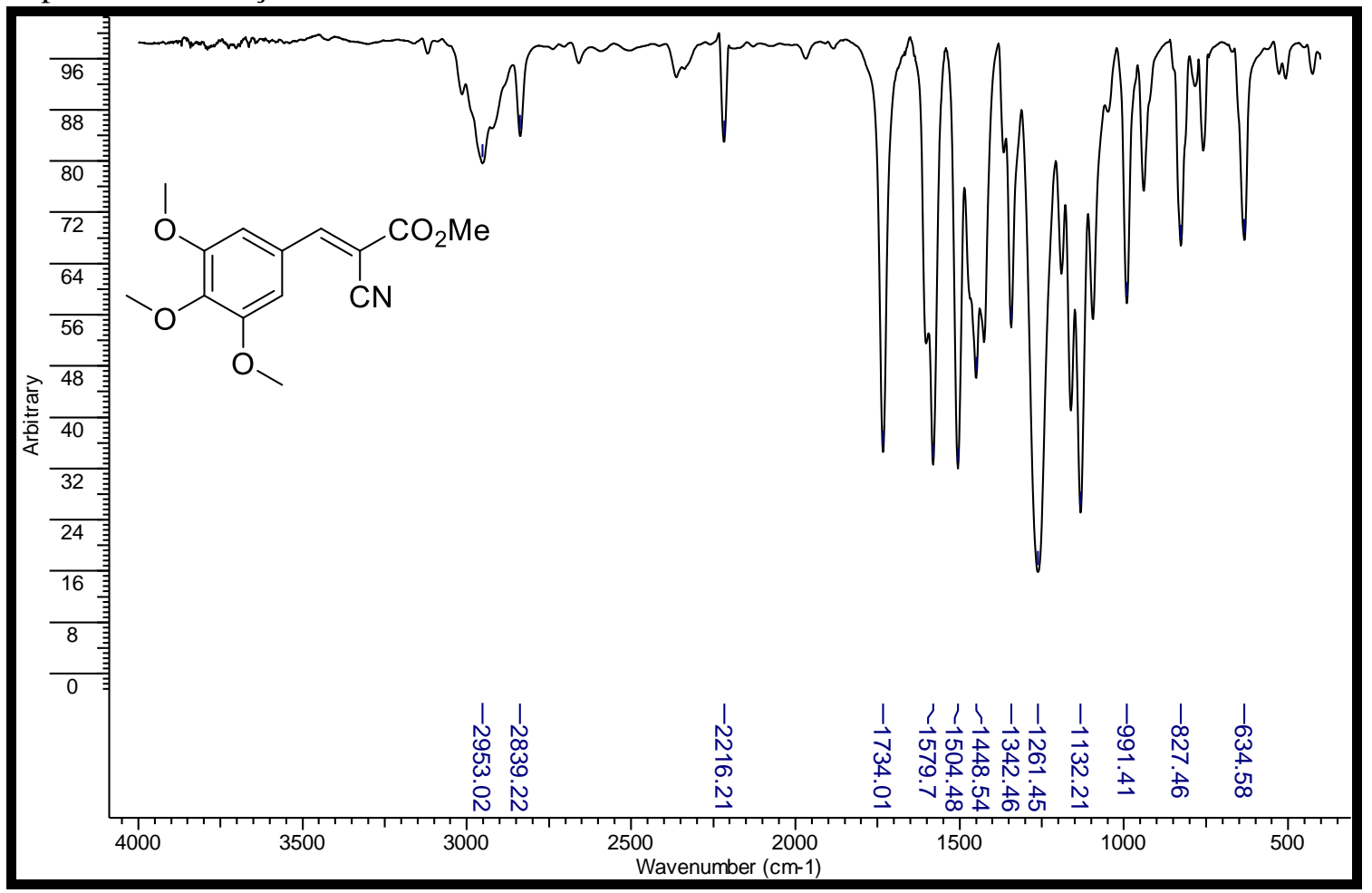

Espectro de massas (IE, $70 \mathrm{eV}$ ) do aduto $\mathbf{2 k}$.

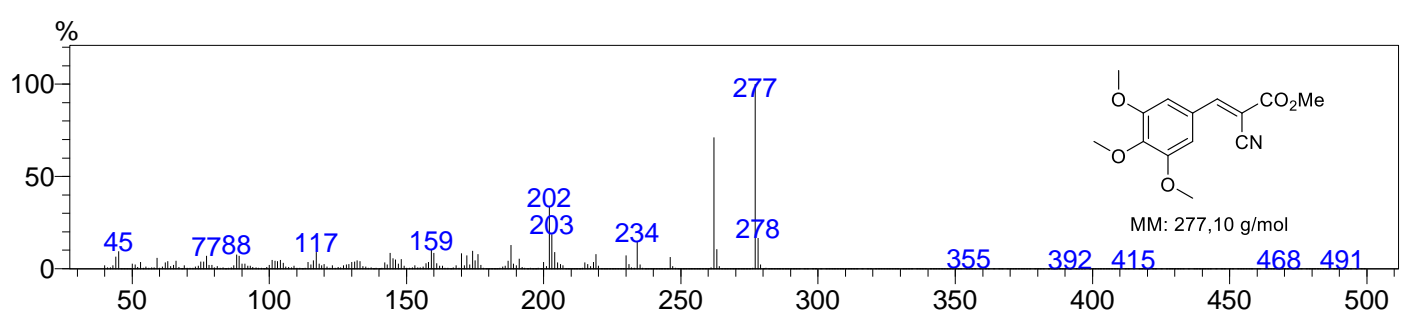


Espectro de RMN de ${ }^{1} \mathrm{H}\left(400 \mathrm{MHz}, \mathrm{CDCl}_{3}\right)$ do aduto $2 \mathbf{2}$.

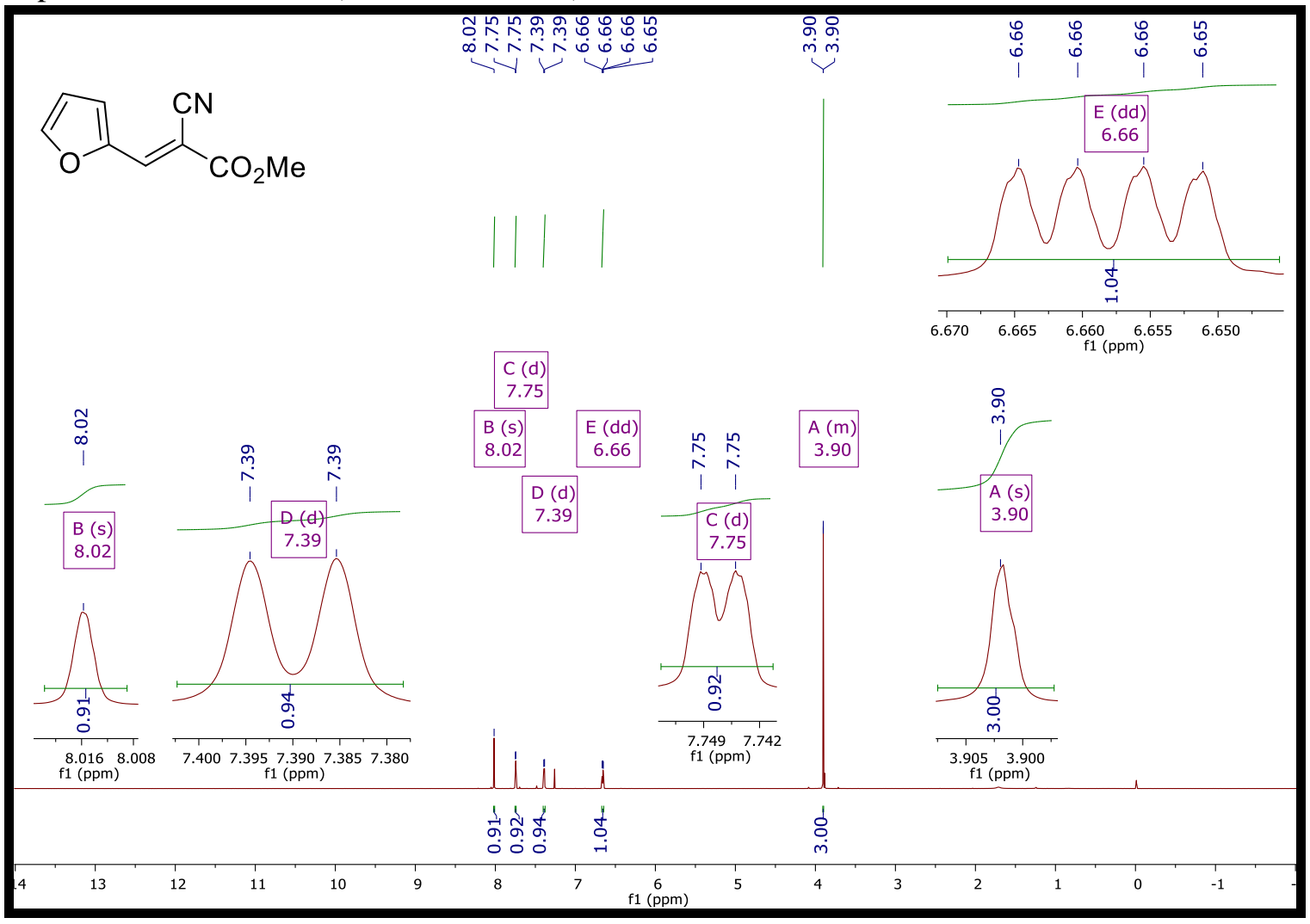

Espectro de RMN de ${ }^{13} \mathrm{C}\left(100 \mathrm{MHz}, \mathrm{CDCl}_{3}\right)$ do aduto $2 \mathbf{l}$.

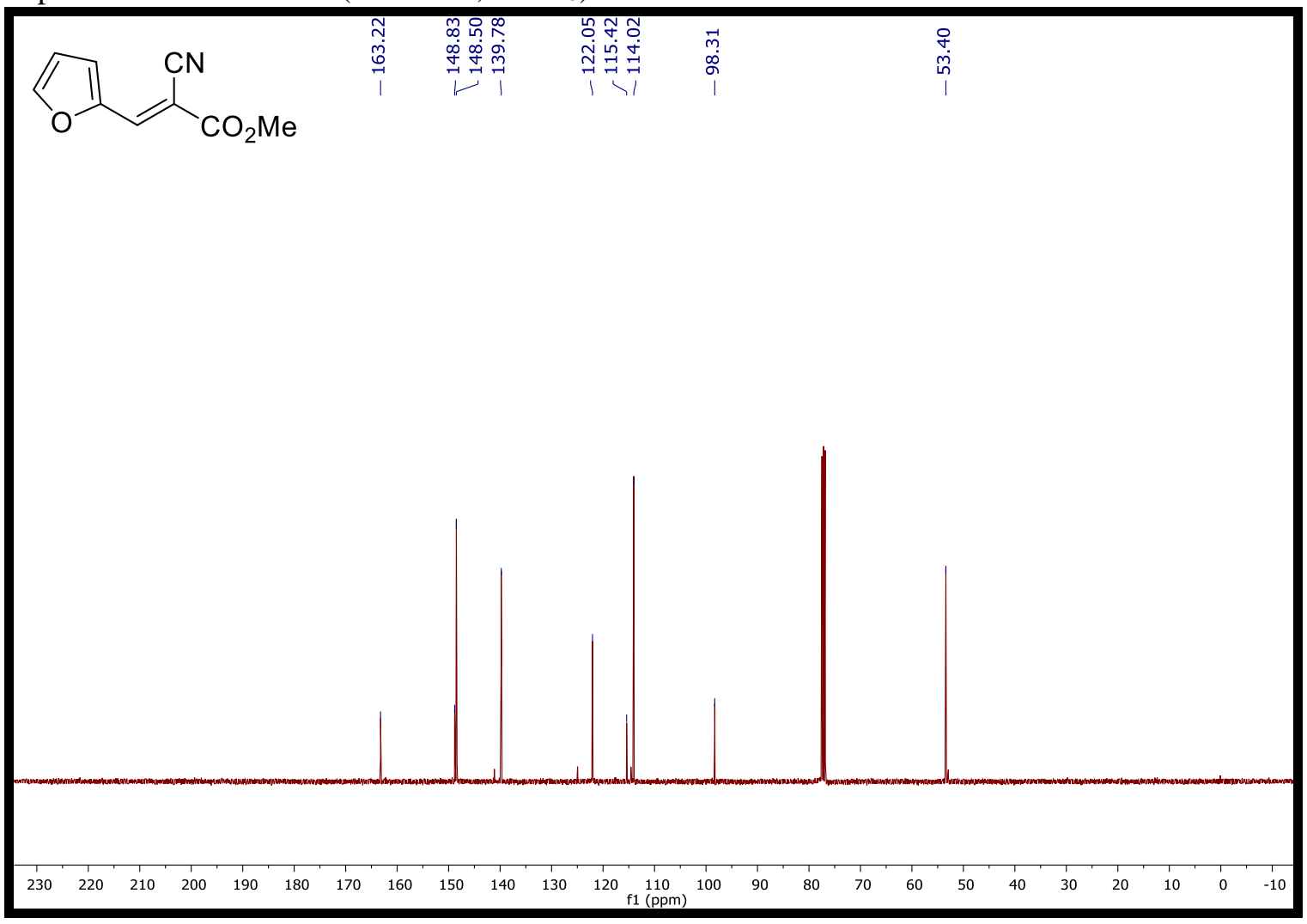


Espectro de absorção no infravermelho do aduto $2 \mathbf{2}$.

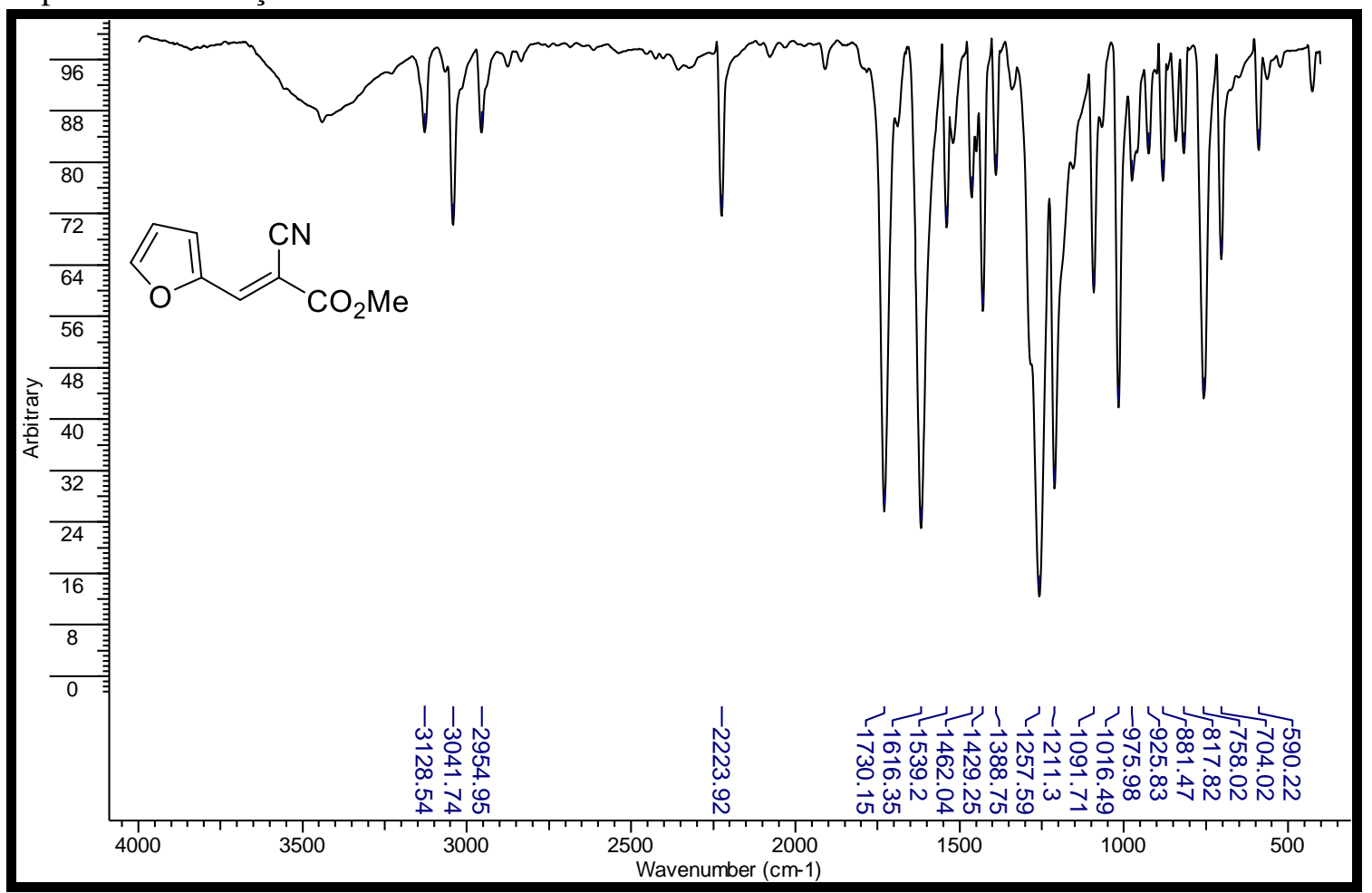

Espectro de massas (IE, $70 \mathrm{eV}$ ) do aduto 21.

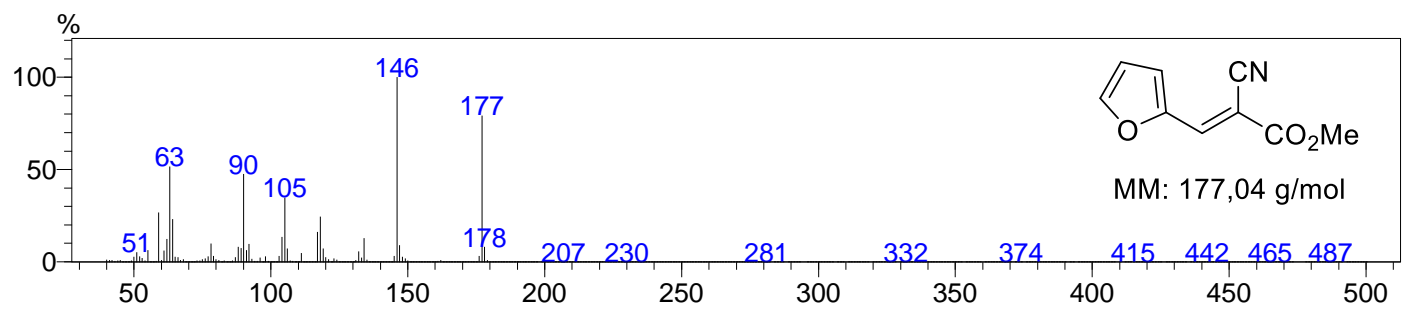




\subsection{Espectros dos $4 H$-cromenos 3a-j}

Espectro de RMN de ${ }^{1} \mathrm{H}\left(400 \mathrm{MHz}, \mathrm{DMSO}-d_{6}\right)$ do $4 H$-cromeno 3a.

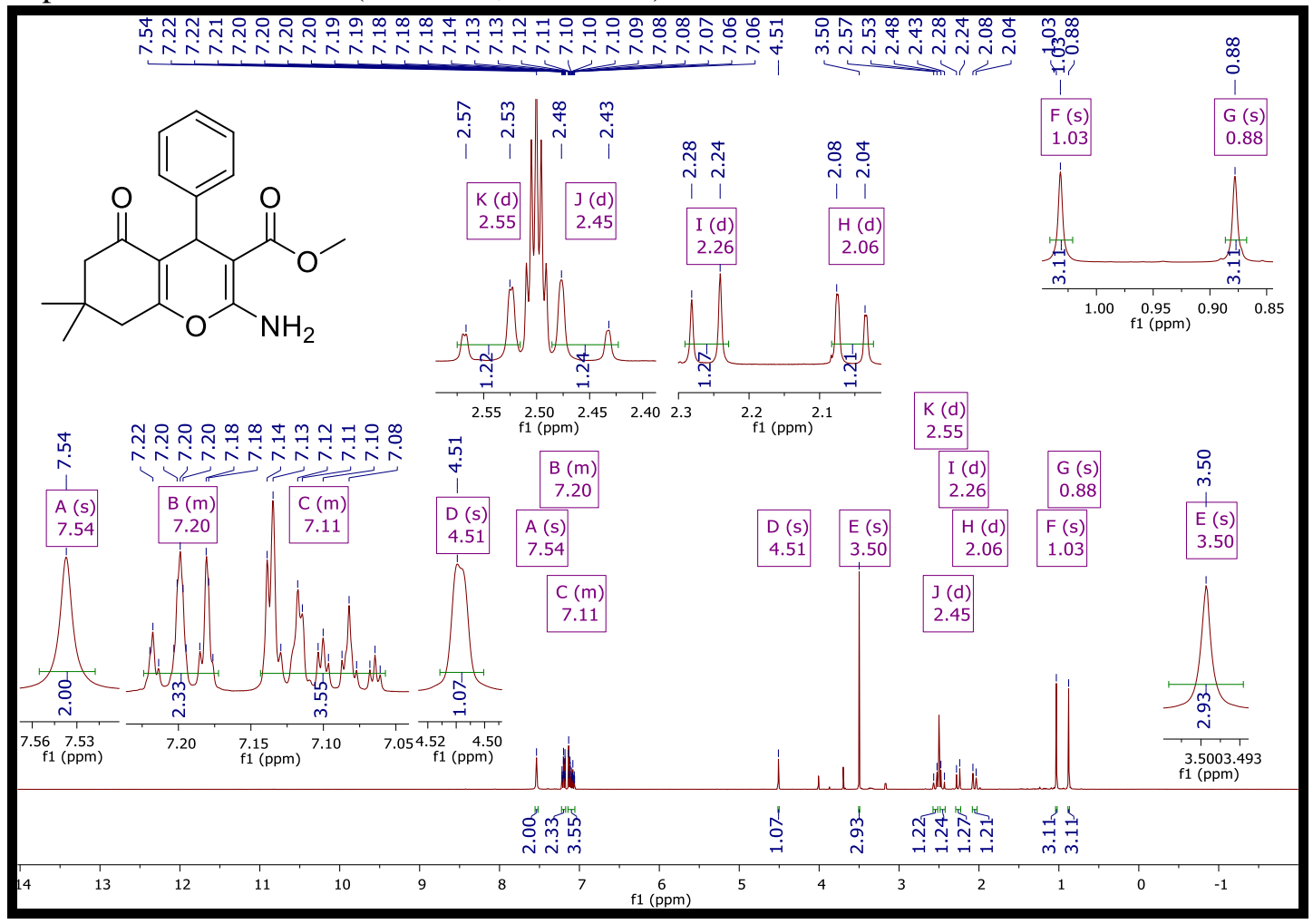

Espectro de RMN de ${ }^{13} \mathrm{C}$ (100 MHz, DMSO- $\left.d_{6}\right)$ do $4 H$-cromeno 3a.

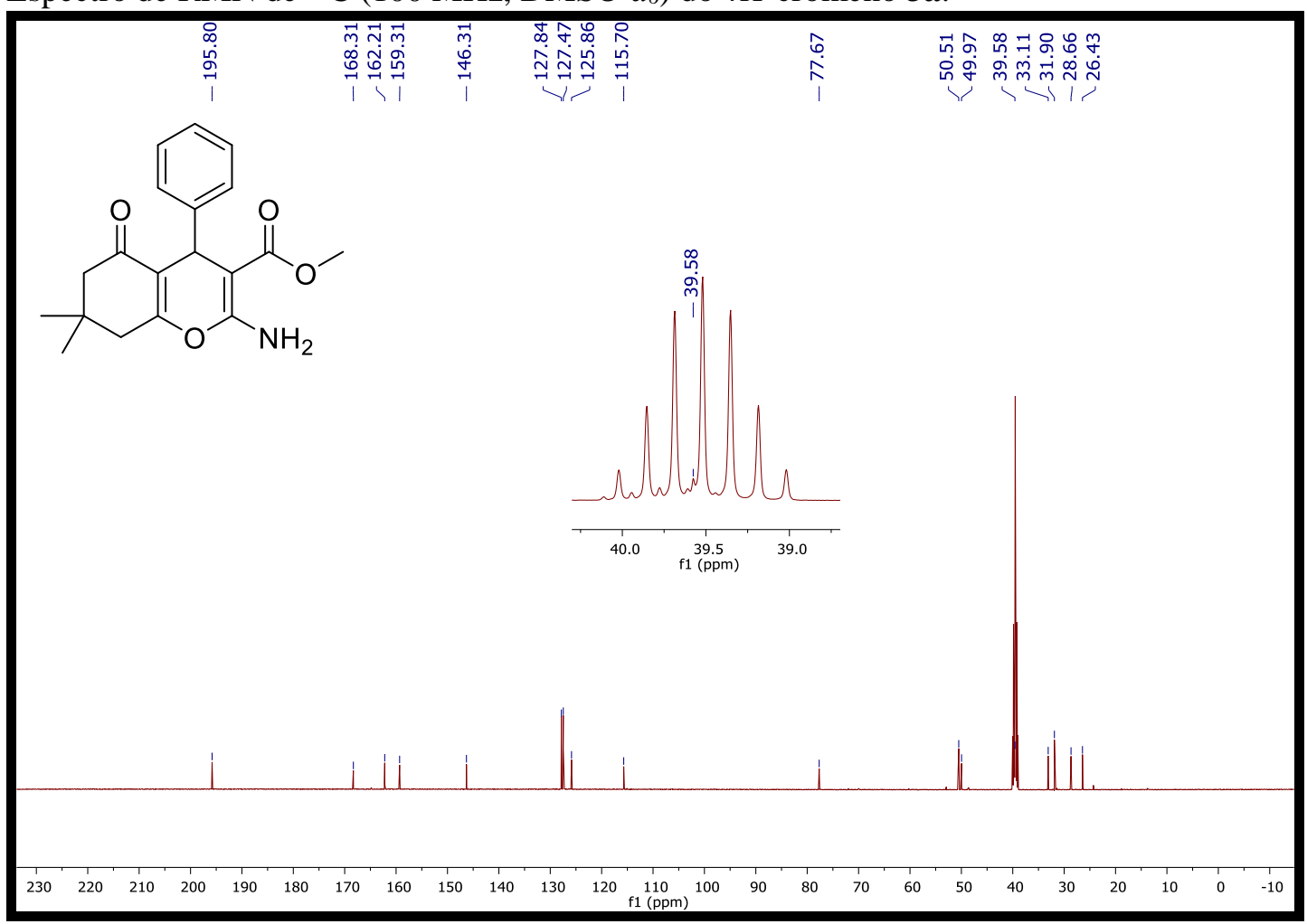


Espectro de massas de alta resolução LTQ-Orbitrap Velos (Thermo Scientific), com fonte de ionização eletronspray em modo positivo $[\mathrm{M}+\mathrm{H}]^{+}$para o $4 H$-cromeno 3a.

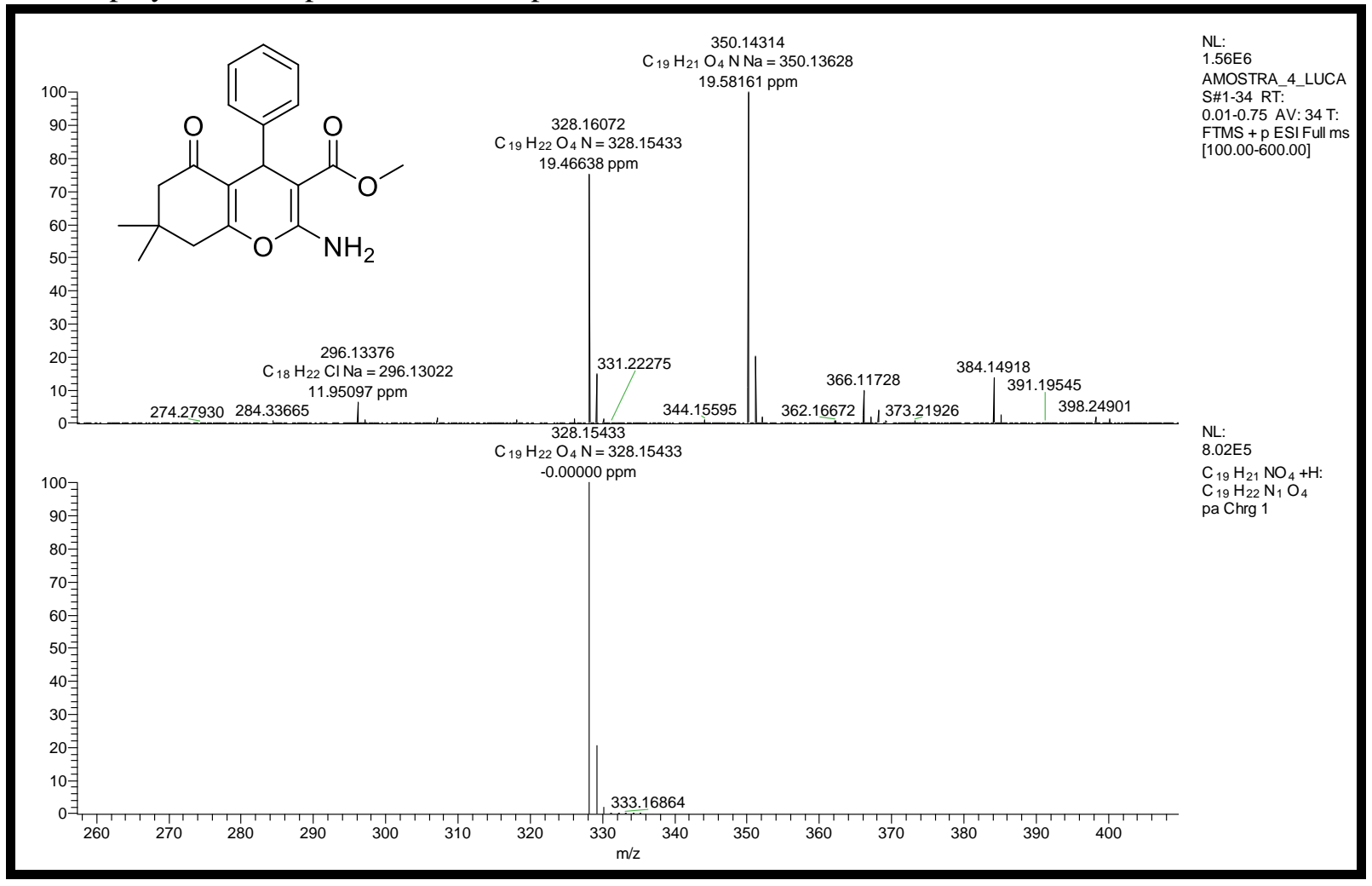

Espectro de absorção no infravermelho do $4 H$ cromeno $\mathbf{3 a}$.

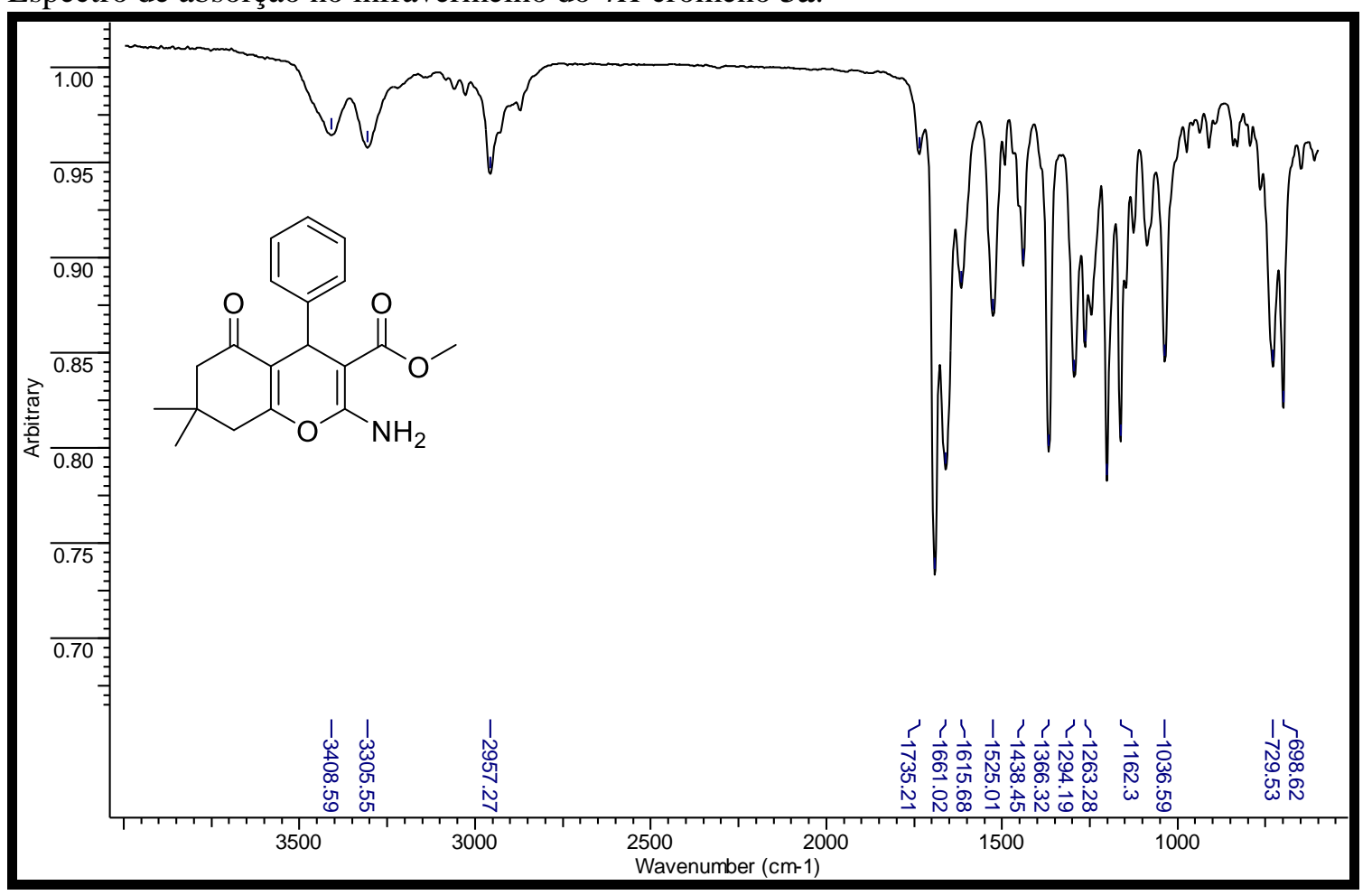


Espectro de RMN de ${ }^{1} \mathrm{H}\left(400 \mathrm{MHz}, \mathrm{DMSO}-d_{6}\right)$ do $4 H$-cromeno 3c.

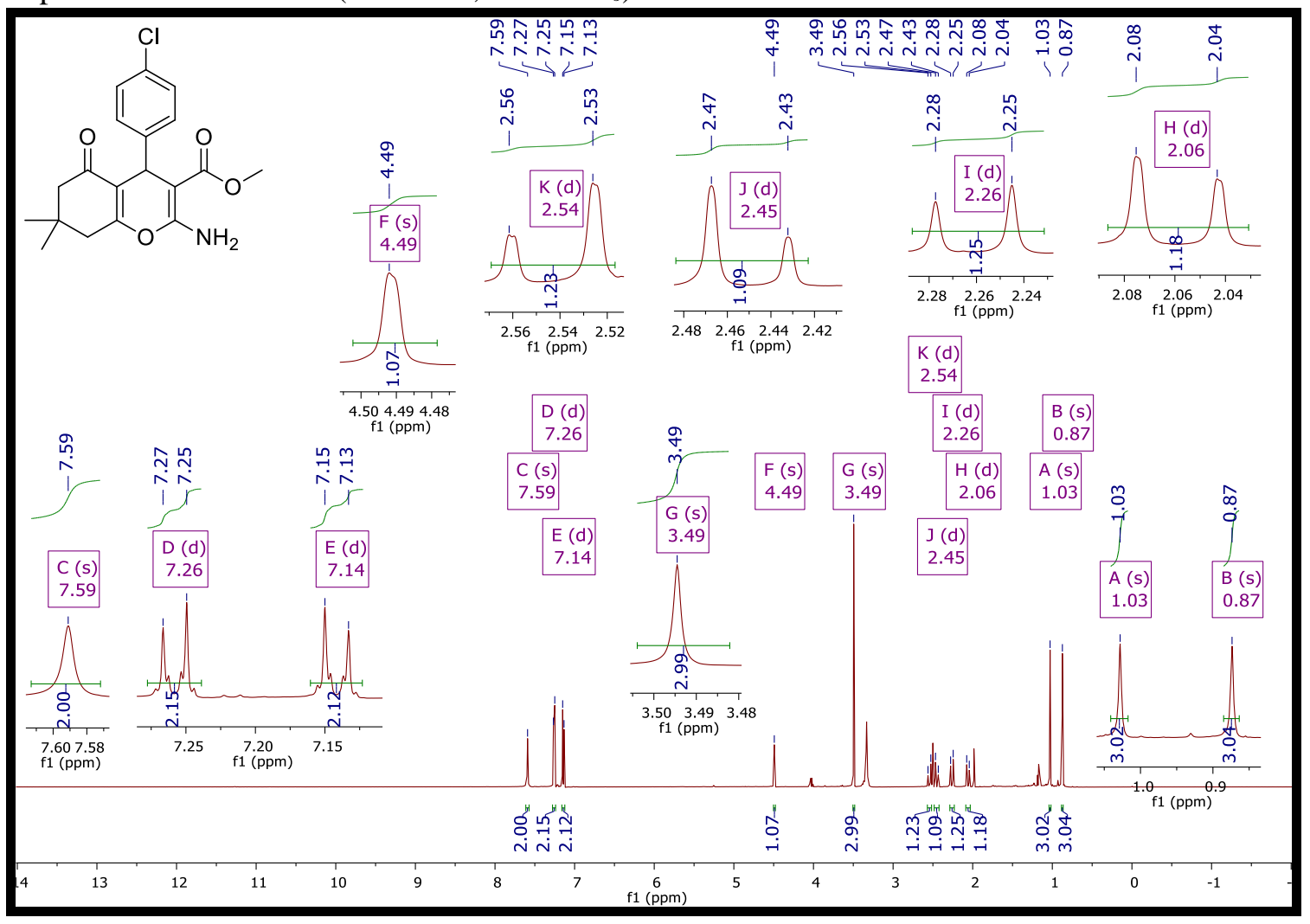

Espectro de RMN de ${ }^{13} \mathrm{C}\left(100 \mathrm{MHz}\right.$, DMSO- $\left.d_{6}\right)$ do $4 H$-cromeno 3c.

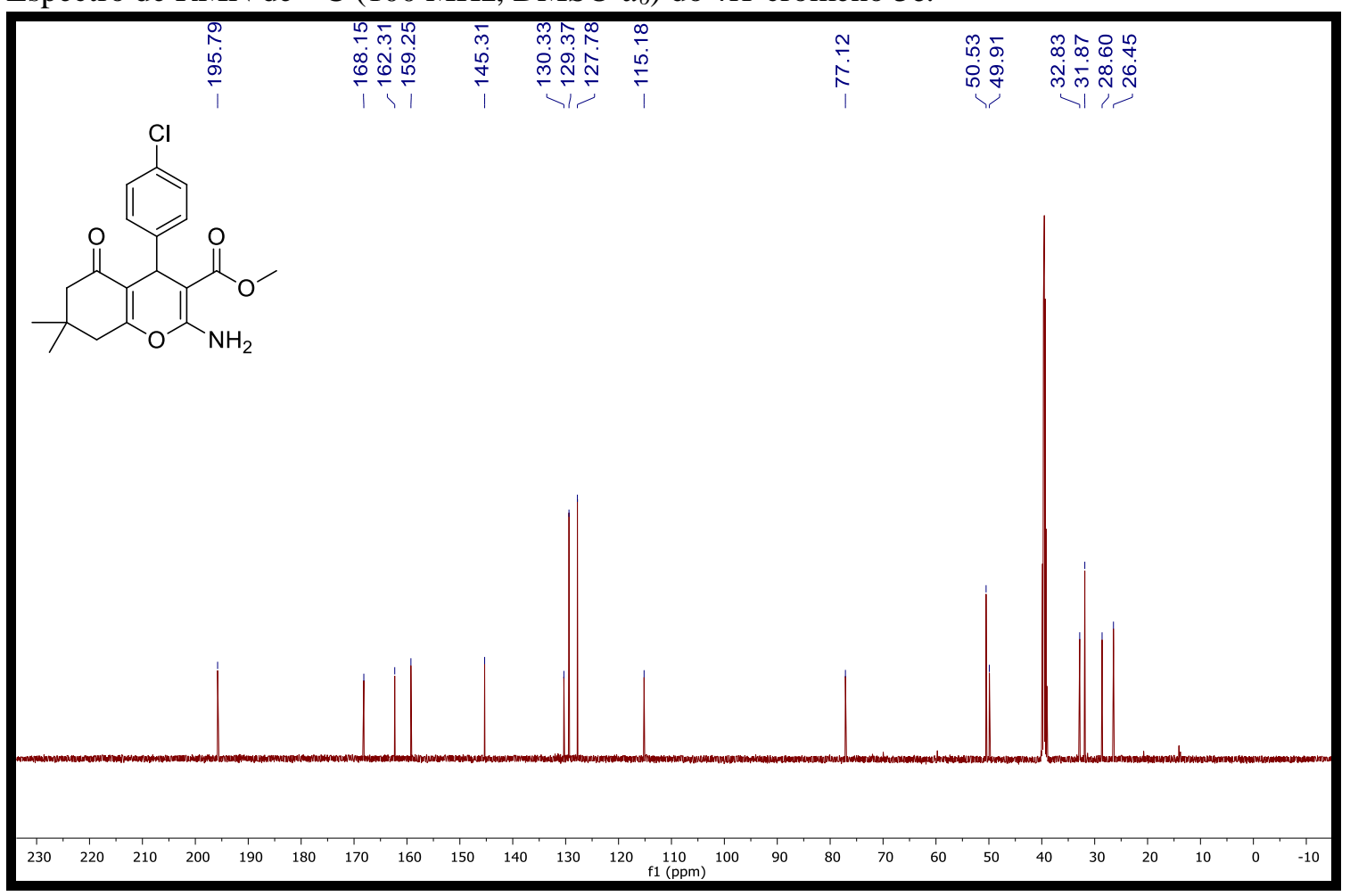


Espectro de massas de alta resolução LTQ-Orbitrap Velos (Thermo Scientific), com fonte de ionização eletronspray em modo positivo $[\mathrm{M}+\mathrm{H}]^{+}$para o $4 H$-cromeno $3 \mathbf{c}$.

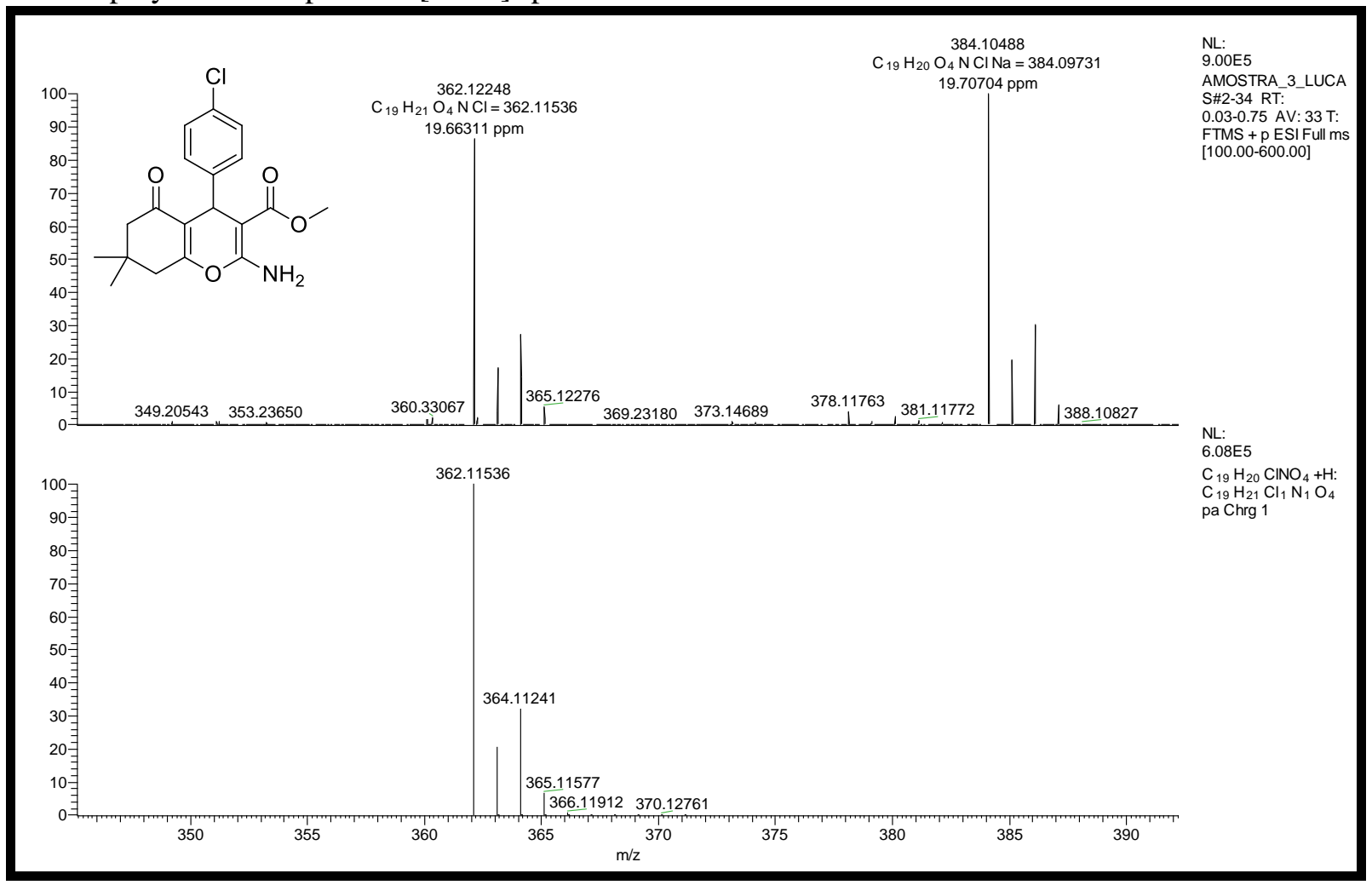

Espectro de absorção no infravermelho do $4 H$-cromeno 3c.

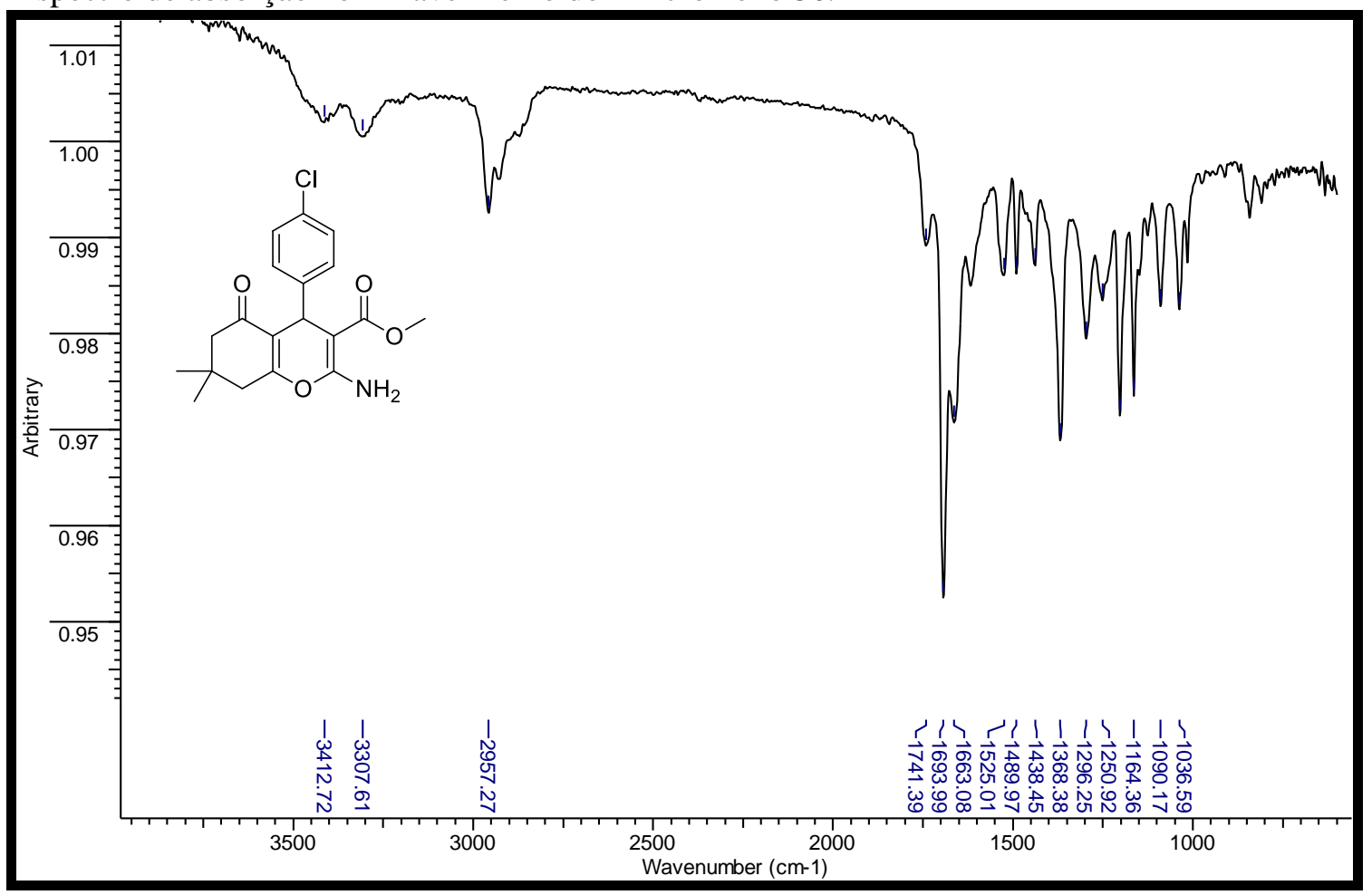


Espectro de RMN de ${ }^{1} \mathrm{H}\left(400 \mathrm{MHz}, \mathrm{DMSO}-d_{6}\right)$ do $4 H$-cromeno 3d.

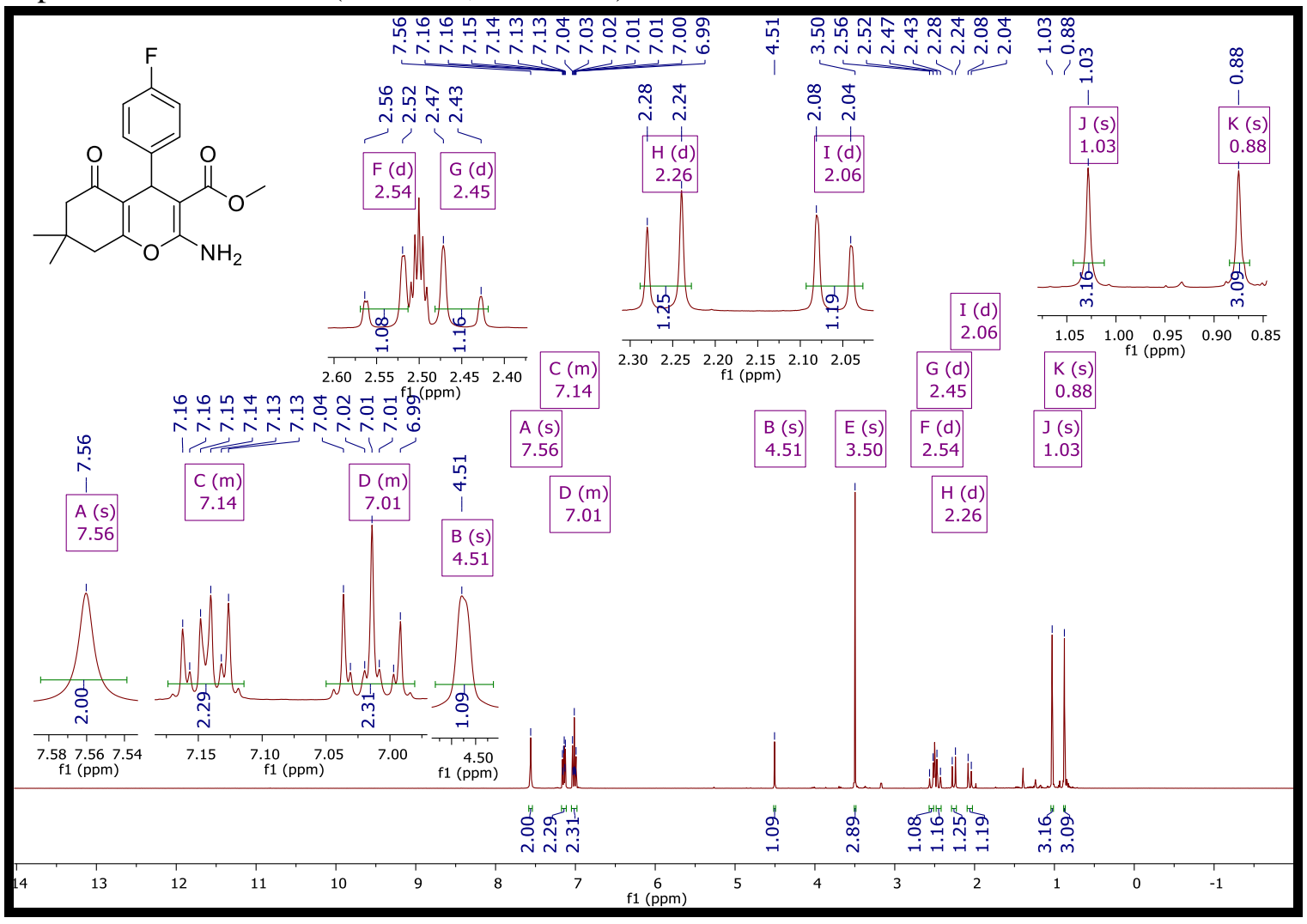

Espectro de RMN de ${ }^{13} \mathrm{C}$ (100 MHz, DMSO- $\left.d_{6}\right)$ do $4 H$-cromeno 3d.

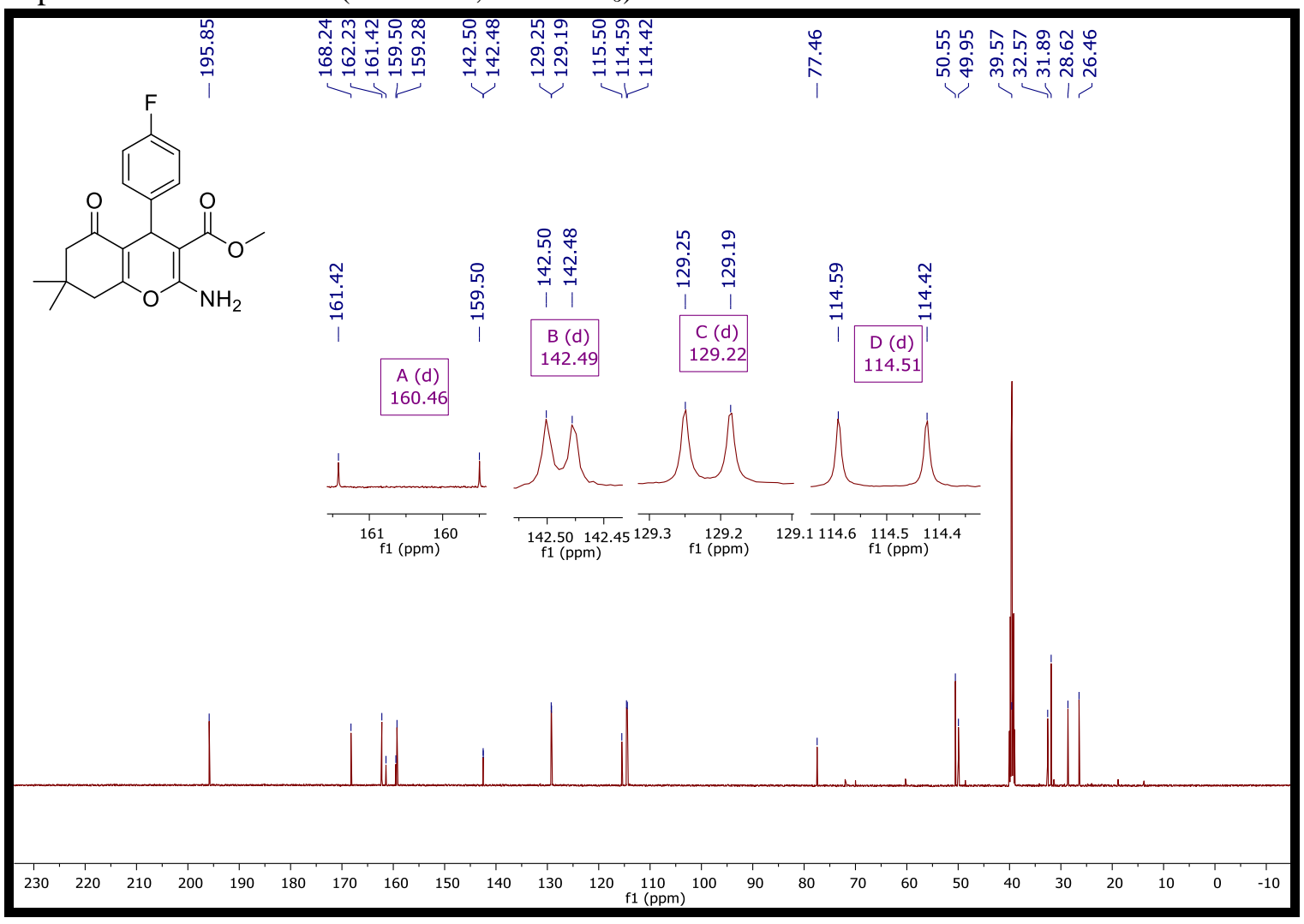


Espectro de massas de alta resolução LTQ-Orbitrap Velos (Thermo Scientific), com fonte de ionização eletronspray em modo positivo $[\mathrm{M}+\mathrm{H}]^{+}$para o $4 H$-cromeno $3 d$.

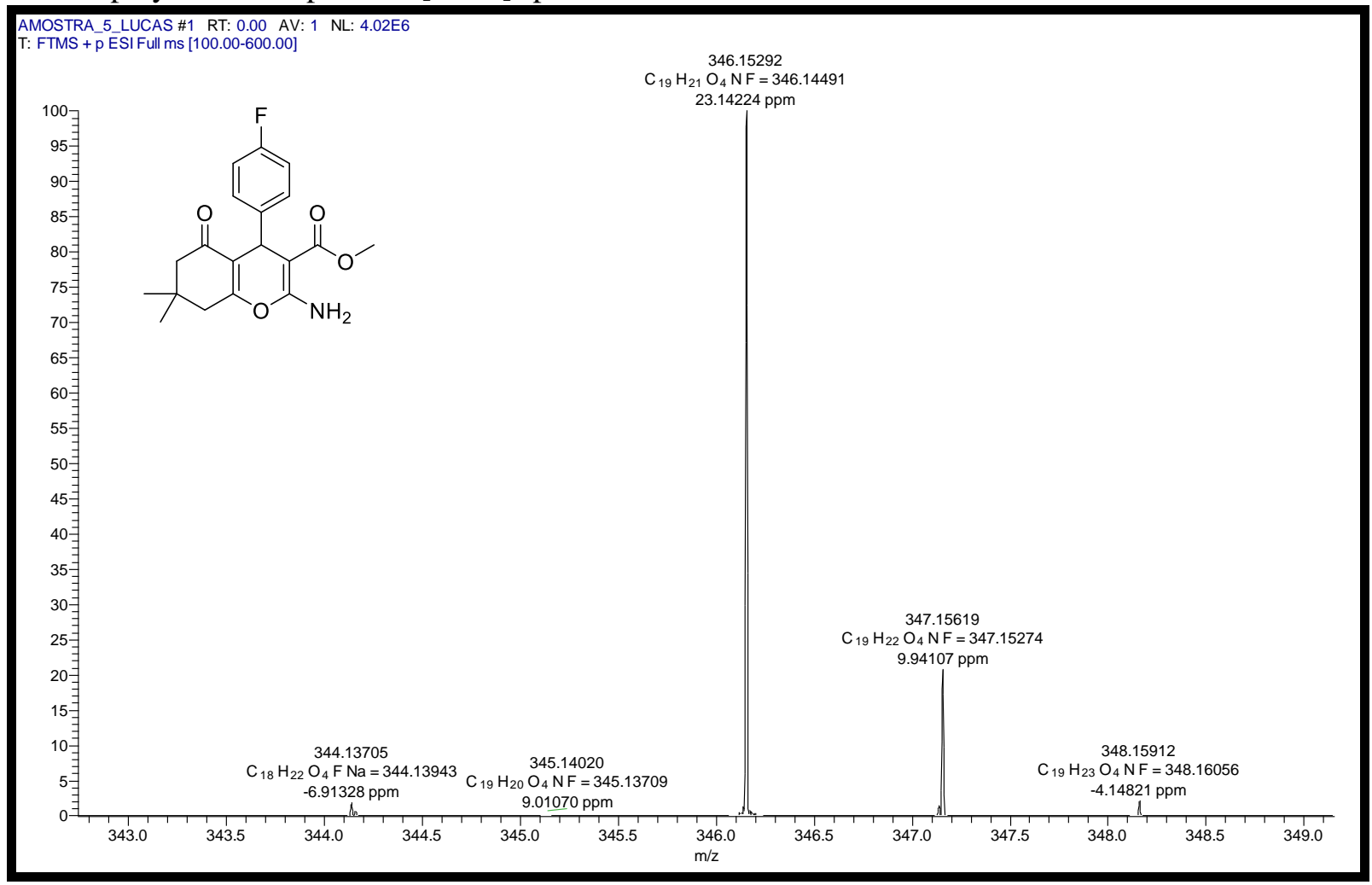

Espectro de absorção no infravermelho do $4 H$-cromeno 3d.

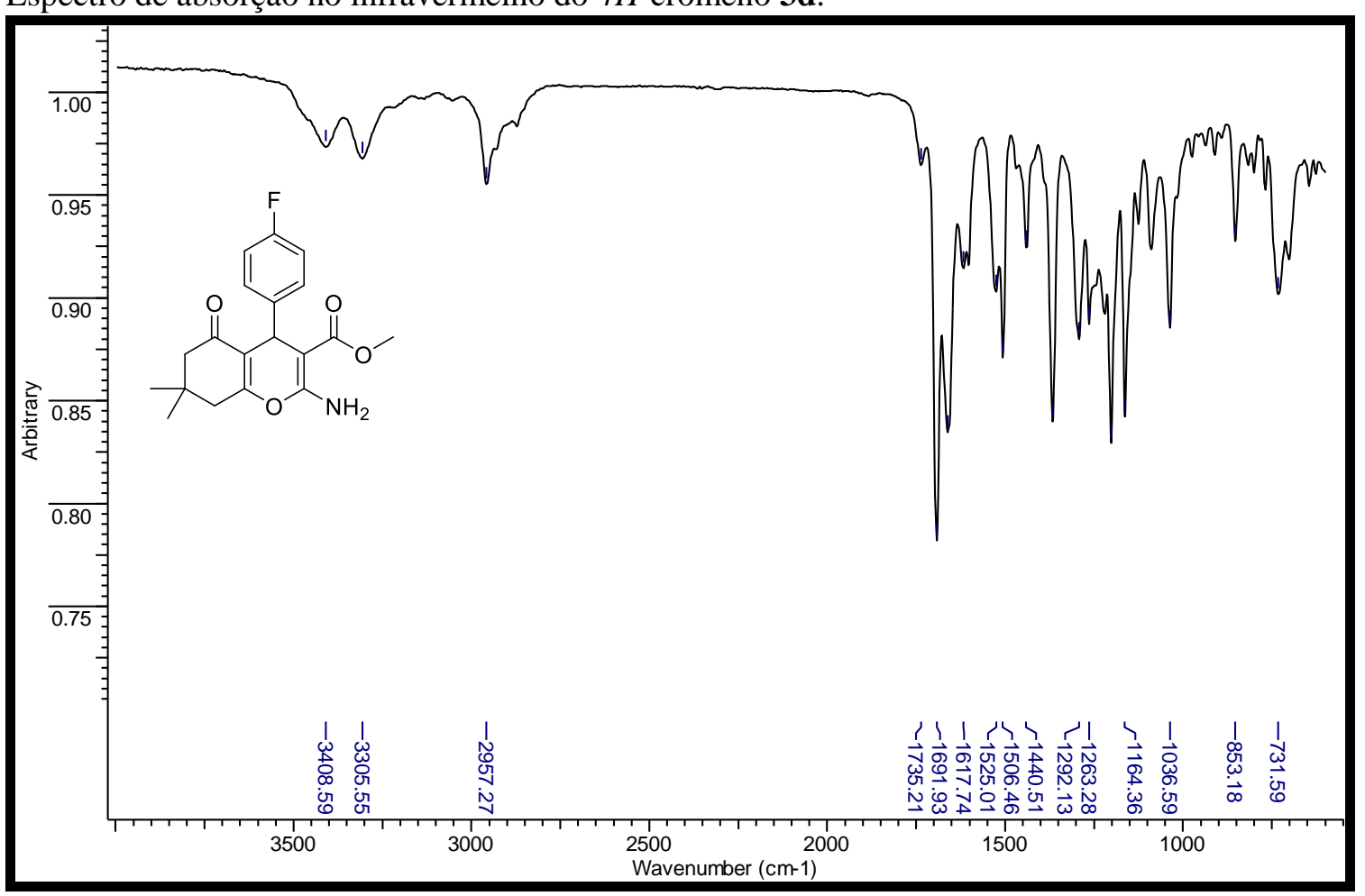


Espectro de RMN de ${ }^{1} \mathrm{H}\left(400 \mathrm{MHz}, \mathrm{DMSO}-d_{6}\right)$ do $4 H$-cromeno $3 \mathbf{e}$.

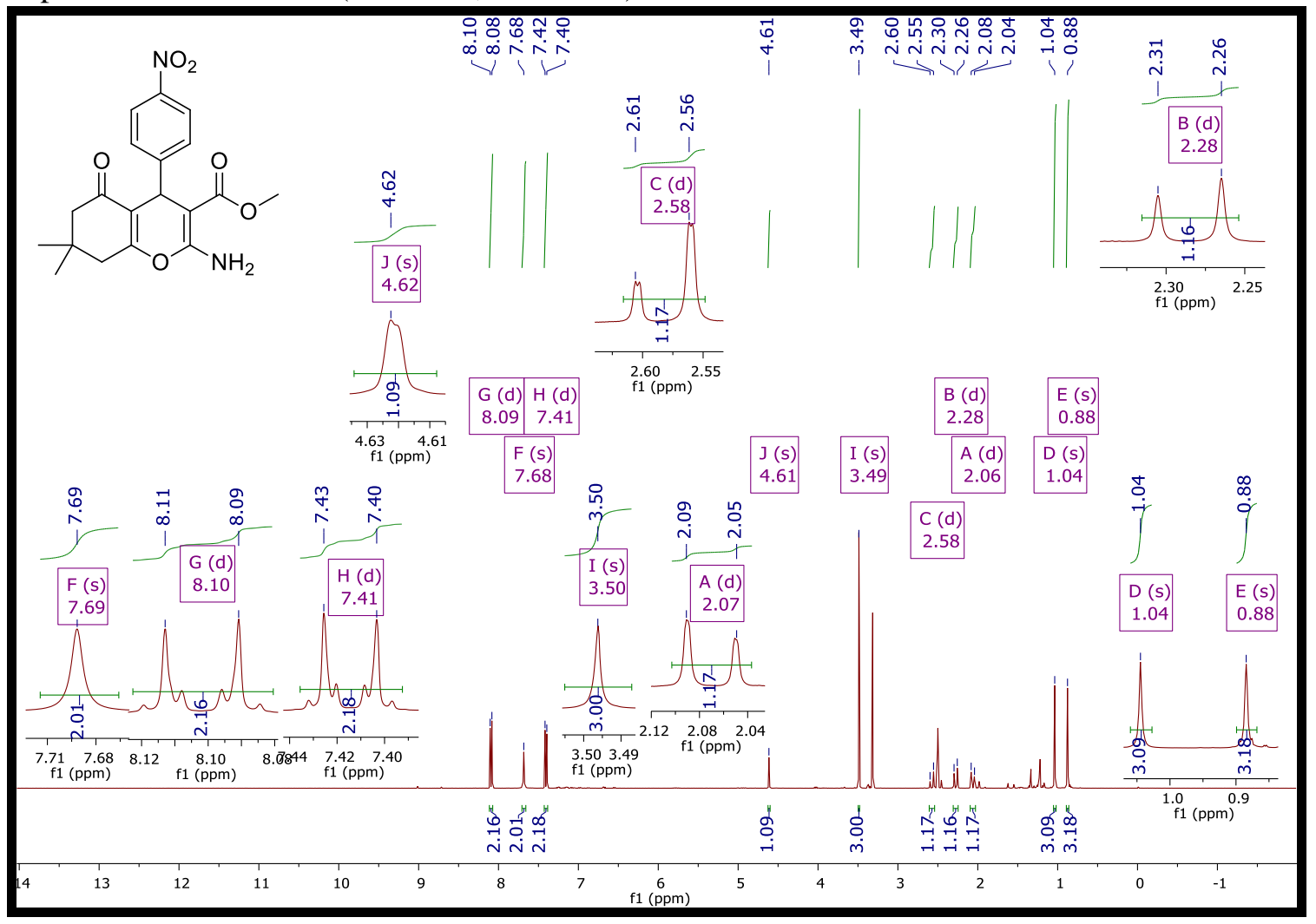

Espectro de RMN de ${ }^{13} \mathrm{C}\left(100 \mathrm{MHz}\right.$, DMSO- $\left.d_{6}\right)$ do $4 H$-cromeno $3 \mathbf{e}$.

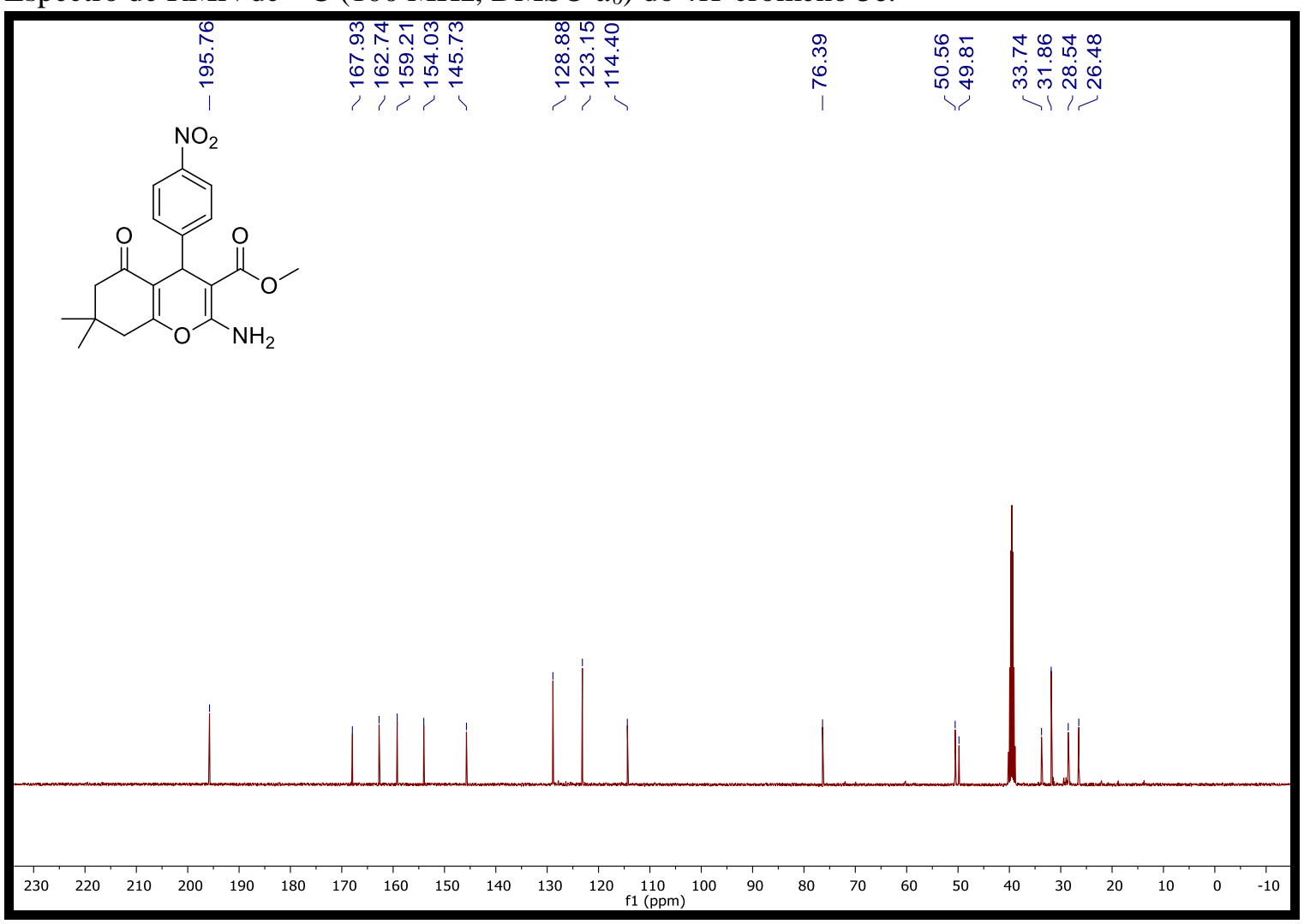


Espectro de massas de alta resolução LTQ-Orbitrap Velos (Thermo Scientific), com fonte de ionização eletronspray em modo positivo $[\mathrm{M}+\mathrm{H}]^{+}$para o $4 H$-cromeno $3 \mathbf{e}$.

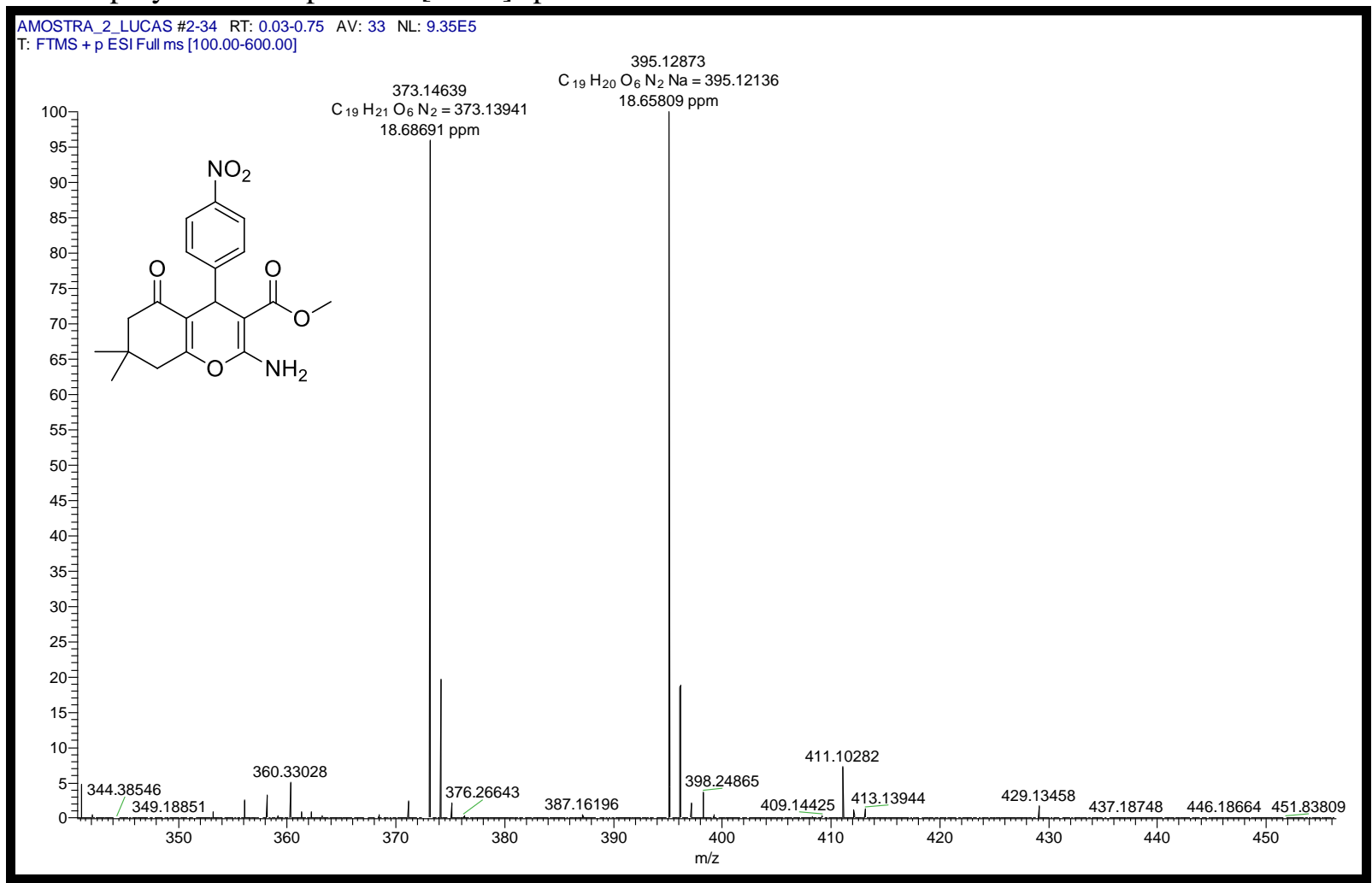

Espectro de absorção no infravermelho do $4 H$-cromeno $\mathbf{3 e .}$

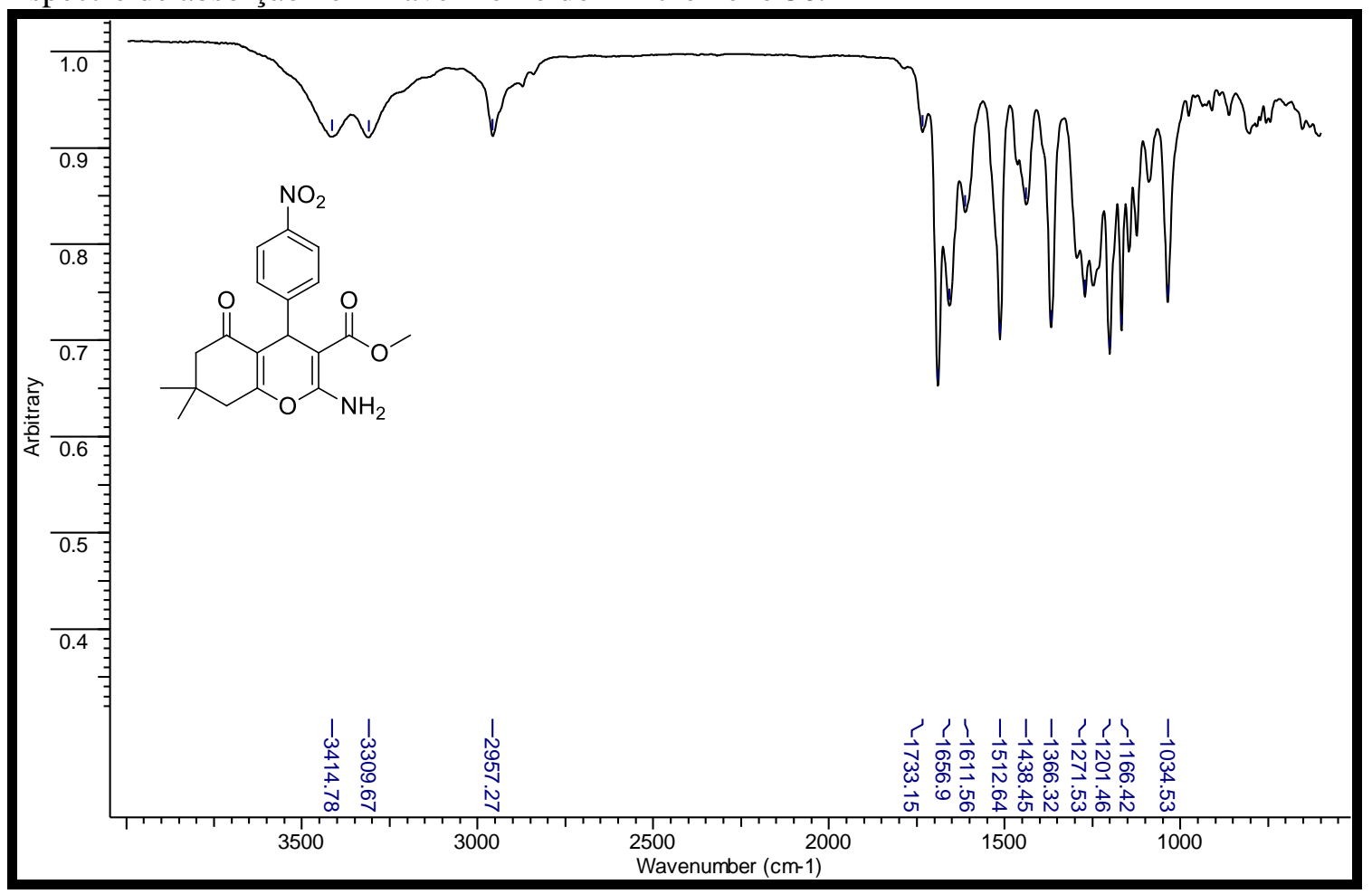


Espectro de RMN de ${ }^{1} \mathrm{H}\left(400 \mathrm{MHz}, \mathrm{DMSO}-d_{6}\right)$ do $4 H$-cromeno 3f.

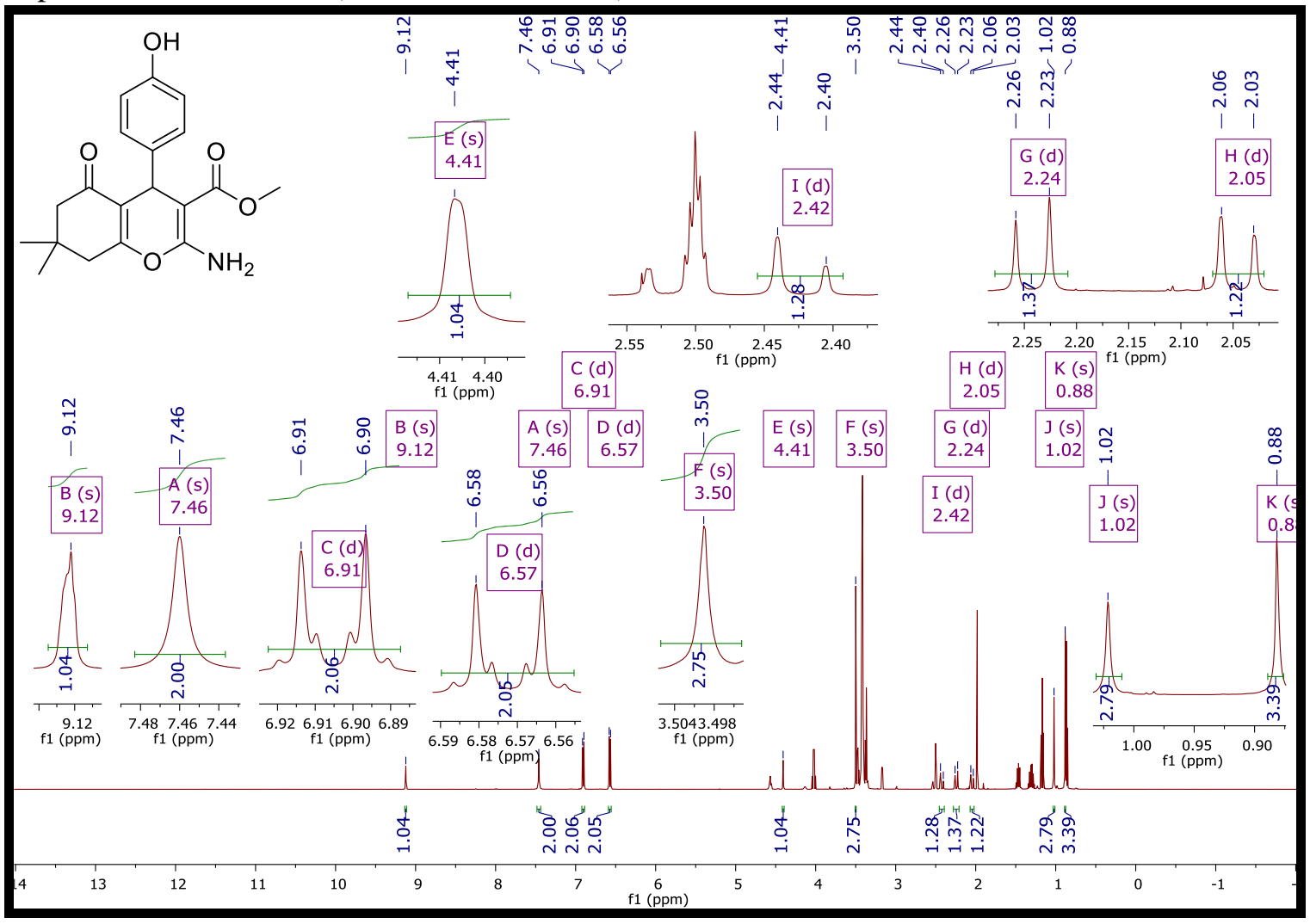

Espectro de RMN de ${ }^{13} \mathrm{C}$ (100 MHz, DMSO- $\left.d_{6}\right)$ do $4 H$-cromeno $3 f$.

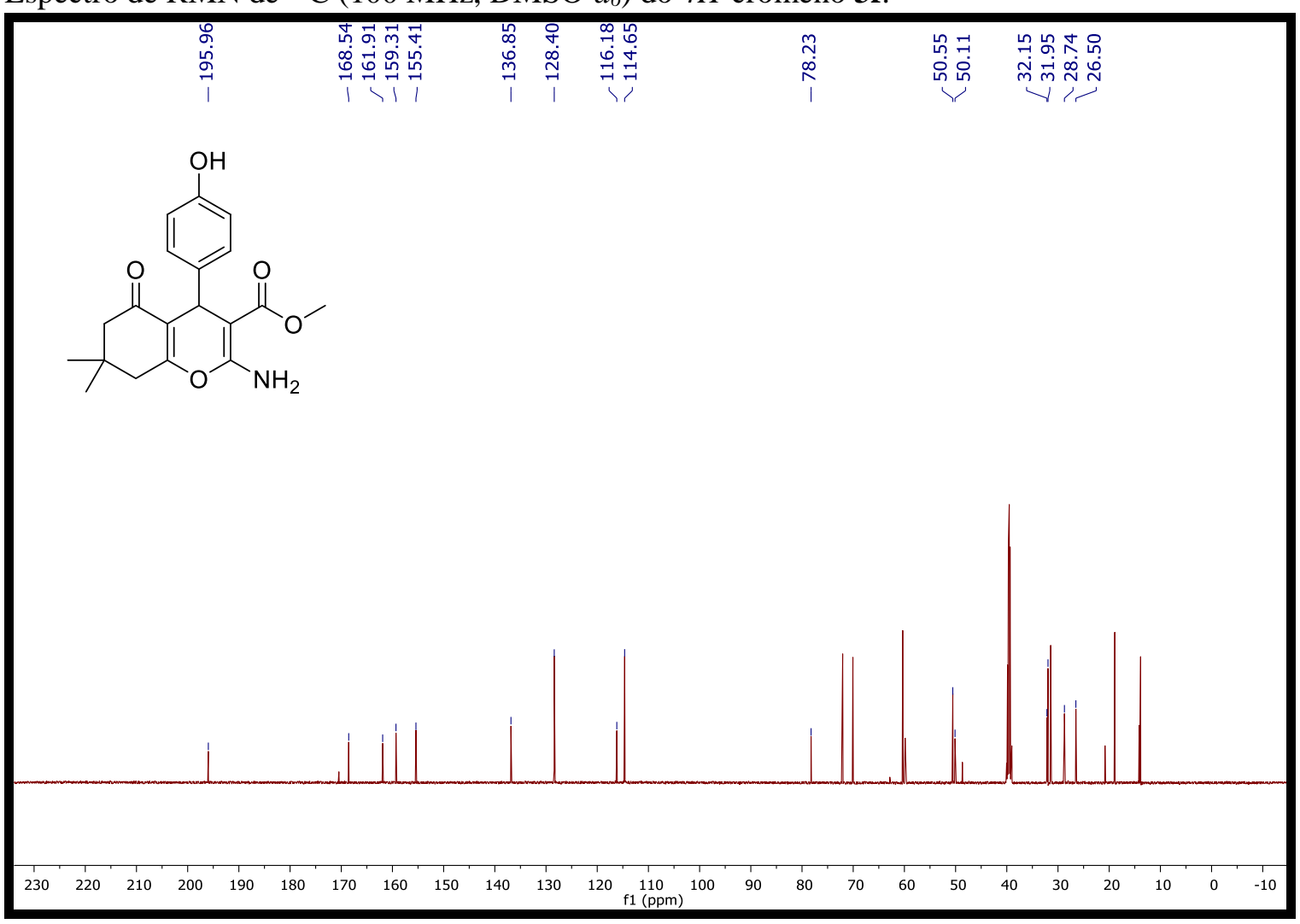


Espectro de absorção no infravermelho do $4 H$-cromeno $\mathbf{3 f}$.

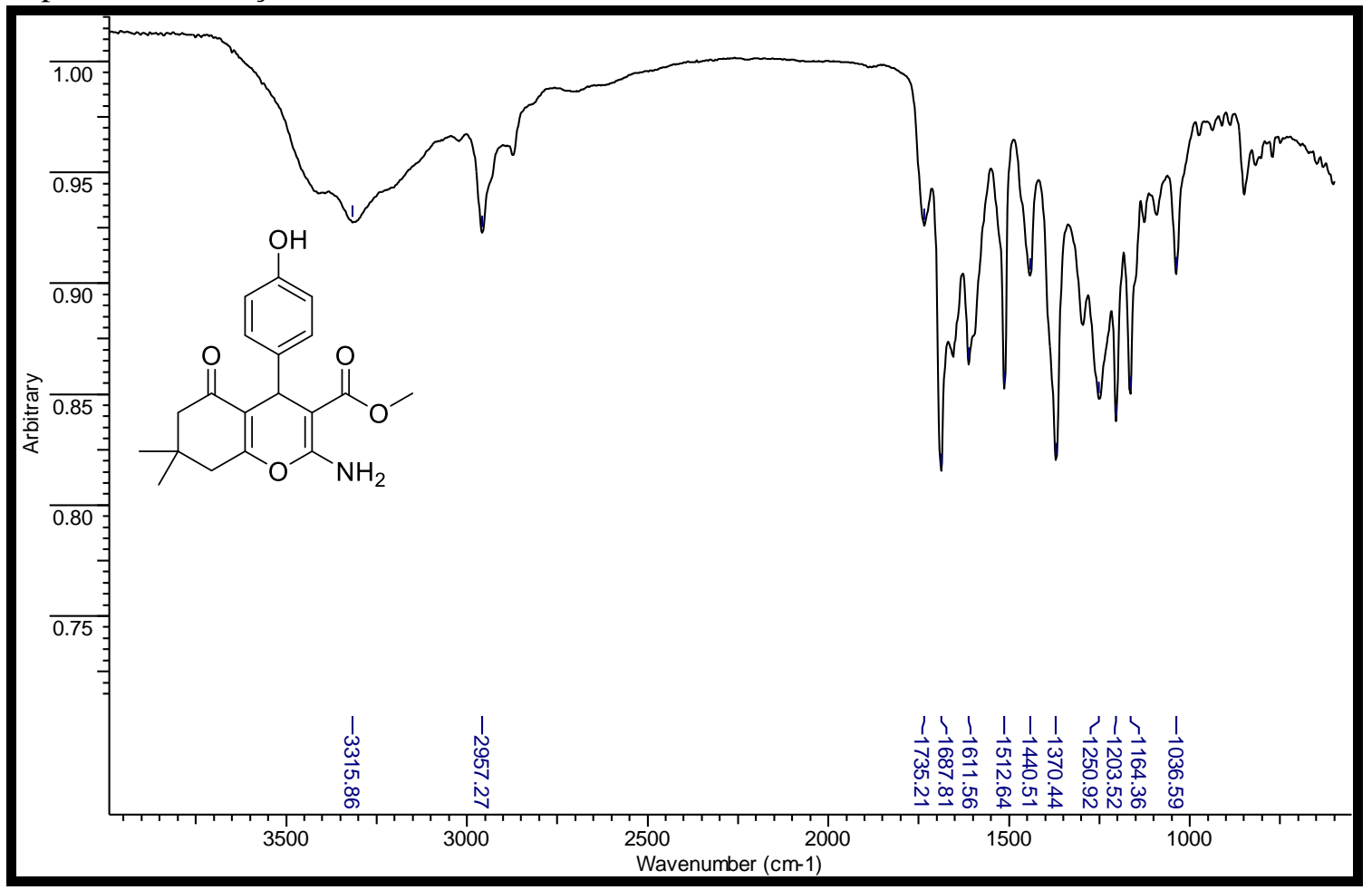


Espectro de RMN de ${ }^{1} \mathrm{H}\left(400 \mathrm{MHz}, \mathrm{DMSO}-d_{6}\right)$ do $4 H$-cromeno $3 \mathbf{g}$.

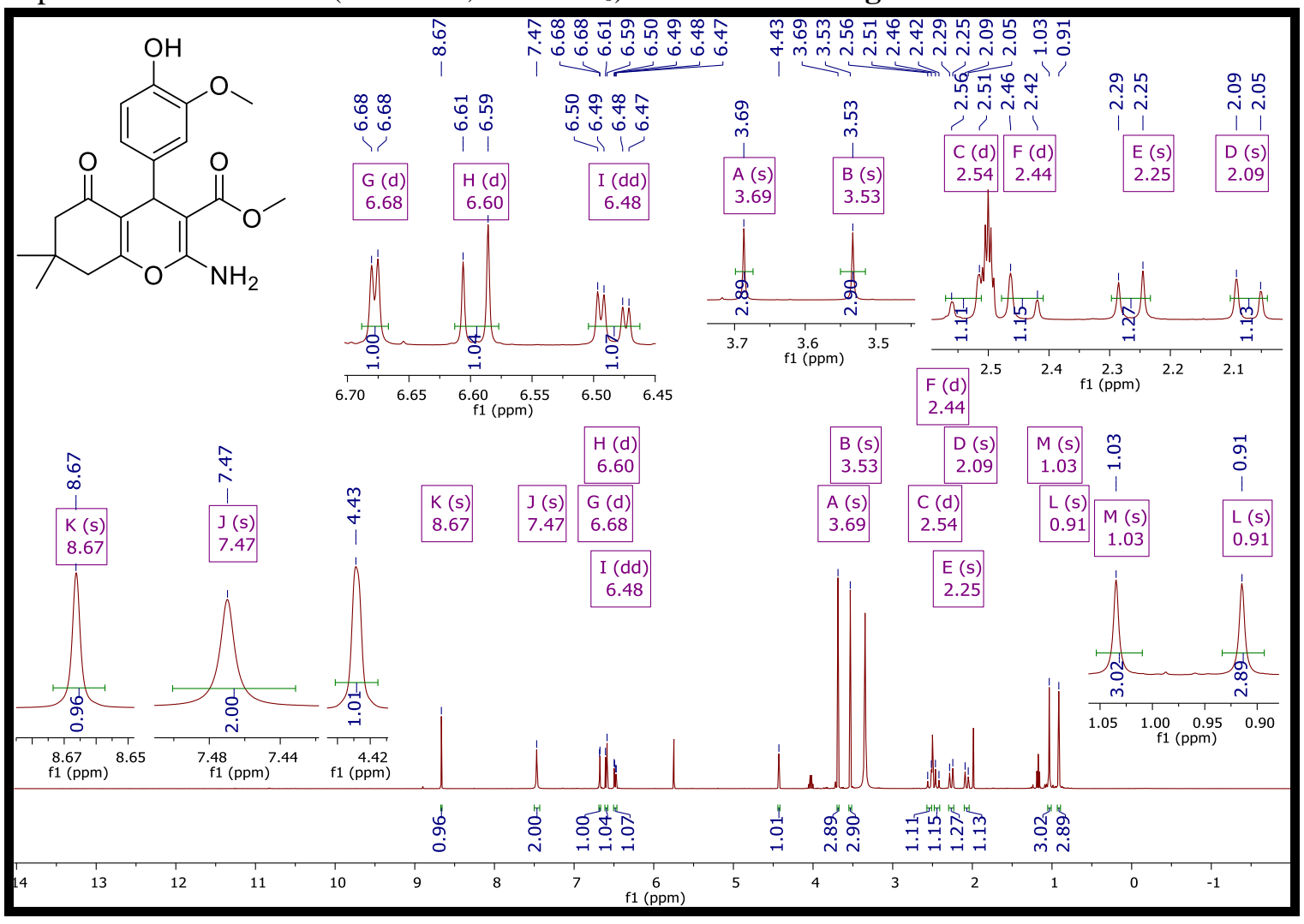

Espectro de RMN de ${ }^{13} \mathrm{C}\left(100 \mathrm{MHz}, \mathrm{DMSO}-d_{6}\right)$ do $4 H$-cromeno $3 \mathrm{~g}$.

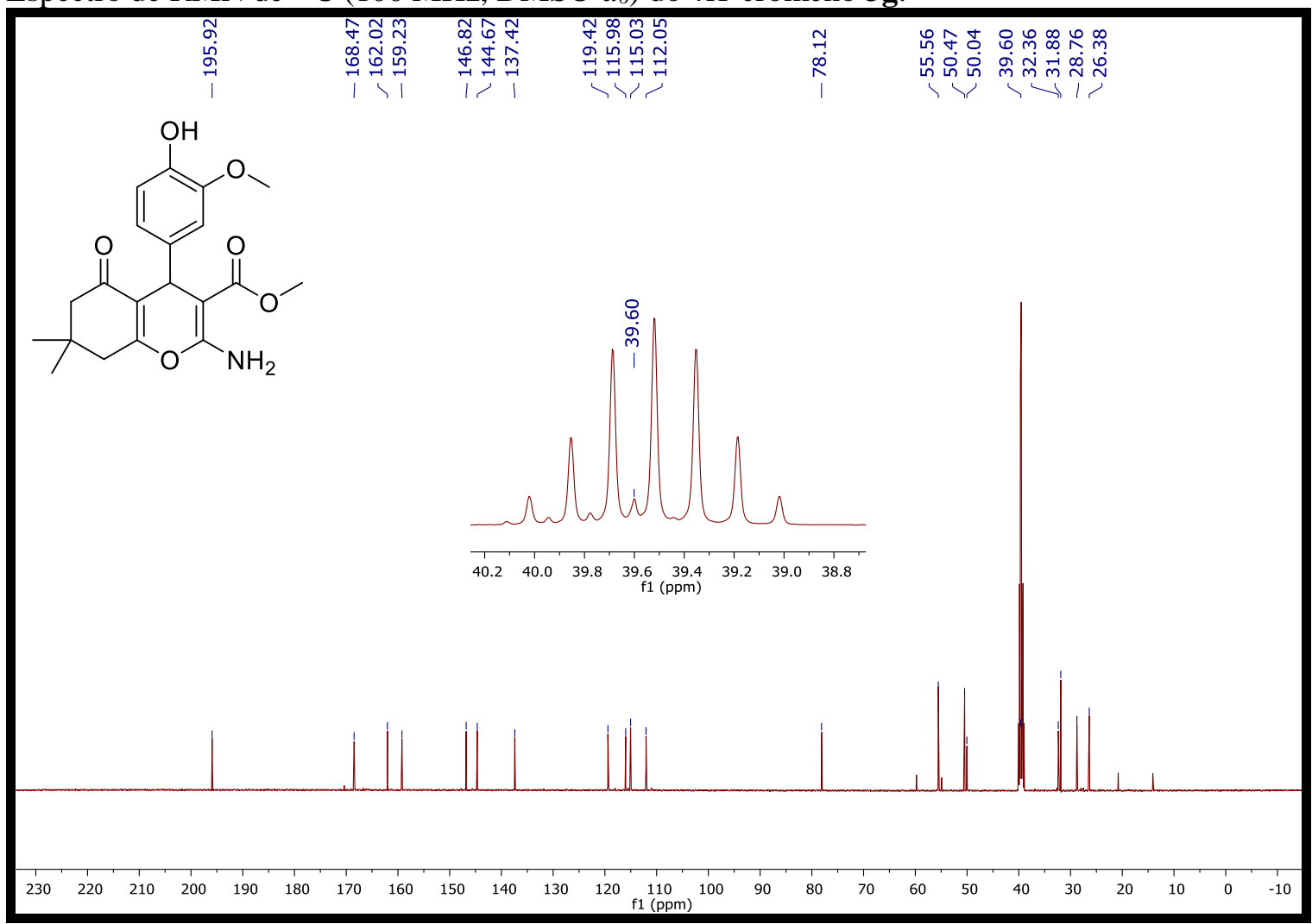


Espectro de absorção no infravermelho do $4 H$-cromeno $\mathbf{3 g}$.

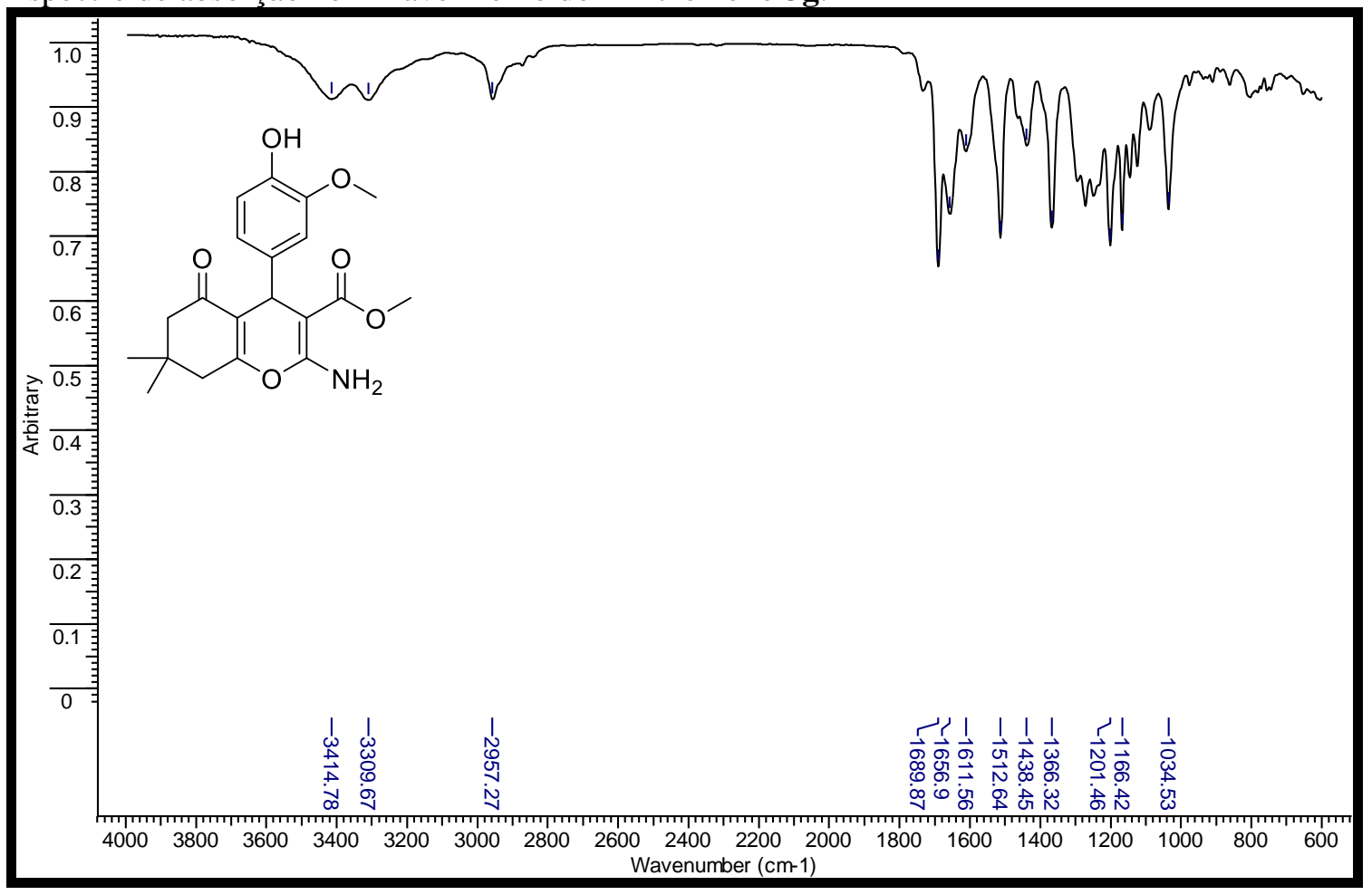


Espectro de RMN de ${ }^{1} \mathrm{H}\left(400 \mathrm{MHz}, \mathrm{DMSO}-d_{6}\right)$ do $4 H$-cromeno $\mathbf{3 h}$.

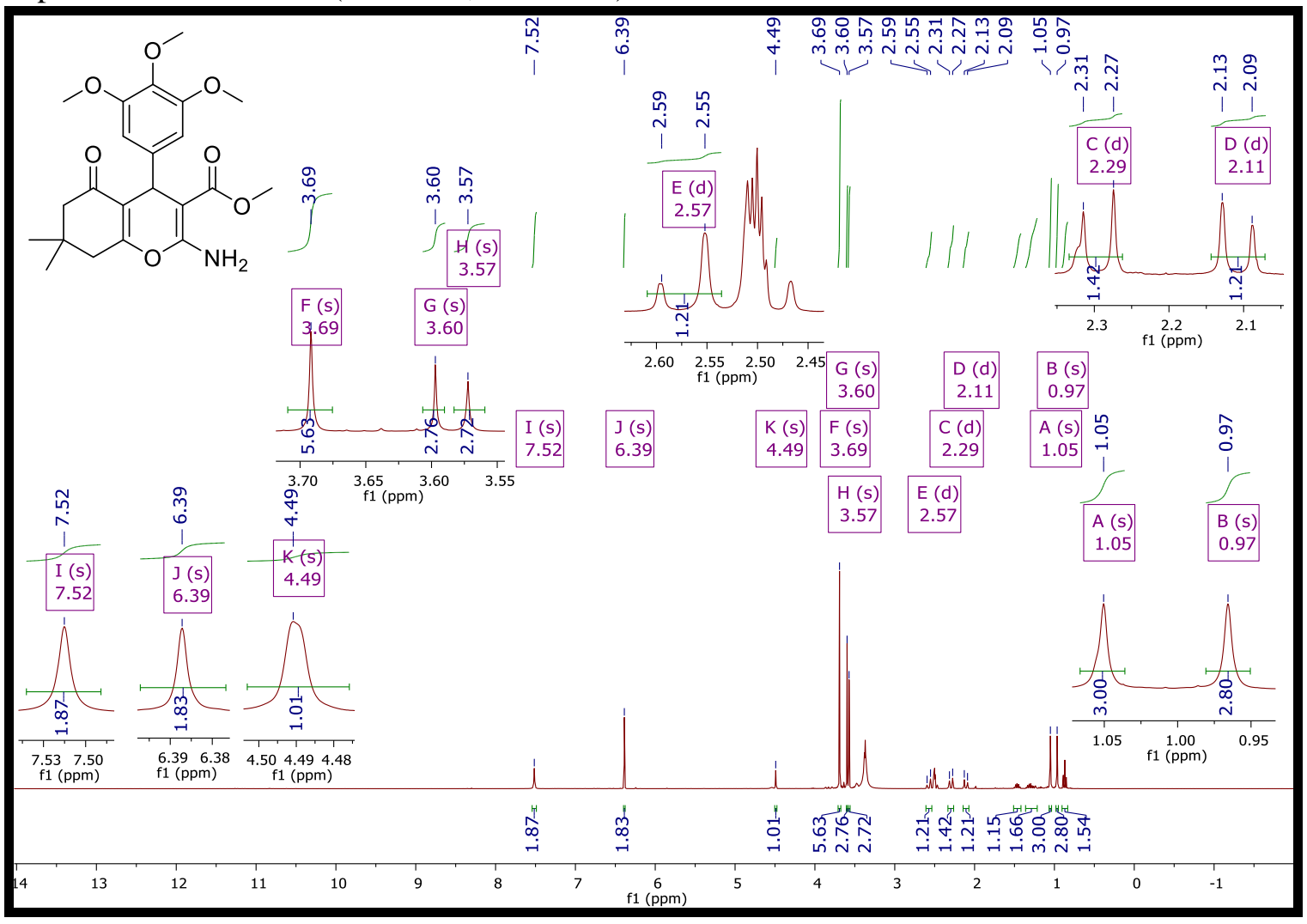

Espectro de RMN de ${ }^{13} \mathrm{C}$ (100 MHz, DMSO- $\left.d_{6}\right)$ do $4 H$-cromeno 3h.

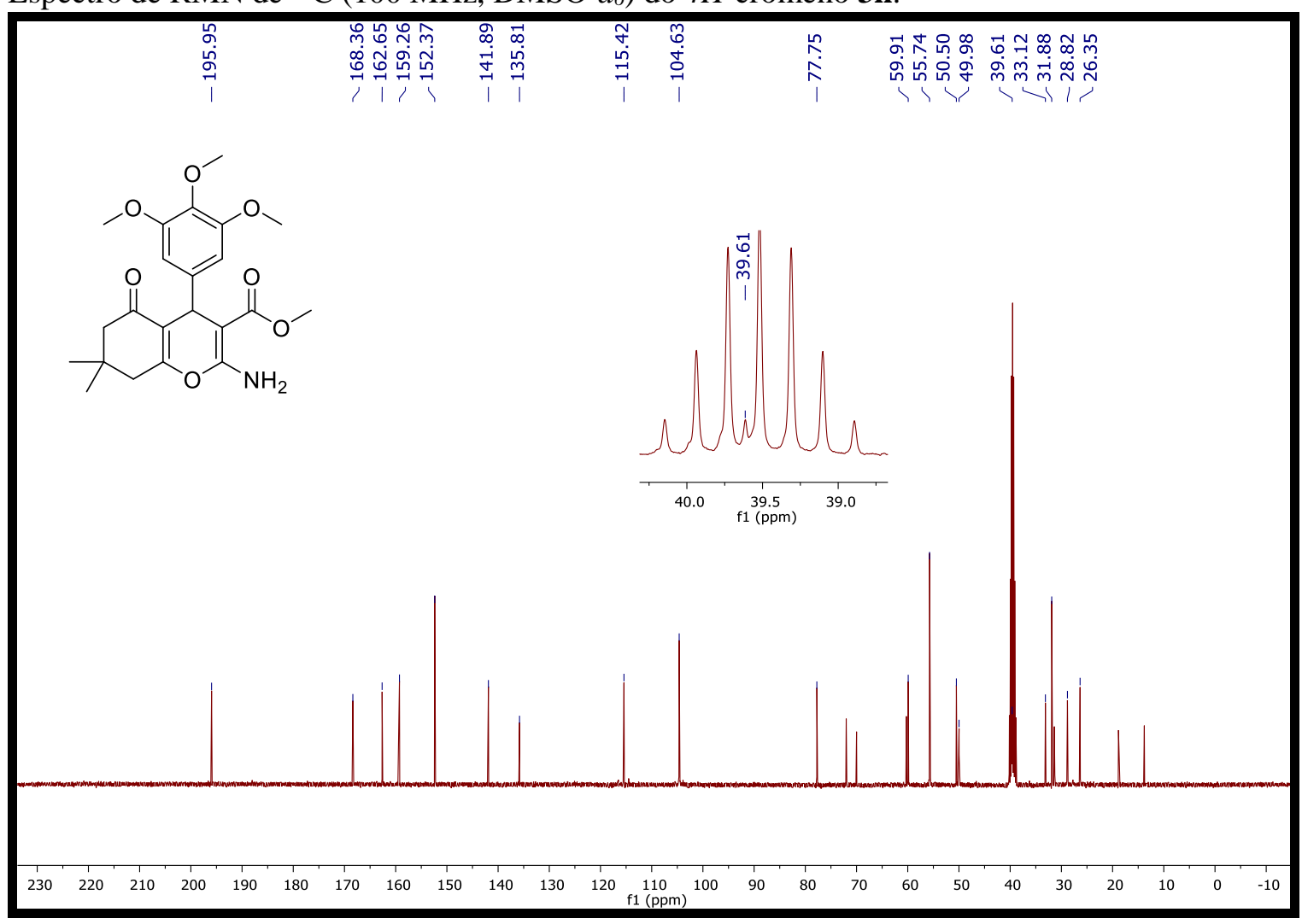


Espectro de absorção no infravermelho do $4 H$-cromeno $\mathbf{3 h}$.

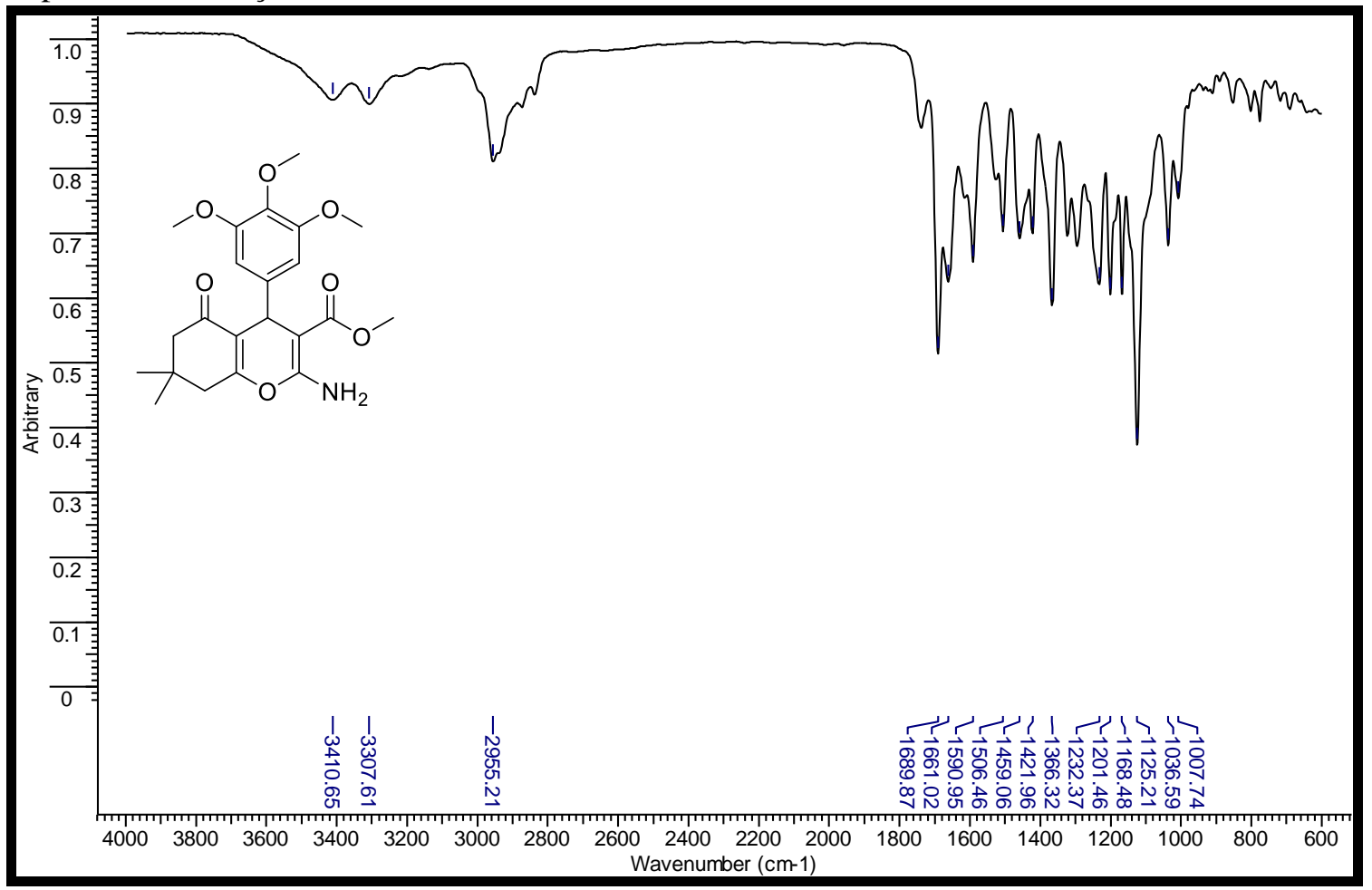


Espectro de RMN de ${ }^{1} \mathrm{H}\left(400 \mathrm{MHz}\right.$, DMSO- $\left.d_{6}\right)$ do $4 H$-cromeno $3 \mathbf{3}$.

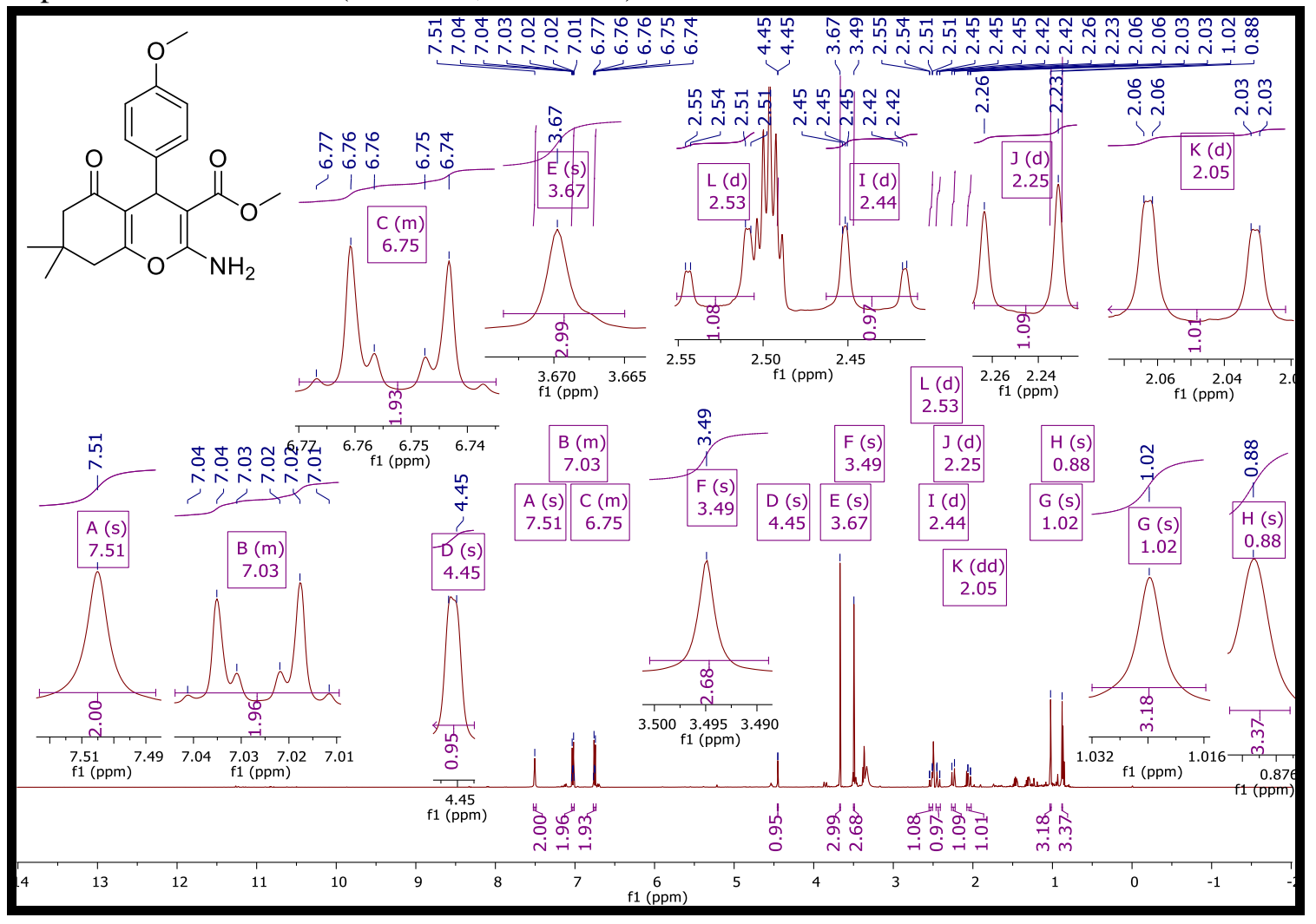

Espectro de RMN de ${ }^{13} \mathrm{C}\left(100 \mathrm{MHz}, \mathrm{DMSO}-d_{6}\right)$ do $4 H$-cromeno 3i.

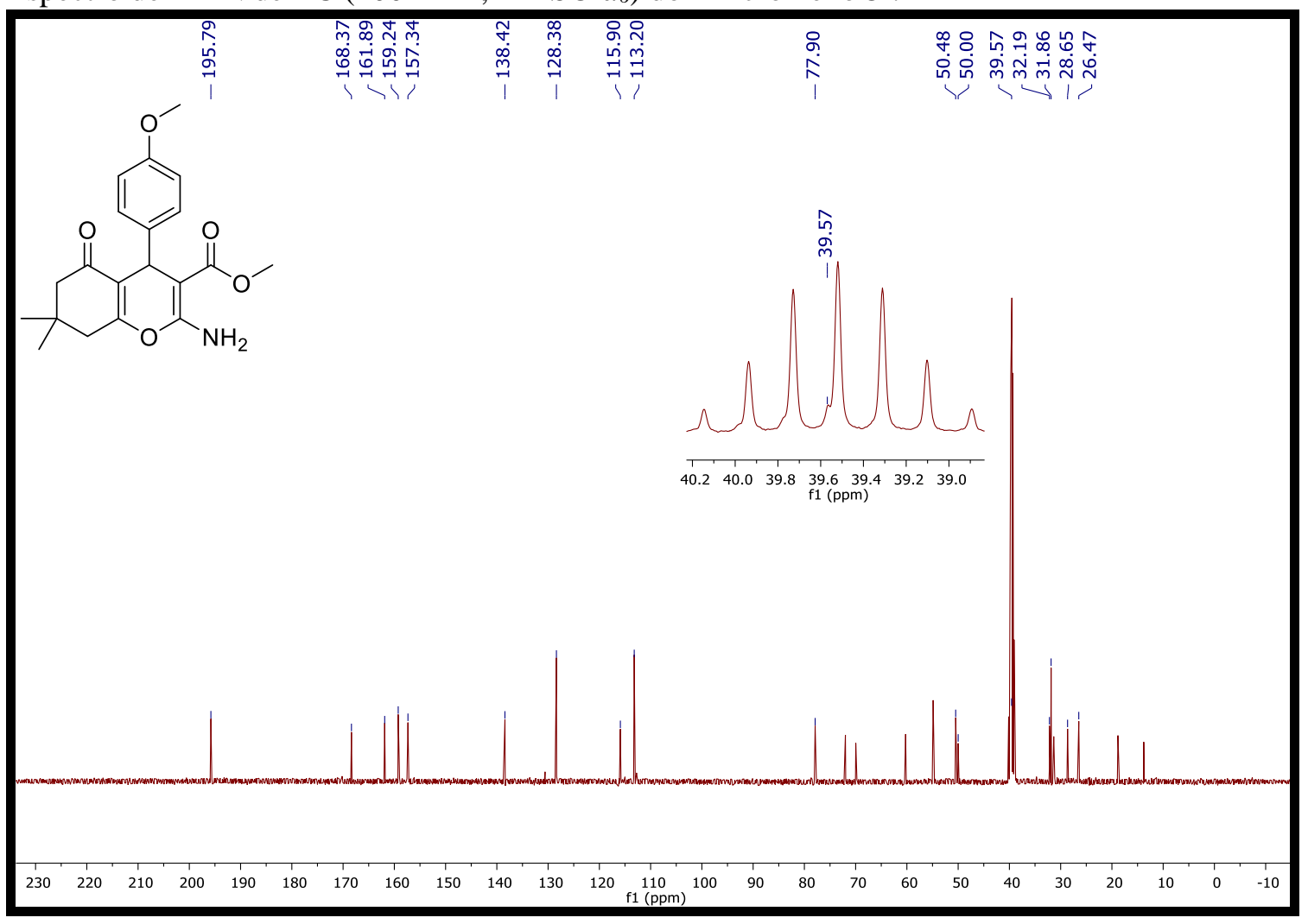


Espectro de absorção no infravermelho do $4 H$-cromeno $\mathbf{3 i}$.

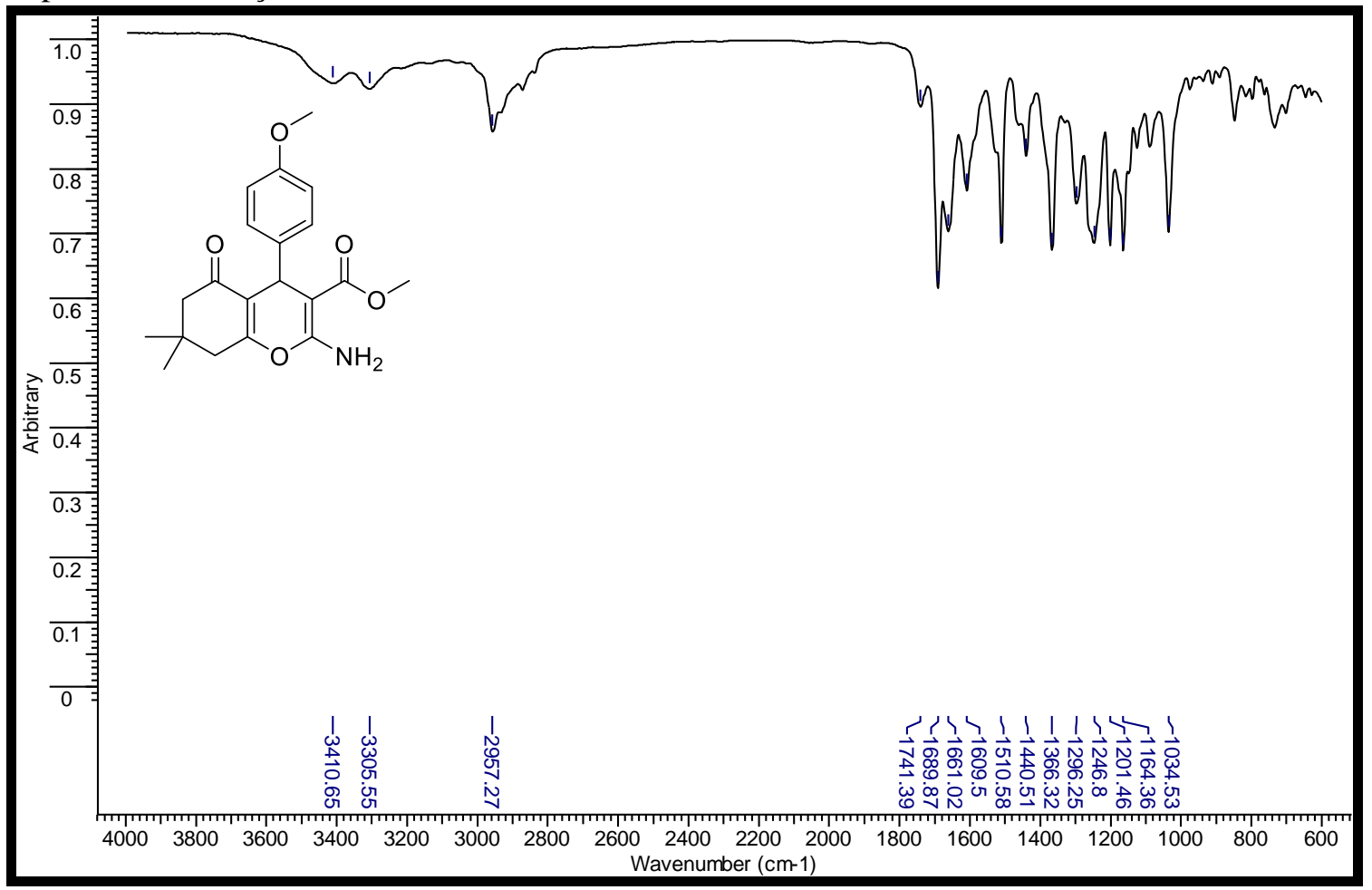


Espectro de RMN de ${ }^{1} \mathrm{H}\left(400 \mathrm{MHz}\right.$, DMSO- $\left.d_{6}\right)$ do $4 H$-cromeno $\mathbf{3 j}$.

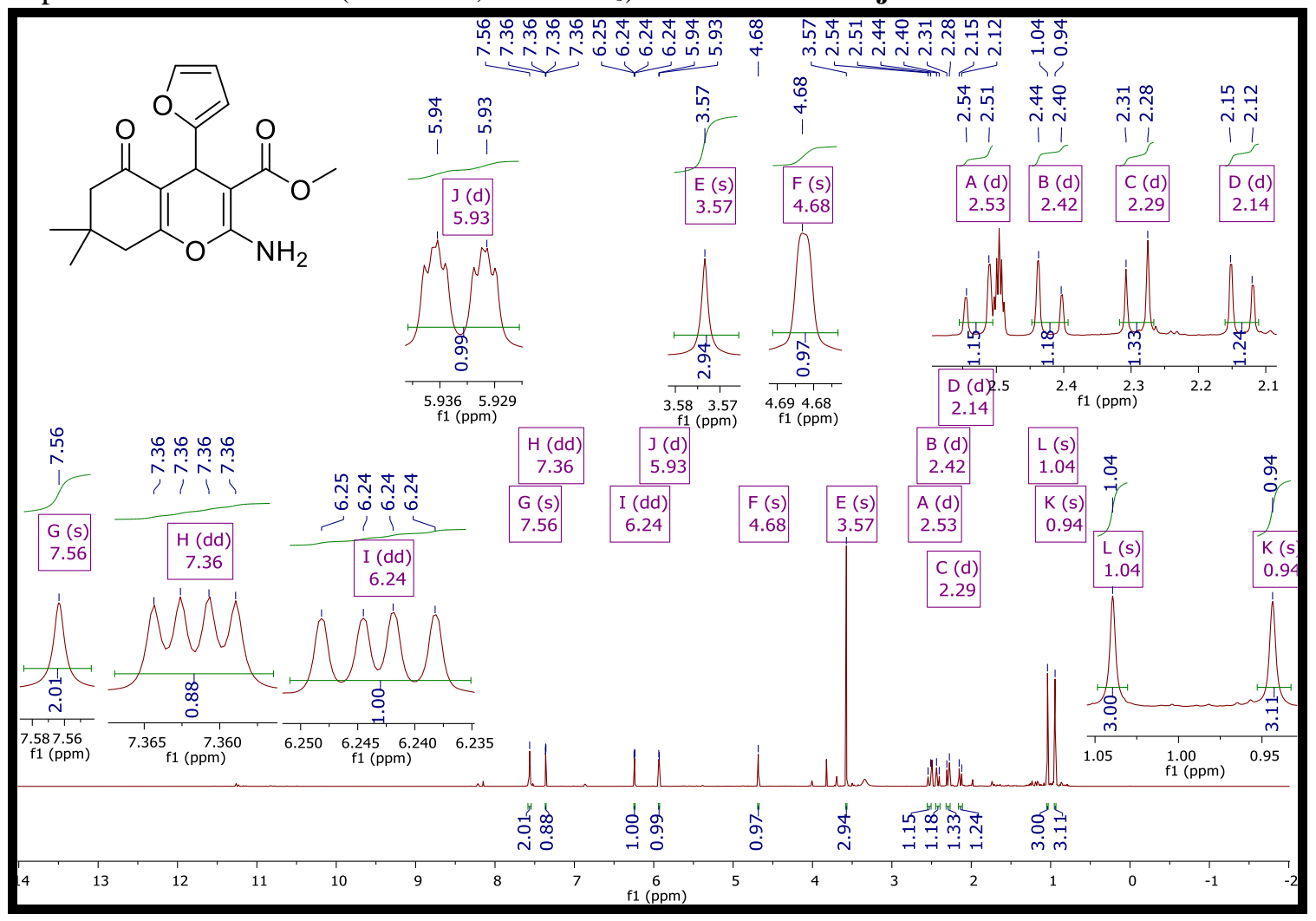

Espectro de RMN de ${ }^{13} \mathrm{C}\left(100 \mathrm{MHz}\right.$, DMSO- $\left.d_{6}\right)$ do $4 H$-cromeno $3 \mathbf{j}$.

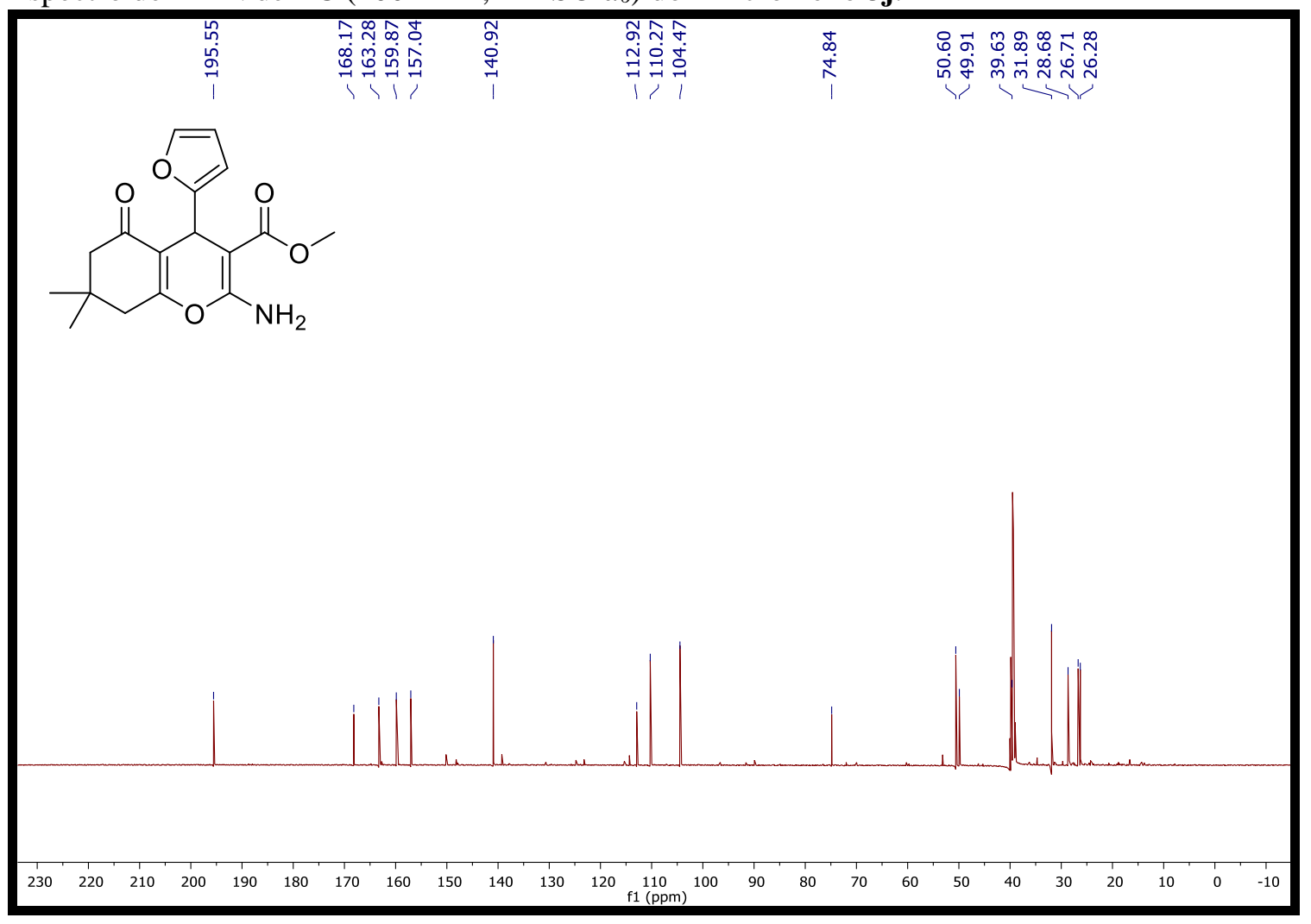


Espectro de massas de alta resolução LTQ-Orbitrap Velos (Thermo Scientific), com fonte de ionização eletronspray em modo positivo $[\mathrm{M}+\mathrm{H}]^{+}$para o $4 \mathrm{H}$-cromeno $\mathbf{3 j}$.

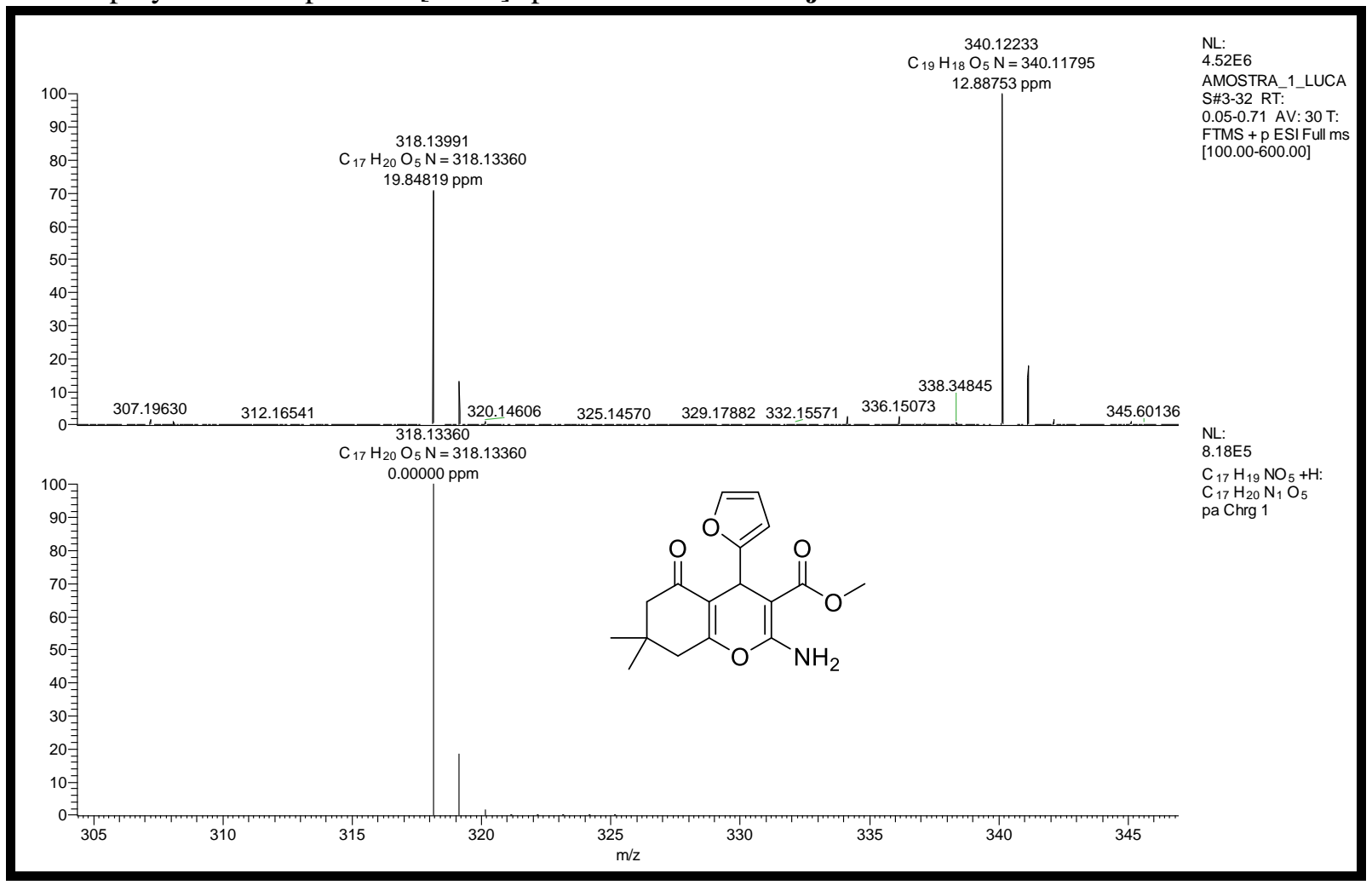

Espectro de absorção no infravermelho do $4 H$-cromeno $\mathbf{3 j}$.

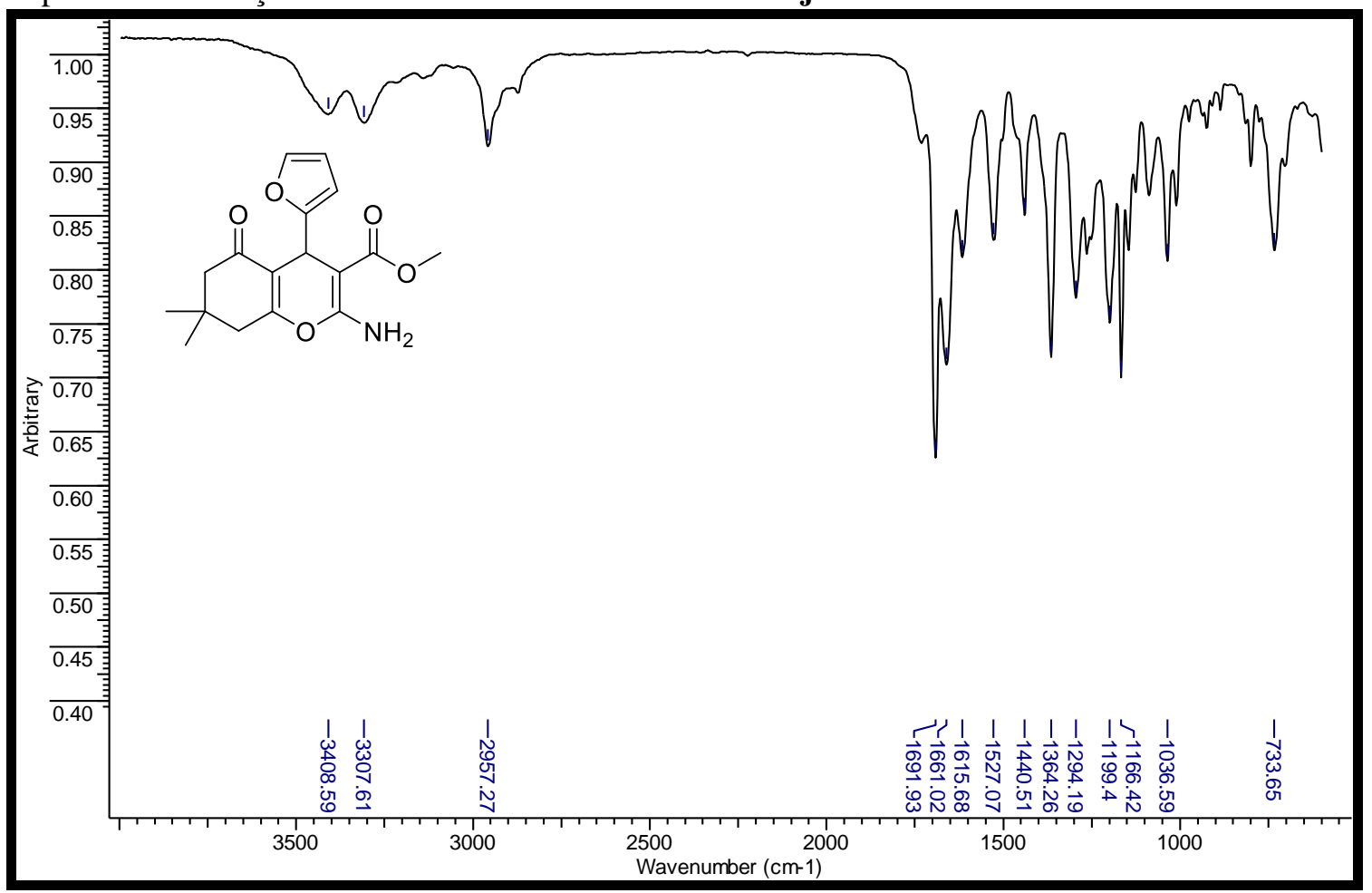


7.3. Espectros dos adutos 5b, 5e e 5f sintetizados entre cetonas aromáticas e a malononitrila 5 ,

Espectro de RMN de ${ }^{1} \mathrm{H}\left(400 \mathrm{MHz}\right.$, Acetona- $\left.d_{6}\right)$ do aduto $\mathbf{5 b}$.

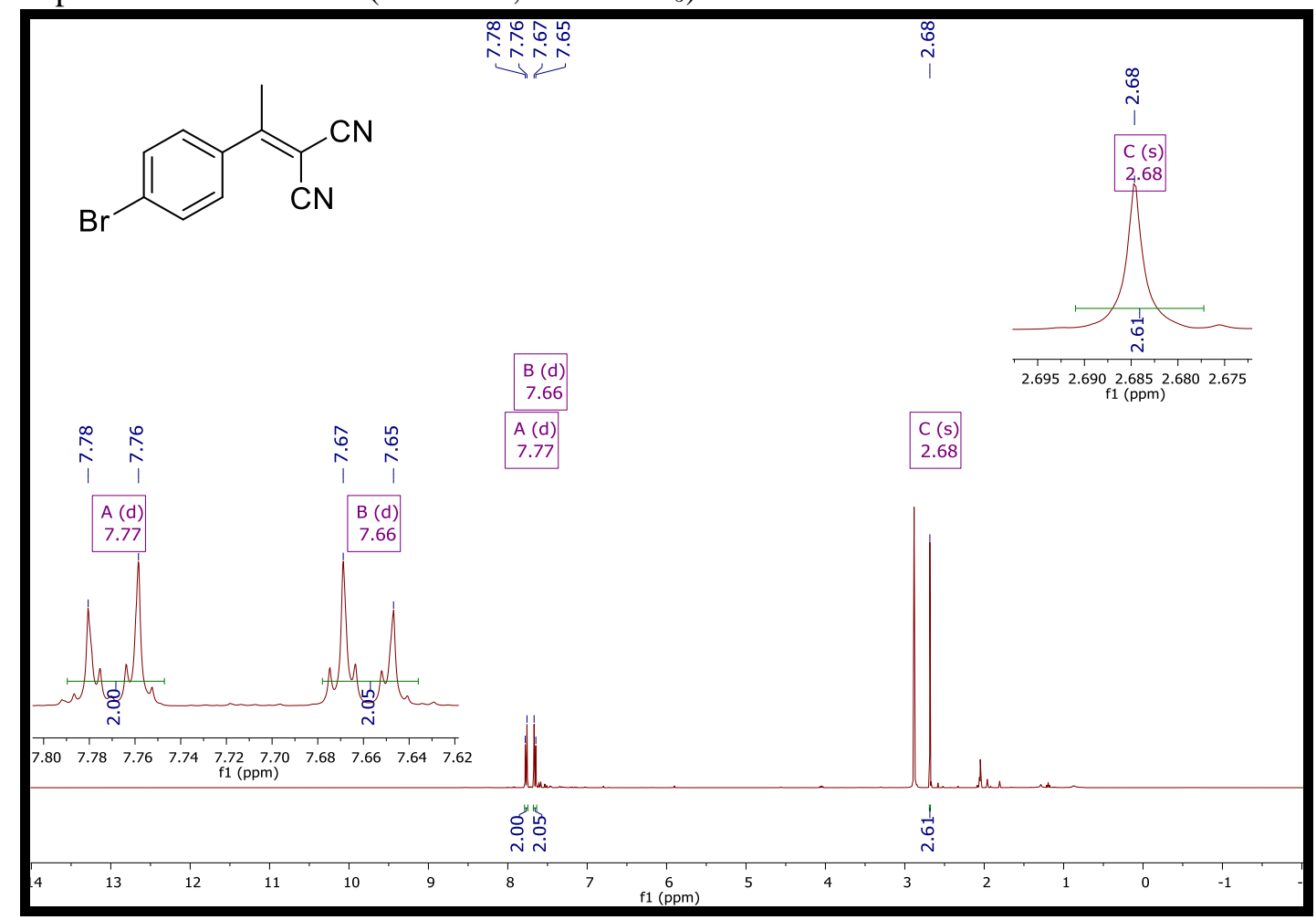

Espectro de RMN de ${ }^{13} \mathrm{C}\left(100 \mathrm{MHz}\right.$, Acetona- $\left.d_{6}\right)$ do aduto $\mathbf{5 b}$.

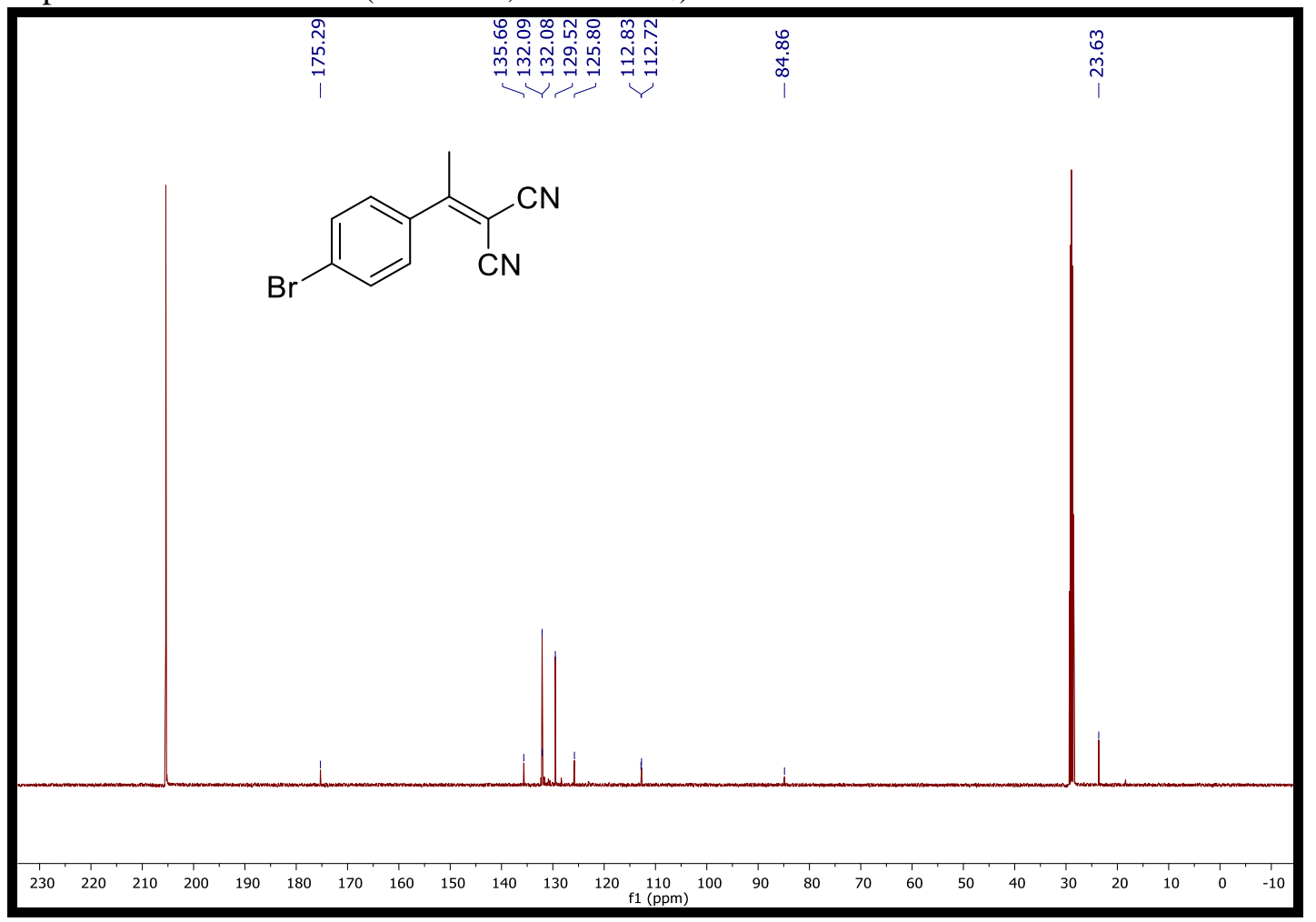


Espectro de absorção no infravermelho do aduto $\mathbf{5 b}$.

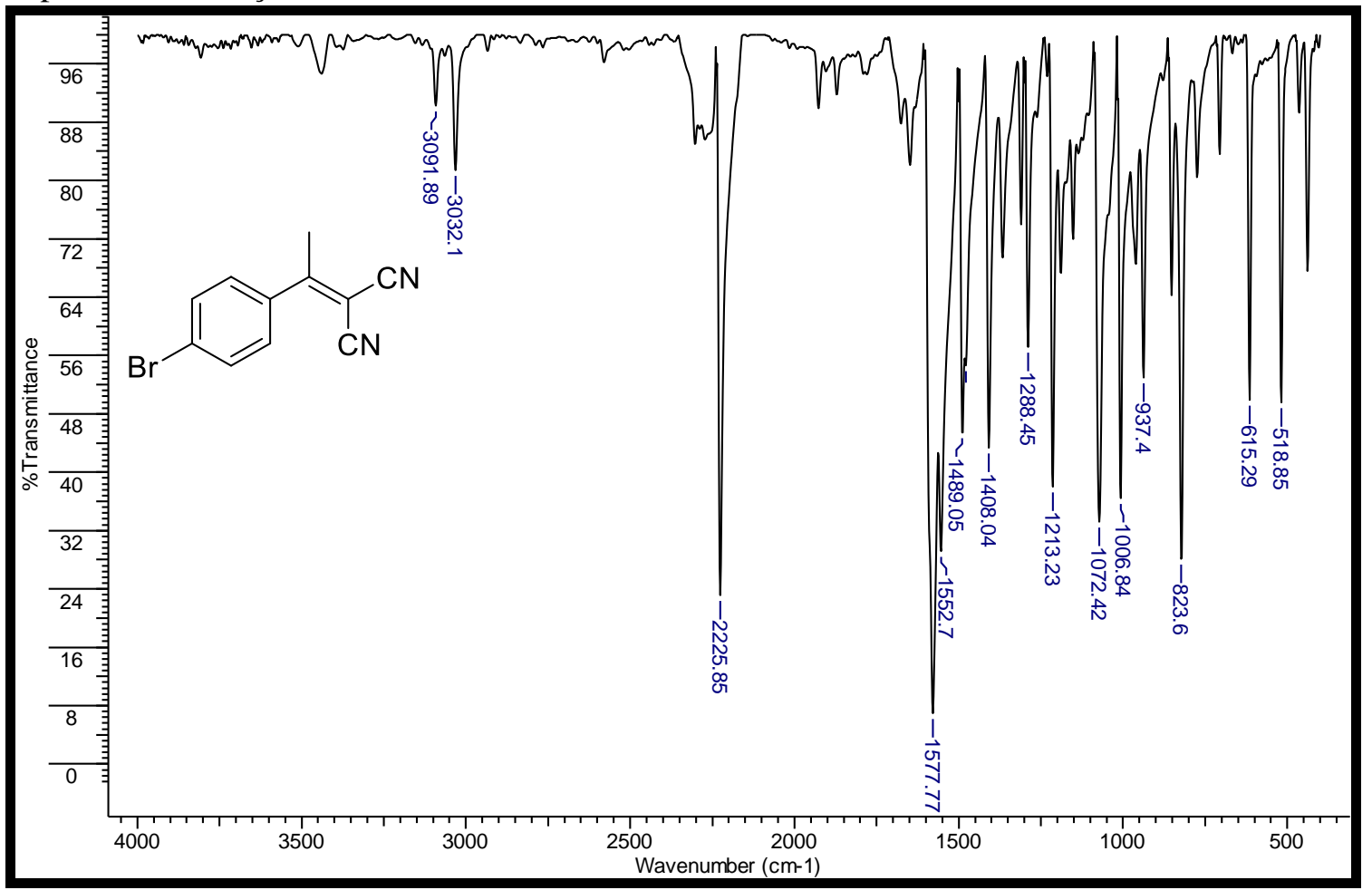


Espectro de RMN de ${ }^{1} \mathrm{H}\left(400 \mathrm{MHz}, \mathrm{CD}_{3} \mathrm{OD}\right)$ do aduto $5 \mathbf{e}$.

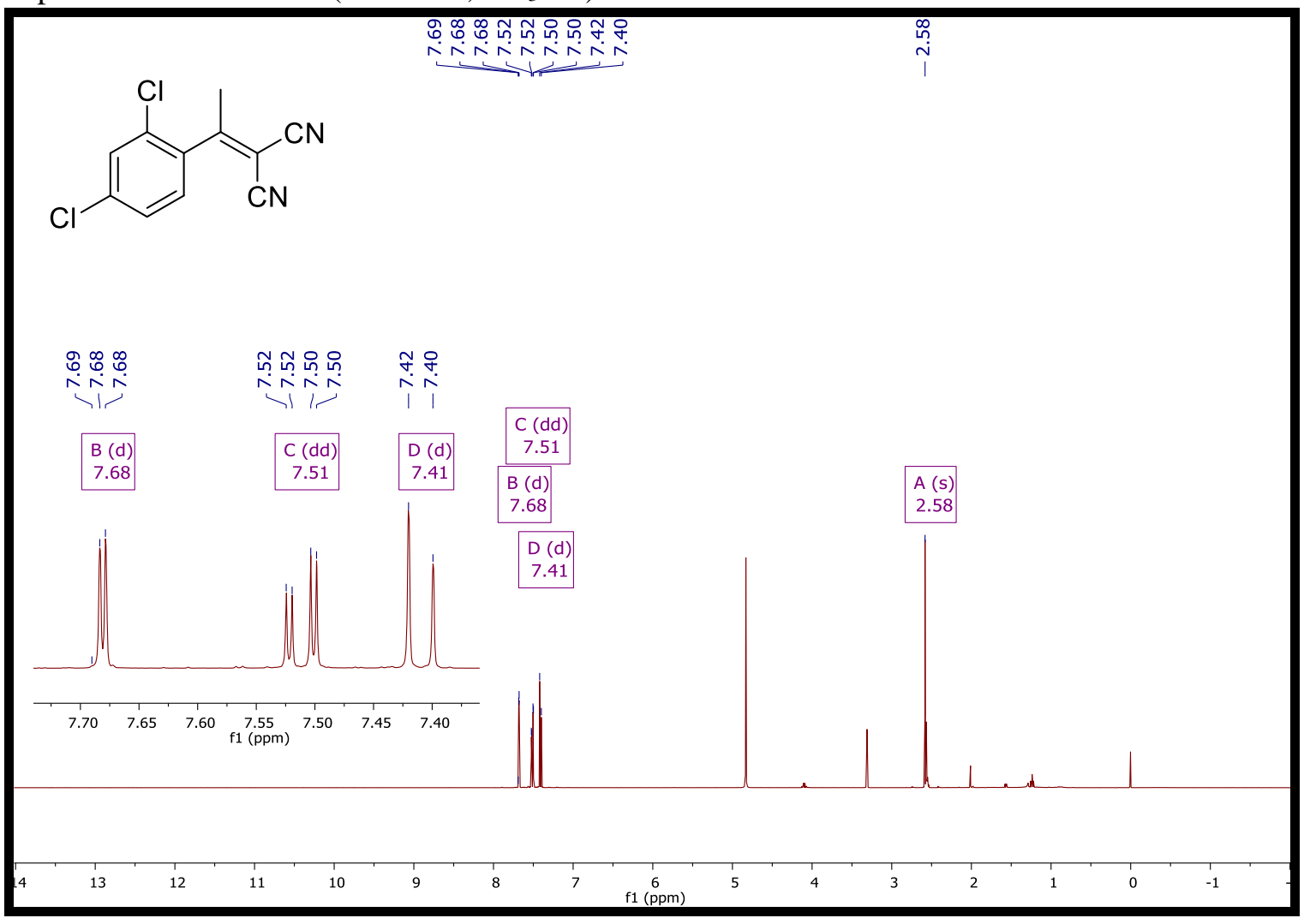

Espectro de RMN de ${ }^{13} \mathrm{C}\left(100 \mathrm{MHz}, \mathrm{CD}_{3} \mathrm{OD}\right)$ do aduto $5 \mathbf{e}$.

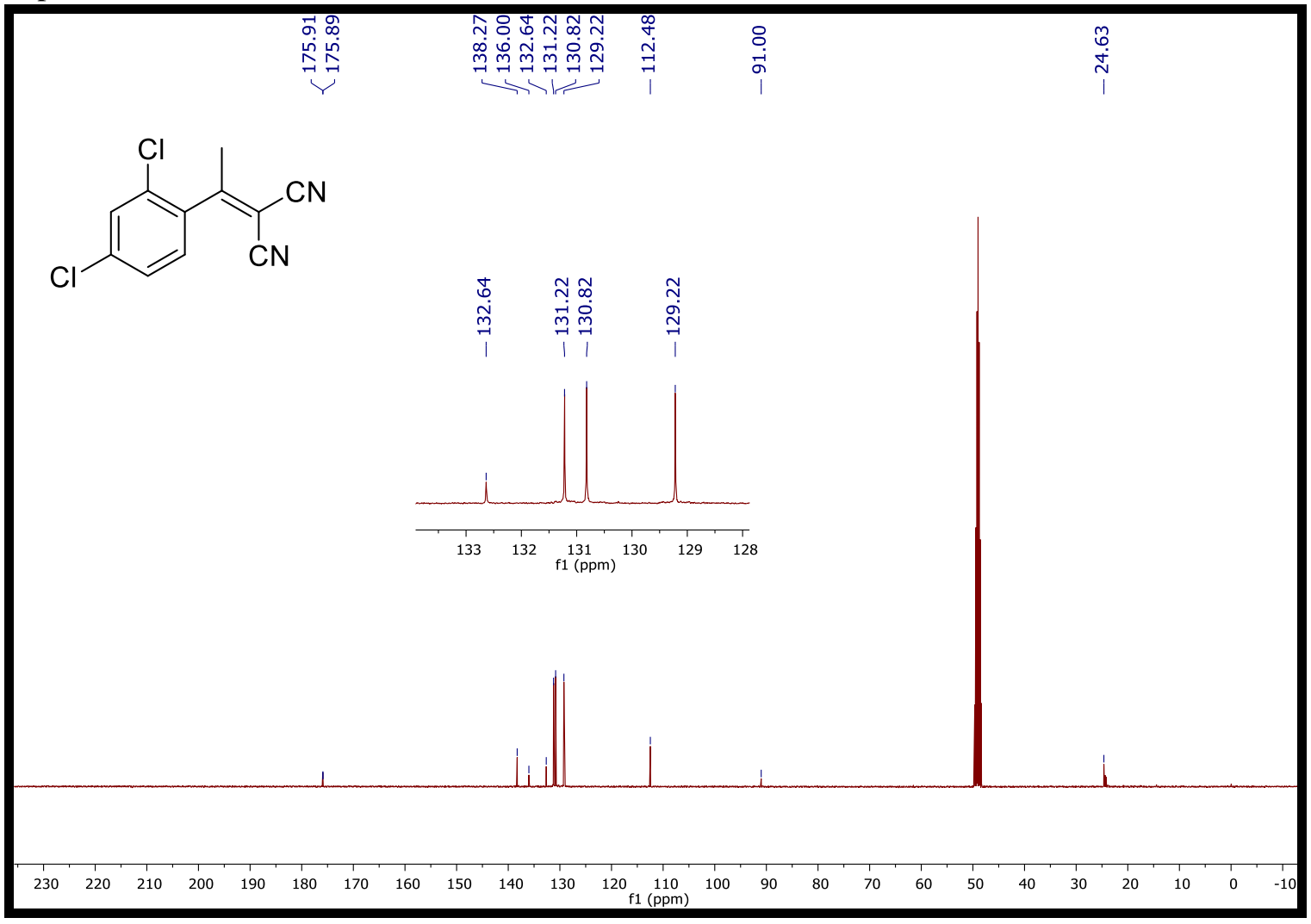


Espectro de absorção no infravermelho do aduto 5e

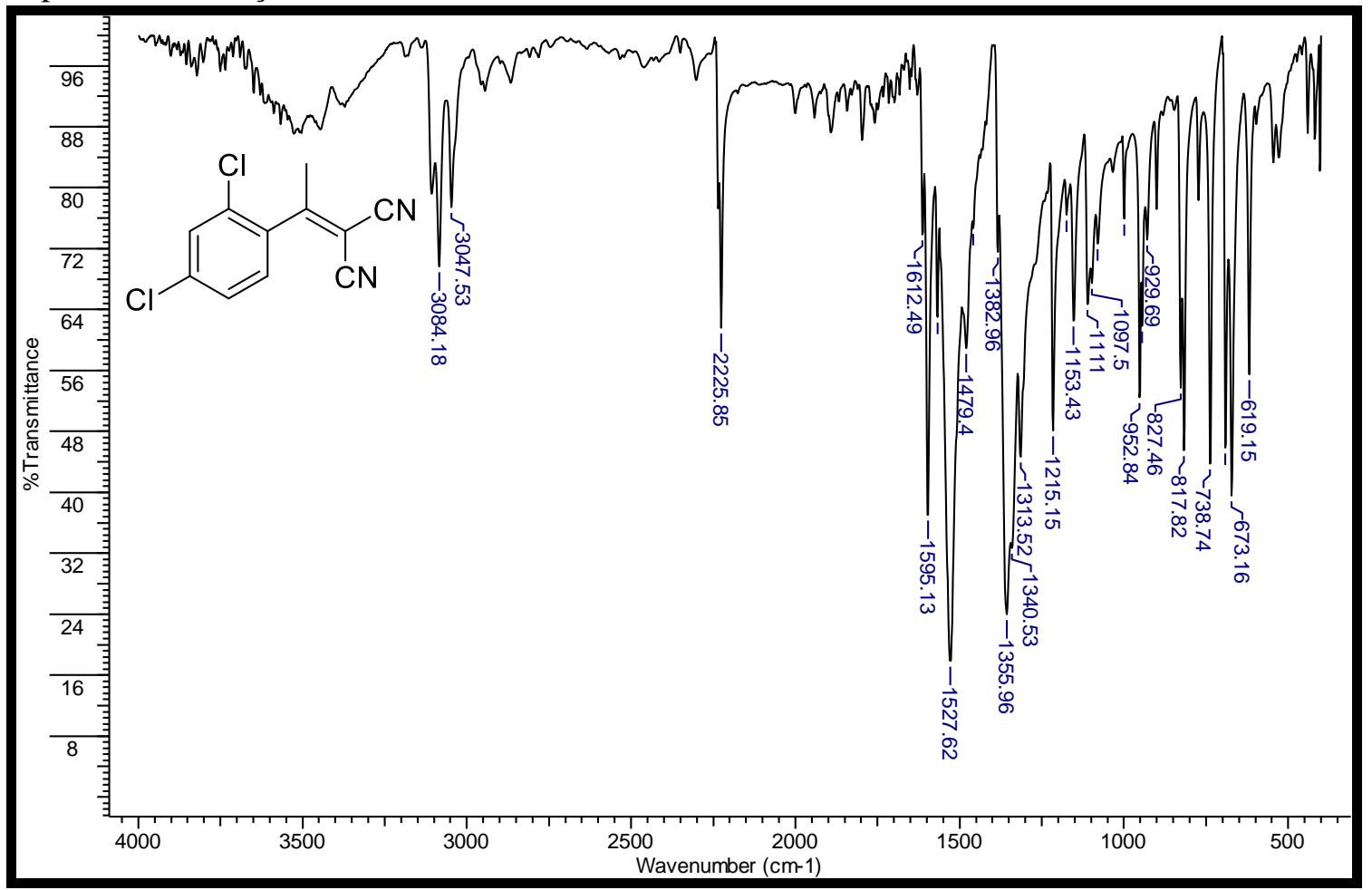


Espectro de RMN de ${ }^{1} \mathrm{H}\left(400 \mathrm{MHz}, \mathrm{CD}_{3} \mathrm{OD}\right)$ do aduto $5 \mathbf{f}$.

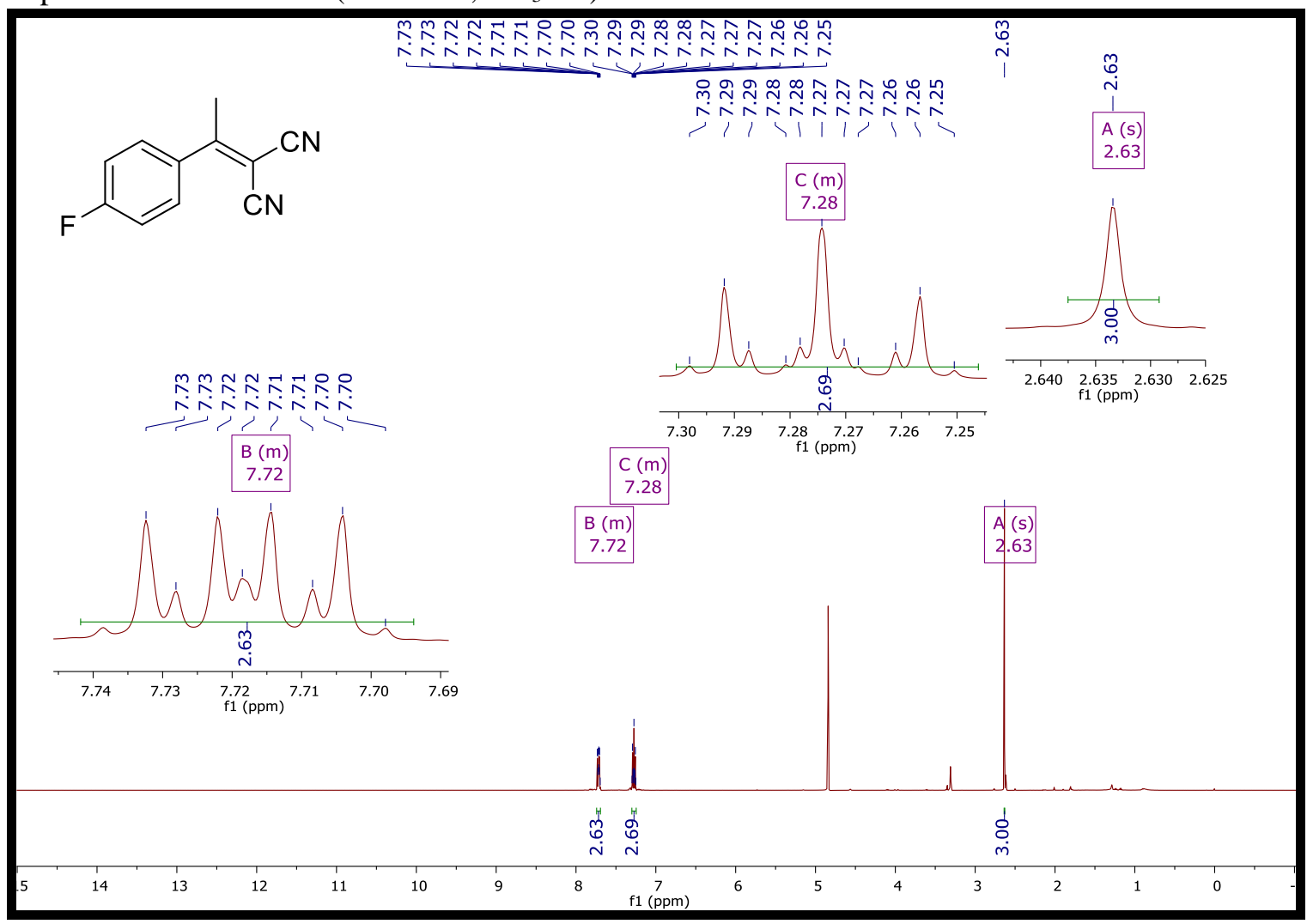

Espectro de RMN de ${ }^{13} \mathrm{C}\left(100 \mathrm{MHz}, \mathrm{CD}_{3} \mathrm{OD}\right)$ do aduto $\mathbf{5 f}$.

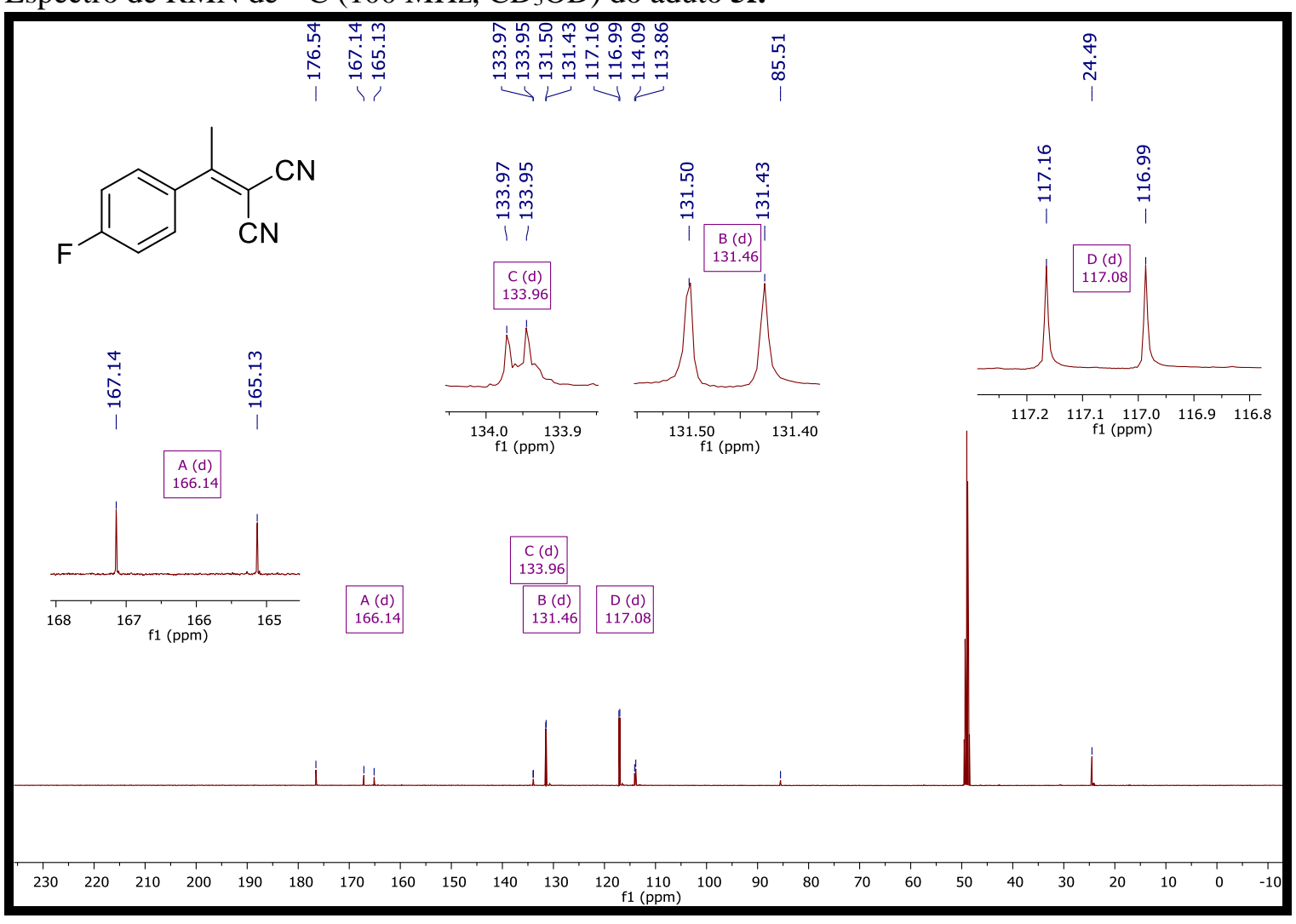


Espectro de absorção no infravermelho do aduto $\mathbf{5 f}$

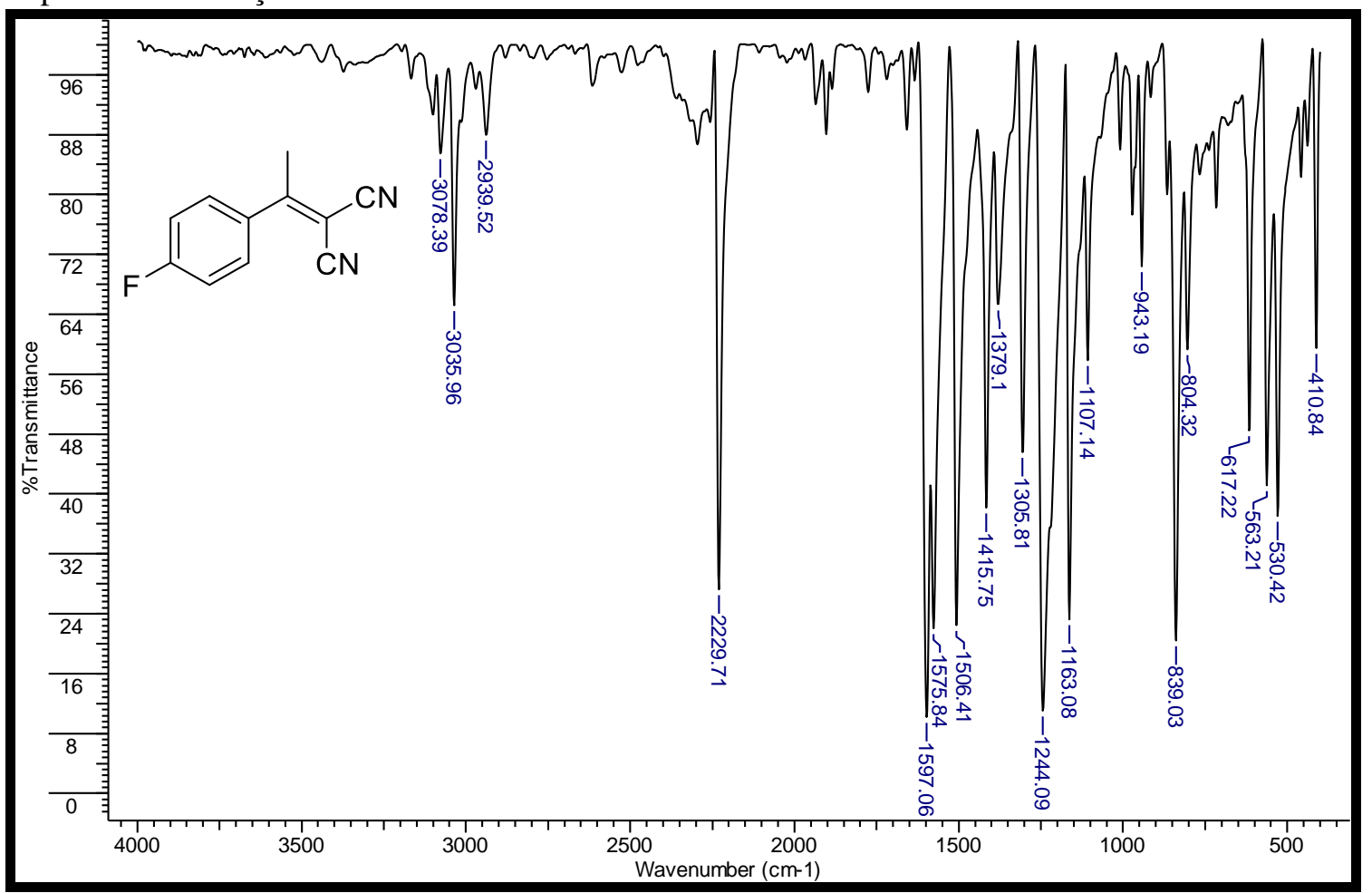

